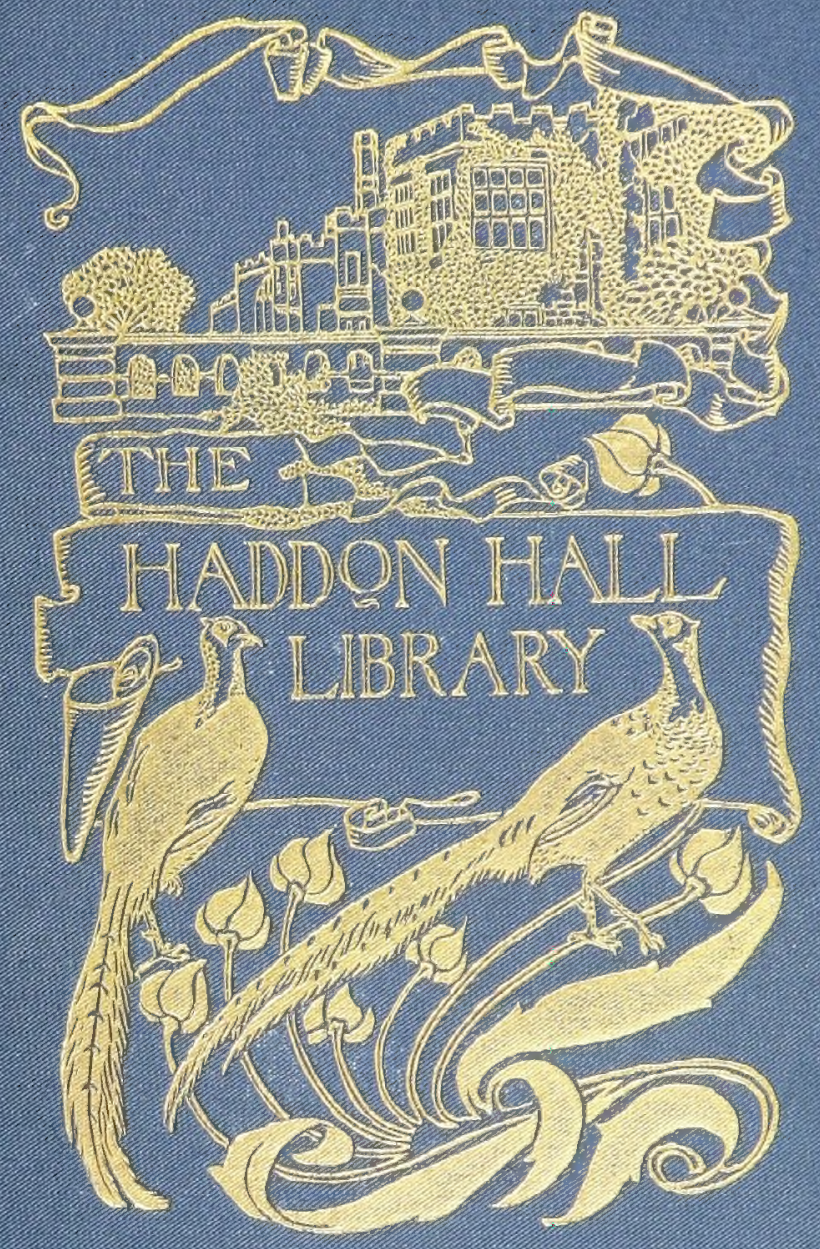




\section{ALBERT R. MANN LIBRARY}

New York State Colleges

OF

Agriculture AND Home Economics

AT

Corneli University
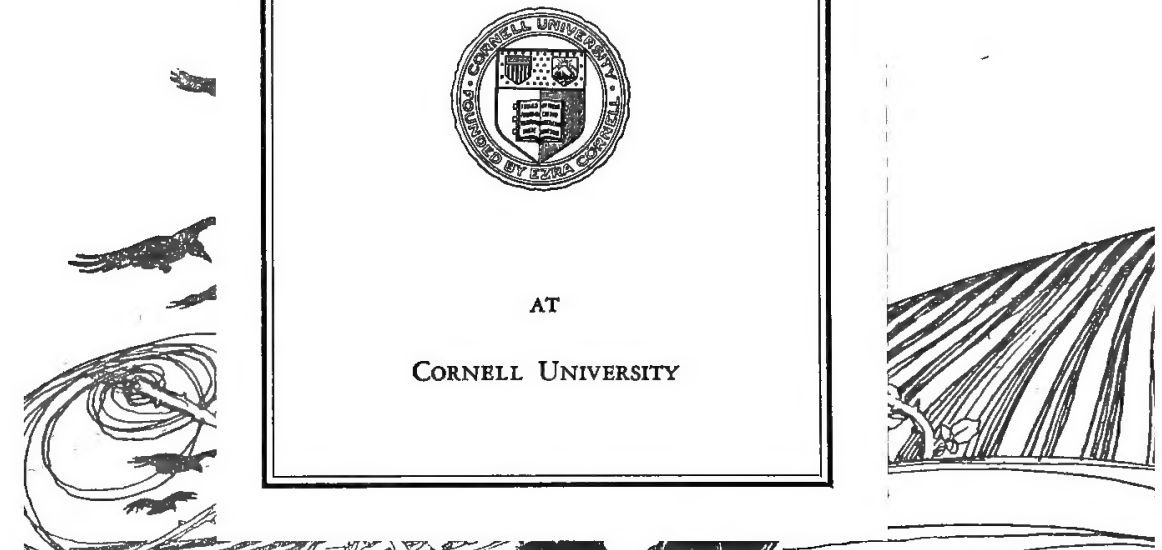

$\underbrace{}_{4}$

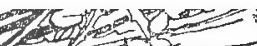
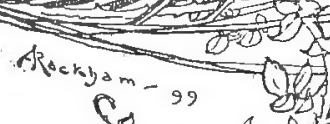

C $99 \quad$ by
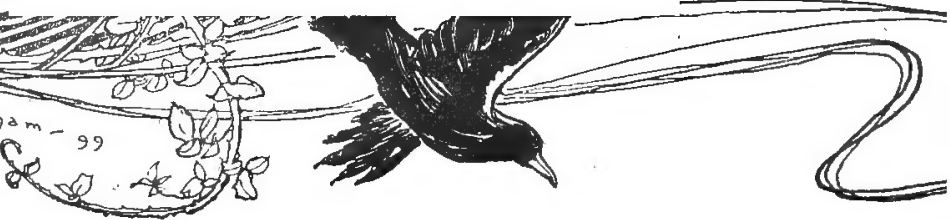

Fist Editian, with Ullustrations of anchur Racheom. 

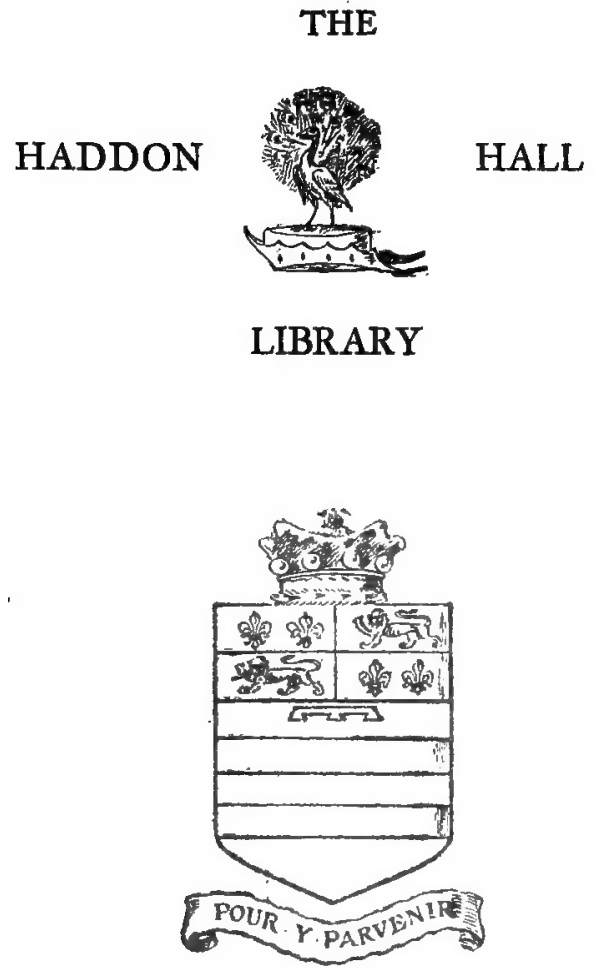

EDITED

BY THE

MARQUESS OF GRANBY

AND MR.

GEORGE A. B. DEWAR 
All rights reserved 


\section{Cornell University Library}

The original of this book is in the Cornell University Library.

There are no known copyright restrictions in the United States on the use of the text.

http://www.archive.org/details/cu31924000160493 


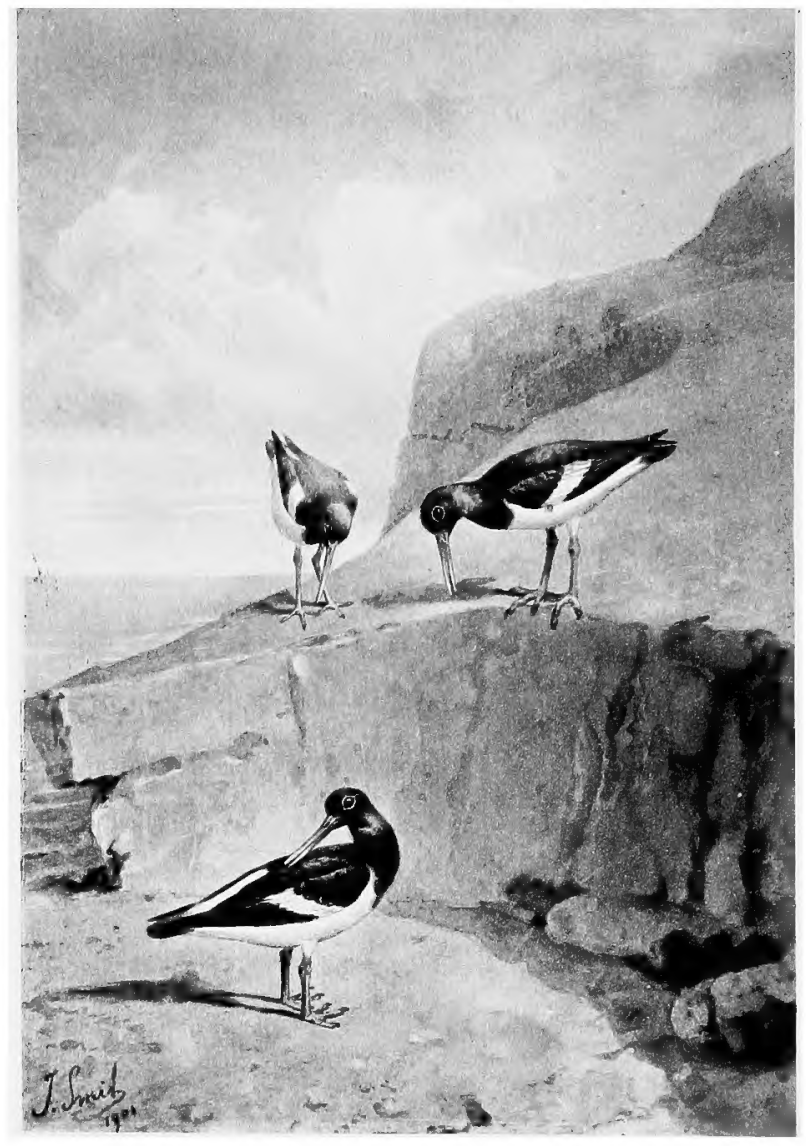






\title{
BIRD WATCHING
}

\author{
BY \\ EDMUND SELOUS \\ $=$
}

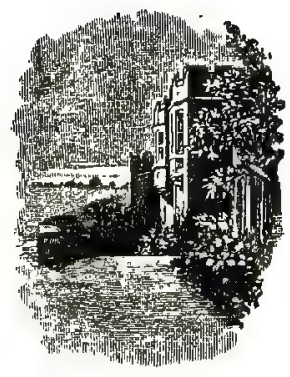

LONDON

J. M. DENT \& CO., ALDINE HOUSE 29 \& 30 BEDFORD STREET, W.C.

I 90 I

$c . T$ 
QL

676

546

184828 


\section{CONTENTS}

CHAP.

PAGE

I. WATCHING GREAT PLOVERS, ETC. . . . 3

II. WATCHING RINGED PLOVERS, REDSHANKS, PEEWITS, ETC. • . . . • • . 2 I

III. WATCHING STOCK-DOVES, WOOD-PIGEONS, SNIPE, ETC. • • . • . • • . 35

IV. WATCHING WHEATEARS, DABCHICKS, OYSTER-CATCHERS, ETC. . . . . . 67

V. WATCHING GULLS AND SKUAS • • 96

VI. WATCHING RAVENS, CURLEWS, EIDERDUCKS, ETC. . . . . . . . . 129

VII. WATCHING SHAGS AND GUILLEMOTS . . I63 VIII. WATCHING BIRDS AT A STRAW-STACK . 199

IX. WATCHING BIRDS IN THE GREENWOODS . 225

X. WATCHING ROOKS . . . . . . . 257

XI. WATCHING ROOKS-CONTINUED • • • 274

XII. WATCHING BLACKBIRDS, NIGHTINGALES,

SAND-MARTINS, ETC. . . . . . . 30r

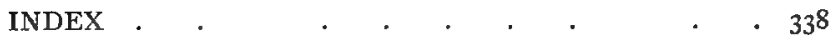


$-$ 


\section{LIST OF ILLUSTRATIONS}

Male Oyster-catchers piping to the Female .

- Frontispiece Photogravure

Dancing of Great Plovers in Autumn . facing page 12 Photogravure

Great Plovers: A Nuptial Pose . : . Page 19

Master and Pupil: Hooded-Crow flying with Peewits " 29

Stock-Doves: A Duel with Ceremonies . . . " " 4 운

Turtle Doves: The Nuptial Flight . facing page 5o Photogravure

Great Skuas: Nuptial Flight and Pose. ", " Ior Photogravure

Ravens: The Game of Reversi . . . Page 135

Habet! Great-crested Grebe attacked by another under water . . . . . . $\quad$. I50

Love on a Rock: Shags during the breeding season . . . . . . facing page 168 Photogravure

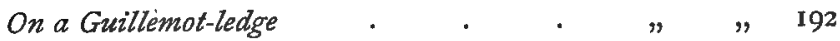

Fairy Artillery: Willow-Warbler pecking catkins in flight . . . . . . . Page 254

Rooks : $A$ Winter Scene . . . . . $\quad$ " 279

In a Sand-pit . . . . . . f facing page 329

Photogravure

All the above from Drawings by J. SMiT. 


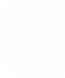

$-$ 


\section{P R E F A C E}

I SHOULD like to explain that this work, being, with one or two insignificant exceptions, a record of my own observations only, it has not been my intention to make general statements in regard to the habits of any particular bird. In practice, however, it is often difficult to write as if one were not doing this, without its having a very clumsy effect. One cannot, for instance, always say, "I have seen birds fly." One has to say, upon occasions, "Birds fly." Moreover, it is obvious that in much of the more important business of bird-life, one would be fully justified in arguing from the particular to the general: perhaps (though this is not my opinion) one would always be. But, whether this is the case or not, I wish it to be understood that, throughout, a remark that any bird acts in such or such a way means, merely, that I have, on one or more occasions, seen it do so. Also, all that I have seen which is included in this volume was noted down by me either just after it had taken place or whilst it actually was taking place; the quotations (except when literary or otherwise explicitly stated) being always from my own notes so made. For this reason I call my work "Bird Watching," and I hope that the title will explain, and even justify, a good deal which in itself is certainly a want ix 
and a failing. One cannot, unfortunately, watch all birds, and of those that one can it is difficult not to say at once too little and too much: too little, because one may have only had the luck to see well a single point in the round of activities of any species -one feather in its plumage, so to speak-and too much, because even to speak of this adequately is to fill many pages and deny space to some other bird. All I can do is to speak of some few birds as I have watched them in some few things. Those who read this preface will, I hope, expect nothing more, and I hope that not much more is implied in the title which I have chosen. Perhaps I might have been more explicit, but English is not German. "Of-somefew - birds - the-occasional-in-some-things-watching" does not seem to go well as a compound, and "Observations on," etc., sounds as formidable as "Beobachtungen über." It matters not how one may limit it, the word "Observations" has a terrific sound. Let a man say merely that he watched a robin (for instance) doing something, and no one will shrink from him; but if he talks about his "Observations on the Robin-Redbreast" then, let these have been ever so restricted, and even though he may forbear to call the bird by its Latin name, he must expect to pay the penalty. The very limitations will have something severe-smacking of precise scientific distinction - about them, and the implied preference for English in such a case will appear affected and to be a clumsy attempt, merely, 
to make himself popular. Therefore, I will not call my book "Observations on," etc. I have watched birds only, I have not observed them. It is true that, in the text itself, I do not shrink from the latter word, either as substantive or verb, or even from the Latin name of a bird, here and there, when I happen to know it (for is there not such a thing as childish pride?). But that is different. I do not begin at once in that way, and by the time I get to it anyone will have found me out, and know that I am really quite harmless. Besides, I have now set matters in their right light. But I was not going to handicap myself upon my very cover and trust to its contents, merely, for getting over it. That would have been over-confidence.

Again, in the following pages there are some points which I just touch upon and leave with an undertaking to go more fully into, in a subsequent chapter. This I have always meant to do, but want of space has, in some instances, prevented me from carrying out my intention. For this, I will apologise only, leaving it to my readers to excuse me should they think fit. Perhaps they will do so very readily.

Also,--but I cannot afford to point out any more of my shortcomings. That, too, I must leave to "the reader," who, I hope, will in this matter but little deserve that epithet of "discerning" which is often so generously - not to say boldly - bestowed upon him. 


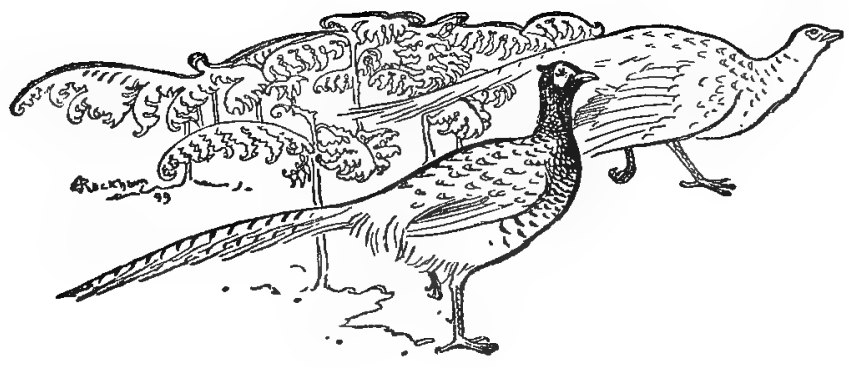




\section{BIR D WATCHING}





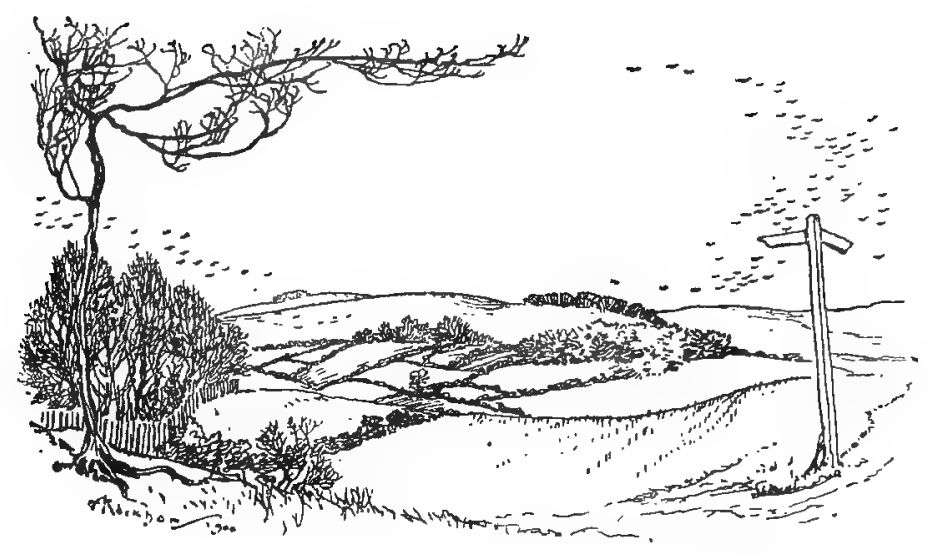

CHAPTER I

\section{Watching Great Plovers, etc,}

IF life is, as some hold it to be, a vast melancholy ocean over which ships more or less sorrow-laden continually pass and ply, yet there lie here and there upon it isles of consolation on to which we may step out and for a time forget the winds and waves. One of these we may call Bird-isle-the island of watching and being entertained by the habits and humours of birds-and upon this one, for with the others I have here nothing to do, I will straightway land, inviting such as may care to, to follow me. I will speak of birds only, or almost only, as I have seen them, and I must hope that this plan, which is the only one I have found myself able to follow, will be accepted as an apology for the absence of much which, not having seen but only read of, I therefore say nothing about. 
Also, if I sometimes here record what has long been known and noted as though I were making a discovery, I trust that this, too, will be forgiven me, for, in fact, whenever I have watched a bird and seen it do anything at all-anything, that is, at all salientthat is just how I have felt. Perhaps, indeed, the best way to make discoveries of this sort is to have the idea that one is doing so. One looks with the soul in the eyes then, and so may sometimes pick up some trifle or other that has not been noted before.

However this may be, one of the most delightful birds (for one must begin somewhere) to find, or to think one is finding things out about, is the great or Norfolk plover, or, as it is locally and more rightly called-for it is a curlew and not a plover *-the stone-curlew. These birds haunt open, sandy wastes to which but the scantiest of vegetation clings, and here, during the day, they assemble in some chosen spot, often in considerable numbers-fifty or more I have sometimes seen together. If it is early in the day, and especially if the weather be warm and sunny, most of them will be sitting, either crouched down on their long yellow shanks, or more upright with these extended in front of them, looking in this latter attitude as if they were standing on their stumps, their legs having been "smitten off" and lying before them on the ground. Towards evening, however-which is the best time to watch these birds -they stand attending to their plumage, or walk with picked steps in a leisurely fashion, which, with their lean gaunt figure, sad and rusty coloured, and a

* I understand Professor Newton to say this. 
certain sedateness, almost punctiliousness, of manner, fancifully suggests to one the figure of Don Quixote de la Mancha, the Knight of the rueful countenance, with a touch or two, perhaps, thrown in of the old Baron of Bradwardine of Tullyveolan. One can lie on the ground and watch them from far off through the glasses, or, should a belt of bracken fringe the barren area, one has then an excellent opportunity of creeping up to within a short or, at least, a reasonable distance. To do this one must make a wide circuit and enter the bracken a long way off. Then having walked, or rather waded for some way towards them, at a certain point-experience will teach the safety-line-one must sink on one's hands and knees, and the rest is all creeping and wriggling, till at length, lying flat, one's face just pierces the edge of the cover and the harmless glasses are levelled at the quarry one does not wish to kill. The birds are standing in a long, straggling line, ganglion-like in form, swelling out into knots where they are grouped more thickly with thinner spaces between. As they preen themselves-twisting the neck to one or the other side so as to pass the primary quill feathers of the wings through the beak -one may be seen to stoop and lay one side of the head on the ground, the great yellow eye of the other side staring up into the sky in an uncanny sort of way. The meaning of this action I do not know. It is not to scratch the head, for the head is held quite still ; and, moreover, as, like most birds, they can do this very neatly and effectively with the foot, other methods would seem to be superfluous. Again, and this is a more characteristic action, one having stood 
for some time upright and perfectly still, makes a sudden and very swingy bob forward with the head, the tail at the same time swinging up, just in the way that a wooden bird performs these actions upon one's pulling a string. This again seems to have no special reference to anything, unless it be deportment.

All at once a bird makes a swift run forward, not one of those short little dainty runs-one and then another and another, with little start-stops betweenthat one knows so well, but a long, steady run down upon something, and at the same moment the glasses -if one is lucky and the distance not too greatreveal the object which has occasioned this, a delicate white thing floating in the air which one takes to be a thistle-down. This is secured and eaten, and we may imagine that the bird's peckings at it after it is in his possession are to disengage the seed from the down. But all at once-before you have had time to set down the glasses and make the note that the great plover (Edicnemus Crepitans) will snap at a wandering thistle-down, and having separated the delicate little seed-sails from the seed, eat the latter, etc., etc.-a small brown moth comes into view flying low over a belt of dry bushy grass that helps, with the bracken, to edge the sandy warren, for these wastes are given over to rabbits and large landowners, and are marked "warrens" on the map. Instantly the same bird (who seems to catch sight of the moth just as you do) starts in pursuit with the same rapid run and head stretched eagerly out. He gets up to the moth and essays to catch it, pecking at it in a very peculiar way, not excitedly or wildly, but with little precise pecks, the head closely and guardedly following the moth's 


\section{WATCHING GREAT PLOVERS, ETC. 7}

motions, the whole strongly suggestive of professional skill. The moth eludes him, however, and the bird stops rigidly, having apparently lost sight of it. Shortly afterwards, after it has flown some way, he sees it again and makes another swift run in pursuit, catching it up again and making his quick little pecks, but unsuccessfully, as before. Then there is the same pause, followed by the same run, then a close, near chase, and finally the moth is caught and eaten. Other moths, or other insects, now appear upon the scene, or if they do not appear-for even with the best of glasses such pin-points are mostly invisibleit is evident from the actions of the birds that they are there. Chase after chase is witnessed, all made in the same manner, with sometimes a straight-up jump into the air at the end and a snap that one seems almost to hear-a last effort, but which, judging by the bird's demeanour afterwards, fails, as last efforts usually do.

A social feeling seems to pervade these huntingscenes, a sort of "Have you got one? I have. That bird over there's caught two" idea. This may be imaginary, still the whole scene with its various little incidents suggests it to one. The stone-curlew, therefore, besides his more ordinary food of worms, slugs, and the like-I have seen him in company with peewits, searching for worms, much as do thrushes on the lawn - is likewise a runner down and "snapper up of" such "unconsidered trifles" as moths and other insects on the wing. I had seen him chasing them, indeed, long before I knew what he was doing, for I had connected those sudden, racing runs-seen before from a long distance-with 
something or other on the ground, imagining a fresh object for each run. Often had I wondered, first at the eyesight of the bird, which seemed to pierce the mystery of a worm or beetle at fifty or sixty yards distance, and then at its apparent want of interest each time it got to the place where it seemed to have located it. Really it had but just lost sight of what it was pursuing, but aerial game had not occurred to me, and the tell-tale spring into the air, which would have explained all, had been absent on these occasions. I have called such leaps "last efforts," but I am not quite sure if they are always the last. More than once I have thought I have seen a stonecurlew rise into the air from running after an insect, and continue the pursuit on the wing. This is a point which I would not press, yet birds often act out of their usual habits and assume those proper to other species. I remember once towards the close of a fine afternoon, when the air was peopled by a number of minute insects, and the stone-curlews had been more than usually active in their chasings, a large flock of starlings came down upon the warrens and began to behave much as they were doing, running excitedly about in the same manner and evidently with the same object. But what interested me especially was that they frequently rose into the air, pursuing and, as I feel sure, often catching the game there, turning and twisting about like flycatchers, though with less graceful movements. Often, too, whilst flying-fairly high-from one part of the warrens to another, they would deflect their course in order to catch an insect or two en passant. I observed this latter action first, and doubted the 
motive, though it was strongly suggested. After seeing the quite unmistakable fly-catcher actions I felt more assured as to the other. Yet one may watch starlings for weeks without seeing them pursue an insect in the air. Their usual manner of feeding is widely different-viz. by repeatedly probing and searching the ground with their sharp spear-like bills, as does a snipe (with which bird they will sometimes feed side by side) with his longer and more delicate one. This is well seen whilst watching them on a lawn. They do not study to find worms lying in the holes and then seize them suddenly as do thrushes and blackbirds. With them it is "blind hookey"; each time the beak is thrust down into the grass it may find something or it may not. The mandibles are all the time working against each other, evidently searching and biting at the roots of the grass, and at intervals, but generally somewhat long ones, they will be withdrawn, holding within their grasp a large, greyish grub.

Returning to the stone-curlews. During the day, as I have said, these birds are idle and lethargicsitting about, dozing, often, or sleeping - but as the air cools and the shadows fall, they rouse into a glad activity, and coming down and spreading themselves over the wide space of the warrens, they begin to run excitedly about, raising and waving their wings, leaping into the air, and often making little flights, or rather flittings, over the ground as a part of the disport. As a part of it I say advisedly, for they do not stop and then fly, and on alighting recommence, but the flight arises out of the wild waving and running, and this is resumed, without a pause, as 
the bird again touches the ground. All about now over the warrens their plaintive, wailing notes are heard, notes that seem a part of the deepening gloom and sad sky; for nature's own sadness seems to speak in the voice of these birds. They swell and subside and swell again as they are caught up and repeated in different places from one bird to another, and often swell into a full chorus of several together. Deeper now fall the shadows, "light thickens," till one catches, at last, only "dreary gleams about the moorland," as now here, now there, the wings are flung upshowing the lighter coloured inner surface - till gradually, first one and then another, or by twos or threes or fours, the birds fly off into the night, wailing as they go. But this note on the wing is not the same as that uttered whilst running over the ground. The ground-note is much more drawn out, and a sort of long, wailing twitter - called the "clamour"-often precedes and leads up to the final wail. In the air it comes just as a wail without this preliminary. But it must not be supposed that all the birds perform these antics simultaneously. If they did the effect would be more striking, but it is generally only a few at a time over a wide space, or, at most, some two or three together - as by sympathy - that act so. The eye does not catch more than a few gleams-some three or four or five -of the flung-up wings at one time over the whole space. It is a gleam here and a gleam there in the deepening gloom. "Dreary gleams about the moorland"-for warren, here, purples into moor and moor saddens into warren-is, indeed, a line that exactly describes the effect. 
These birds, then, stand or sit about during the day in their chosen places of assemblage, and, if not occupied in catching insects or preening themselves, they are dull and listless. But as the evening falls and the air cools, they cast off their lassitude, think of the joys of the night, there is dance and song for a little, and then forth they fly. Sad and wailing as are their notes to our ears, they are no doubt anything but so to the birds themselves, and as the accompaniment of what seems best described by the word "dance" may, perhaps, fairly be called "song." The chants of some savages whilst dancing, might sound almost as sadly to us, pitched, as they would be, in a minor key, and with little which we would call an air. Again, if one goes by the bird's probable feelings, which may not be so dissimilar to the savage's - or indeed to our own - on similar occasions "song" and "dance" seems to be a legitimate use of words.

But whatever anyone may feel inclined to call this performance- "dance" or "antics" or "display" - it varies very much in quality, being sometimes so poor that it is difficult to use words about it without seeming to exaggerate, and at other times so fine and animated, that were the birds as large as ostriches, or even as the great bustard, much would be said and written on the subject. Moreover, so many variations and novelties and little personal incidents are to be noticed on the different occasions, that any general description must want something. I will therefore give a particular one of what I witnessed one afternoon when the dancing was especially good. It was about 5.30 when I got to the edge 
of the bracken, which to some extent rings round the birds' place of assembly.

"A drizzling rain soon began, and this increased gradually, but not beyond a smart drizzle. The birds, as though stimulated by the drops, now began to come down from where they had been standing on the edge of the amphitheatre, and to spread all over it till there were numbers of them, and dancing of a more pronounced, or, at least, of a more violent kind than I had yet seen, commenced. Otherwise it was quite the same, but the extra degree of excitement made it much more interesting. It was, in fact, remarkable and extraordinary. Running forward with wings extended and slightly raised, a bird would suddenly fling them high up, and then, as it were, pitch about over the ground, waving and tossing them, stopping short, turning, pitching forward again, leaping into the air, descending and continuing, till, with another leap, it would make a short eccentric flight low over the ground, coming down in a sharp curve and then, at once, meme jeu. I talk of their 'pitching' about, because their movements seemed at times hardly under control, and, each violent run or plunge ending, in fact, with a sudden pitch forward of the body, the wings straggling about (often pointed forward over the head) in an uncouth dislocated sort of way, the effect was as if the birds were being blown about over the ground in a violent wind. They seemed, in fact, to be crazy, and their sudden and abrupt return, after a few mad moments, to propriety and decorum, had a curious, a bizarre effect. Though having just seen them behave so, one seemed almost to doubt that they had. One bird that had 




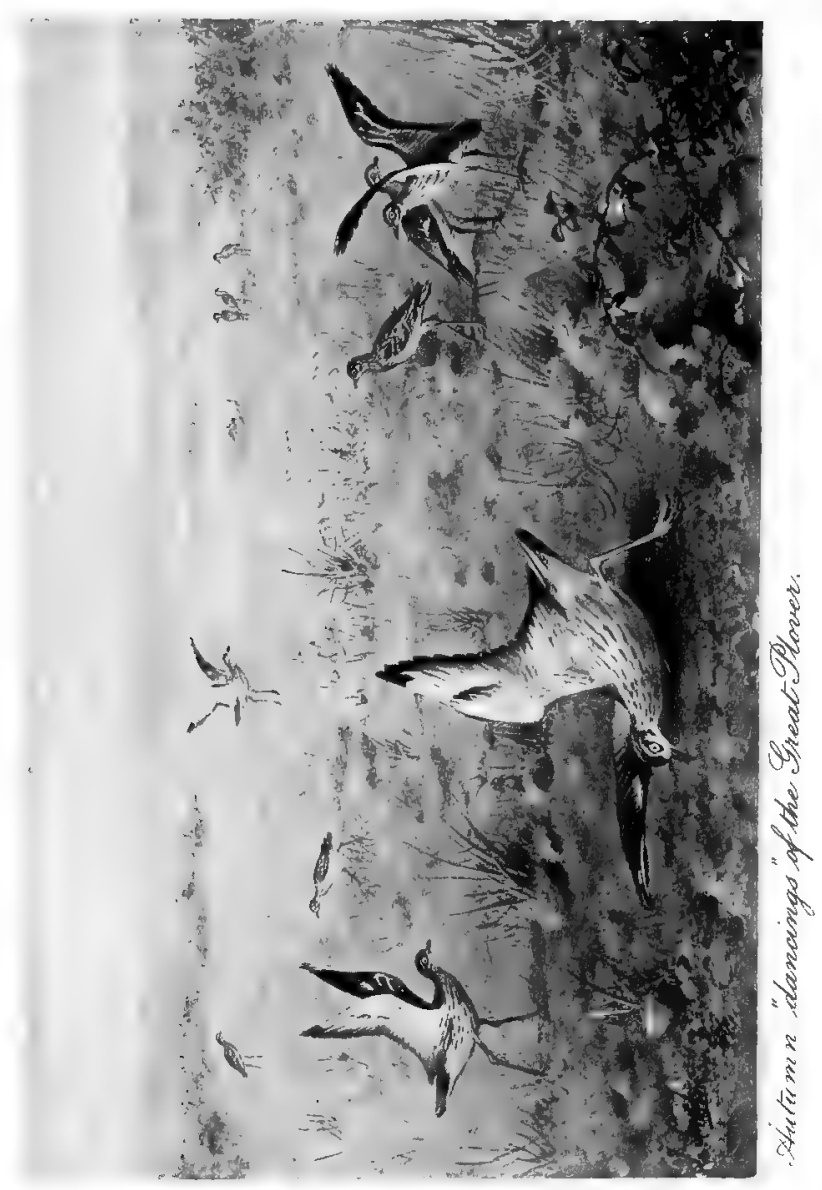



come to within a moderate distance of me, made three little runs-advancing, retiring, and again advancing -all the time with wings upraised and waving, then took a short flight over the ground, describing the segment of a circle, and, on alighting, continued as before. Half-a-dozen others were gathered together under a solitary crab-apple tree-a rose in the desert - less than 100 yards off, and both with the naked eye and the glasses I observed them all thoroughly well. One of them would often run at or pursue another with these antics. I saw one that was standing quietly, caught and, as it were, covered up in a little storm of wings before it could run away and begin waving its own.

"This and the general behaviour of the group makes it evident that the birds are stimulated in their danceantics by each other's presence. For these little chases were in sport, clearly, not anger. Very different is the action and demeanour of two birds about to fight. This is by far the finest display of the sort that I have yet seen, and must be due, I think, to the rain, which the birds obviously enjoyed. They had been quite dull and listless before, but as soon as it fell they spread themselves over the plateau, and the dancing began. It was not only when the birds threw up their wings and, as one may say, let themselves go, that they seemed excited. The constant quick running and stopping whilst the wings were folded appeared to me to be a part - the less excited part - of the general emotion out of which the sudden frenzies arose. There was also the usual vocal accompaniment. The wailing note went up, and was caught and repeated from 
one part to another at greater or lesser intervals, the whole ending in flight as before."

When I first saw these dances I thought that they arose out of the excitement of the chase-that chase of moths or other insects flying low over the ground which I have noticed-that they were hunting-dances, in fact. I thought the motions of the wings were to beat down the escaping quarry, and I confounded the little springs and leaps into the air, arising out of the dance and being a part of it, with those other ones made with a snap and an object not to be mistaken; but I soon discovered my error. Insecthunting is only indulged in occasionally, when a wandering moth or so happens to fly by. The general hunt which I have described was incident, I think, to an unusually large number of insects in the air over the warrens, by which not only a band of starlings -as before mentioned-was attracted, but, afterwards, swallows and martins. On such occasions, dancing might conceivably grow out of the excitement of the chase, so as to appear a part of it, but though the two forms of excitement may sometimes intermingle, the tendency would probably be for the one to diminish and interfere with the other. At any rate, almost every dance which I have witnessed has been a dance pure and simple.

What, then, is the meaning of this dancing, of these strange little sudden gusts of excitement arising each day at about the same time and lasting till the birds fly away? We have here a social display as distinct from a nuptial or sexual one, for it is in the autumn that these assemblages of the great plovers take place, after the breeding is all 
over; the deportment of the courting or paired birds towards each other - their nuptial antics - is of a different character. With birds, as with men, all outward action must be the outcome of some mental state. What kind of mental excitement is it which causes the stone-curlews to behave every evening in this mad, frantic way? I believe that it is one of expectancy and making ready, that these odd antics-the mad running and leaping and waving of the wings-give expression to the anticipation of going and desire to be gone which begins to possess the birds as evening falls. They are the prelude to, and they end in, flight. The two, in fact, merge into each other, for short flights grow out of the tumblings over the ground, and it is impossible to say when one of these may not be continued into the full flight of departure. They are a part of the dance, and, as such, the birds may almost be said to dance off. Surely in actions which lead directly up to any event there must be an idea, an anticipation of it, nor can the idea of departure exist in a bird's mind (hardly, perhaps, in a man's) except in connection with what it is departing forfood, namely, in this case, a banquet. So when I say that these birds "think of the joys of the night" need this be merely a figure? May it not be true that they do so and dance forth each night, to their joy?

I have said that the social or autumn antics of the stone-curlews - their dances, as I have called them, using the usual phraseology - are distinct from the nuptial or courting ones which they indulge in in the spring. These latter are of a different char- 
acter altogether, but much more interesting to see than they are easy to describe. The birds are now paired, or in process of becoming so, and it is fashionable for two of them to walk side by side, and very close together, with little gingerly steps, as though "keeping company." They seem very much en rapport with each other - sehr einig as the Germans would say - also to have a mutual sense of their own and each other's importance, of the seemly and becoming nature of what they are doing, and (this above all) of the great value of deportment. Something there is about them-now even more than at other times - very odd, quaint, old-world, oldfashioned. The last best describes it; they are old-fashioned birds. Were the world occupied in watching them, and were they occasionally to overhear themselves being talked about, they would catch that word as often as did little Paul Dombey.

Whilst watching a couple walking side by side in this way that I have described, one of them may be seen to bend stiffly forward till the beak just touches the ground, the tail and after part of the body being elevated in the air. The other stands by, and appears both interested in and edified by the performance, and when it is over both walk on as before. Or a bird may be seen to act thus whilst walking alone, upon which another will come running from some distance towards it, as though answering to a summons or to some quite irresistible form of appeal. Upon coming close up to the rigid bird this other one stops, and turning suddenly, but also setly and rigidly, round, makes a curious little run away from it with lowered head and precise formal steps, 
full of a peculiar gravity and importance. Having thus played his part he again stops, and, standing idly about, seems lapsed into indifference. Meanwhile, the rigid one having remained in its set attitude for some little time longer at length comes out of it, and advancing with the same little picked, careful, gingerly steps that I have noticed, before long assumes it again, and then, relaxing, crouches low on the ground as though incubating. Having remained thus for a minute or two it rises and stands at ease. "A third bird now appears upon the scene (for this, I must say, was a little witnessed drama), advancing towards the two. As he approaches, one of them-the one which has run up in response to the appeal, and which I take to be the malebecomes uneasy as recognising a rival. $\mathrm{He}$ first either runs or walks (the pace, though it may be quick, is solemn) to the female, and makes her some kind of bow or obeisance of a very formal nature. Then, straightening and turning, he instantly becomes a different bird, so changed is his appearance. $\mathrm{He}$ is now drawn up to his full height, with the head thrown a little back, the tail is fanned out into the shape of a scallop-shell (looking very pretty), the broad, rounded end of which just touches the ground at the centre, and thus 'set,' as it were, for action, he advances upon the intruding bird with quick little stilty steps, prepared, evidently, to do battle. The would-be rival, however, retreats before this display, and the accepted suitor, having followed him thus for some little way-not rushing upon him or forcing a combat, but more as gravely and seriously prepared for one-turns and with his former formal pace goes back 
to his hen." Or shall we not, rather, say to his Dulcinea del Toboso? for never does this strange, gaunt, solemn, punctilious-looking bird, with the tall figure and the strain of madness in the great glaring eyes, more remind one-fancifully - of Cervante's creation than now. Surely in that formal approach and deep reverence to his mistress, before entering upon this, perhaps, his first "emprise," we have the very figure and high courteous action of the knight, and seem almost to hear those words of his spoken on a similar occasion: "Acorredme, señora mia, en esta primera afrenta que a este vuestro avasallado pecho se le ofrece; no me desfallezca en este primera trance vuestro favor $y$ amparo." ("Sustain me, lady mine, in this first insult offered to your captive knight. Fail me not with your favour and countenance in this my first emprise.")

In the above case it was, presumably, the female bird who assumed the curious rigid attitude, with the tail raised and head stooped forward to the ground. The attitude, however, assumed by the male, which I have described as a bow or obeisance-and, indeed, it has this appearance-was much of the same nature, if it was not precisely the same, and as far as I have been able to observe, none of the many and very singular attitudes and posturings in which these birds indulge are peculiar to either sex. At any rate, that one which would seem par excellence to appertain to courtship or matrimony, and which is often (as it was in the instance I am about to give) immediately followed by the actual pairing of the birds, is common to both the male and the female. The following will show this :- "A bird which has for some time been 
sitting now rises and shakes itself a little, presenting, as it does so, a very 'mimsy' and 'borogovy' appearance (for which adjectives, with descriptive plate, see 'Through the Looking-Glass'). It then begins uttering that long, thin, 'shrilling' sound, which goes so far and pierces the ear so pleasantly. This is answered by a similar cry, quite near, and I now see,

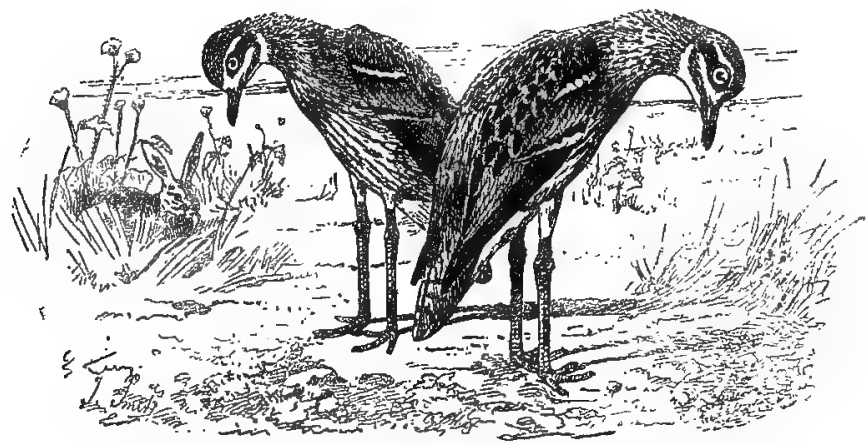

Great Plovers: A Nuptial Pose

for the first time, another bird advancing quickly to the calling one, who also advances to meet it. They approach each other, and standing side by side, with, perhaps, a foot between them, but looking different ways, each in the direction in which it has been advancing, both of them assume, at the same time, a particular and very curious posture, worth waiting days to see. First they draw themselves tall-ly up on their long, yellow, stilt-like legs, then curving the neck with a slow and formal motion, they bend the head downwards-yet still holding it at a height-and stop thus, set and rigid, the beak pointing to the ground. 
Having stood like this for some seconds, they assume the normal attitude. This wonderful pose, conceived and made in a vein of stiff formality, but to which the great, glaring, yellow eye gives a look of wildness, almost of insanity, has in it, both during its development and when its acme has been reached, something quite per se, and in vain to describe. But again one is reminded of what is past and old-fashioned, of chivalry and knight-errantry, of scutcheons and heraldic devices, of Don Quixote and the Baron of Bradwardine."

It is not only when two birds are by themselves that these or other attitudes are assumed. They will often break out, so to speak, amongst three or four birds running or chasing each other about. All at once one will stop, stiffen into one of them-that especially where the head is lowered till the beak touches, or nearly touches, the ground-and remain so for a formal period. But all such runnings and chasings are, at this time, but a part of the business of pairing, and one divines at once that such attitudes are of a sexual character. The above are a few of the gestures or antics of the great plover or stone-curlew during the spring. I have seen others, but either they were less salient, or, owing to the great distance, I was not able to taste them properly, for which reason, and on account of space, I will not further dwell upon them. What I would again draw attention to, as being, perhaps, of interest, is that here we have a bird with distinct nuptial (sexual) and social (non-sexual) forms of display or antics, and that the former as well as the latter are equally indulged in by both sexes. 


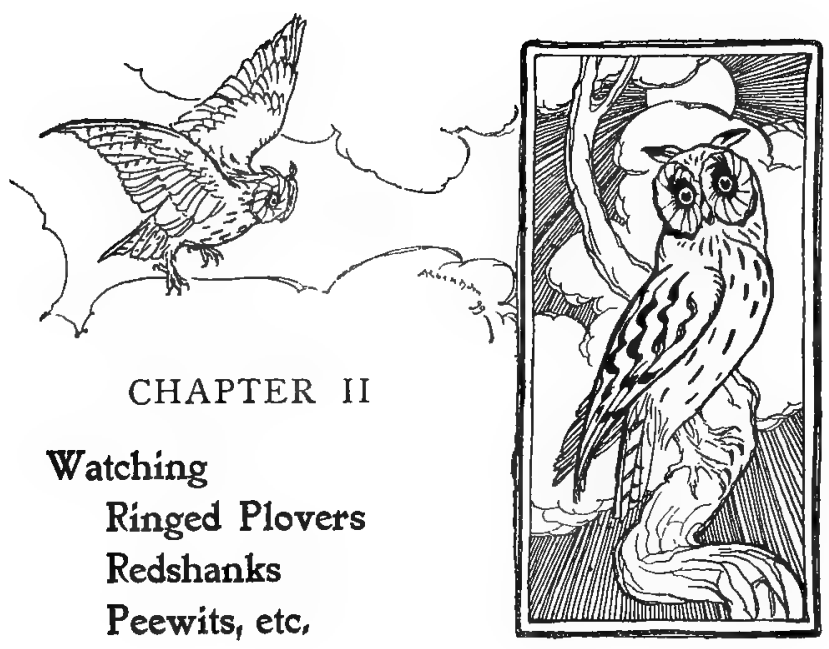

THE pretty little ring-plover (Agialitis hiaticola) belongs properly to the sea-shore, but he haunts and breeds inland also, and is especially the companion of the stone-curlew over the stony, sandy wastes that they both love so well. These little birds have both a nuptial flight and a courting action on the ground. In the former a pair will keep crossing and recrossing as they scud about, or they will sweep towards and then away from each other in the softest and prettiest manner imaginable, or each will sweep first up to a height and then swiftly down again and skim quite low along the ground, thus delighting the eye with the contrast. Their flight is all in graceful sweeps, for even when they beat the air with their slender, pointed pinions, it is rather as though they kissed than beat it, and they seem all the while to be sweeping on without effort, so soft is their motion. 
Another salient feature is the varied direction of their flight, for though this is in wide, spacious circles around their chosen home, yet within this free limit they set their sails to all points of the compass, veering from one to another with so joyous a motion, each change seems an ecstasy-as indeed it is to behold. Their mode of alighting on the ground after flight is very pretty, for they do so as if they meant to continue flying. Sometimes the wings are still raised, still make their little spear-points in the air as they softly stop; or the bird will hold them drooped and but half-spread, and skim like this, just above the ground. At once he is on it, but there has been no jerk, no pause. He has been smooth in abruptness: settling suddenly, there has been no sudden motion. These things are as magic,- - they are, and yet they cannot be. It is a contradiction, yet it has taken place.

In formal courtship on the ground "the male approaches the female with head and neck drawn up above the usual height, so that he presents for her consideration a broader and fuller frontage of throat and breast than upon ordinary occasions. He does not raise or otherwise disport with his wings, but through the glasses one can see that his little legs -which now that he is more upright are less invisible -are being moved in a rapid vibratory manner, whilst he himself seems to be trembling, quivering with excitement. The motion of the legs does not belong to the gait, for the bird stands still whilst making it, and then advances a few steps at a time, with little pauses between each advance, during which the legs are quivered." The legs of the ringed plover are of 
a fine orange colour, and the male's drawing himself up so as to display them more fully, and then moving them quickly in this way before the female, suggests that they are appreciated by her. But it is not only the legs that are thus well exhibited. By drawing up the head, the throat, in which soft pure white and velvet black are boldly and richly contrasted, as well as the little smudged pug face and the bright orange-yellow bill, are all shown off to advantage.

The wings, however, in the instance which I observed and noted at the time, were kept closed. I can hardly think this is always the case. If it is, it may be because, though pretty enough-indeed lovely to an appreciative human eye - they yet do not in their colouring present anything like so bold and salient an appearance as the parts mentioned, with the display of which they might, perhaps, interfere, though I confess I do not think they would.

With the redshank this is different, for "the redshank, when standing with wings folded, is a very plain-looking bird, the whole of the upper surface being of a drabby brown colour, and the under parts not being seen to advantage. But as he rises in flight all is changed, for the inner surface of his wingswith, in a less degree, the whole under part of his body-are of a delicate, soft, silky white, looking silvery, almost, as the light falls upon it and causes it to gleam. This, with an upper quill-margin of bolder white on the wings, which, when they are closed, is concealed, now catches the eye, and the bird passes from insignificance into something almost distinguished, like a homely face flashing into beauty 
by virtue of a smile and fine eyes." Now the male redshank, when courting the female, makes the most of his wings, whilst at the same time moving his legs - which are coloured, as his name implies-in the same manner as does the ringed plover. He did so at any rate in the following instance. "The male bird, walking up to the female, raises his wings gracefully above his back. They are considerably elevated, and for a little he holds them thus aloft merely, but soon, drooping them to about half their former elevation, he flutters them tremulously and gracefully as though to please her. She, however, turned from him, walks on, appearing to be busy in feeding. The male takes, or affects to take, little notice of this repulse. $\mathrm{He}$ pecks about, as feeding too, but in a moment or so walks up to the hen again, and now, raising his wings to the fluttering height only, flutters them tremulously as before. She walks on a few steps and stops. He again approaches and, standing beside her (both being turned the same way), with his head and neck as it were curved over her, again trembles his wings, at the same time making a little rapid motion with his red legs on the ground, as though he were walking fast, yet not advancing." Now here (and this, if I remember, was the case with the ringed plovers also) the female did not appear to take much notice of the male bird's behaviour. She was turned away and, for some time, feeding. But it must not be forgotten that the eyes of most birds are not set frontally in the head as are ours, but on each side of it, so that their range of clear vision must be very much wider, probably including all parts except directly behind them. They also turn the head 
about with the greatest ease, and the slightest turn must be very effective. They would, therefore, often see quite plainly whilst appearing to us not to be noticing, and that the female should get the general effect of the male's display is all that is required by the theory of sexual selection-as conceived by Darwin. Darwin has expressly said that he does not imagine that the female birds consciously pick out the most adorned or best-displaying males, but only that such males have a more exciting effect upon them, which leads, practically, to their being selected. But though he has said this, it seems hardly ever to be remembered by the opponents of his view who, in combating it, almost always raise a picture of birds critically observing patterns and colours, as we might stuffs in a shop. However, having regard to the bower-birds, and especially that species which makes an actual flower garden, even this does not seem so absolutely impossible. The fact is, we are too conceited. With regard to the female bird sometimes, as here, keeping turned from the male while thus courted by him, this is, I think, capable of explanation in a way not hostile but favourable to the theory of sexual selection. At any rate, in both these instances, "il faut rendre a cela" either was, or seemed to be, the final conclusion of the female.

As the nuptial season approaches, the peewits begin to "stand," singly or in pairs, about the low, marshy land, or to fly "coo-ee-ing" over it. "Coooo-oo, hook-a-coo-ee, coo-ee," is their cry, far more, to my ear, resembling this than the sound "pee-weet" or "pee-wee-eet," as imitated in their name. At 
intervals one or another of them will make its peculiar throw or somersault in the air. This, in its completest form, is a wonderful thing to behold, though so familiar that no attention is paid to it. The bird in full flight - in a rushing torrent of sound and motion-may be seen to partially close the wings, and fall plumb as though it had been shot. In a moment or two, but often not before there has been a considerable drop, the wings are again partially extended, and the bird turns right head over heels. Then, sweeping buoyantly upwards, sometimes almost from the ground, it continues its flight as before. Such a tumble as this is a fine specimen. They are not all so abrupt and dramatic, but there is one point common to them all, which is the impossibility of saying exactly how the actual somersault is thrown. Do these tumblings add to the charm of the peewit's flight? To the charm, perhaps; certainly to the wonder and interest, but hardly (unless we are never to criticise nature) to the grace. The contrast is too great, there is something of violence, almost of buffoonery, about it. It is as though the clown came tumbling right into the middle of the transformation scene.

As the birds sweep about, they begin to enter into their bridal dances, pursuing each other with devious flight, pausing, hanging stationary with flapping wings one just above the other, then sweeping widely away in opposite directions. Shortly afterwards they are again flying side by side, or the sun, "in a wintry smile," catches both the white breasts as they make a little coquettish dart at each other. Then again they separate, and again the joyous "coo-0o-0o, hook- 
a-coo-ee, coo-ee" flits with them over marsh and moor. Sometimes a bird will come flying alone, somewhat low over the ground, in a hurrying manner, very fast, and making a sound with the wings, as they beat the air, which is almost like the puffing of an engine -indeed, one may easily, sometimes, imagine a train in the distance. As one watches him thus scudding along, tilting himself as ever, now on one side, now on another, all at once he will give a sharp turn as if about to make one of his wide, sweeping circles, but almost instantly he again reverses, and sweeps on in the same direction as before. This trick adds very much to the appearance, if not to the reality, of speed, for the smooth, swift sweep, close following the little abrupt twist back, contrasts with it and seems the more fast-gliding in comparison. Or one will fly in quick, small circles, several times repeated, a little above the spot where he intends to alight, descending, at last, in the very centre of his airdrawn girdle with wonderful buoyancy.

A hooded crow now flies over the marsh, and is pursued by first one and then another of the peewits. There is little combination, nor does there seem much of anger. It is more like a sport or a practical joke. It is curious that the crow's flight has taken the character of the peewit's, for they sweep upwards and downwards together, seeming like master and pupil. I have never seen a crow fly so, uninfluenced, and this, again, gives an amicable appearance. I have seen a peewit make continual sweeps down at a hen pheasant as she stood in a wheat-field, striking at her each time with its wings, in the air, obviously not in play but in earnest. The pheasant dodged, or 
tried to dodge, each time, and this lasted some while. Here it seems very different; and now again a compact little flock of peewits is flying backwards and forwards over the river with a hooded crow-not the same bird but another-right amongst them. This continues for some little time, till the peewits go down on the margin, and the crow then flies into a tree hard by. After a little interval the peewits fly off again, and almost directly the crow is with them, and again they fly backwards and forwards over the water, for some time, as before. And again I noteand this time it is still more marked and unmistakable -that the crow is flying amongst the peewits exactly as they fly. At least he is speaking French with them "after ye school of Stratford-at-y-Bow," for who flies exactly like a peewit but a peewit? But he sweeps with them-now upwards, now downwards -in smooth, gliding sweeps, a curious, rusty-looking, black and grey patch in the midst of their gleaming greens and whites. Yet he is a handsome bird too, is the hooded crow, but not when he flies with peewits. Now the peewits again go down, and the crow straightway flies into another tree. Shortly afterwards, a moor-hen, feeding on the grass, is hustled by one of the peewits into the water. Here, again, hostility was evident, whereas with the crow I could see no trace of it. He seemed to be enjoying himself, whilst the peewits, on their part, showed no objection to his company.

"Late in the afternoon there is a pause and hush. The birds have ceased flying till dusk, and are either standing still or walking over the ground. One I can see motionless amidst the brown, tufted grass. 
No, not quite motionless. Ever and anon there comes the strained, grating call-note of another peewit, and then this one rears up the body and jerks the head a little back, then jerks it flexibly forward again. At first he does this in silence, but

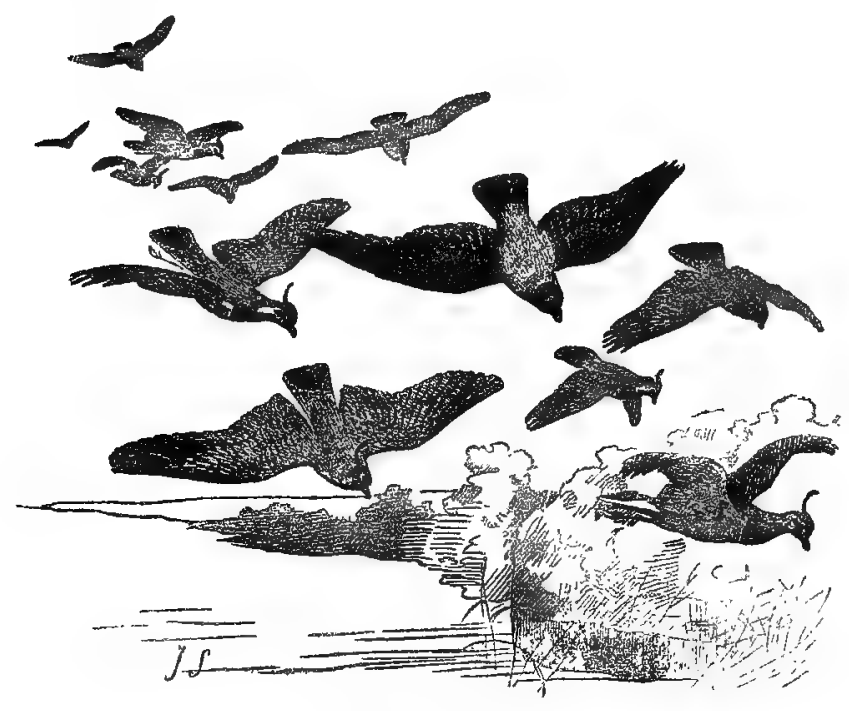

Master and Pupil

soon answering the cry. You see the thin little black bill divide as he bobs, and the sound comes out of it as though drawn by a wire-so roopy and raspy is it. Now he can contain himself no longer, but begins to walk about through the grass, making a devious course, and uttering the call at intervals. Very different is this note from the joyous, musical 'coo-oo-oo, hook-a-coo-ee, coo-ee.' Still, it is in 
harmony with nature, with the stillness, the sadness, the loneliness. This standing or pacing about whilst calling roopily, and, as it were, in a stealthy manner to each other, should be a very prosaic affair, one would think, for a pair of peewits after such glorious flying, but, no doubt, there is some excitement in it. Perhaps it is thought a little fast, as some slow things with us are, and hence the peculiar charm.

"Now these two birds are standing lazily on two of the black molehills which are all about the marshy land-some of them of a size beyond one's comprehension-and making the wire-drawn cry at intervals to each other. Lazily they stand, lazily they utter it, and seem as though they had taken up their roosting-place for the night. But when the night falls they will be hurrying shadows in it, and their cries will come out of the darkness, mingling with the bleatings of the snipe."

There is a sameness and yet a constant difference in the aerial sports and evolutions of peewits. It is like a continual variation of the same air or a recurrent thread of melody winding itself through a labyrinth of ever-changing notes. Parts of the melody are where two skim low over the ground in rapid pursuit of each other. One settles, the other skims on, then makes a great upward sweep, turns, sweeps down and back again, again rises, turns and sweeps again, and so on, rising and falling over the same wide space with the regular motions and long rushing swing of a pendulum. Each time it eomes rushing down upon the bird that has settled, and each time, at the right moment, this one makes a little ascension towards it, sometimes floating above 
it as it passes, sometimes beneath, alighting again immediately afterwards. This may continue for some little time, the one bird passing backwards and forwards over or under the other as long as he is received in the same way. Gradually, however, these little sorties against him from being at first hardly more than balloon-jumps - springs with aid of wings -become more and more prolonged, and extended outwards into his own radius of flight. The bird making them no longer alights in the same or nearly the same place as where he went up, but farther and farther away from it, the figure is lost, or becomes indistinct, "as water is in water," till at last the two are flying and chasing each other again.

This upward sweep from near the ground-sometimes from nearly touching it - with its attendant sweep back again, is one of the greatest beauties of the peewit's flight-a flight that is full of beauties. He does it often, but not always in quite the same way; it is a varying perfection, for each time it is perfect, and sometimes it seems to vie with almost any aerial master-stroke. The bird's wings, as it shoots aloft, are spread half open, and remain thus without being moved at all. The body is turned sideways-sometimes more, sometimes less-and the light glancing on the pure soft white of the under part, makes it look like the crest of foam on an invisible and swiftly-moving wave. As the uprush attains its zenith, there is a lovely, soft, effortless curling over of the body, and the foam sinks again with the wave. Such motions are not flight, they are passive abandonings and givings-up-to, driftings on unseen currents, bird-swirls and feathered eddies in the thin 
ocean of the air. It is, I think, the cessation of all effort on the bird's part which makes the great loveliness here. The impetus has been gained in flight before-acres of moorland away sometimes-it "cometh from afar." The upward fall, the delicious, crested curl and soft, sinking swoon to the earth are all rest-rhythmical, swift-moving rest.

Another curious and extremely pretty performance - a familiar bar of that thread of melody, that "main theme" of the "movement"-is when two birds, one just a little behind the other, and at slightly different elevations, both make the same movements, in quick succession, the bird behind mimicking the one in front of him in a kind of aerial follow-my-leadership. Does the one pause and hang on extended wings that rapidly beat the air, the other does so too. Does it sail on a little, and then make a sideway dive, it is imitated in the same way, and thus, often for quite a little while, the two will understudy each otherfor each, I think, may alternately become the leader. Again-if this is not merely a development of the above-two of them will hover on outstretched wings directly over and almost touching each other. Sometimes, indeed, they do touch, for the bird that is stretched above is continually trying to strike down on the other one with his wings, and often succeeds by making a sudden little drop on to him-a drop which is only of an inch or so-quite covering him up for a moment. Then, disjoining, they will flap along for some while, still close together, flashing out alternately dark and silver, as if showing their glints to each other, till in two "dying falls" they sweep apart, and skim the ground and double-loop the heavens. 
When peewits seem thus to battle together with their wings, in the air, it may well be that they are really fighting, in which case we may perhaps assume that they are two males, and not male and female. But as what I shall have to say with regard to the stock-dove on this point may be applied to the peewit, and as I have better evidence in the case of the former bird, I will not dwell on it longer here.

But the question arises whether in many other cases, when the sporting birds would seem to be male and female, this is really the case. One is apt to think so at first, but when one sees, often, a third bird associate itself with a pair who are thus behaving, and join for a little in their antics, or when one of a pair desisting and alighting on the ground, the other continues to sport in precisely the same way with another bird, or when, again, the supposed lovers become two of a small flock or band, and all sport thus together, crossing and intermingling till they again separate: one must suppose that these evolutions, though they may be mostly of a nuptial character, are not sexual in the strictest sense of the term, but that the social element enters more or less largely into them. But amongst savages there are, I believe (if not, let us imagine that there are), dances, the theme of which is marriage, where sometimes men, sometimes women, sometimes men and women, dance together, all having in their mind the primitive ideas suggested by that great institution, men thinking of women, women of men, under every kind of grouping. One may suppose it to be thus with the peewits, as they sport with one another in the air during the nuptial season, in which case the social and sexual elements would be a 
changing and varying factor. One may say, indeed, that there can be no sexual sport or play into which the social element does not also, and necessarily, enter. This is, no doubt, true, strictly speaking, but the latter may be so merged in the former that practically it does not exist.

Some of the peewits' nuptial and non-aerial bizarreries are of this nature, but as they are peculiar, and seem to stand in some relation to another great class of avian activities, I shall reserve them for a future chapter.

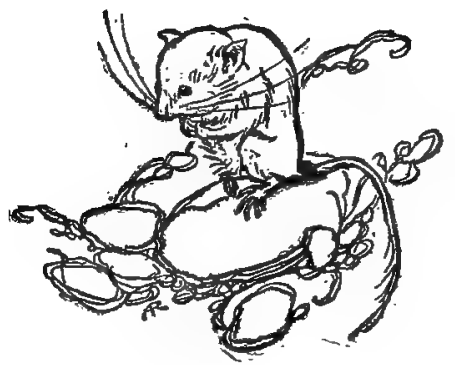




\section{CHAPTER III}

\section{Watching}

Stock doves

Wood pigeons

Snipe, etc,

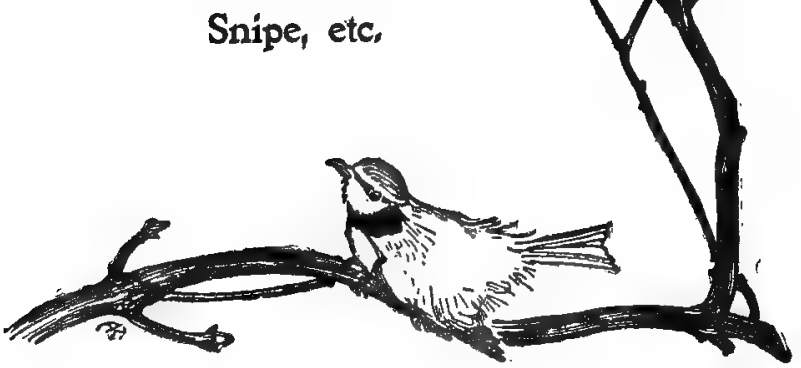

I HAVE alluded to the aerial combats of the stockdove during the nuptial season as elucidating similar movements on the part of the peewit, though I was not able so fully to satisfy myself as to the meaning of these in the latter bird. The fighting of birds on the wing has sometimes-to my eye, at least-a very soft and delicate appearance, which does not so much resemble fighting as sport and dalliance between the sexes. Larks, for instance, have what seem, at the worst, to be delicate little mock-combats in the air, carried on in a way which suggests this. Sometimes, rising together, they keep approaching and retiring from each other, with the light, swinging motion of a 
shuttlecock just before it turns over to descend, and this resemblance is increased by their flying perpendicularly, or almost so, with their heads up and tails down. Indeed, they seem more to be thrown through the air than to fly. Then, in one fall, they sink together into the grass. Or they will keep mounting above and above each other to some height, and then descend in something the same way, but more sweepingly (for let no one hope to see exactly how they do it), seeming to make with their bodies the soft links of a feathered chain-or as though their own "linked sweetness" of song had been translated into matter and motion. In each case they make all the time, as convenient, little kissipecks, rather than pecks, at each other.

Again, in the case of the redshank, though I have little doubt now that the following, which was both aquatic and aerial, was a genuine combat between two males, yet often at the time, and especially in its preface and conclusion, it seemed as though the birds were of opposite sexes, and, if fighting at all, only amorously. "Two birds are pursuing each other on the bank of the river. The water is low, and a little point of mud and shingle projects into the stream. Up and down this, from the herbage to the water's edge and back again, the birds run, one close behind the other, and each uttering a funny little piping cry-' tu-tu-oo, tu-oo, tu-oo, tu-oo.' It is one, as far as I can see, that always pursues the other, who, after a time, flies to the opposite bank. The pursuer follows, and the chase is now carried on by a series of little flights from bank to bank, sometimes straight across, sometimes slanting a little up or down the stream, whilst 
sometimes there is a little flight backwards and forwards along the bank in the intervals of crossing. This continues for something like an hour, but at last the pursuing bird, as both fly out from the bank, makes a little dart, and, overtaking the other one, both flutter down into the stream. They rise from it straight up into the air like two blackbirds fighting, then fall back into it again, and now there is a violent struggle in the water. Whilst it lasts the birds are swimming, just as two ducks would be under similar circumstances, and every now and then, in the pauses of exhaustion, both rest, floating on the water. The combat would be as purely aquatic as with coots or moor-hens, if it were not that the two birds often struggle out of the water and rise together into the air, where they continue the struggle, each one rising alternately above the other and trying to push it down-it would seem with the legs. These were the tactics adopted in the water too, but yet, with a good deal of motion and exertion, there seems but little of fury. The birds are not acharne, or, at least, they do not seem to be. It is a soft sort of combat, and now it has ended in the combatants making their mutual toilette quite close to one another. One stands on the shore and preens itself, the other sits just off it on the water and bathes in it like a duck."

Even here, owing principally to the friendly toilettescene, I was not quite clear as to the nature of the bird's actions. How completely I at first mistook it in the case of the stock-dove with the way in which it was afterwards made plain to me, the following will show:- 
"Most interesting aerial nuptial evolutions of the male and female stock-dove.-They navigate the air together, following each other in the closest manner, one being, almost all the while, just above the other, their wings seeming to pulsate in time as soldiers (if sweet birds will forgive such a simile) keep step. Now they rise, now sink, making a wide, irregular circle. Both seem to wish, yet not to wish, to touch, almost, yet not quite, doing so, till, when very close, the upper one drops lightly towards the one beneath him, who sinks too; yet for a moment you hear the wings clap against each other. This sounds faintly, though very perceptibly; but the distance is great, and it must really be loud. Every now and again the wings will cease to vibrate, and the two birds sweep through the air on spread pinions, but, otherwise, in the manner that has been described. I must have watched this continuing for at least a quarter of an hour before they sunk to the ground together, still maintaining the same relative position, and with quivering wings as before. Here, however, something distracted me, the glasses lost them, and I did not see them actually alight. Another pair rise right from the ground in this manner,* one directly above the other, quiver upwards to some little height, then sweep off on spread pinions, following each other, but still at slightly different elevations. They overtake one another, quiver up still higher, with hardly an inch between them, then suddenly, with an, as it were, 'enough of this,' sweep apart and float in lovely circles, now upwards now downwards. As they do this another bird rushes through the air

* But I did not see what they were doing before they rose. 
to join them, he circles too, all three are circling, the light glinting on one, falling from another, thrown and caught and thrown again as if they played at ball with light."

I thought, therefore, that birds when they flew in pairs like this were disporting themselves together in a nuptial flight, and making-as indeed this, in any case, is true-a very pretty display of it. What was there, indeed - or what did there seem to be - to indicate that angry passions lay at the root of all this loveliness? But I had not taken sufficiently into consideration that sharp clap of the wings indicating a blow-a severe one-on the part of one of the birds with a parry on that of the other. This is how stock-doves, as well as other pigeons, fight on the ground, and it is as an outcome and continuation of these fierce stand-up combats - which there is no mistaking - that the contending birds rise and hover one over the other, in the manner described. My notes will, I think, show this, as well as the curious and, as it were, formal manner in which the ground-tourney is conducted.

"Two stock-doves fighting.-This is very interesting and peculiar. They fight with continual blows of the wings, these being used both as sword-or, rather, partisan-and shield. The peculiarity, however, is this, that every now and again there is a pause in the combat, when both birds make the low bow, with tail raised in air, as in courting. Sometimes both will bow together, and, as it would seem, to each otherfacing towards each other, at any rate-but at other times they will both stand in a line, and bow, so that one bows only to the tail of the other, who bows to 
the empty air. Or the two will bow at different times, each seeming more concerned in making his bow than in the direction or bestowal of it. It is like a little interlude, and when it is over the combatants advance, again, against each other, till they stand front to front, and quite close. Both, then, make a little jump, and battle vigorously with their

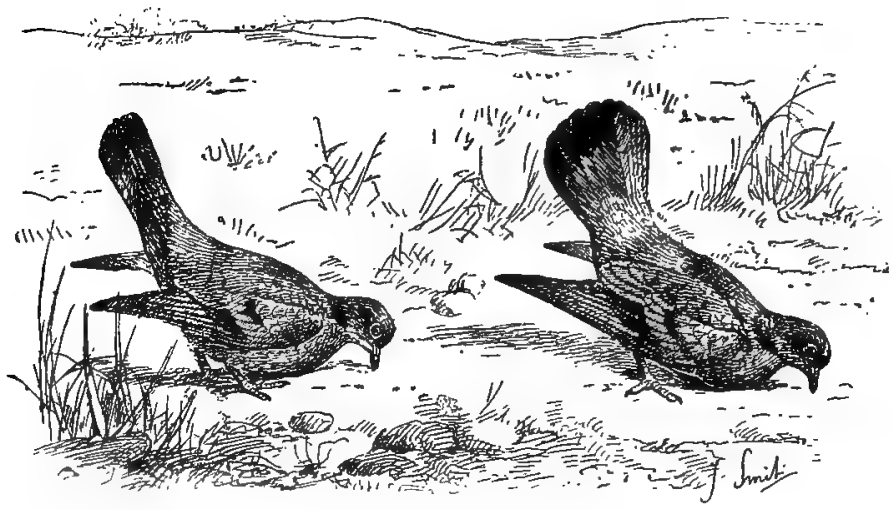

Stock-doves: A Duel with Ceremonies

wings, striking and parrying. One now makes a higher spring, trying, apparently, to jump on to his opponent's back, and then strike down upon him. This is all plain, honest fighting, but there is a constant tendency-constantly carried out-for the two to get into line, and fight in a sort of follow-my-leader fashion, whilst making these low bows at intervals. It is a fight encumbered with forms, with a heavy, punctilious ceremony, reminding one of those ornate sweeps and bowing rapier-flourishes which are entered 
into before and at each pause in the duel between Hamlet and Laertes, as arranged by Sir Henry Irving at the Lyceum. There were four or five birds together when this fight broke out, but I could not feel quite sure whether the non-fighting ones watched the fighting of the other two. If they did, I do not think they were at all keenly interested in it. Also, the fighting birds may sometimes, when they bowed, have done so to the birds that stood near, but it never seemed to me that this was the case, and it certainly was not so in most instances."

In the spring from the ground which one of the fighting birds sometimes makes, coming down on the other one's back and striking with the wings, we have, perhaps, the beginning of what may develop into a contest in the clouds, for let the bird that is undermost also spring up, and both are in the air in the position required; and it is natural that the undermost should continue to rise, because it could more easily avoid the blows of the other whilst in the s air, by sinking down through it, than it could on the ground at such a disadvantage. Whether, in the following instance, the one bird jumped on to the other's back does not appear, but, as will be seen, the flight, which I had thought to be of a sexual and nuptial character, was the direct outcome of a scrimmage. "A short fight between two birds.-It is really most curious. There is a blow and then a bow, then a vigorous set-to, with hard blows and adroit parries, a pause with two profound bows, another set-to, and then the birds rise, one keeping just above the other, and ascend slowly, with quickly and constantly beating wings, in the way so often 
witnessed. It would appear, therefore, that the curious flights of two birds up into the air, the one of them exactly over, and almost touching, the other-wherein, as I have noted, there is frequently a blow with the wings which, to judge by the sound reaching me from a considerable distance, must be sometimes a severe one-are the aerial continuations of combats commenced on the ground." Sometimes, that is to say. There seems no reason why birds accustomed thus to contend, should not sometimes do so $a b$ initio, and without any preliminary encounter on mother earthand this, I believe, is the case.

Here, then, in the stock-dove we have at the nuptial season a kind of flight which seems certainly to be of the nature of a combat, very much resembling that of the peewit at the same season. I have seen peewits fighting on the ground, and once they were for a moment in the air together at a foot or two above it, and the one a little above the other. This, however, may have been mere chance, and I have not seen the one form of combat arise unmistakably out of the other, as in the case of the stock-doves. But assuming that in each case there is a combat, is it certain that the contending birds are always, or generally, two males, and not male and female? It certainly seems natural to suppose this, but with the stock-dove, at any rate (and I believe with pigeons generally), the two sexes sometimes fight sharply; and, moreover, the female stock-dove bows to the male, as well as the male to the female, both which points will be brought out in the following instances:-

"A hen bird is sitting alone on the sand, a male 
flies up to her and begins bowing. She does not respond, but walks away, and, on being followed and pressed, stands and strikes at her annoyer with the wings, and there is, then, a short fight between the two. At the end of it, and when the bowing pigeon has been driven off and is walking away, having his tail, therefore, turned to the one he is leaving, this one also bows, once only, but quite unmistakably. The bow was directed towards her retiring adversary, and also wooer, the two birds therefore standing in a line." And on another occasion "A stock-dove flies to another sitting on the warrens, and bows to her, upon which she also bows to him. Yet his addresses are not successfully urged."

The sexes are here assumed, for the male and female stock-dove do not differ sufficiently for one to distinguish them at a distance through the glasses. When, however, one sees a bird fly, like this, to another one and begin the regular courting action, one seems justified in assuming it to be a male and the other a female. Both, however, bowed, and there was a fight, though a short one ( $I$ have seen others of longer duration), between them. It becomes, therefore, a question whether the much more determined fights which I have witnessed are not also between the male and the female stock-dove, and not between two males. If so, the origin of the conflict is, probably, in all such cases-as it certainly has been in those which I have witnessed - the desires of the male bird, to which he tries to make the female submit. That she, in the very midst of resisting, taken, as it would seem, "in her heart's extremest hate," should yet bow to her would - be 
ravisher seems strange, but she certainly does so. Whether it would be more or less strange that two male birds, whilst fiercely contending, should act in this way, I will leave to my readers to decide, and thus settle the nature of these curious ceremonious encounters and their graceful and interesting aerial continuations, to their own satisfaction.*

However it may be, the bow itself-which I will now notice more fully-is certainly of a nuptial character, and is seen in its greatest perfection only when the male stock-dove courts the female. This he does by either flying or walking up to her and bowing solemnly till his breast touches the ground, his tail going up at the same time to an even more than corresponding height, though with an action less solemn. The tail in its ascent is beautifully fanned, but it is not spread out flat like a fan, but arched, which adds to the beauty of its appearance. As it is brought down it closes again, but, should the bow be followed up, it is instantly again fanned out and sweeps the ground, as its owner, now risen from his prostrate attitude, with head erect and throat swelled, makes a little rush towards the object of his desires. The preliminary bow, however, is more usually followed by another, or by two or three others, each one being a distinct and separate affair, the bird remaining with his head sunk and tail raised and fanned for some seconds before rising to repeat. Thus it is not like two or three little bobs-which is the manner of wooing pursued by the turtle-dove-

* With this suggestion, however, that fighting may be blended with sexual display in the combats of male birds owing to association of ideas, for rivalry is the main cause of such combats. 
but there is one set bow, to which but one elevation and depression of the tail belongs, and the offerer of it must not only regain his normal upright attitude, but remain in it for a perceptible period before making another. This bow, therefore, is of the most impressive and even solemn nature, and expresses, as much as anything in dumb show can express, "Madam, I am your most devoted."

I believe-but I am not sure, and quite ready to be corrected-that the stock-dove's bow is either a silent one, or, at least, that the note uttered is subdued - the latter seems the more probable. At any rate, I was never able to catch it, either when watching on the warrens at a greater or less distance, or when not so far, amongst trees - for the stock-dove woos also amongst the leafy woods, as does the woodpigeon, of which it is a smaller replica, but without the ring. "The male wood-pigeon, when courting, bows to the female lengthways along the branch on which he is sitting, elevating his tail at the same time, in just the same way as does the stock-dove. As he does so, he says 'coo-0o-oo,' the last syllable being long drawn out, and having a very intense expression, with a rise in the tone of it, sometimes almost to the extent of becoming a soft shrillness. Having delivered himself of this long 'coo-oo-oo,' he says several times together in an undertone, and very quickly, 'coo, coo, coo coo,' or 'coo, coo; coo, coo, $\mathrm{coo}, \mathrm{coO}, \mathrm{coo}$,' after which, rising, and then bowing again, he recommences with the long-drawn, impassioned 'coo-oo-oo,' as before. All this he repeats several times, the number, probably, depending on whether the female bird stays to hear his addresses 
or, as is usual in the contrary, flies away. If she admits them pairing may take place, and at the conclusion of it both birds utter a peculiar, low, deep, and very raucous note which I have heard on this occasion, but on no other."

If the courting of the female stock-dove by the male whilst on the ground, or amongst the branches of a tree, is of a somewhat heavy nature - more pompous than beautiful-as is, I think, the case, it is lightened in the most graceful manner by the aerial intermezzos - the broidery of the theme-which charmingly relieve and set it off; for often, "after bowing and walking together a little, near, but not touching-a Hermia and Lysander distance-both rise, both mount, attain a height, then pause, and, as from the summit of some lofty precipice, descend on outspread joy-wings in a very music of motion. It is pretty, too, to watch two of them flying together and then alighting, when one instantly bows before the other with empresse mien. Before, you have not known which was which, or who was escorting the other. Now you feel sure that it is he-the empresse, the pompously bowing bird-who has taken her-the retiring, the coy one-for a little fly." For though it is undoubted that the female stock-dove bows to the male, yet, in courting, it is the male, I believe, who commences and carries it to a fine art.

There are no birds surely-or, at least, not many - who can sport more gracefully in the air than these. "One is sitting and cooing almost in a rabbit-burrow, and so close to a rabbit there that it looks like a little call. Sure enough, too, after a while, the bird, who, of course, is the visitor, rises-but into the air sans 
ceremonie-and makes as though to fly away. But having gone only a little distance, with quick strokes of the wings, it rests upon their expanded surface, and, in a lovely easy sweep, sails round again in the direction from whence it started. It passes beyond the place, the wings now again pulsating, then makes another wide sweep of grace and comes down near where it was before. In a little it again rises, again sweeps and circles, and again descends in the neighbourhood. Another now appears, flying towards it, and as it passes over where the first is sitting, this one rises into the air to meet it. They approach, glide from each other, again approach, and thus alternately widening and narrowing the distance between them, one at length goes down, the other passing on to alight, at last, at that distance which the etiquette of the affair prescribes. This circling flight on swiftly resting wings is most beautiful. The pausing sweep, the lazy onwardness, the marriage, as it were, of rest and speed is a delicious thing, another sense, a delicate purged voluptuousness, a very banquet to the eye." Such beauty - flights are almost always in the early morning, when appreciative persons are mostly in bed, seen only by the dull eye of some warrener walking to find and kill the beasts that have lain tortured in his traps all night, exciting (if any) but a murderous thought at the time, with the after-reflection, "If I'd a had a gun now"

Stock-doves, as is well known, often choose rabbitburrows to lay their eggs in, and, having regard to their powers of flight and arborial aptitudes, it might be thought that but for the rabbits they would never 
be seen on these open, sandy tracts, the abode of the peewit, stone-curlew, ringed plover, red-legged partridge, and other such waste-haunting species. But the nesting habits of a bird must follow its general ones almost necessarily in the first instance, and though there are many apparently striking instances to the contrary, they are probably to be explained by the former having remained fixed whilst the latter have changed. No doubt, therefore, the stockdove began to spend much of its time on the ground before it thought of laying its eggs there, and of the facilities offered by rabbit-holes for so doing. That the habits as well as the organisms of all living creatures are in a more or less plastic and fluctuating state is, I believe, a conclusion come to by Darwin, and it agrees entirely with the little I have been able to observe in regard to birds. I have seen the robin redbreast become a wagtail or stilt-walker, the starling a wood-pecker or fly-catcher, the tree-creeper also a fly-catcher, the wren an accomplished treecreeper, the moor-hen a partridge or plover, and so on, and so on, all such instances having been noted down by me at the time. Most birds are ready to vary their habits suddenly and de novo if they can get a little profit on the transaction, and the extent to which they have varied gradually in a long course of time and under changed conditions is, of course, a commonplace after Darwin. The wood-pigeon has not yet begun to lay its eggs in rabbit-holes or anywhere but in trees and bushes, but that it may some day do so is not improbable, for it comes down sometimes, though not very frequently, on the same sandy wastes that are loved by the stock-dove, 
and here, like him, the male will court the female as though on the familiar bough.* When I have seen him courting her thus on the ground, the low bow which he makes her has been prefaced by one or more curious hops, which I have not seen in the stock-dove's courting. They look curious because they are so out of character, hopping being, as far as I know, a mode of progression foreign to all the columbide. Whether the wood-pigeon hops upon any other occasion I cannot be sure. If he does notand it is certainly not his usual habit-his adoption of it here may be looked upon as a purely nuptial antic. In this the lark, which is also a stepping and not a hopping bird, keeps him company, as would the cormorant, were it not that he hops often as a matter of convenience. Larks I have not seen hop in everyday life, though sometimes I have thought that they did when running quickly over ploughed land in winter, as starlings often do when they break from a run which has become too quick for them into a running hop. But I came to the conclusion that this was only apparent, and due to their up and down motion over the clods of earth. A hop is quite foreign to the lark's disposition, yet, when courting, "the male bird advances upon the female with wings drooped, crest and tail raised, and with a series of impressive hops." The hop of the wood-pigeon, under similar circumstances, is of a heavy and deliberate nature, as might be expected his build and size, and has the same set and formal from character as the bow which immediately follows it.

The turtle-dove bows too, in courtship, but it is a

* The same remark applies to the turtle-dove. 
series of quick little bows, or, rather bobs, which he makes to his fiancée instead of one or more slower and much more imposing ones. Essentially, however, it is the same thing. The pace has been quickened and the interval lessened, whilst, to allow of the increased speed, the bow itself has been shorn of much of its pomp and circumstance, so that it has become, as I say, a mere bob. The turtle-dove may perform some half-dozen or more of these bobs, taking less time, perhaps, to get through them than do his larger relatives to achieve one of their solemn and formal bows. Still he is pompous too, he bends down low at the shrine, and though each little bob may not be much in itself, yet, when thus strung together, the display as a whole is equal to the other two.

All the time he is thus bowing or bobbing the turtle-dove utters a deep, rolling, musical note which is continuous (or sounds so), and does not cease till he has got back into his more everyday attitude. The hen looks sometimes surprised, sometimes as though she had expected it, and sometimes, I think, -but of this I am not quite positive-she will return the little series of musical bobs. This is in tree-land; but I have seen the turtle-dove court on the ground, and he then, between his bobbings, made a curious dancing step towards the female, who retired and gave her final answer by flying away. But, besides this, these birds have another and most charming nuptial disportment. Sitting a deux in some high tree, one of them will every now and again fly out of it, mount upwards, make one or two circling sweeps around and above it, then, after remaining poised for some seconds, descend on spread wings 




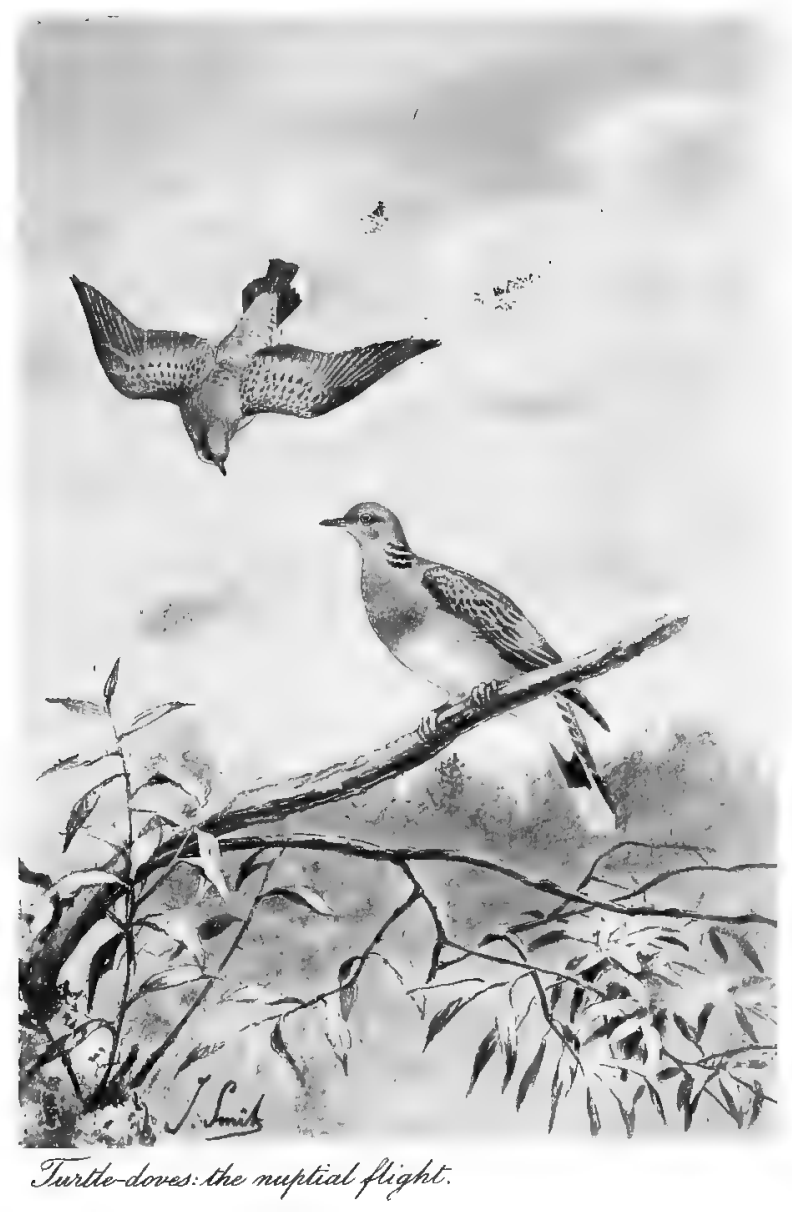


in the most graceful manner, alighting on the same branch beside the waiting partner. This is a beautiful thing to see, and especially in the early fresh morning of a clear, lovely day. It seems then as if the bird kept flying up to greet "the early rising sun," or as rejoicing in the beauty of all things. These are the coquetries, the prettinesses of loving couples, as to which-on one side at least-what has not been said by the writers of our clumsy race! But "if the lions were sculptors "- How might a bird novelist expatiate!

Not less beautiful is the nuptial flight of the woodpigeon. Of this, the clapping of the wings above the back is the most salient feature, a sound which is never heard during the winter or after the breedingseason is fairly over. "In full flight, the bird smites its wings two or three times smartly together above the back, then, holding them extended and motionless, it seems to pause for one instant-if there can be pause in swiftest motion-before sinking and then rising and sinking again, as does a wave, or as though it rested on an aerial switchback. Then continuing his flight-recommencing, that is to say, the strokes of his wings-he may do the same when he has gone a few air-fields farther, and so "pass in music out of sight." Sometimes there will be only a single clap of the wings instead of two or three,* but always it is made just before the still-spreading of them, and the hanging pause in the air; for let the speed be never so great-and it hardly seems possible that it could be checked so suddenly, and why should the bird wish to check it?-yet the effect upon the eye of the wings extended and motionless after they have

* Sometimes, too, not any, the flight being the same. 
been pulsating so rapidly is as of a pause. This pause, or rather this rest-in-speed, as the bird, renouncing all effort, is carried swiftly and placidly onwards in a curve of the extremest beauty has a delicious effect upon one. One's spirit goes out until one seems to be with the bird oneself, hanging and sweeping as it does. Yet in this glory of motion it will often be shot by beings, in all grace and beauty and poetry of life, how infinitely its inferiors! This makes me think of Darwin's comment upon Bate's account of a humming-bird caught and killed by a huge Brazilian spider, wherein the destroyer and the victim - " one, perhaps, the loveliest, the other the most hideous in the scale of creation"*-are contrasted. Spiders, too, had they their Phidiases, might be idealised and made to look quite beautiful in marble, even perhaps to our eyes (what cannot genius do?) whilst to their own, of course, the spider form would be "the spider form divine."

Wood-pigeons will also fly circling about above the trees in which they have been sitting, in rapid pursuit of each other, and whilst doing so, one or other of them may be heard to make a very pronounced swishing or beating sound with the wings, reminding one of the peewit, nightjar, and a great many other birds. Of instrumental music produced during flight, the snipe is a familiar example. Here, however, the very peculiar and highly specialised sound known as bleating or drumming is produced, not by the feathers of the wing, but by those of the tail, which have been specially modified, as we may suppose (those, at least, of us who are believers in that force), by a pro-

* I quote from memory. 
cess of musical sexual selection. To quote Darwin: "No one was able to explain the cause until $\mathrm{Mr}$ Meves observed that on each side of the tail the outer feathers are peculiarly formed, having a stiff sabre-shaped shaft with the oblique barbs of unusual length, the outer webs being strongly bound together. $\mathrm{He}$ found that by blowing on these feathers, or by fastening them to a long thin stick and waving them rapidly through the air, he could reproduce the drumming noise made by the living bird. Both sexes are furnished with these feathers, but they are generally larger in the male than in the female, and emit a deeper note."

The possibility of reproducing the sound in the manner described seems conclusive as to the cause of it. Otherwise I should have come to the conclusion, by watching the bird, that the wings and not the tail were the agency employed.

"I have just been watching for some time a snipe continually coursing through the air and making, at intervals, the well-known drumming or bleating sound,-bleating certainly seems to me the word which best expresses its quality. The wings are constantly and quickly quivered, not only when the bird rises or flies straight forward, but also during its swift oblique descents, when one might expect that they would be held rigid in the ordinary manner. From each sweep down the bird rises and beats again upwards, but when the flight has been continued long enough the wings are pressed to the sides as the plunge to earth is made, which is also one way in which the lark descends. It is during these downward flights-but not during the descent 
to earth-that the sound strikes the ear. A second bird flies, to my surprise and interest, quite differently. After scudding about for some little time in a devious side-to-side pathway, less up and down, as it seems to me, than the other, it suddenly tilts itself sideways, or almost sideways-one wing pointing skywards, the other earthwards-and makes a rapid swoop down, with the wings not beating. I watch it doing this time after time, both with the naked eye and through the glasses, and each time that the swoop is made no bleating or other sound accompanies it: the flight is noiseless, like that of an ordinary bird. Two other snipes are now flying about in this latter way and chasing each other. At first-and this included a great many sweeps down-I heard no sound. Afterwards I thought I heard it faintly sometimes, but could not be sure that it was not made by another bird-a frequent difficulty in watching snipe." Again, "A snipe is standing alone 'in the melancholy marshes,' quite still, and uttering the creaky, sea-sawey note. I can see the two long mandibles of the beak dividing slightly and again closing. The note is now thin and subdued, but, the bird taking flight suddenly, it becomes much accentuated. It joins two other birds in the air, and all three now sport and pursue each other about, constantly uttering this cry, but bleating only occasionally. I am lying flat on the ground, and they often fly close about and over me, the light, too, being good, it being all before 5.40, and not much after 5, perhaps, when it commenced (this was April 4th). I note that they often descend through the air without vibrating the wings, and there is 
then no bleating sound-this whilst quite close. I think-but am not yet quite sure-that they sometimes descend in this way uttering the cry. When they bleat, however, there is never the cry at the same time. It is impossible to tell when these birds are going to alight, as they often descend in the manner that they use when alighting, but, when almost down, skim a little just over the ground, and, rising again, continue their flight as before. Yet that they have had it in their mind to alight I feel sure, for they always do so with that particular action."

Since, then, the snipe has two ways of making his rapid descents through the air, in one of which he quivers his wings and in the other not, and since, on the latter occasion, the bleat is not heard or, if heard, only faintly, it would be natural to suppose that the sound-if not vocal-was produced by the rapidly vibrating feathers of the wing when in swift downward motion rather than by those of the tail, which should not, one would think, be affected by the difference. Also the fact of the vocal note not being uttered at the same time as the bleat might make one think that this, too, was vocal. Such arguments, however, would be at best but "poor seemings and thin likelihoods"-the last one, I believe, not supported by what we know (at least I cannot at the moment think of a bird that produces vocal and instrumental music at the same time). If the sound can really be reproduced by waving the modified feathers of the tail, then this is a demonstration.*

Snipe, as already observed, descend to the ground

* I have lately observed that when the snipe descends with quivering wings, some outer feathers of the tail on each side are shot out from 
in order to alight upon it in a manner quite different to the oblique downward-shooting sweeps, with wings extended, whether vibrating or not, as practised in ordinary nuptial flight. There are three ways, possibly more; but three I have seen. In the first the bird shoots gracefully down, with the wings pressed to the sides, as already described. In the second the wings are raised straight, or almost straight, above the back, and this gives, perhaps, a still more graceful appearance. The third way is not nearly so usual a one as the other two-in fact, I only recall having seen it once. In this the wings are but half spread (whilst held in the ordinary manner) and motionless, and the bird descends in several sweeps to one side or the other, something after the manner in which a kite comes to the ground. No sound attends any of these forms of descent.

The cry of the snipe which I have alluded to, is of a curious nature, something like the word "chackwood, chack-wood, chack-wood, chack-wood," constantly repeated, and having a regular rise and fall in it, which is why I call it a "see-saw note." Sometimes, when the bird is a little way off, it sounds very much like a swishing of the wings; but when these are really swished, as they often are-purposely, I believe, and as a nuptial performance-the difference is at once apparent. "Two snipes will often fly chasing each other, uttering this note, and making from time to time the loud swishing with the wings. Often, too, there will be a short, harsh cry-harsh, but with that wild, loved harshness that lives in the notes it in a most noticeable manner, making-or looking like-two little curved tufts. They are not seen before, which seems to me strong evidence. The tail itself is fanned. 
of birds that haunt the waste-which is instantly followed by a swishing of the wings, making quite a music in the air. When at its loudest and harshest, this cry, which then becomes a scream, is quite an extraordinary sound, having a mewing intonation in it suggesting a cat as the performer. Yet it is nothing so extraordinary as some notes of the snipe which I have heard, mostly during the winter, and which are indeed-at least they have struck me as being soamongst the most wonderful that ever issued from the throat of bird. I will recur to them again when I come to the moor-hen (for it was in his company I heard them), a bird that is itself as a whole orchestra of peculiar brazen instruments. These wild cries and screams blend harmoniously with the curious, monotonous, yet musical bleating, and come finely out of the gloom of the evening thickening into night, as it descends over the wide expanse of the fenlands. Best heard then-and there: the darkening sky, the wide and wind-swept waste of coarse tufted grass, amongst which brown dock-stalks stand tall-ly and thinly, the long, raised bank with its thin belt of reeds beyond, emphasising rather than relieving the flatness, the lonely thorn-bush, the stunted willow or two, the black line of alders marking the course of the sluggish river, the wind, the sad whispered music in the grasses, the wilder music in the air, the aloneness, the drearness-such voices fit such scenes."

The male and female snipe both bleat, but the feathers in the tail which produce the sound are less modified in the female, and the sound which they produce is said to be different in consequence. That there must be a difference would seem to follow of 
necessity; but, according to my own experience, it requires a nice ear to distinguish the bleating of the one sex from that of the other. There is, indeed, some slight difference in the sound made by each individual snipe, but I only once remember hearing one bleating with a markedly different tone. Here the sound had a lower, softer, and deeper intonation, and was, to my mind, a more musical sound altogether. When heard just before or after the bleat of another snipe the difference was very marked, but I considered it to be rather an individual than a sexual distinction, for I do not know that there is any reason to suppose that the female snipe bleats less frequently than the male except when she is sitting on her eggs.

Snipe, when bleating, fly round and round in a wide irregular circle, and for a long time one will not overstep the invisible boundary so as to encroach upon the domain of the other. It seems-but the illusion will be broken after a time-as though each bird had his allotment in the fields of air and knew that he would be guilty of a rudeness in entering that of another. Thus, though three or four of them may be flying and bleating in the neighbourhood, it is often difficult to watch more than one at a time with anything like closeness of observation, a difficulty which is often increased by the failing light; for, in my own experience, snipe bleat best either in the earlythough not very early-morning, or when evening has begun to close in. To follow their wide, swift, eccentric circle of flight one must keep turning round on a fixed point, and this, amidst swamp and grasstufts, is difficult to do without losing one's balance. Yet still one watches and turns and strains one's eyes 
into the darkness, unable to go, for one loves to see that small, swift, vocal shadow appearing out of the great, still, silent ones and disappearing, again, into them. When thus disporting, each within its own charmed circle, the downward rush and bleat of one snipe will often for a long time immediately precede or follow that of another, bleat answering to bleat, till at length the duet is broken and complicated by a third intermingling voice. At last a bird, trampling on etiquette, will flit into the circle of the one you are watching, and the two, excitedly pursuing each other with "chack-wood, chack-wood," or, with the harsh, wild scream and loud swish of pinions, will speed off and vanish together.

No doubt the male snipes bleat against each other in rivalry, but it would also seem (a sentence, I confess, which I never use when I have an undoubted instance to give) that the male and female bleat to one another connubially, or in a lover-like manner. Here, however, is an instance (as I translate it) of the one bleating whilst the other sits listening and responding vocally on the ground.

"A snipe flies with a scream over the marshy meadows. As he passes one little swampy bit another snipe utters from out of it the see-sawey, 'chackwood' note, in answer, as it appears, to the scream. The first snipe now flies round about over the meadows and land adjoining, bleating, whilst the other one in the grass continues to see-saw."

Many birds, as is well known, have the instinct, when suddenly discovered with their young ones, of tumbling over or fluttering along the ground as though they had sustained some injury which had 
rendered them unable to fly, so that the murderous or thievish longings of "the paragon of animals" being diverted from their progeny to themselves, the former may take thought and escape. The nightjar, partridge, and, especially, the wild-duck, are good instances of this, and in every case where I have come upon them under the requisite conditions they have never failed to show me their shrewd estimate of man's nature. With all these three birds, however, it has always been the presence of the young that has moved them to act in this manner, their conduct during incubation being quite different. The instance which I am now going to bring forward with regard to the snipe has this peculiarity, if it be one, that the bird was hatching her eggs at the time and was still engaged in doing so a few days afterwards, proving that the young were not just on the point of coming out on the occasion when she was first disturbed. As I noted all down the instant after its occurrence, the reader may rely upon having here just exactly what this snipe did.

"This morning a snipe flew out of some long reedy grass within a few feet of me, and almost instantly taking the ground again - but now on the smooth, green meadow - spun round over it, now here, now there, its long bill lying along the ground as though it were the pivot on which it turned, and uttering loud cries all the while. Having done this for a minute or so, it lay, or rather crouched, quite still on the ground, its head and beak lying along it, its neck outstretched, its legs bent under it, with the body rising gradually, till the posterior part, with the tail, which it kept fanned out, was right in the air. And 
in this strange position it kept uttering a long, low, hoarse note, which, together with its whole demeanour, seemed to betoken great distress. It remained thus for some minutes before flying away, during which time I stood still, watching it closely, and when it was gone, soon found the nest, with four eggs in it, in the grass-tuft from which it had flown. Its action whilst spinning over the ground was very like that of the nightjar when put up from her young ones." It is to be noted here that this snipe flew a very little way from the nest, and when on the ground did not travel over it to any extent, but only in a small circle just at first, after which it kept in one place. The Arctic skua (Richardson's skua, as some call it, but I hate such appropriative titles-as though a species could be any man's property!) behaves in the same kind of way, for, lying along on its breast, with its wings spread out and beating the ground, it utters plaintive little pitiful cries, keeping always in the same, or nearly the same, spot. This has, of course, the effect of drawing one's attention to the bird, and away from the eggs or young (whether it acts thus in regard to both I am not quite sure, but believe that it does), but the effect produced on one - though here, of course, as throughout, I only speak for myself-is that the bird is in great mental distress-prostrated as it were-rather than acting with any conscious "intent to deceive." The same is the case with the nightjar, whose sudden spinning about over the ground in a manner much more resembling a maimed bluebottle or cockchafer than a bird, seems to proceed from some violent nervous shock or mental disturbance. The same, too, though 
in a lesser degree, may be said of the partridge, and in all cases it is obvious that the bird is very much excited and ausser sich.

Darwin, if I remember rightly, ${ }^{*}$ found it difficult to believe that birds, when they thus distract our attention from their young to themselves, do so with a full consciousness of what they are doing and why they are doing it. When the female wild-duck, however, acts in this manner, it is difficult, I think, to escape from this conclusion. She flaps for a long way over the surface of the water, pausing every now and again and waiting, as though to see the effect of her ruse, and continuing her tactics as soon as you get up to her. Having thus led you a long distance away, she rises, and leaving the river, flies in an extended circle, which will ultimately bring her back to it by the other bank when you are well out of the way. The chicks, meanwhile, have (of course) scuttled in amongst the reeds and rushes, though they often take some little while to conceal themselves. She acts thus on a river or broad stretch of water, which enables her to keep you in sight for some time. But it is obvious that if you come upon her with her family in a very narrow and sharply winding stream, the first bend of it will hide you from her, and she would then, assuming that she is acting intelligently, have all the agony of mind of not knowing whether her plan was succeeding or not. It was in such a situation that I met her only last spring, and to my surprise-and indeed, admiration-instead of flapping along the water as I have always known her to do before in such a contre-

* But I have not been able to find the passage, so may be mistaken. 
temps, she instantly flew out on to the opposite bank, and began to flap and struggle along the flat marshy meadow-land, of course in full view. I crossed the stream and pursued her, allowing her to "fool me to the top of my bent," and this she appeared to me to do, or to think she was doing, on much the same kind of indicia as one would go by in the case of a man. Now, unless this bird had wished to keep me in view, and thus judge of the effect of her stratagem, or unless she feared that "out of sight" would be "out of mind" with regard to herself (but this would be to credit her with yet greater powers of reflection), why should she have left the water, the element in which she usually and most naturally performs these actions, to modify them on the land? Yet to suppose that it has ever occurred suddenly, and as a new idea, to any bird to act a pious fraud of this kind, would be to suppose wonders, and also to be unevolutionary (almost as serious a matter nowadays as to be un-English).

But may we not think that an act, which in its origin has been of a nervous and, as it were, pathological character, has become, in time, blended with intelligence, and that natural selection has not only picked out those birds who best performed a mechanical action-which, though it sprung merely from mental disturbance, was yet of a beneficial naturebut also those whose intelligence began after a time to enable them to see whereto such action tended, and thus consciously to guide and improve it? There is evidence, I believe - though neither space nor the nature of this slight work will allow me to go into it-that such abnormal mental states as of old in- 
spired "the pale-eyed priest from the prophetic cell," and to-day influence priests or medicine-men amongst savages (to go no farther), can be, and are, combined with ordinary shrewd intelligence; nor does it seem too much to suppose that a bird that was always seeing the effect of what it did when it, as it were, fell into hysterics, should have come in time to reckon upon the hysterics, to know what they were good for, and even to some extent to direct them-as a great actor in an emotional scene must govern himself in the main, though, probably, a great deal of the gesture, action, and facial expression is unconsciously and spontaneously performed.

Now, if we assume that these ruses employed by birds for the protection of their young-as in the case of the wild-duck-have commenced in purely involuntary movements, without any proposed object, the instance here given of the snipe may perhaps throw some light upon their origin. A bird, whilst incubating, and thus, hour after hour, doing violence to its active and energetic disposition, is under the influence of a strong force in opposition to and overcoming the forces which usually govern it. Its mental state may be supposed to be a highlywrought and tense one, and it therefore does not seem surprising that some sudden surprise and startle at such a time, by rousing a force opposite to that under the control of which it then is, and producing thereby a violent conflict, should throw it off its mental balance and so produce something in the nature of hysteria or convulsions. But let this once take place with anything like frequency in the case of any bird, and natural selection will begin to act. 
As the eggs of a bird are stationary, and do not run away or seek shelter whilst the parent bird is thus behaving in their neighbourhood, it would, on the whole, be better for it to sit close or to fly away in an ordinary and non-betraying manner. Allowing this, then, as the eggs of a bird would be less exposed to danger the less often the sitting bird went off them in this way, might not natural selection keep throwing the impulse to do so farther and farther backwards till after the incubatory process was completed? Then the tendency would be encouraged-at least in the case of birds whose young can early get about-for, as a rule, such antics would shield them better than sitting still. The young would generally be in several places - giving as many chances of discovery - and, on account of the suddenness of the surprise, would often be running or otherwise exposing themselves. Take, for instance, the case of the wild-duck, where I have always found the brood a most conspicuous object at first, and taking some time, even on reedy rivers, to get into concealment.

And I can see no reason why an aiding intelligence in the performance of such movements should not be selected pari passu with the movements themselves, though of a nervous and, originally, purely automatic character. Natural selection would, in this way, develop a special intelligence in the performance of some special actions, out of proportion to the general intelligence of the creature performing them, though, no doubt, this also would tend to be thereby enlarged. And this is what, in fact, we often do see or seem to see.

I may add that when, a few days afterwards, I again approached this same nest the bird went off it 
without any performance of the sort. This, if we could be sure that it was the same bird, would seem to show that the habit was in an unfixed and fluctuating condition. On the other hand, a bird that acts thus in the case of its young, would, I think, always act so.

Perhaps it may be wondered why I have not included the peewit in the list of birds which employ, or appear to employ, a ruse in favour of their young ones, since this bird is always given as the stock instance of it. The reason is, that whilst the birds I mentioned have always, in my experience, gone off, so to speak, like clock-work, when the occasion for it arrived, I have never known a peewit to do so, though I have probably disturbed as many scores - perhaps hundreds - of them, under the requisite conditions, as I have units of the others. I have also inquired of keepers and warreners, and found their experience to tally with mine. They have spoken of the cock bird "leading you astray" aerially, whilst the hen sits on the nest, and of both of them flying, with screams, close about your head when the young are out, which statements I have often verified. But they have never professed to have seen a peewit flapping over the ground as with a broken wing, in the way it is so constantly said to do. I cannot, therefore, but think that, by some chance or other, an action common to many birds has been particularly, and yet wrongly, ascribed to the peewit. As it seems to me, this is just one of those cases where negative evidence is almost as strong as affirmative, and though, of course, quite ready to accept any properly witnessed instance of the peewit's acting in this way, I cannot but conclude that it does so very rarely indeed. 


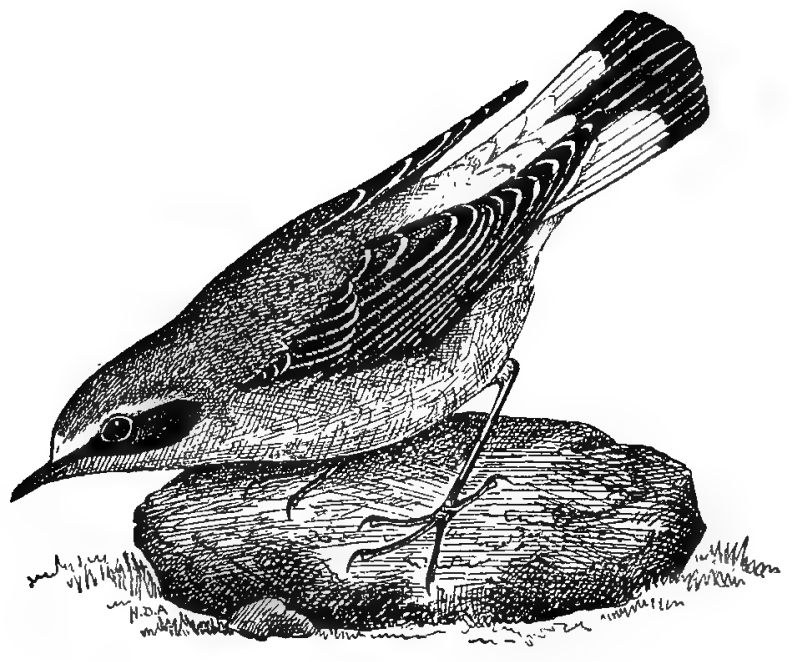

CHAPTER IV

\section{Watching Wheatears, Dabchicks, Oyster- catchers, etc.}

THE wheatear is common over the warren-lands, and as I have been so fortunate as to witness for a whole afternoon, and very closely, a series of combined displays and combats on the part of two rival males, which struck me as very interesting, and as bearing on the question of sexual selection, I will give the account in extenso, as I noted it down from point to point between the intervals of following the birds about on my hands and knees. Should the narrative be tedious-and it is, I confess, somewhat minute-I need not ask my readers to absolve nature and give me the blame of it, for I am assured that anyone in 67 
the least degree interested in birds and their ways might have lain and watched these bizarreries a hundred times repeated, without wishing to get up and go. My observations were made on the last day but one of March, and are as follows:-

" 2.30 (about).-Two male wheatears have for some time been hopping about in each other's company, and one now makes a hostile demonstration against the other. This he does by advancing and lowering the head, with the beak pointed straight forward, ruffling out the feathers, fanning the tail, and making a sudden, swift run towards him. He stops, however, before the point of actual contact, and the two birds hop about, each affecting to think very little about the other." The wheatear, I should say, always hops, and, by so doing, always give me something of a surprise, for there is that in his appearance which does not suggest hopping, but rather that he would run over the ground like a wagtail. His hops, however, are so quick, and take him forward so smoothly, that the effect on the eye is often much more like running than hopping. I therefore often speak of him as running, though, I believe, he never does so in the strict sense of the word. To continue. "After some time, during which there was nothing specially noteworthy in their behaviour, the two birds flew, one after the other, to some little distance off on a higher and more sandy part of the warren, and here a female wheatear appeared, hopping near them. One of the males at once ran to her, but had instantly to fly before the fierce wrath of the other. The hen then flew to a stunted willow in the neighbourhood, where she sat perched amongst the topmost twigs, the males 
not following her, but continuing to hop about in each other's vicinity as before. She remained there some five or ten minutes, when she flew out over the warrens, and with my attention concentrated on the rival birds, I lost her, and cannot say where she went down.

"One of the male wheatears now enters a shallow depression in the ground-not a hole, or the mouth of a rabbit-burrow, but one of those natural fallings away of the soil which make rugged and give a character to these sandy, lichen-clothed wastes. As soon as he is in it he seems to become excited, and running forward and coming out on the opposite brink, he flies from this to the one by which he has entered, hardly two feet off, then instantly back again, again to the other, and so backwards and forwards some dozen or twenty times, so rapidly that he makes of himself a little arch in the air constantly spanning the hollow, all in the greatest excitement. Finishing here, he runs a little way to another such depression, enters it, and coming out again, acts in precisely the same way, making the same little rapidly moving arch of two black up-and-downpointed wings, moving now this way, now that, now forwards, now backwards, from edge to edge of the trough, perching each time on each edge of it, but so quickly, it seems rather to be on the points of the wings than the feet that he comes down. Wings are all one sees ; they whirl forwards and backwards, backwards and forwards, making a little arch or bridge, the highest point of which, in the centrewhich is the point of the upper wing-is some two feet from the floor of the trough, whilst the point 
of the lower one almost touches it. All this time the other male bird is quite near, but seems to take little notice of the performance. At length the frenzied one desists from his madness of motion, and the two now hop about over the warren as before, closely in each other's company. In some ten minutes or so there is the same display-or rather frenzy-but whether made by the same bird or the other one I am unable to say. This time it commences on the even turf and not in a hollow, but after a few throws the bird finds one and throws, thenceforth, over that." I have seen, I think, a Japanese acrobat throw a wonderful succession of somersaults backwards and forwards within his own length. With the bird there was no somersault, but the effect was something the same. The man's body also presented the appearance of an arch in the air (as when one vibrates a lighted joss-stick from side to side), but, as the bird moved much more quickly, the resemblance in its case was more perfect.

"Once or twice again, now, one of the two birds acts in the same way, always seeming to prefer to do so over a depression in the ground. One then flies up a little way into the air, descends again, and, on alighting, instantly recommences as before, again, I think, over a slight hollow. The motion is equally violent, but not so long continued, some seven or eight flings, perhaps, in all. At the end of it he stops still, advances the head straight forwards, lowering it a trifle, swells the feathers, and broadly fans the tail. Then the two birds fly at each other, but almost in the act of closing they part, with a little twitter, and commence hopping over the warren 
as before. It is a constant little run of hops, a pause, and then another little run of hops, each bird following the other about in turn, the distance between them being, as a rule, from two or three feet to five or six paces.

"3.ro.-Another little fly up into the air, followed by the frenzied dance on descending. Then the two come together in the mouth of a rabbit-burrow, fly at each other as before, separate again almost immediately, and continue their hopping over the warren, the one still dogging the other.

"3.30.- The two fly at each other as though to fight; but, again, just as they seem about to meet, they avoid, and quicker than the eye can follow they are a yard or so apart. One of them then dances violently from one depression of the soil to another, arching the space between the two; at the end of it he fans out the tail and stands looking defiantly at his rival, who fans his and returns the glance, then makes a little run towards him, sweeping the ground with it. Instead of fighting, however, which both the champions seem to be chary of, one of them again runs into a hollow-this time a very shallow one-and begins to dance, but in a manner slightly different. He now hardly rises from the ground, over which he seems more to spin in a strange sort of way than to fly-to buzz, as it were-in a confined area, and with a tendency to go round and round.* Having done this a little, he runs quickly from the hollow, plucks a few little bits of grass, returns with them into it, drops them there, comes out again,

* Very like the action of the nightjar when disturbed with the young chicks. 
hops about as before, flies up into the air, descends, and again dances about.

"At about four the female reappears, flying from the warren towards the same willow-tree where she had before sat. She perches in it again, and after remaining but a short time, flies down, and once more becomes invisible. Shortly afterwards one of the male birds flies to a little distance, but whether towards her or not I cannot say. He then rises into the air and descends with a twittering song, upon which the other one, who has remained where he was, does so too. The two are now a good way apart, but the distance is soon diminished till they are again quite near, when one of them flies away, then turns and flies back again and settles not quite so near. As he does so, the other one flies in an opposite direction, and at the end of his flight rises into the air with the twitter-song and descends, when the other immediately does the same, just as before. Then again they hop, now this way, now that way, but always diminishing the distance, till at length not more than some three or four feet separates them. But it must not be supposed (and this applies throughout) that the birds seem to have any sinister intention, or even any impertinent curiosity, in regard to each other. They do not advance openly to the attack, but get to close quarters in a very odd sort of way. Seeming for the most part to be unconscious of each other's presence, hopping constantly away from and approaching one another but obliquely, they in reality dog each other's steps and keep a constant eye on each other's movements. When at length there is but this short space be- 
tween them, they stand for a moment looking at each other, yet without any very warlike demonstration. Then, all at once, one darts upon the otherso swiftly that I cannot be sure whether he flies, hops, or does both-and there is now a fierce and prolonged fight. For a moment or two they are in the air (though not at any height), then struggling on the ground, when one, getting uppermost, holds the other down. At last they separate, and for a few seconds stand close together as though recovering breath. Then, as by mutual consent, they retire from each other to a short distance and hop about again in the same manner as before. One of them then again flies singing into the air, and on coming down dances, but to this the other does not respond, and now all goes on in the usual way, the birds getting once or twice again quite close, but separating without fighting. At half-past four there is another twittering flight into the air, and a dance on descent, which is emulated in a few minutes by the rival bird. Shortly afterwards one flies a considerable way off, but is followed almost at once by the other, and the same thing goes on. Then there is another flight and song with, this time, no dance on descent, but, as though to make up for this omission, on the next occasion, which is some few minutes afterwards, there are two distinct transports on alighting, separated by a short interval. On this occasion the bird did not sing either in ascending or descending.

"Here some other birds claimed my attention, and I was away for a quarter of an hour. On returning, at a quarter to five, I found the two wheatears still together, and precisely the same thing going on. 
Shortly after five they again fought, but this time entirely in the air. They mounted, fighting, to a considerable height, descended, still doing so, and separated in alighting. Afterwards both of them sang whilst on the ground, and then one mounted up, still singing, and danced when he came down. At half-past five I could only see one of the birds, and this one I noticed to run several times in and out of one of those sandy depressions I have spoken of, and which seem to play such a part in these curious performances. A little later both of them seem gone, but now, at a quarter to six, as I am about to follow their example, I again see them, in company with the hen. She shortly runs a little away from them, the two males remaining together, but making no further demonstration. In a little, one of them flies to her, and these two are now in each other's company, singing, flying, and twittering, for some ten minutes. It would seem as though she had made her choice, and that this was submitted to by the rejected bird, but just before leaving at six o'clock all three are again together."

It is to be observed here that these two birds, though they were in active and excited rivalry for the greater part of an afternoon, and though they made many feints and, as it were, endeavours to fight, yet only really fought twice, seeming, indeed, to have a considerable respect for each other's prowess, and "letting I dare not wait upon I will" during most of the time. Perhaps they were brave, but the idea given me by the whole thing was that of two cowards trying to work themselves up into a sufficient degree of fury to overcome, for a 
moment or two, their natural timidity. "Willing to wound, but yet afraid to strike," seemed to me to describe their mental attitude.

Much has been said as to the pugnacity of birds, but I think that a large amount of timidity often mingles with this pugnacity, even in the most pugnacious kinds. I have seen, for instance, two pheasants sit, first, face to face, pecking timidly at, or rather towards, each other, and then, on rising, make various little half-hearted feints and runs, one at another, as though trying to fight and not being able to, and this for quite a long time. At last one of them ran to some distance away, and then, turning, made a most tremendous, fiery rush down upon the other one, like a knight in the tilt-yard. Nothing could have looked bolder, more spirited, more full of fire and fury, but-just like these wheatears-at the very moment that he should have hurled himself upon his foe he swerved timidly aside, and all his brave carriage was gone in a moment. And what struck me (and, indeed, as humorous) was that this other bird-the one thus charged down upon-who had been just as timid, and had seemed to find fighting equally difficult, did not retreat, as one might have expected, before this great show, but sat quietly, as knowing it to be "indeed but show," and that there was nothing really to fear. In fact, it was like the drawing of swords between Nym and Pistol in Henry $V$., each being afraid to use his, and knowing the other to be so too. Black-cocks, again, are often very ready to avoid a conflict, and dance much more fiercely than they fight. A bird, indeed, which is a very demon in the "spiel" or 
"lek-platz" may, as I have seen, become meek and retreat from it upon the entry of another, which other is then, of course, ipso facto, the boldest bird in existence. Blackbirds are considered to be quarrelsome, and I know that even the hens - or, perhaps, they especially - will sometimes fight in the most vindictive manner. But, as with these wheatears, I have seen in the case of rival cock blackbirds a great deal of chariness of real fighting mingle with much ostentation of being ready to fight.

I am not, of course, disputing the pugnacity of birds during the breeding season and often at other times. That is quite beyond doubt, and proofs or instances of it are altogether superfluous. But the pugnacity is all the greater if, in order for it to assert itself, a greater or less degree of timidity, varying, of course, in different species and individuals, must first be overcome. Assuming that this is sometimes the case (and I know not how else such instances as I have given are to be explained), is it so unlikely that rival birds, wishing to fight yet half afraid to, and being thus in a state of great nervous tension, should fall into certain violent or frenzied movements, into little paroxysms of fury, as when a man is popularly said to "dance with rage"? Anything that excites highly tends to exalt the courage and conquer fear, as we know with our own martial music, to say nothing of the "pyrrhic" and other dances. It seems possible,

- Whereas the thrush (it is usually added) is peaceable. But this is one of those passed-on things with which natural history is burdened. From my own experience, I know it to be otherwise. I have watched thrushes fighting furiously, not only with one another but with the blackbird also, 
therefore, that such violent movements as are here imagined might have this effect, and thus, though excited originally by rage-or some high state of emotion-only, might be persisted in and increased through experience of their efficacy. But if this does ever happen, may we not have here the origin -or one of the origins-of those undoubted displays made by the male bird to the female, on which the theory of sexual selection is chiefly based? That the male birds should, in the beginning, have consciously displayed their plumage, in however slight a manner, to the females, with an idea of it striking them, seems improbable, and, even if we might assume the intelligence requisite for this, the theory of sexual selection supposes the beauty of the plumage to have been gained by the display of it, not that the display has been founded upon the beauty. Then what should first lead a bird of dull plumage consciously to display this plumage before the female? A mere habit of the male, increased and perfected by the selective agency of the female (as this is explained by Darwin), has hitherto-as far as I know -been considered a sufficient explanation of the origin and early stages of such displays as are now made by the great bustard, the various birds of paradise, or the argus pheasant. But if we can show a likelihood as to how this habit has arisen we are, at least, a step farther forward, even if a slight difficulty has not thereby been removed.

Now, with regard to these wheatears, it will, I think, be admitted that the little frenzies of the male birds-as I have described them-were of a very marked, and, indeed, extraordinary nature, and 
also, perhaps, that it is more easy to look upon them as sudden bursts of excitement-nerve-storms or emotional whirlwinds, so to speak-than as displays intended to attract the attention of the female bird. Certainly there was nothing like a set display of the plumage; and, with regard to the female, the question arises, Where was she, at least during the greater part of the time? The two male birds in the course of their drama got over a considerable amount of ground, and constantly flew from one part to another, so that, in order to have had anything like a good view, the female must have accompanied them, and I must then, perforce, have seen her, which I did not, except on the occasions related. She was, therefore, not with them, and, if watching them at all, could only have been doing so from such a distance that the dancings of the male birds would have been very much thrown away. Yet that she took some interest in what was going on appears likely from her flying up twice into the willow tree during its continuance, and being with the two rivals at the end of the day. She might, too, have been listening to the song and observing the flights up into the air, which would have been much more noticeable from a distance.

One might expect a female bird to take some interest in two male ones fighting for her merely, without any adjunct, and if they added to the fighting peculiar violent movements, such as those here described, that interest would tend to become increased. Now I can imagine that with this material of violent motions on the one side and some amount of interested curiosity on the other, the former might gradually come to be a display made entirely for the female, 
and the latter a greater or lesser degree of pleasurable excitement raised by it with a choice in accordance, which is sexual selection. And that the display would come at last to be made intelligently, and with a view to a proposed end-as in the case supposed of the female wild duck (or other bird) diverting attention from its young-I can also understand. In both instances mere nervous movements due to a high state of excitement would have been directed into a certain channel and then perfected by the agency either of natural or sexual selection.

On this view the curiosity (passing insensibly into interest and satisfaction) of the female bird would have been directed, at first, not to the plumage but to the frenzied actions-the antics-of the male, and he, on his part, would have first consciously displayed only these. From this to the more refined appreciation of colours and patterns may have been a very gradual process, but one can understand the one growing out of the other, for waving plumes and fluttering wings would still be action, and action is emphasised by colour.

Where, however, such movements had not been seized upon and controlled by the latter of these two powers - i.e. sexual selection - (and there is no necessity that they should be), we should have antics not in the nature of sexual display properly speaking, but which might yet bear a greater or less resemblance to such. That this is, in fact, the case has been pointed out by the opponents of sexual selection, and often as if it were evidence against it (though no one, unfortunately, can point to men as a ground for disbelief in armies). Mr Hudson, for 
instance, in his very interesting work, "The Naturalist in La Plata," after bringing forward a number of cases of curious dance-movements (or of song), performed by birds, and which are, in his opinion, not to be explained on the theory of sexual selection, says, in regard to other cases brought forward by Darwin in support of that theory :

"How unfair the argument is, based on these carefully selected cases gathered from all regions of the globe, and often not properly reported, is seen when we turn from the book ${ }^{*}$ to nature, and closely consider the habits and actions of all the species inhabiting any one district!"

Now, had Darwin been of opinion that antics performed by a bird which could not, or could not easily, be explained by his theory, were fatal to it in other cases-if he had thought that the one was inconsistent with the other-then, no doubt, it would have been unfair on his part to have marshalled the affirmative evidence without concerning himself with the negative. But why should he have held that view, or on what good grounds can such a view be maintained? As well might it be argued - so it appears to me - that woollen or other goods could only have been produced through the action of the loom, or some such special machinery. But let the wool be there, and it can be worked up in various ways. Mr Hudson would account for all such displays or exhibitions by " a universal joyous instinct" present throughout nature, but to which birds are more subject than mammals. I do not dispute the instinct -or rather, perhaps, the emotion-or that some of

"But from which "book"? Not, I suppose, from Darwin's alone. 
the displays in question may be due to it simply and solely: but I cannot believe that all are. Why should this be the case, or how can movements which are often of a complex and elaborate nature be explained solely by reference to some large general factor, such as joy or vital energy? These may lie at the root of all; but something else, some more special process is, I think, in many cases required. One would not be content to explain all the phenomena of history by a reference to human nature, and though it may be true, as the Kaffirs say, that in a cattle-kraal there can only be one bull, yet nature is a good deal larger than a cattle-kraal. I believe myself that various antics which are performed by birds have grown out of various nervous, excited, or automatic movements arising under the influence of various special causes. Two such possible causesviz. ( 1 ) sudden alarm whilst incubating, and (2) paroxysms of rage or nervous excitement during rivalry for the female I have already indicated. Two other possible ones have also been suggested to me by some of my observations, and I will now, by the aid of these, make an attempt-I daresay a lame one-to throw light on the possible origin of a very extraordinary case of bird-antics, described by $\mathrm{Mr}$ Hudson in the work I have mentioned, and which is believed by him to be unique.

The bird in question is the spur-winged lapwing, and the following is $\mathrm{Mr}$ Hudson's account of its performances :-

"If a person watches any two birds for some timefor they live in pairs-he will see another lapwing, one of a neighbouring couple, rise up and fly to them, 
leaving his own mate to guard their chosen ground; and instead of resenting this visit as an unwarranted intrusion on their domain, as they would certainly resent the approach of almost any other bird, they welcome it with notes and signs of pleasure. Advancing to the visitor, they place themselves behind it; then all three keeping step begin a rapid march, uttering resonant drumming notes in time with their movements, the notes of the pair behind being emitted in a stream, like a drum-roll, while the leader utters loud single notes at regular intervals. The march ceases; the leader elevates his wings and stands erect and motionless, still uttering loud notes; while the other two, with puffed-out plumage, and standing exactly abreast, stoop forward and downward until the tips of their beaks touch the ground, and, sinking their rhythmical voices to a murmur, remain for some time in this position. The performance is then over, and the visitor goes back to his own ground and mate, to receive a visitor himself later on."

Now the most curious point in this remarkable performance, so well described, is that three birdsa pair (male and female), and one other, whether male or female is not stated-take part in it, and how is this fundamental peculiarity to be explained better on the theory of "a universal joyous instinct" than on that of sexual selection, if, indeed, the former one helps us so well? Joy, no doubt, is there, but something else - some shaping force-is surely required to account for the particular form in which it finds expression. Now with regard to the peculiarity pointed out-the odd bird (though all act oddly) - I have, whilst watching birds in the early spring, been struck by the 
frequency with which three of the same species will be seen in each other's company, usually chasing one another about, and, as with the spur-winged lapwing, these three are almost always made up of a pair (a male and female) and another bird, a male, as I believe. It may be said that here there can be no analogy, for that it is either merely a case of two males courting one female, or that the odd male is both a rival and intruder, endeavouring to come between the married happiness of two who have made their choice. This latter explanation is the one that has generally seemed to me to meet the case, but what I have frequently noticed with surprise is that the state of anger, or, indeed, fury, which one might imagine would obtain under such circumstances between the two male birds, is either wholly absent, or very much subdued. Now it is in the case of our own peewit, more than with any other species, that I have noticed this quite amicable association of three birds, two of which would often seem to be a paired couple, and as my notes, made whilst I had the birds under observation, both illustrate the point and contain the explanation of it which I have to offer, I will here quote from them:

"February 25th.-Three peewits in company with each other. Two are flying close together, as though they were a paired couple, whilst one follows them at a short interval.

"February 27th.-Three peewits flying together in the same way as before-that is to say two, which may be paired birds, are close together, whilst there is commonly a short space between them and the third one. This arrangement may be temporarily 
suspended or reversed by the bird that has been separated getting up to the other two, when one of these will often fall behind, so that now the bird which was the follower makes one of the two advanced ones, whilst one of these has taken its place. As there is no sexual distinction in the plumage of peewits, ${ }^{*}$ it is impossible to be quite sure to what sex each of these birds belongs, but I believe that two of them are male and female, and the third a male, either of the two males being alternately in the close company of the female. This, indeed, may be in the nature of the matter. The pairing off of the birds, we will suppose-as is likely at this timeis not yet completed, and, assuming two of the three to be of one sex, it may not be quite settled with which of them the third will pair. It is not, indeed, necessary to suppose that either of the three will eventually pair with one of the others, though this may be probable. But what appears to me to obtain is this, that the association of two birds (male and female) together has a tendency to bring up a third, presumably a male, who envies this arrangement, and would fain itself make one of the two. But how, then, is the amicableness-or, at any rate, the absence of any marked evidence of hostility - to be accounted for? I believe that at this early season the sexual feelings have not yet become fully developed, or so strong as to produce jealousy to any active extent. Things are only beginning, the emotions are, as yet, in their infancy, and thus, I believe, the curious, not fully defined nature of the actions of the three birds -their seeming to be half unconscious of what they

* For ordinary field observation at least. 
really want or mean-may be accounted for. As the season advances, the tendency will be more and more for the two birds (but I here speak of birds generally) to avoid, or actively to drive away, the third, and for the third to find another bird for a partner, the whole being tempered by the character both of the species of bird and the individual birds belonging to it. The three birds being thus brought together, without the feelings being of a very strong or defined character, and the feelings of animals generally being, as I believe they are, of a very plastic nature (by which I mean that they pass easily from one channel into another), I can understand a sort of sport or game of three birds together arising, at first almost imperceptible, till, by the fundamental laws of evolutionvariation and inheritance-it might pass into something highly peculiar, as in the case of the spurwinged lapwing-for though such sport might commence in the air, there would be no reason why it should not pass from thence on to the ground. And that the number should be three, and not more, is thus also explained, for whilst the sight of a paired male and female bird would be likely to excite the sexual feelings - even though, as here supposed, somewhat languid-of another male, so as to make it join them, three together would hardly have this effect in an equal degree, and, moreover, more than three would tend to become a flock, when other feelings would come into play. However this may be, I have, as a matter of fact, been struck with the frequency with which, in the early spring, three birds will keep together, as and in the manner before stated."

This, it will be observed, was written at a time of 
year when peewits are only beginning their nuptial antics, though, as to their having begun them, there is no doubt, as I had carefully noted this at a still earlier date. But long subsequent to this, and when the theory of a not fully developed state of the sexual feelings could no longer be tenable as an explanation of non-combativeness, I noticed, or thought I noticed, a more than usual tendency in this species for a single bird to project itself, so to speak, into the midst of a married pair, and for its presence not to be resented, but rather otherwise. If this be really so-for, of course, I may be deceived-it is interesting, and perhaps assists the suggestion which I have offered as to the origin of the astonishing conduct of the spur-winged lapwing, the two being such near relations. When the habit had once commenced, it might continue and become fixed, irrespective of season.

But it may be said that all the evidence which I here bring forward is of three birds being together, and that there is none as to any sport or antic, of however incipient or rudimentary a nature. I have, however, often seen peewits sport and wanton in the air in threes, but I admit that more evidence in this direction is wanted. The little that I have, and will here give, relates, not to the peewit, but to two birds very different both to it and to each other. The first of these is that attractive and delightful little creature, the dabchick or little grebe (Podiceps fuviatilis), a bird whose society I have always cultivated to the best of my ability. My first note, taken on I4th December, I give merely by way of showing that sexual feelings in birds may not always lie entirely 
dormant, even in the depth of winter; for, from having long watched the same birds in the same little reedy creek, I feel sure that the two I here chronicle were male and female.

These were "pursuing each other, first over the water-fly-flapping along the surface in their peculiar way - then on and under it, ducking, coming up close together, ducking again, and so on, flapping, ducking, and swimming, each in turn. It is very sustained and animated, suggesting an amorous pursuit of the female by the male, even at this time of year. They make a great noise and splashing, they are obstreperous, and a hen moor-hen standing staidly on some bent reeds gives a look as though doubtful of the strict propriety of such conduct,-in the winter,--then with an 'Ah, well! dabchicks will be dabchicks, I suppose, at all times,' resigns herself to the inevitable, and takes to preening her feathers." In the other case, which is the one that bears more directly on the question under discussion, three dabchicks pursued each other in this manner, one behind the other, and following the course of the stream. The last bird was particularly energetic, and seemed determined to interfere with the pursuit of the foremost by the one just in front of him. "When quite near me they all three pitch down and instantly dive. The first to come up stops dead still on the water, looking keenly and expectantly over it, his neck stretched rigidly out, his head darting forward from it at a right angle, as rigid as the neck. The instant another one appears, he dives again with a suddenness as of the lid of a box going down with a snap, and this other one has seen him at the same time, and dives still 
more quickly, if that were possible-so quickly that there is just a swirl on the water, the appearance seems part of the disappearance, 'and nothing is but what is not.' And this, as I think, continues, but owing to the rapid progress of the birds under the water, and their getting amongst flags and weeds, I never have an equally 'convincing' sight of it."

Now, here, on the 4th February, we have, as in the case of the peewits, three birds together, all in pursuit of each other, but two, as it appeared to me, in a little more intimate association, and the third seeming to wish to make a third. They chase each other excitedly down the stream for a little, then all pitch down upon it and dive, and one, upon coming up, dives again at the merest sight of another who behaves similarly, a peculiarly set and rigid attitude being adopted by the waiting bird. Is this not something like a little romp or water-dance following on the excitement of the chase? True, it may have been fighting between the two males, for dabchicks, like the great crested grebe and other water-birds, probably fight by diving and attacking each other beneath the surface. To my eyes, however, it had very much the appearance of a romp, or, at anyrate, a something betwixt sport and earnest. Assuming it to have been so, then here is a habit of a sport or antic between three birds at the end of an excited chase of each other. Now supposing this habit to increase, then, as the birds became more enamoured of their little sport-as it became more and more a fixed habit with them-is it not likely that the preliminary chase before the romp began would be thrown more 
and more into the background? The more one enjoys a thing, the more eager is one to begin it, and as here, the longer the chase lasted, the longer must the romp at the end be postponed, the tendency would be for the former to become shortened and shortened, till at length it ceased altogether, the approach of the one bird getting to be associated in the minds of the other two with the sport or game alone. In the final stage this last might be extraordinary in a high degree, but every trace of its origin, as here suggested, would have vanished. And so strongly might the habit or instinct of thus romping $a$ trois be now implanted, that one of any pair of birds would be ready to join any other pair, and they to receive him, in order to indulge in it.

I can, indeed, see no reason why birds that sported well should succeed in life better than others, but if such sporting were an outcome of general vigour, and vigorous birds were selected, their sportings would be selected also. And that movements of this sort would tend sooner or later-if only by mere preference-to fall into some sort of form, also seems not unlikely. It will be remembered that what I have just recounted took place early in February, whereas the dabchick does not, in my experience, commonly build before May. One would not, at so early a period, expect to find the jealous and combative feelings of the male in regard to the female bird fully awake, but if there were apt to be occasional sudden outbursts of this-little flare-ups, inducing appropriate action for a few moments and then passing quickly away - the birds might be left, as it were, surprised at themselves and not quite knowing what had started 
them off. The originating cause would have ceased or subsided, but the excitation consequent on the bodily activity which had been thus aroused would require a further outlet, and this might pass in time into some prescribed play or antic which might afterwards be indulged in for its own sake.

My other instance is that of the oyster-catcher. If anyone will watch these birds closely, he may see three of them go through a performance bearing the same sort of resemblance to that of the spur-winged lapwing, that the combs of the humble-bee do to the more perfect ones of the hive-bee. $\mathrm{He}$ may see, for instance, two standing side by side with their heads bent forwards and downwards, as the two lapwings bend theirs, though here the length of the brilliant, orange-red bills, the tips of which, also, almost touch the ground, make the angle of inclination a much lesser one. In this attitude they both of them utter a long, continuous, piping note, of a very powerful and penetrative quality, sometimes swaying their heads from side to side as though in ecstasy at their own performance, and seeming to listen intently in a manner strongly suggestive of the musical connoisseur. The third bird, who is obviously the female, either stands or walks at a short distance from the two pipers, who will frequently follow and press upon her, and then, though the march is not quite so formal and regular, it yet bears for a few moments a considerable resemblance to that of the spur-winged lapwing, as described and figured in Mr Hudson's work. Of course, there is really no march at all in the proper sense of the word, but there is the occasional resemblance, and 
the resemblance suggests the origin. In the case of the spur-.winged lapwing the play is commenced by one bird of a pair flying to another pair, and thus making the trio. There is the same kind of rough and imperfect resemblance to this in the way in which these oyster-catcher trios commonly open, but as an account of what I actually saw may give a better idea of how the birds act than can a mere generalisation, I will illustrate the last point, as well as those others which I have mentioned, by this means.

"When one of the male birds-standing near the female-commences thus to pipe, the other one, if on the same rock, runs excitedly up to him, and pushing him out of the way so as to occupy almost his exact place, pipes himself, as though he would do so instead of him. The other, however, is not to be silenced, but standing close by him the two pipe together, throwing their heads from time to time in each other's direction, and then back again, in a frenzy or ecstasy, as though they were Highland bagpipers of rival clans piping against each other, and swinging their instruments as they grew inspired by their strains. Continuing thus to act, the two male birds approach and press upon the female. She flies to a corner of the rock, the two, still piping vigorously, follow and again press upon her. She flies down upon a lower ledge of it, the two pipe down at her from above. She flies from the rock, they half raise their heads, and cease to pipe, then with single querulous notes, and in their ordinary attitude, walk disconsolately about.

"After some ten minutes the female flies back again. 
The demeanour of the two birds is at once visibly affected, and they begin to pipe again, though not so vigorously as before. They continue to do so, more or less, at intervals, the third bird (the female) remaining always passive, and never once piping. All at once one of the two pipers flies violently at the other, who flies off, and is closely pursued by him. They alight-it would seem together-on the edge of a great rocky slab, but are instantly at some little distance apart, looking at each other and bearing themselves after the manner of rivals. How they separated, whether as recoiling from a conflict, or avoiding it, I cannot now say. The movements of birds are often so quick, that the eye, though it may follow, forgets them as they pass. On another occasion, a bird close to where I sit, on hearing the pipe from a rock a little off the shore, becomes excited, pipes for a moment itself, and then darts off to the rock. On alighting, he instantly runs to the piping bird, and the two pipe together to a third, exactly as before. This third one, silent and unresponsive, soon flies away. The piping instantly ceases, and the two birds assume normal attitudes.

"The note of the male oyster-catcher when thus courting the female differs both from its ordinary one, and, as I think, from that of the female. The usual note is a loud 'wich, wich, wich,' or some similar sharp, penetrative cry, constantly reiterated. The pipe is a much more wonderful affair, and, though harsh, is like a real composition. It is of long continuance, beginning with something like 'kee, kee, kee, kee, ker-vie, ker-vie, ker-vie, ker-vie, ker-vie,' a loud and ear-piercing clamour. Gradually, however, 
it sinks, becoming in its later stages quite faint, and ending, commonly, in a sort of long-drawn-out, quavering trill which the bird seems to pause upon with pleasure. Holding down its head all the time, it seems to drink in every tittle of the sound, and to strive to give it its full and just expression. So much has it, whilst doing this, the appearance of a musician, and so much does the long, straight, orange bill resemble a pipe it is playing on, that if fingers were to appear there of a sudden, and begin to 'govern the stops,' one would hardly feel surprise-for a moment or two. A point to be noted is that the piping bird is not always turned towards the female he is courting, even when close beside her. He turns towards her, commonly (perhaps always), when he begins, but having once begun, he seems more enthralled by his own music than by her, and will turn from side to side, or even right round and away from her, as though in the rhythmical sway of his piping."

Here, then, at last, we have upon our own shores, and amongst our own birds, an unmistakable case of a display or performance of a very marked character, in which three birds are present, though one takes only a passive part. The motive power here is obviously sexual; two males are, at least to all appearance, courting one female. But I made at the time this special observation, that, though the rival birds did, upon two occasions, fly at each other, and though the piping of one always brought the other over to him to pipe in rivalry, yet, when once they began to pipe vigorously, their interest seemed to become centred in, and, as it were, abstracted into this. The actual display, in this case vocal, seemed 
to have become, or to be in process of becoming, of more importance than the emotion which had given birth to it, the essence seemed merged into the form, the book had become its binding. I suggest that this may be sometimes actually the case in nature, that a movement, or a note, or series of notes, may become itself so all-absorbing as to demand the whole consciousness of the bird who, in performing it, forgets the why and the wherefore of the performance. Let this process once commence, and certain movements-antics-performed at first with ${ }^{\circ}$ a definite object, might be gone through at last for themselves alone, the object having become now merely to perform them. In this case, we should have a pure antic or display, the reason of it being unobvious and its origin a puzzle. Such a principle, if it exists, might, perhaps, be called the "law of the formalisation of actions once purposive" (which sounds learned enough), and perhaps traces of it may be seen amongst ourselves. What, for instance, are our civilised dances except movements which have become quite formal and meaningless, but which once, as in the war-dance of the savage, had an intense significance? The analogy is not quite perfect, unless we could show that actual war, for instance, had sometimes passed into a dance. Whether this has ever been the case with man I do not know, but I believe that it may have actually happened with some birds, for which idea I will further on adduce my, perhaps, somewhat slender evidence. But, coming back to the oyster-catchers, I can understand that under such a law as this, the actions of the two male birds in regard to the female might gradually get to be 
of a quite formal and non-courting nature, and, though I will not here try to indicate the steps by which the female bird might gradually enter into the dancemovements or the song, they do not seem to me impossible to conceive of. The number of performers, however, having once become fixed, would be likely to continue, through habit, as long as no other influence arose to affect it.

The fact that it was in the early days of July, when the true courting-season should have been over, that I witnessed these movements, may perhaps strengthen the above view.

In seeking to explain such performances as those of the spur-winged lapwing in this latter way, one must assume the number of three birds to have originated in accordance with general principles, and that first there has been a real courtship of the female bird by two males, the antics proper to which have, at last, become stereotyped into a formal dance or display. This, however, would not exclude the possibility of what I have suggested in the case of the dabchicks and common peewit, and I believe myself that it is not by one only, but by many causes, that the many curious antics of birds are to be explained.

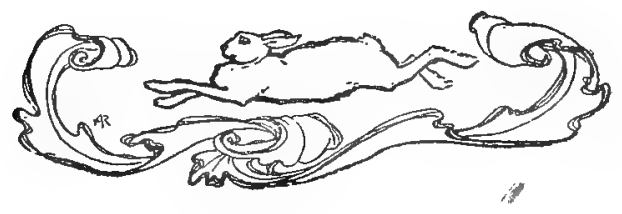




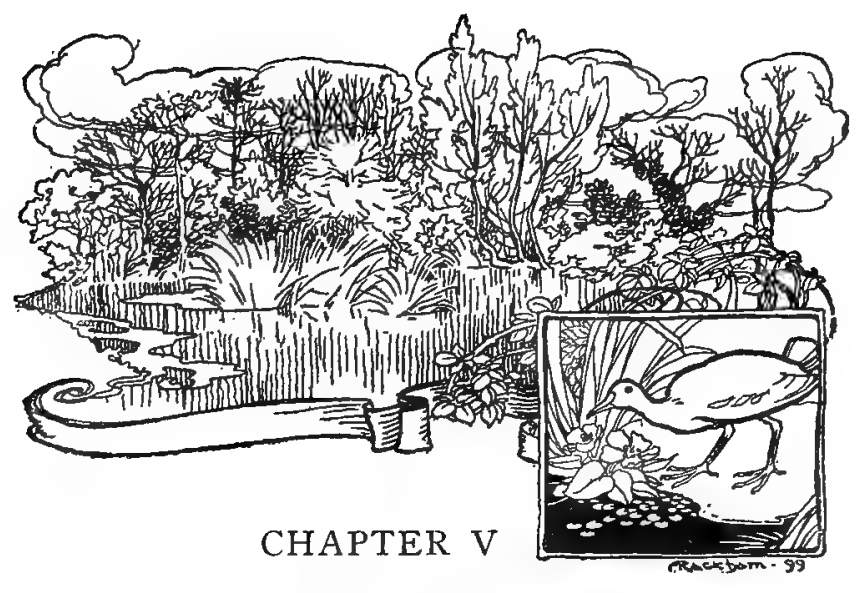

\section{Watching Gulls and Skuas}

THE oyster-catcher brings us to the sea, so to seabirds I will consecrate the next few chapters.

Gulls and skuas are best watched on some lonely, island, where they breed, and thither we will now transfer ourselves.

They breed together, or, more strictly speaking, conterminously, and more than half of the whole island-all that part where it is a peaty waste clothed with a thin brown heather-is now, in early June, their assembly ground and prospective nursery. The gulls are in much the greater numbers, and all of them here are of the black-backed species, mostly the lesser of the two so named, but with a fair sprinkling of the greater black-backed also. Lying down and sweeping the distance with the glasses-for near they have risen and float overhead in a clamorous cloud-one sees everywhere the bright, white dottings of their breasts, soft-gleaming amidst the uniform 
brown of the heather. They are not at all crowded, but scattered widely about at irregular and, for the most part, considerable intervals. There is rarely a group, and though many pairs may be seen standing closely together, yet this is the exception rather than the rule. Most birds of such pairs as are present are some three or four to a dozen or twenty yards apart, whilst the greater number of the whole assembly stand singly, the bird nearest to each, at a much greater distance, being one of another pair. This is because the partner birds are for the time being absent, but every now and again one may be seen to fly up and join the solitary one, whilst, similarly, one of a couple will from time to time fly off and leave the other alone. Thus, though the eye will distinguish at any time many paired couples, to the majority of the birds it will not be able to assign a partner with certainty. But this varies very much. On some occasions there will be many more close couples than on others, and it is when this is the case that the gullery has the most pleasing appearance. Here and there one sees a bird, not standing, but couched closely down amidst the heather. These birds have laid, and are now hatching, their eggs. For the most part they are alone, but as the season advances and they become more and more numerous, the partner may often be seen standing near the nest, and presenting every appearance of a joint interest and proprietorship in it.

When a bird flies up to its partner it usually comes down close beside it. The two will then be together for awhile, but soon they either walk or fly to a little distance from one another. After remaining apart 
for a longer or shorter time they visit again, then again separate, and so they continue to act, at longer or shorter intervals, till one or other of them flies off to sea.

This system of making each other little visits and then going away and remaining for some time apart, seems a feature of the gull tribe generally, and it is particularly marked in the case of the great skua. A pair of these birds will each have its apartments, so to speak, and, by turns, each will be the caller on or the receiver of a call from the other. Either, one will walk or fly directly over to where the other is standing or reclining, or it will make several circling sweeps before coming down beside it, or else-for this is another fashion-each of them will set out to call on the other, and meeting in the centre between their respective places, have their gossip there.

However the meeting takes place, when the birds are together one of them will commonly bow its head down towards the ground in a heavy sort of manner, whilst the other stands facing it with the head and bill lifted into the air. All at once one of the birdsusually, I think, the caller, if either has remained at home-turns round, raises its wings above its back, and holding them thus, makes a heavy sort of spring or running leap forward along the ground. This it does several times, lowering the wings each time that it pauses, and raising them again to make the leap. From this it might be thought that the bird flew rather than leapt, but this, when I saw it, did not appear to me to be the case. It did not fly, but only jumped with the wings held up. The birds 
are now apart again as before, but after a short interval the one that has behaved in this odd way returns, and they again stand vis-a-vis, regarding each other, but this time without so much bowing or raising of the head. Then one of them-and I think it is the same one-turning as before, there is almost an exact repetition, and this may take place some three or four times in the course of an hour.

The two will then often take wing and fly for a while together, sometimes over the sea, but more often in a series of wide circles round and about their home. They are masters of flight, and, after two or three flaps, will glide for long distances without an effort, alternately rising and sinking, varying their direction by a turn of the head or, as it seems, by presenting the broad surface of their wings to the different points of the compass, and sweeping either with or against the wind, apparently with equal ease. Or, with the wind blowing violently (its normal state), they will neither advance nor recede, and it is certainly a very surprising thing to see one of these great sombre-plumaged birds hanging motionless, or almost motionless at but a foot or so above the long coarse grass, which is being all the while bent and swayed in the direction towards which its head is turned; if it advances at all, it is against the bend of the grass.

But though I have said that the great skua is a master of flight, I have not yet termed its flight either graceful or majestic. For a long time, indeed (during which I had only seen it near its temporary home), I was unable to do so, not, at least, with a full con- 
viction, for though I admired it, yet there seemed always to be in it some want which I felt, but was unable to define. It puzzled me, but at last I discovered what it was, and my discovery, which acquits the bird and is to the honour of nature, I will give as I wrote it down directly after I had made it.

"One of the great skuas has now flown right out to sea. There its flight, which is peculiar, becomes instantly very graceful. Descending with a sweep, which, though majestic, is yet soft and gentle, it seems about to sink upon the waves, when, almost as it touches them, it glides again softly upwards, to descend once more in the same manner. Thus, ever rising and sinking, seeming always about to rest, yet never resting, it glides, tireless, and seems to coquet with the sea. On land, too, these wide circling sweeps had had a grace and charm, but it had not entirely pleased the eye. Something had been absent, but what that something was, it had been beyond me to say. Now, I knew it. What it wanted had been the illimitable plain of the ocean which, in a moment, took away all heaviness from the form and all harshness from the colouring. The sombreness of the sea blends now with its own, and the waves are moving with its own motion. A11 is in harmony, the picture has found its frame." Gulls, too, are more graceful when they sweep over the sea than the shore near it. They have then softness and expanse as a background. The latter, I think, is the more important, and may be unconsciously demanded by association of ideas. Earth had not been wide enough for the great skua.

Often when one of the great skuas is circling 




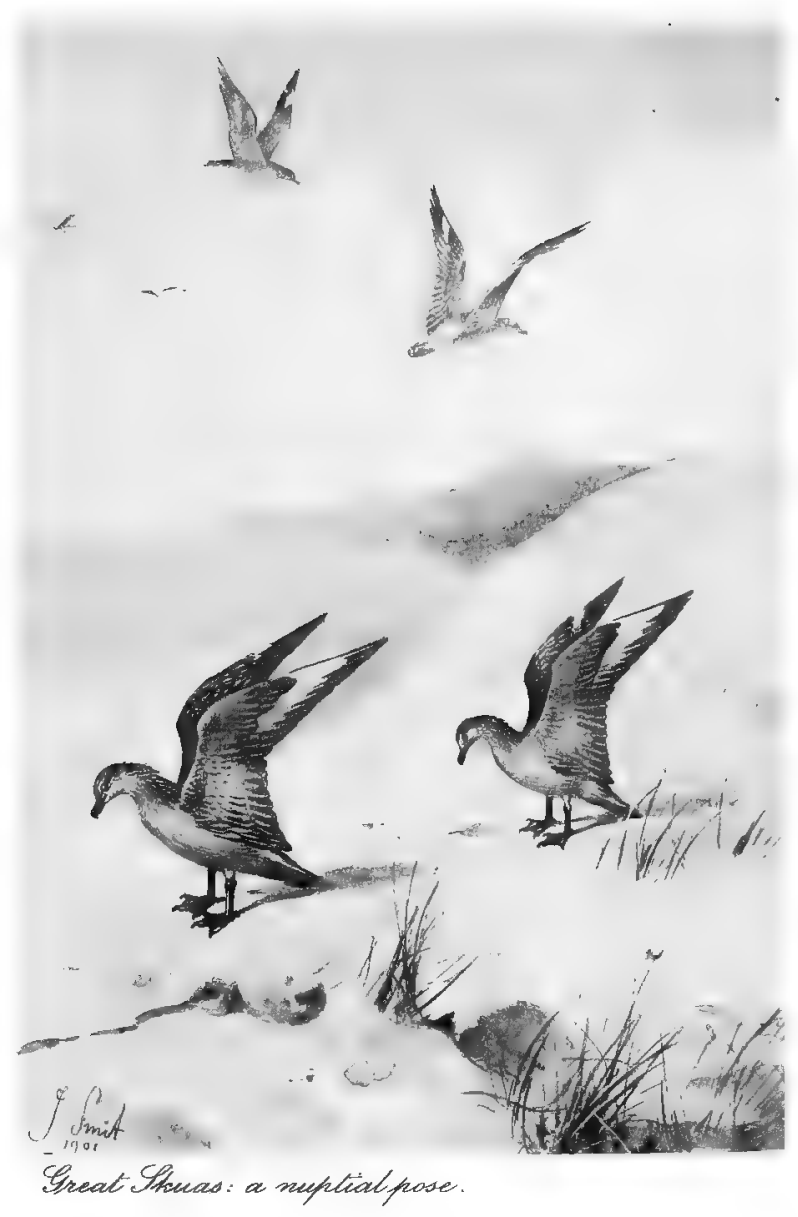


$\because+$ 
round, and the other standing at its post, this one will stretch itself up and raise its wings above the back every time its partner passes. This raising of the wings enters into one of the most salient of the many nuptial antics of this bird, which I will now describe. In its completest form it commences aerially. "The two birds have been circle-soaring one above the other, and are now at a considerable height above one of their chosen standing-places, when the lower one floats with the wings extended, but raised very considerably - half-way, perhaps, towards meeting over the back-an action which, in their flight, is uncommon. As it does this it utters a note like 'a-er, a-er, a-er' ( $a$ as in 'as'), upon which, as at a signal, the other one floats in the same manner, and both now descend thus, together, to the ground. Standing, then, the one behind the other, at about a yard's distance and faced the same way, both of them throw up their heads, raise their wings above their backs, pointing them backwards, and stand thus for some seconds fixed and motionless, looking just like an heraldic device. At the same time they utter a cry which sounds like 'skirrr' or 'skeerrr.' The foremost bird then flies off, and is instantly followed by the other."

If the wings were not extended, this pose would somewhat resemble that of the great plovers, for though the neck is stretched more forwards, it is curved in the same curious way, and the head, though held high, is bent towards the ground. The wings, however, give it quite a different character, and I have, I feel sure, seen some figures of birds on a shield whose attitude bore a wonderful resemblance to that 
of these skuas. May not some of the figures of animals in heraldry have come right down from savage times, even if they do not represent totems? Savages, as we know, catch the more salient and strongly characterised attitudes of animals with wonderful truth and force.

The two birds will often (as might be expected) assume this pose without any previous descent on upraised wings, and, presumably, such descent need not be followed either by this or any other special attitude. Also, when so posing, they do not always stand in line, but indifferently sometimes, as far as relative position is concerned, though at the same approximate distance from one another. I have seen the descent followed by the pose, but not in line, and I have seen the pose exactly as I have described it, but not preceded by the descent.

Obviously (or, at least, in all probability), the birds would be as likely to stand in line when posing on one occasion as on another, and I have therefore put them into line here to give a picture of this nuptial sport when at its best and fullest.

Sometimes during these visits that the birds pay to each other, the two will bend their heads down together and pick and pull at the grass. When they raise them there may be a blade or two of it in the bill of one, which is allowed to drop in a negligent, desultory way. Or one, which I take to be the female, plucks up a tuft and walks with it to the male as though to show him. She lets it drop, and then both birds, standing front to front, lower their heads at the same time and utter a shrill though not a loud cry. This seems as though one bird were suggesting 
to the other the propriety of building a nest, but it may be the actual manner in which the nest is built. There would, of course, be no doubt as to this, if the birds-or one of them-were to continue thus to pluck and bring tufts or blades of grass. But this was never the case when I saw them, nor did I ever remark any action on their part that had more the appearance of systematic nest-building than this. The nest of the great skua is very slight, a mere pressed-down litter of coarse long grass, shallow, and having a pulled, tattered look round the edges suggestive of the crown of a shabby straw hat or bonnet from which the remaining portion has been torn. Compared to it, the nest of a gull, being formed of quite a considerable quantity of bog-moss and heather, basinshaped, and fairly regular and with well-formed, soft, cushiony rim all round it, is almost a work of architecture.

Yet neither do gulls seem to work regularly or systematically in the building of their nests. One may be seen piking into the ground with its powerful beak and then withdrawing it with a tuft of moss or a sprig of heather held between the mandibles. After making a few sedate steps with this the bird lays it down, but instead of fetching some more, now, and continuing the work, it merely stands there and appears to forget all about it. Another will fly up with some material, and, after circling a little above its partner on the ground, will alight and lay it down as a contribution beside it, in a very stolid sort of way. The other bird does not help, and does not seem particularly interested, and the two now stand side by side for about half-an-hour, when the one that has last 
arrived flies away, and, on returning again, brings nothing. Sometimes a gull may be seen walking with moss or heather in the bill, whilst its consort walks beside it, but without having anything. When the heather is placed by the one bird, the other stands by and seems interested, but does not assist, and no further supply is brought. It would appear, therefore, that only one bird-and this, no doubt, the femaleactually builds the nest, though the other-the male -may look on and take a greater or less amount of intelligent interest in what she is doing. But though the above is from the life it hardly seems possible that gulls could get their nests done at all if they worked no better than this. When I first got to that island "de cuyo nombre no quiero acordarme," but few eggs had yet been laid and many of the nests were only half finished, or not even so far advanced as that. Most, however, were completed, or nearly so, and it is probable that what I saw represented merely the finishing touches, which will also apply to the great skuas.

What I saw was, indeed, very little, and it is only a surmise that the female gull builds the nest without being aided by the male. I think so, however, because usually, when both the male and female assist in the building, they work together, and whilst collecting the materials keep more or less in each other's company, arriving with them either at the same time or shortly after each other. This, at least, has been the case with those birds which I have watched. I have, indeed, seen two gulls pulling up the moss or heather within a yard or so of each other, and these I at first put down as a married couple. This, however, was not 
the case, for they laid down what they pulled in different places, and several times they attacked each other ard fought quite fiercely. With other birds, too, I have noticed a kind of rivalry between the females when collecting materials for the nest. Hen chaffinches seem particularly jealous of each other in this respect. They pull the lichens from the trunks of trees, fluttering up against them, and using both their claws and beaks, and when thus engaged, or when flying off with what they have got, two will often fly at each other and fight furiously in the air. I do not think that the one tries to take what the other has collected-there ought, one would think, to be enough for all-but, rather, that the sight of one when thus occupied, has an irritating effect on the other, and so it seemed to be with these two gulls.

Male gulls fight, too, as might be expected, the motive being usually, if not always, jealousy. Sometimes a little drama may be witnessed, as when a pair who would fain be tender are annoyed and hampered by a rejected suitor-the villain of the piece. This odious bird advances upon them with a menacing and, it would almost seem, a scandalised demeanour every time that he detects the smallest disposition towards an impropriety of behaviour, and when the husband-lover rushes furiously upon him he flies just out of his danger, and acts in the some way on the next occasion, which is immediately afterwards. This goes on for some time, the envious bird becoming more and more rancorous and more and more torn between rage and discretion every time valour assaults him. At last rage carries it, and, strange to say,considering it as melodrama-he, the villain, makes 
quite a spirited stand against the "good" hero, who, by all the laws of such things, should fell him to the ground and spurn him, so as to make the orthodox situation. Instead of this there is an equal combat which ends only in " nothing neither way," except that, as the bad gull still goes on afterwards, it is more in his favour than the other's. He wins, in fact, for the lovers are at length wearied out, and the contemplated impropriety never does take place. It is a pity almost that it cannot sometimes go like this in stage reality. To see the hero, just when most reeking with noble utterance, put suddenly into an unshowy position by the "hound" or the "cringing cur" would be a glorious thing, a delightful - almost a Gilbertian dénouement. One could applaud it "to the very echo that should applaud again," but one never gets the chance-or, rather, one would not if one tried, for I will not suppose that anyone with a taste for nature affects the melodrama-or even the drama nowadays.

Gull-fights are sometimes very fierce and determined, and when this is the case they often cause great excitement among a number of others. As on the human plane, fights between birds make impressions upon one according to the greater or lesser amount of intensity manifested, becoming sometimes quite tragic in their interest. Not only is this the case with oneself, but birds that are not fighting seem affected in the same way. I have noticed this with partridges somewhat-but more in the gullery. An ordinary scuffle between two birds attracts little if any notice from the others, but when it is sustained and bitter, supported with great courage on either side, there may be quite a crowd of excited on- 
lookers. I have seen a very desperate combat which I at first thought was a general scrimmage. It was not so, however. Two alone were engaged, but a cloud of gulls swept over and hovered about them, often hiding them from view. All were interested, and interested, it seemed to me, against one of the two birds who stood all the time on the defensive, beating or trying to beat off with wings and beak the continual eager rushes of his assailant. Many times they closed and went struggling and flapping over the ground, attended all the time by gulls in the air and gulls walking about and near them. When they disengaged, the same bird-as I inferred from the dramatic unity of its conduct-attacked again in the same eager way, as though the greater vivacity of its feelings or disposition made it always more quick than the other, though this one was equally brave and determined. One might almost fancy that the attacking gull had had some great wrong done it by the one it attacked. This latter, however, a powerful and steady fighter, finally beat off its assailant, who now took to the air. Sweeping backwards and forwards above the hated one, it made each time that it passed a little drop down upon it with dangling legs and delivered, or tried to deliver, a blow with the feet, a strategy which the other met by springing up and striking with the beak.

Such a conflict as this makes quite a commotion in the gull world, all those birds that have been standing anywhere in the neighbourhood flying and circling excitedly about above the combatants, or settling and walking up to them. I did not see the casus belli, so merely assume it to have been jealousy between two rival males. Quite possibly the birds 
were females. In none of these fights, nor in others that I have seen between black-backed gulls on the island, did there seem to be any special set method either of attack or defence, as is so noticeable in the case of some birds. It was a generalised fight_- "a pankration" - in which each bird did whatever it could without art or plan. A fight between two herring-gulls that lasted a long time was of another character. "They fought most savagely, but in a curious manner. Each seized the other by the beak, which they then (or one of them) endeavoured to extricate by pulling backwards, so that the stronger bird, or each alternately, dragged the other over the ground, a process which the one being dragged tried to resist by spreading the wings at right angles and opposing them to the ground. To me it seemed that one of the birds had each time seized the other to advantage and strove to retain its hold against the efforts of the less fortunate one to disengage. The length of time during which they remained with the beaks thus interlocked was remarkable. I was not able to time them, but it was so long as to grow tedious, and I several times turned the glasses on to other objects and, after a short interval, brought them back again, always finding them as before. A quarter of an hour, or, at the very least, ten minutes, would not, I think, be an over-estimate of the time they sometimes remained in this connection. The instant the beaks were unlocked the birds fiercely seized each other by them again, there was the same dragging and resistance, the same lengthy duration, and this was repeated three or four times in succession. At length there was a very violent struggle, and the bird that 
seemed to have the advantage in its hold, by advancing upon the other while never relaxing this, forced its head backwards and at length right down upon its back, the bird so treated being obviously much distressed. At last, with a violent effort, this latter got its bill free, and the two, grappling together, and one, now, seizing hold of the other's wing, rolled together down the steep face of the rock. At the bottom they separated. The bird, as I think, that had had the worst of it all along flew back to the place from which they had fallen, while the other remained, seeming somewhat hurt by the fall. Some time later there was another conflict between the same two gulls which was similar in all respects, including the place at which it was fought, except in its ending. This time there was no fall down the rock, but the one bird flew off, soon, however, to alight again, the other one pursuing and continuing to molest it with savage sweeps from side to side."

No doubt, in a fight like this, each bird seizes the other by the beak, as fearing what it might otherwise do with it, as two men with knives might seize hold of each other's wrists. But this might become in time so confirmed a habit that the birds, when fighting, would have no idea of doing anything else, and thus not attack each other in any less specialised way, however much one might have the other at an advantage. I do not mean to say that it has really come to this with the gulls in question-the facts, indeed, do not bear out this view-but several times, when watching birds fighting, I have seen, as I believe, a tendency in this direction, and it has occurred to me that the process might be carried even further. 
There was no other bird very near to these two gulls during all the long time that they fought, no female who was obviously the cause of the affair, and to whom either of them went, or showed a desire to go, either in the interval between the two combats or at the end of it all. Yet that the two were rival males seems hardly to be doubted, taking the season into consideration. This-and the same observation applies to the two wheatears who fought for hours without the female being at all en evidence-seems to show a power of retaining a vivid mental impression of the loved or coveted bird in her absence, to which is added a tranquil pleasure of the paired birds in each other's society apart from mere sensual gratification. It is absurd, therefore, to keep the word "love" to ourselves, as we do in the spirit if not the letter. As in other things, there is no line drawn here in nature, and it is in watching animals that one gets to know the real meaning of all our high terminology. It is wonderful how long two birds who have chosen each other will stand quite motionless close together, as though they were a couple of stones, and then show by some mutual or dependent action that each is in the other's mind. Here is an instance. "A pair of herring-gulls have been standing for a long time one just behind the other on the edge of the grassy slope of the cliff, quite motionless, looking like the painted wooden birds of a Noah's ark. All at once both, as in obedience to a common impulse, burst into wild clamorous cries for a few seconds and then fly out over the sea. Quite soon they return and, settling again in precisely the same spot and relative position, stand motionless as before, 
for full three hours, when one, uttering a little chattering, almost talking note, again launches himself from the verge and flies around for some three or four minutes in the near neighbourhood, with a frequent 'how, how, how.' He then re-settles just in his old place behind the other, talks a little, again flies off, returns and talks as before. The other gull has remained motionless, or almost so, all the time, and the two now stand silently as before." It seems strange that the birds should first act so mutually and then so independently of each other, but far stranger, as it struck me, was the absolute instantaneousness with which, on the first occasion, they both burst out screaming.

It is possible that close attention to animals might lead to evidence pointing in a new and unexpected direction, but I will leave this for another chapter.

Gulls have no very salient or pronounced courting antics-I mean I have observed none-and, in the same sense, there is no special display of the plumage by one sex to the other. When amorous, they walk about closely together, stopping at intervals and standing face to face. Then, lowering their heads, they bring their bills into contact, either just touching, or drawing them once or twice across each other, or else grasping with and interlocking them like pigeons, raising then, a little, and again depressing the heads with them thus united, as do they. After this they toss up their heads into the air, and open and close their beaks once or twice in a manner almost too soft to be called a snap. Sometimes they will just drop their heads and raise them again quickly, without making much action with the bills. This is 
dalliance, and between each little bout of it the two will make little fidgety, more-awaiting steps, close about one another. Always, however, or almost always, one of the birds-and this one I take to be the female - is more eager, has a more soliciting manner, and tender-begging look, than the other. It is she who, as a rule, commences and draws the male bird on. She looks fondly up at him, and raising her bill to his, as though beseeching a kiss, just touches with it, in raising, the feathers of his throat-an action light, but full of endearment. And in every way she shows herself the most desirous, and, in fact, so worries and pesters the poor male gull that often, to avoid her importunities, he flies away. This may seem odd (to non-evolutionists), but I have seen other instances of it. No doubt in actual courting, before the sexes are paired, the male bird is usually the most eager, but after marriage the female often becomes the wooer. Of this, I have seen some marked instances. That of a female great plover calling up the male by her cries, when pairing took place between them, I have already given, and I have seen precisely the same thing in the case of the kestrel hawk. Female rooks, too, are often very importunate with the males in the rookery when building is going on. It is always a great satisfaction when the male and female of a species differ noticeably in their plumage, as then one is never in uncertainty as to which of them it is that performs any act. Often one must remain quite in the dark as to this, and often, again, one can only surmise. Of course, when one watches birds for any time in the breeding season, one gets clear ideas as to which 
is the male and which the female, but certainty is better, and certainty, at any moment or on any occasion, unless there is some marked difference between the sexes, one cannot have. In the case of gulls, however, though the plumage is alike, there is a difference in size sufficient to strike the eye, the male being larger - in the great black-backed gull, greatly larger-than the female.

Leaving the palled blandishments of its spouse, the gull husband cleaves the air, cuts the dark line of beetling precipice, and seeks the free haven of the open sea, where, with other sensible, repentant Benedicts, it wheels and circles. Suddenly a dusky form, slender and swallow-like, though as large as a pigeon, shoots over the rounded bastion of the heather, and sweeping upwards as it nears the cliffs, darts upon one of the gulls. A second pirate follows. With wild cries, and long, gliding sweeps, they press and harass the larger bird, who, doubling, twisting, avoiding, dodging, but never resisting, utters again and again a cry of distress and complaint. Its companions sweep and eddy about them, shooting athwart and between. They protest, they cry to heaven, their wild voices mingle in harsh, discordant unison with the rock-dash of the waves, and the everlasting notes of the wind. Suddenly something drops from the oppressed gull. There is a sinking towards it of one of the dark shadows-swift beyond telling, but so soft that the speed is not realised-the object is covered, lost, and almost with a jerk, the eye-or rather the brain-realises that it has been caught in the descent. Empty, and now unregarded, the robbed bird sweeps on, the pirates sweep back 
to the heather, the cloud of witnesses disperse themselves, and, as with us each day, each hour, things smooth themselves again over the high-placed acts of successful villainy. Who troubles over a robbed gull? What moral Nemesis concerns itself with the wrongs of some cheated, done-to-death savage or tribe of savages? Over both there is some shrieking, some eloquence at the time, but both are soon lost in oblivion, the waves close over, the world jogs on its way. Retribution, retributive justicesuch fine things may exist, perhaps, but, if so, it is for showier matters. Had the skuas robbed an albatross, something, perhaps, would have happened. Their sin might have found them out-then. A gull is like an Armenian, or ... but there are so many.

Thus closes one of nature's wild dramas. The gulls are circling again now, and all is as before.

"Es pfeift der Wind, die Möven schrein

Die Wellen, die wandern und schäumen."

Such a scene as the above may often be witnessed as one lies on the heather and watches, but for one actual robbery that one sees there will be a dozen or so unsuccessful attempts at it. Yet, if one believes those who have the best opportunities of knowing, neither the great nor the Arctic skua-the latter is the bird to which attention has just been called-ever eat a fish that has not first been swallowed by a gull or tern. They say, moreover-at least, this assertion is made in regard to the great skua - that if the booty is not secured in mid-air, but falls either on the sea or land, no further attention is paid to it by the 
robber. For myself, I believe that the skuas always, or almost always, feed in this way, because I think that when, in the satisfaction of such a daily and almost constant want as hunger, some curious and bizarre method had been adopted it would tend to become habitual, to the exclusion of all others. Two such different plans of obtaining fish as are, respectively, swooping upon them whilst swimming in the water, and catching them in the air upon their being disgorged by another bird, after a chase which is often long and arduous, could hardly be carried on by the same bird; for it is probable that either one, to be successful, would have to be habitually employed, thus leaving no room for the other. Moreover, the adoption of such a peculiar method of obtaining food at all implies a great advantage over the older method, and this being the case it would tend entirely to supersede it. But that the Arctic skua, at any rate, thus habitually chases and robs gulls one can easily satisfy oneself, nor have I ever seen either it or the great skua stooping on fish, like terns, gulls, or gannets.

The young of the great skua are fed entirely on herrings, which are first swallowed by the parent bird, and then disgorged on to the ground in the neighbourhood of the nest. I cannot say that I have myself seen this done, for it is impossible to watch the nesting habits of a bird that always attacks you when you approach its nest, and continues to do so as long as you stay anywhere near it. In these grey desolate islands there is no sort of cover, no tree or bush with the branches of which one can make oneself a shelter, and watch unobserved. More- 
over, as there is no night properly so speaking, only a portentous lurid murkiness towards midnight, which seems neither to belong to night nor day, and in which, as you can read small print, the skua can very naturally see you, there is no approaching under cloud of darkness and being there, ensconced, when morning dawns. But that the bird disgorges the herrings for the young ones after the manner of gulls generally, and does not carry them in its beak or claws, which is contrary to their practice, there can be no doubt. Now, as every one of these herrings has - as I believe it has - been secured in the manner above described, it is curious to reflect that, when finally swallowed by the young skua, it "goes a progress" for the third time, nor would it be easy, perhaps, to find another instance (outside this family of birds) of prey that has been twice given up, through fear once, and then, again, through love.

The herrings lying about the nest, and which have thus been recently disgorged for the second time, look almost as fresh and clean as if nothing peculiar had happened to them. They are disgorged whole, or nearly so; for, as I myself observed, in the great majority of cases the head is absent. Thus at one nest, in the neighbourhood of which (but this means often a considerable space of ground) forty-one herrings or their remains were lying, only ten retained the head or any part of it. At another, where there were thirteen, all were entirely headless: at another there were eight, of which one only had part of the head remaining : at another ten, eight of which were headless: at another seven, six of which were: and at another four, of which one retained the 
entire head. Thus, out of eighty-three herrings, only fifteen had the heads to them, though the proportion of the one to the other was different at different nests. The heads when thus absent are entirely so-that is to say, they are not to be found lying about separately. That the chick should eat the head of the herring by preference seems unlikely, and particularly when it is quite young. Yet I have seen four herrings lying about a newly-hatched chick, which were quite fresh and almost untouched, but headless. The question, therefore, arises whether the parent-bird eats the head after disgorging the whole fish, or whether, in the majority of cases, it is disgorged minus the head. Fish are, I believe, always swallowed by birds which prey upon them, head first, and would therefore, one would suppose, lie in the gullet in this direction. If disgorged again tail first, as they lay, the gills, by expanding, might offer such resistance that the head would be in most cases torn off. If this be so, then the skua may often receive the fish headless from the gull, or, if otherwise, the head would be still more likely to be torn off, on a second disgorgement. This, however, one would think, must be a very disagreeable process for the bird disgorging, and it would seem more probable that the fish can be turned or shifted in the gullet, by some muscular action on its part, so as to be brought up head foremost, as it descended; but whether there is any evidence as to this, I do not know. If the head of the herring does not remain in the gullet, then it must be eaten by the parent skuas after ejection, and it would seem that they looked upon this portion as their peculium, to which 
they were honestly entitled, for they seem to leave the rest, mostly, for the chicks, of which there are, commonly, two. At any rate, a number of the herrings will have only a small portion eaten off them. There is a great profusion, amounting to waste, and there does not seem any reason why the skuas should vary their diet during the breeding season, as they are asserted to do, since they have the sea always at hand, and the gulls, that are to them as their milch cows, breed in their close proximity.

In the skuas we see the habit of obtaining food by forcing another bird to disgorge what it has swallowed, perfected and become permanent, so that the birds practising it have risen-shall we say? -into rapacious parasites; but amongst the gulls themselves, who suffer by the practice, we may see, if I am not mistaken, the habit in its incipiency, and may get a hint as to how it might have arisen. When fishing-smacks are in harbour they are thronged round, sometimes, by hundreds of gulls, all the more common kinds-viz. the lesser and greater black-backed, herring-gulls, and kittiwakesbeing mixed and crowded together. When some offal is thrown out, the birds that secure any are at once mobbed, and often it is torn away from them almost before they have swallowed a mouthful. To avoid this, they often rise with it in the beak and get it down as fast as they can on the wing, dodging and jerking their head from side to side amongst the pursuing crowd. But I have observed that the pursuit does not always cease after the morsel has been swallowed, and sometimes-whether rarely or frequently I am unable to say-the oppressed gull disgorges it again, in order 
to be left in peace. Now, amongst a crowd of birds like this, the greater number would be unable to see whether the one they were pursuing had swallowed his morsel or not, and would therefore keep pressing about him in the hope of being able to snatch at it. But, of course when birds that were hustled began to disgorge, this would be noticed and soon remembered, and they would then be hustled so that they might do so. In this, or in some similar way, I can understand the habit arising without any initial act of intelligence on the pursuing bird's part.

Perhaps, however, there would be no great unlikelihood in assuming such an act of intelligence. For one gull to conceive the idea of making another bring up what it had swallowed, might not be so very much more than for the sea-eagle to think, in regard to the osprey with the fish in his talons, "I'll make him drop it." With all the gull tribe the bringing up of the food again after swallowing it is an easy and habitual action. Not only are the young fed thus, but I have some reason to think that, during the nuptial season, the presenting in this manner of some "pretty little tiny kickshaw" by the male bird to the female is looked upon as a chivalrous and lover-like act. Perhaps such acts are reciprocal, but I will give my two little instances and let my readers draw their own conclusions. The first is the case of a herring-gull. I was watching the mother bird (as I suppose) sitting on the nest over two young ones, one of which had been hatched either only that day or the day before, and the other a day or two earlier. "At 12 o'clock a chick moves out from under the mother, and leaves the nest. It is quite active, and has the general appearance 
of a young chicken, being fluffy and of a yellowish grey colour, speckled with black. At I2.40 the second young one appears, pushing itself out from under the mother bird as she rises a little in the nest. At halfpast one the male gull, which has been near all the while, walks slowly and importantly to the nest, which he passes and then, turning back towards it, disgorges on to the rock a small fish, which he takes up in just the tip of his bill and pushes towards both the chick on the rock and the mother on the nest, all slowly and with a dry sort of manner, as though the bird were a cynic. The mother gull leans forward from the nest and takes it, and, first, holds it on the ground, while the chick outside pecks at it. Then she swallows it herself. The male now produces in the same way a small something-I suppose a gobbet of fish-and draws the chick's attention to it by touching it with his bill and pushing it a little towards him. The chick then swallows it, upon which the male flies off and takes his accustomed stand on a large projecting point of rock close at hand." This is a conjugal, a domestic, picture. The other, which I shall now give, and in which the hero was an Arctic skua, was, perhaps, " more condoling."

"The one bird stands still and upright, whilst the other, holding the neck constrainedly down, but with the head raised as far as is compatible with this, keeps moving round and round it. After revolving thus several times, keeping, always, very close to and, sometimes, actually touching the standing bird, this one also stands still, always in the same attitude, and opens his beak. The other one, standing as before, now raises the head and opens the beak also, upon 
which the satellite bird, assuming, at last, his proper height, delivers into it, from his own, something which he appears to bring up, and this, as it seems to me, is swallowed by the bird receiving it. The morsel is small, but the actions of giving and taking, and, afterwards, the movements of the beak and throat of the bird that has parted with it, are unmistakable. This would appear, therefore, to be a little friendly act, or, perhaps, an act of courtship-a love-token between the male and female bird-and I take the bird who delivers the morsel, and who is cream-marked, to be the male, and the other, who is uniformly dark, the female."

Skuas, as is well known, attack one if one comes at all near to their nest, and gulls-at any rate the two black-backed kinds-will sometimes, though much more rarely, come very near to doing so too. For instance, the greater black-backed gull swoops at one backwards and forwards, in the same way (though more clumsily) as do the skuas, except that he neither touches you nor comes so near. Every time he passes he gives a loud, harsh, tuneless cry, and drops down his legs as though intending to strike with them. When he does this, he may be some five or six feet above one's head-a little more, perhaps, or a little less-and presents an odd, uncouth appearance. The skuas swoop in silence, though the great one continually says " $\mathrm{ik}$, $\mathrm{ik}$ " (or words to that effect), whilst circling between the swoops. "On another occasion two of the lesser black-backed gulls acted in this way, though one of them continued to do so for a much longer time. These two seemed to be angry with each other, making little motions and opening their bills in the air as though each thought it was the 
other's fault." This little trait, which would seem to raise them nearer humanity, I particularly noted. The mode of attack, when thus aerialy delivered, is the same in all these birds, and, as it seems to me, curiously ineffective. The beak, a powerful weapon, is not employed, nor is a blow-which, if it were, might be of real force-delivered with one of the wings. Instead, the webbed feet, which would seem to be weak in comparison, and have no talons or grasping power, are made use of in the way I have already described in the case of the two gulls fighting, when, after the tussle on the ground, the one was swooped at by the other.

The following account of the attack of the smaller or Arctic skua, will apply almost equally to the great one. "The bird comes swooping down in a slanting direction, with great speed and impetus, and as it passes over one's head, makes a slight drop with the feet hanging down, so that they administer a flick just on the top of it, as it shoots by. Having made its demonstration, it shoots on and upwards, and turning in a wide sweep, again comes rushing down to repeat it, and so forwards and backwards for perhaps some half-a-dozen times, after which the intervals will become longer, the circling sweeps which fill them up wider and more numerous, till the attacks cease, and the bird flies away." (The great skua, however, will attack almost indefinitely.) "The force of the downward rush is in all cases very great, and the 'swirr' which accompanies it quite startling, suggesting a larger bird, or something of a more portentous nature altogether. In striking, the bird shoots the feet forward as they dangle, so that they 
hit one with the anterior surface, and there is not the slightest attempt to scratch or grasp with them. The force that can be put into such a blow is but slight, and, even in appearance, there is something trivial and inadequate about it that takes away from the effect of the bold sweep, which, in the case of the great skua especially, strikes the imagination, and is, indeed, a fine sight. A terrific blow with the wing, or a seizing and tearing with beak and claw, as with an eagle, would seem the fitting sequel to such power and fierceness."

This failure of the sublime, and falling almost into the ridiculous, cannot be observed when one is oneself the object of attack, and, moreover, the buffets that one is constantly receiving, though quite out of proportion to the size and fury of the birds, are often so stinging and disagreeable as to spoil one for looking at the matter from such a point of view. A ruse, however, may be adopted, and the scales then fall from one's eyes. For instance: "To-day I sat down by the almost fledged chick of a pair of great skuas, and, drawing my plaid over my head, numbered the attacks of the parent birds. When I began to count it was 3.I3 P.M., and at 3.30 they had made between them-turn and turn about- 136 swoops at me. Of these, 67 were hits and 69 misses. Some of the hits were very - indeed, extremely-violent, so that without the plaid I could not have stood it, and even as it was, it was unpleasant. The blow is always delivered with the feet, though sometimes (and pretty often as it seemed to me) a portion of the bird's body touches one at the same time, thus giving more weight and force to it. The 
force of the swoop is tremendous, and did the bird strike one full with its whole bulk, it would, I believe, knock one over, as a hare, it is said, has sometimes done by accident, in leaping over a hedge. After this heroism, I stuck my umbrella (staff, or even stick, would sound better, but it was an umbrella) into the ground, arranged my plaid upon it, and walked to a little distance. The birds, one after another, swooped at the plaid but never hit it. As they got just above it they stretched down their legs, but at the last moment seemed to think something was wrong, and rose, so as just to clear it. 'But out upon this half-faced fellowship!' This dangling down of the legs, in which the speed is checked and the grand appearance lost, is quite pitiful. Why cannot the birds fell you with a blow, or tear you with the hooked beak? This would be 'Ercle's vein, a tyrant's vein,' but a flick with the feet merely-it is a tame conclusion!"

I doubt now, if the bird ever does strike you with the body even lightly. It feels as if there must be more than the feet at the time, but, probably, this is not the case.

Both the male and female of the great skua defend the nest-and especially the young-in this manner, but the swoopings of one of them, probably of the female, are generally fiercer than those of the other. In my limited experience this dual attack was almost invariable, but in one instance the nest was guarded by one bird alone. This bird, as though to make up for the deficiency, was even more than usually fierce, making long rushing swoops from a great height and distance, which would, I believe, have been effective each time had I not bobbed. The 
other bird circled at a still greater height, and never once joined in the attack. The height, I may say, from which the birds swoop is not, as a rule, very considerable. The above does not apply equally to the Arctic skua-at least in my own experiencefor though often the two birds would attack, yet in the greater number of cases only one of them did so. Now the Arctic skua, as I have mentioned elsewhere, is one of those birds which employs strategy (begging here the question for the sake of brevity) as well as force to defend its young, and it occurred to me that here might be a case of cooperation, the male bird most probably attacking, and the female employing the ruse. I satisfied myself, however, that the same bird sometimes does both one and the other. How often this is so, and whether there is a tendency on the part of either sex to resort by preference to one or the other method, it might be difficult to find out. Yet I cannot help thinking that this is the case, and that a process of differentiation is in course of taking place. The facts are-or appeared to me to bethese. In the case of the great skua, both sexesalmost, but not quite, always-attack, and there is no ruse. In that of the Arctic skua both sexes sometimes attack, but far more frequently (that, at least, was my own experience) one alone does so, and here a ruse is employed. In the former case we just see occasionally, as an exception, the raw material (the non-attacking of the one bird) that might conceivably be utilised by nature for the elaboration of another form of defence. In the latter we may see this other form being elaborated. 
Questions of this nature might be settled in the future on facts observed now, as easily as a reference to an iron ring where boats were once moored settles the question as to whether the coast has risen or the sea encroached. The coast and the sea, however, remain. Birds, slaughtered by millions each year, must cease almost as a class before any great period has gone by. Of what use then the ring, the record when what it speaks of is no more?

Another interesting point in the Arctic skua (which it shares with at least one other species of the genus) is its dimorphism - or rather, to describe it more properly, its polymorphism. To me it seems to offer a case of a species in course of variation from one form into another. In the two extreme forms the plumage is, respectively, either entirely sombre both above and below, or the whole throat, breast and under surface, with a ring round the neck, and more or less of the sides of the head, is of a fine cream colour. Between these extremes there are various gradations, the cream being sometimes on the breast only, whilst the throat is of a lighter or deeper grey, more or less mottled with the still darker shade, or the lighter colour is hardly or not at all discernible on these parts, whilst lower down it becomes less and less salient till it is merely a not so dusky duskiness. The cream-coloured birds, though numerous, are in the minority, and both this and their being much handsomer suggests that the process of change is in this direction, whilst the intermediate tintings may represent the steps in this process. To what form of selection (if to any) are we to attribute the change? As the cream colouring makes the bird more con- 
spicuous, natural selection (as distinct from sexual) seems excluded, unless it could be shown that the change of colour is correlated with some still greater advantage, and this is neither apparent nor likely. There remains sexual selection, which to my mind is strongly suggested. The modified colouring is, it is true, shared by the two sexes, but this is quite compatible with the theory, which supposes the tintings of the male kingfisher and numerous other brilliant birds to have been thus acquired and transmitted in each stage of progress to the female. It would, therefore, be interesting, though, no doubt, difficult, to determine by observation whether the creamy-coloured male birds were on an average more attractive to the females than the other kind, and also whether the more handsome form was increasing. In regard to the last point, this was the opinion of a man guiltless of theories, but with a large amount of experience of the birds.

Of these two species of skua, the great and the lesser or Arctic one, the latter appears to me to be the boldest and most aggressive. It will chase not only gulls, but ocasionally the great skua also, this last, as it would seem, for sport or pleasure rather than for any particular object. In the same way they often chase each other. A too near approach to the nest may, perhaps, be the reason in either case, but having watched them attentively I do not think that the pursuing bird is often under any real apprehension. Gulls are persecuted by them in the manner I have described, and sometimes, I think, also in mere wantonness. The larger ones seem never to resist, but the kittiwake will sometimes go down upon the water, 
turn to bay, and drive the robber off. Gulls seem to fear the great skua less than the Arctic one, and will sometimes mob and molest it. A single pair that had nested on the outskirts of a gullery were a good deal subject to this annoyance. One and then another gull would pursue them when they flew near, and sometimes even swoop at them from side to side as they stood upon the heather. But I never saw them annoy the Arctic skuas in this manner. The latter, however, were much more numerous.

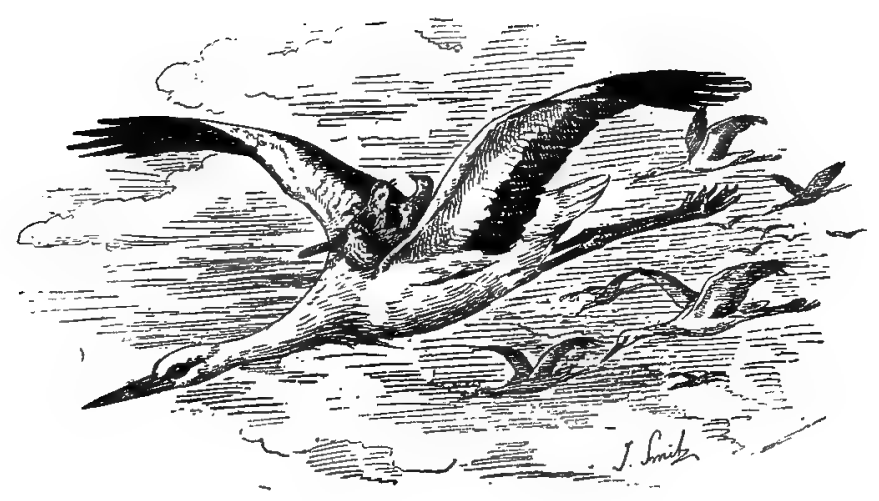




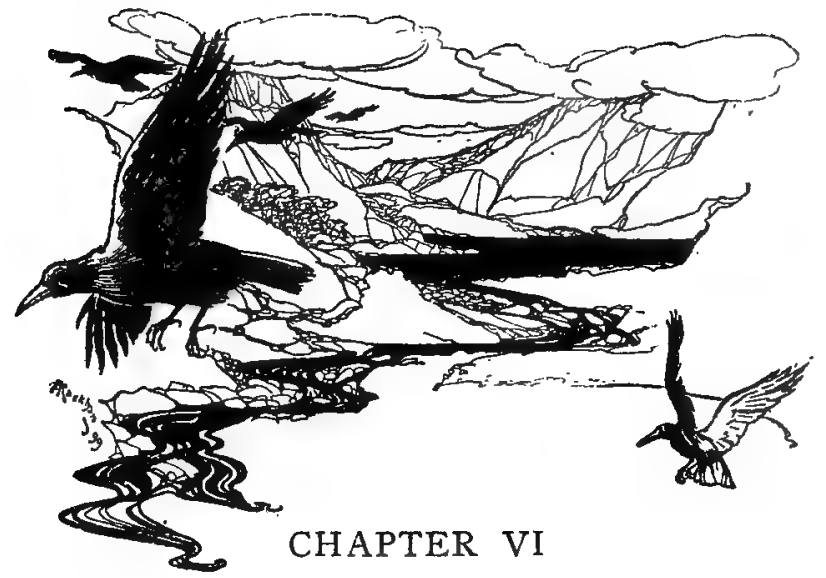

\section{Watching Ravens, Curlews, Eiderducks, etc,}

A PAIR of ravens on our island are also molested by the gulls, and when either of them flies from one point to another of the coast in their neighbourhood its path is marked by a constant succession of "annoying incidents" of this nature. That these stately birds should have to put up with rudeness from mere gulls does not seem right; but so it is, nor did I ever see either of the two make any serious attempt to overawe them. Personally, I must say that I was at first so little impressed by these ravens, that for a long time I did them the injustice of looking upon them as carrion crows. Certainly, the hoarse, bellowing croak which they uttered as they flew round when disturbed by me impressed me and made me wonder, but their size appeared altogether incompatible with the state of being a raven. I suppose the great frowning precipices over which they commonly circled had 
a dwarfing effect upon it, but they were manifestly smaller than any of the gulls which molested them, and this I was not prepared for from the specimens which I have seen in museums or languishing in captivity. That they were ravens however, is, I think, certain from the very peculiar croaking note to which I have alluded, and which they uttered at this time almost constantly.

When I came to the island these birds had already hatched out their young, of which there were four lying in a loose cradle of what looked like sticks, but could not have been, since these were nowhere procurable. It was a mass of something having the general appearance of a battered and flattened rook's nest, but what the actual materials of which it was constructed were, I am unable to say. The nest was on a ledge half-way down the face of a huge precipice forming one side of a fissure in the coast-line-the mouth of an immature fiord-dug out in the course of ages by the slow but ceaseless sapping of the sea. From the summit of the opposite side I could look across at and down upon it, having an excellent view. The young birds-five in number -who were well fledged, and within, perhaps, a fortnight of leaving the nest, lay in it very flatly with their wings half spread out, and so motionless that for some time, upon first seeing them, I almost thought they must be dead. The sudden yet softly sudden rearing itself up of one with an expressive opening of the beak-expressive of "surely, surely, it must be meal-time again now"-gave a delightful assurance that this was not the case, and 
then there were more such risings and expressed convictions. At intervals only, however, for it was wonderful how still the young birds would lie for quite a long time, and so closely inwoven within the cup of the nest that it was only when they stirred that five became a possibility. The ledge being quite bare and open, the nest with the young in it, making a black bull's - eye in the midst of a great sheet of white, was conspicuously apparent. Several times I saw the young birds move themselves backwards to the inner edge of the nest, and then void their excrements over it, so that only a little of the quite outer portion was contaminated. By this means the nest is kept clean and dry, whilst all around it is defiled. It would seem as though this power of ejecting their excrements to a distance which various birds possess was, sometimes at least, in proportion to the size and bulk of the nest which they construct. The nest of the shag, for instance (and in a still greater degree that of the common cormorant), is a great mass of seaweed and other materials, and the force with which the excrement is shot out over this, both by the young and the parent birds, astonishes one, as does also its upward direction. I had always felt surprise when seeing cormorants and shags perform this natural function whilst standing on the rocks, but it was not till I had watched the latter birds for hour after hour, as they sat on their nests, that I understood (or thought I understood) the significance of it. In spite of the popular saying, it does not seem probable that all young birds act in this way, and many nests are so constructed that it would hardly 
be possible for them to do so. In most cases every= thing necessary for sanitation or convenience could be effected afterwards by the parent birds, but this would not be the case with ravens and cormorants, or with other such carnivorous or fisheating species. Perhaps, therefore, the power which I speak of may stand in joint relation to the diet and habits of the bird, and the kind of nest which it builds.

I made many attempts to witness the feeding of these young ravens by their parents, but owing to there being no kind of cover from which I could watch, and no means of erecting a proper shelter, I was unable to do so. I did what I could by means of pieces of turf, and a plaid or waterproof stretched over them, but this was not sufficient to allay the suspicions of the old birds, who had always seen me as I came up, and from my first appearance over the brow of the hill flew around croaking and croaking, awaiting impatiently the moment of my departure. It would have been difficult not to sympathise with them, not to feel like an intruding vulgarian amidst that lonely wildness. For my part, I never tried not to, but yielded at once to the feeling, and retired each time with the humiliating reflection that the scene would be the better without me. Yet it seems strange that in any scene of natural beauty or grandeur, the one figure-should it happen to be there-that has the capacity to feel it is just the one that puts it out. Scott, for instance-though he were Scott-would not have improved any Highland bit, and Shakespeare's Cliff would hardly have looked the better for the presence even of Shakespeare himself. 
The samphire-gatherer, however, would have blended artistically, but neither he nor a kilted shepherd or clansman would have had any more appreciative perception of the beauties into which they fitted, than the "choughs and crows" themselves, the sheep, or the majority of tourists. * It is not a matter of clothes alone. It would seem as though one must stand outside of a thing, and therefore be out of keeping with it, before one can feel and grasp it, though, heaven knows, the one need not involve the other.

But, though I missed the feeding, I twice saw the raven mother-the real one-cling on to the side of the nest and look in upon her young ones, who rose and greeted her hungrily. That was a glorious thing to see. There was something in the bird's look almost indescribable, a blending-as it seemed to me-of cunning, criminal knowledge combined with lightheartedness, and strong maternal affection. With the first two of these, and with the stately, yet half grotesque action, the bright, black eyes, and steely, glossy-purpling plumage (it never looked black through the glasses), a faint, flitting idea, as of the devil, was communicated, enhancing and giving piquancy to the delight. She hung thus for some moments, seeming to enjoy the sight of her children, yet all the while having her black, cunning eyes half turned up towards myself. Then she flew away, joining her mate, who had waited for her some way

* Scott, however, credits the Highlanders-I mean the rank and filewith an artistic appreciation of the scenery amidst which they lived (see "Rob Roy"). I should bow to such an authority, but confess I find it hard to believe. 
off at the accustomed place on the cliffs. It was when I saw her like this, and when the glasses isolated her from the general of rock and sea, that this raven seemed to assume her true size and dignity, and to become really a raven. When she flew it was different. Her sable pinions beating against the face of the precipice added no effect to it, but she was instantly dwarfed and dwindled, and became as nothing, a mere insignificant black speck, against its huge frowning grandeur.

Though, really, their plumage is all of gleaming, purply blues, at a little distance, and when they fly, ravens look a dead ugly black, which is also the case with rooks, who are almost equally handsome when seen closely. Their flight is peculiar, and though it strikes the imagination, yet it cannot be called at all grand or majestic in the ordinary sense of those words. The wings, which are broad, short, and rounded-or at any rate present that appearance to the eye-move with regular, quick little beats, or, when not flapped, are held out very straightly and rigidly. When thus extended, they are on a level with or, perhaps, a little below the line of the back, and from this, in beating, they only deviate downwards, and do not rise above it, or very triflingly so, giving them a very flat appearance. A curious curve is to be remarked in the anterior part of the spread wing, at first backwards towards the tail, and then again forwards towards the head. All the primary quills seem to partake of this shape, and they are also very noticeably disjoined one from another, so that the interspace, even whilst the wing is beaten, looks almost as wide as the quill-by which I mean the 
whole feather-itself. I tried to imagine the effect of a number of these sombre, quickly-beating pinions with the short eager croak, having something of a bellowing tone in it (the croaking raven doth bellow for revenge") over the wide-extended carnage

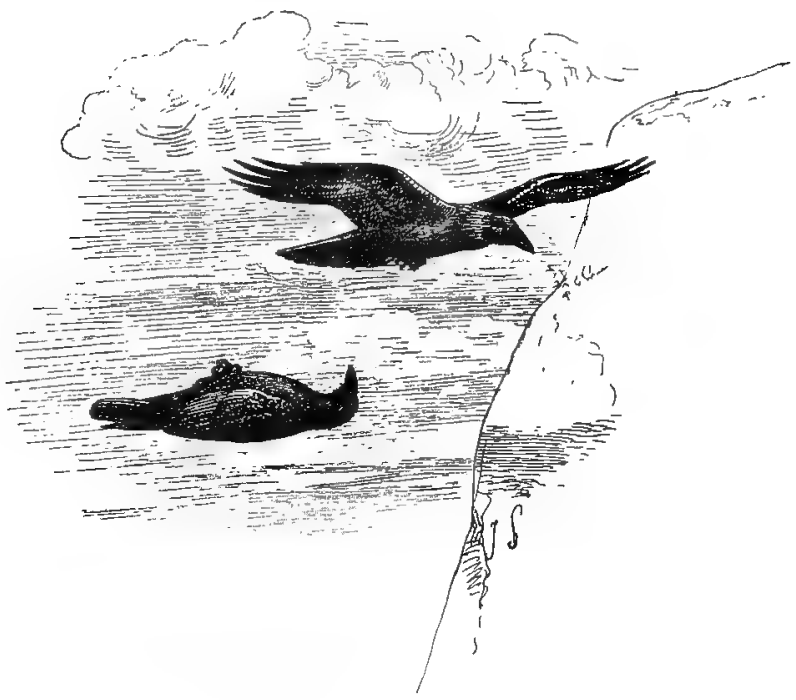

Raven: The Game of Reversi

of an ancient battlefield, and I thought I could do it pretty well-in spite of the difficulty, in the present day, of conjuring up such scenes.

But, though the ordinary flight of ravens be as I have described, it does not at all follow that they may not sometimes soar or sail for long distances through the air, or descend through it at great speed, and with all sorts of whirring and whizzing evolutions. 
For all these things do the rooks, and yet their ordinary flight is of a heavy and plodding character. One very peculiar antic, or "trick i' the air," the raven certainly has. Whilst flapping steadily along with regular, though quick beat of the wings, it closes these all at once, quite tightly, as though it were on the ground, and immediately rolls over to one side or the other. Either the roll is complete, so that the bird comes right round again into its former position, or else, having got only so far as to be back downwards, it rolls back the reverse way. This has a most extraordinary appearance. The bird is stretched horizontally in the position in which it has just been flying, and in rolling over makes one think of a barrel or a man rolling on the ground. Being in the air, however, it may, by dropping a little as it rolls, make less, or, possibly, no progress in a latitudinal direction, though whether this is the case or not I am not sure.

To watch this curious action through the glasses is most interesting. Each time there is a perceptible second or two during which the bird remains completely reversed, back to earth and breast to sky. The appearance presented is equally extraordinary, whether it makes the half roll and returns, or goes completely round. I have sometimes seen rooks make a turn over in the air, but this was more a disorderly tumble, recalling that of the peewit, and, though striking enough, was not nearly so extraordinary as this orderly and methodical, almost sedate, turning upside down. The feat is generally performed four or five times in succession, at intervals of some seconds, during which the steady flight is continued. Most 
often it is done in silence, but sometimes, at each roll over, the raven cries "pyar," a penetrating and striking note.

Sometimes these ravens would roll in this manner whilst pursued by or skirmishing with a gull, and once I saw one of them do so during a curious kind of skirmish or frolic-it was hard to tell its exact character-with a hooded crow. Whether the hooded crow turned itself almost at the same time in a manner somewhat or entirely similar, I am not quite sure, but it struck me that it did do so. Of course, one may very easily just miss seeing the action of a bird clearly, especially if there are two or more together, and it is then, often, very annoying to be left with no more than an impression, which may or may not be correct. It is more satisfactory, almost, to see nothing than not to be sure, but both impression and doubt should be stated, for both are facts, and should not be suppressed. But on no other occasion have I seen a hooded crow behave in this way, though I have watched them often. Once, but only once, I saw one indulging in an antic which was sufficiently striking, but of quite a different character. This bird would spring suddenly from the ground, mount up almost perpendicularly to a moderate height, and then descend again on the same spot or close to it, making a sudden lurch and half tumble in alighting. It did this some dozen times, but not always in so marked a manner, for sometimes the mount or tower was not straight up from this spring-as a mountain sheer from the sea-but arose out of what seemed an ordinary flight over the ground. As it descended for the last time another crow flew up to and 
alighted beside it in a manner which seemed to express an entry into its feelings. This was in East Anglia, on the last day but one of February, and I look upon it as a premature breaking out of the nuptial activities before the birds had taken wing to their more northerly breeding-places. As to these aerial antics of the ravens, I doubt if they were strictly nuptial, on account of their performance of them whilst skirmishing with gulls, or with the hooded crow.

These two ravens were most devoted guardians of their young, and they pursued a plan with me-for I was the only intruder on their island-which was well calculated to blind me with regard to their whereabouts, and would certainly have succeeded in doing so, had not the nest been so openly situated, and such a conspicuous object. They took up their station daily-and in this they never once varied-at a point on the cliffs considerably beyond the place where they had built their nest, and which commanded a wide outlook. As I came each morning along the coast, which rose gradually, I became visible to them whilst about as far from their nest on the one side as they were on the other, and the instant my head appeared over the brow of the hill they rose together with the croaking clamour I have mentioned, and circled about round their own promontory. This strategy could hardly have been improved upon had it been carefully thought out by a man, for in the first place my attention was at once directed to the birds themselves, and then if the likelihood merely of there being a nest had occurred to me, that part of the cliffs from which they rose, and about which they 
wheeled, would have seemed the most likely place in which to search for it. No doubt, had the nest been well concealed, the birds would have done better not to have shown themselves, but conspicuous as it was, they could hardly have adopted a better plan of getting me away from just that part of the coast where it was situated.

I have spoken in the last chapter of the extreme boldness of the smaller of the two skuas, and how, whether in sport or piracy, he chases birds much larger than himself. It was, therefore, something of a surprise to me when I observed one morning this bold buccaneer being himself pursued by another bird. This was one of a pair of curlews, birds that are as the spirit of the sad solitudes in which they dwell. It is, indeed, more as a part of the scene-that treeless, mist-enshrouded waste beneath grey northern skies, which they emphasise and add expression tothan in themselves that one gets to consider them. Just thickening with a shape the dank, moist atmosphere, seeming to have been strained and wrung out from the mist and rain and drizzle, they are, at most, but a moulded, vital part of these. They move like shadows on the mists, when they cry, desolation has found its utterance. And yet, for all this, their general appearance, with their long legs and neck, and immensely long sickle-shaped bill, is very much that of an ibis-insomuch, that seeing them in this bleak northern land, has sometimes almost a bizarre effect. This should seem quite irreconcilable with the other, and yet, though it certainly ought to be, somehow it is not, so that, at one and the same time, this opposite bird brings a picture, by looking like 
an ibis, of Egypt and the South, and is likewise the very incarnation of grey skies, of mist and morass. So strangely can contradictions be reconciled in the mind, or rather so well and impartially can we grasp two aspects of a thing when neither concerns us personally.

When they stand or walk slowly and sedately these curlews hold their long, slender necks very erect, and it is this, with the beak, that gives them their ibis-like character. When they run they lower the neck, and the quicker they go the lower do they hold it. In taking flight they sometimes make a few quick running steps with raised body, as though launching themselves on the air; but at other times they will rise from where they stand without this preliminary. In flight they may be called conspicuous, at anyrate by contrast with the wonderful manner in which they disappear simply_ "softly and silently vanish away" -when on the ground. This is by reason of their colouring, which on all the upper surface of the body and the outside of the wings is of a soft, mottled brown, which blends wonderfully with, or, rather, seems to become absorbed into the general surroundings of moor and peat-bog, so that they never catch the eye, and are simply gone the instant this is taken off them. But the plumage of the under surface of the body and of the inside of the wings is much lighter, and this becomes visible as the bird rises (as with the redshank), and alternates with the other as it flies around. It is thus-round and round in a wide circle-that a pair of them will keep flying when disturbed in their breeding-haunts. But though each bird is equally disturbed and anxious, and 
though their mournful cries answer each other like two sad complaining souls, yet they keep apart, and, on settling, do not run to each other. From the drear slope of a hill a wail goes up, and from another hill, or the cheerless hollow between, the sad sound is answered. Or one will fly wailing whilst the other wails and sits, or the two will follow each other along the ground, but without coming very near. Thus, in a kind of sad, solitary communion, they wail and lament, and so exactly is each the counterpart of the other, one might think that the prophet Jeremiah had been turned into a bird, which had subsequently flown asunder.

In flight the wings are for the most part constantly quivered, with a quick and somewhat tremulous motion, but sometimes the bird will glide with them outstretched, and not moving, just over the ground, before it alights, or make a steep-down descent holding them set in this manner, and so settle. There is also a trick or mannerism of flight which is graceful, and may be of a nuptial character. Rising to a certain height on quivering wings, they sink down, holding them extended and motionless. After but a short descent, they rise again in the same quivering way, and so continue for a greater or lesser space of time.

The note which they utter is, first, a melancholy "too-ee, too-ee, too-ee," then a much louder and sharper "wi-wi, wi-wi, wi-wi" ( $i$ as in "with"), and there are various other ones, one of which-if memory did not trick me-is just, or very, like a note which is but seldom heard of the great plover, "Tu-whi, whi, whi, whi, whi." This bird is itself a curlew, so that 
the resemblance can be understood. Its affinities with the oyster-catcher are (unless it is the other way about) less close; yet some part of the piping of the latter bird reminded me strongly of the "clamour," as it is called, of the former one. Sometimes, but more rarely, the mournful "too-ee, too-ee, too-ee" of the curlew is followed by a note as mournful, but louder and more abrupt. This sounded to my ear something like " chur-wer- whi-wee," but, of course, all such renderings are arbitrary, and more or less fanciful.

One of the strangest sounds that came to me on that lonely island was the courting-note of the male eider-duck. This varies a good deal, not in the sound, which is always the same, but in the duration and division of it. Sometimes it is one long-drawn, soft "oh" or "oo," more generally, perhaps, this is syllabled into "oh-hoo" or "ah-oo," and often there is a much longer as well as very distinct and powerful "hoo-oooooo." The sound seems always to be on the point of catching, yet just to miss, the human intonation, sometimes suggesting a soft (though often loud) mocking laugh, at others a slightly ironical or surprised ejaculation. But this human element only just trembles upon it and is gone. Rousing for a moment the sense of man's proximity with its attendant associations, these vanish almost in the forming, and are replaced by a feeling of unutterable loneliness and wildness. For what recalls, yet is far other, enforces the sense of the absence of that which it recalls. Yet this feeling changed too, or, rather, with it there came another as of the unseen world, also, I think, comprehensible, since what is 
almost, yet not quite, human must needs suggest fays, elves, elementals, and all their company. I loved the sound. If not quite music, it was most softly harmonious, and always, from first to last, brought into my mind with strange insistency, those lines in the Tempest:

$$
\text { "Sitting on a bank, }
$$

Weeping again the King my father's wreck, This music crept by me upon the waters, Allaying both their fury and my passion With its sweet air."

Then, of course, I was on Prospero's island, though, heaven knows, this bleak northern one was little like it. Thus can some poor bird that we murder, by an association merely, or called-up image, as well as by actual song,

\footnotetext{
"Dissolve us into ecstasies, And bring all heaven before our eyes."
}

It was some little time before I could be quite sure to what bird this strange note belonged. It seemed too poetical for a duck, though, indeed, an eider-duck is the poetry of the family. Also, it was difficult to locate, seeming to bear but little relation to the place or distance at which it was uttered. But I soon found that whenever there were eider-ducks I heard the note, whereas I never did when they were nowhere about. At last-quite close in a little bay, as though they had come there to show me-II "tore out the heart of their mystery." It was a lovely sight. Even the female eider-duck, sober brown though she be, has a most 
pleasing appearance, but the male bird is beauteous indeed. In the pure white and deep, rich black of his plumage he looks, at first, as though clothed all in velvet and snow. There are, however, the green feathers on the back of the head and neck, which do not look like feathers at all, but rather a delicate wash of colour, or as though some thin, glazed materialsome finest-made green silk handkerchief-had been tied round his head with a view to health by the female members of his family. And although at first, with the exception of this green tint, all that is not the richest velvet black looks purest white, the eye through the glasses, growing more and more delighted, notices soon a still more delicate wash of green about the upper parts of the neck, and of delicate, very delicate, buff on the full rounded breast just where it meets the water. These glorified males-there were a dozen of them, perhaps, to some six or seven females-swam closely about the latter, but more in attendance upon than as actually pursuing them; for the females seemed themselves almost as active agents in the sport of being wooed as were their lovers in wooing them. The actions were as follows:- The male bird first dipped down his head till his beak just touched the water, then raised it again in a constrained and tense manner-the curious rigid action so frequent in the nuptial antics of birds-at the same time uttering that strange, haunting note. The air became filled with it, every moment one or other of the birds-sometimes several together-with upturned bill would softly laugh or exclaim, and whilst the males did this, the females, turning excitedly, and with little eager demonstrations from one to another of them, kept lowering and ex- 
tending forwards the head and neck in the direction of each in turn.

As there were a good many females in this "reunion," the numbers of the males about any one of them at one time was not great. Some of them were attended by only one cavalier or left quite lonely for a time-but all kept shifting and changing. The birds kept always swimming on, and were now all together, now scattered over a considerable surface of water. Sometimes two males would court one hen, who would then often demonstrate between them in the way I have described. Often, however, the male birds are in excess of the females, and sometimes there will be only one female to a number of males, who then press so closely about her that they may almost be said to mob her, though in a very polite manner. There are then frequent combats between the males, one making every now and again a sudden dash through the water at another, and seizing or endeavouring to seize him by the head or scruff of the neck. The two then struggle together till they both sink or dive under the water. Shortly afterwards they emerge separately, and the combat is over for the time. During, if not as a part of, these nuptial proceedings, the birds of both sexes will occasionally rise in the water and give their wings a brisk flapping. They may also occasionally dive as a mere relaxation, or to give vent to their feelings, at least so it appeared to me.

The female eider-duck-as far as I could observe -does not utter the curious note, but only a deep quacking one, with which she calls to her the male birds. It appeared to me that she would sometimes 
show a preference for one male over another, and also (though of this I cannot be so sure), a power of dismissing birds from her. But if she really possesses such a power, she cannot very well assert it when closely pressed upon by a crowd of admirers. I noticed, too, and thought it curious, that a female would often approach a male bird with her head and neck laid flat along the water as though in a very "coming-on disposition," and that the male bird declined her advances. This, taken in conjunction with the actions of the females when courted by the males, appears to me to raise a doubt as to the universal application of the law that throughout nature the male, in courtship, is eager and the female coy. Here, to all appearance, courtship was proceeding, and the birds had not yet mated. The female eider-ducks, however-at any rate some of them-appeared to be anything but coy. As time went on and the birds became paired this curious note of the males became less and less frequent, and at last ceased, a proof, I think, that the note itself is of a nuptial character, and also that the birds at the time they kept uttering it were seeking their mates.

I regret that I was not able to observe the further breeding or nesting habits of these interesting birds. A few of the females may have laid before I left the island, but the greater number were still on the water. One day I put one up from the heather, upon which I lay down and waited. Soon a pair of them-both females - flew round me and alighted together not far off. Both then lay or crouched in the heather at a few yards from each other. Later, whilst watching from the coast, I saw two female eiders walking side by side 
at a slight distance apart. At intervals they would pause, stand or sit for a little, and again jog on together. These birds must, I think, have been selecting a place in which to lay their eggs, and if so, it would seem that they like to do this in pairs. I also saw a male eider-duck sitting for a considerable time amidst the heather right away from the sea. It is, of course, impossible to mistake the sexes after the males have assumed their adult plumage, and, moreover, this bird subsequently flew down into the little bay just beneath me. I say this because it is authoritatively stated that the male eider-duck never goes near the nest. It is probable that a week or so later this bird could not have sat where he was without being near to a nest at any rate; and, moreover, what should take the male bird from the sea, or its immediate coast, at all, if it were not some impulse appropriate to the season? This and a statement made to me by a native in regard to this point, which went still further against authority, makes me wish that I had been able to see a little more. As it is, I have only a right to ask with regard to this one male eider-duck, "Que diable allait il faire dans cette galere?"

It is difficult to tire of watching these birds, ducks, yet so wonderfully marine. The freedom of the sea is upon them, far more than Aphrodite they might have sprung from its foam-it is of the male with his snowy breast that one thinks this. One cannot see them and think of a pond or a river-yet, always, they are so palpably ducks. It is delicious to see them heave with the swell of the wave against some low sloping rock-lapping it like the water itself-and then remain upon it, standing or sitting-living jetsam that the sea 
has cast up. They ride like corks on the water, they are the arch of each wave and the dimple of every ripple.

Eider-ducks feed by diving to the bottom of the sea off the rocks where it is shallow, and getting there what is palatable. Probably this is, in most cases, eaten under water, but whilst, as a rule, emerging empty-mouthed, they occasionally bring up something in their bill, and dispose of it floating on the surface. In one case this was, I think, a crab; in another, some kind of shell-fish. Their dive is a sudden dip down, and in the act of it they open the wings, which they use under water, as can be plainly seen for a little way below the surface. This opening of the wings in the moment of diving is, I believe, a sure sign that they are used as fins or flippers under water, and that the feet play little or no part.

Birds, amongst others, that dive in this way are-to begin with-the black guillemot.

"Looking down from the cliffs into the quiet pools and inlets, one can see these little birds-the dabchicks of the ocean - swimming under water and using their wings as paddles, perfectly well. Instantly on diving they become of a glaucous green colour, and are then no longer like things of this world, but fanciful merely, suggesting sprites, goblins, little subaqueous bottle imps, for their shape is like a fat-bodied bottle or flat flask. Great green bubbles they look like, and so too but - larger and still greener - do the eider-ducks." In their small size and rounded shape, in their deariness, their pretty little ways and actions, in everything, almost, these little black guillemots are the marine counterpart of 
the dabchick or little grebe. It is pretty to see them, a dozen or so together. They pursue each other under the water-in anger, I think, but it has the appearance of sport; it is a joyous anger. They seem all in a state of collective excitement, and out of this one will make a sudden dart at another, who dives, and the pursuit is then alternately under or on the water, and sometimes just skimming along it on the wing, exactly as dabchicks do. Yet the black guillemot is a fair flier, having to ascend the precipices, and the dabchick too, for the matter of that, can if he chooses rise into the air and fly seriously. There are three modes of delivering the attack in fighting. In the first two the one bird either just darts on the other when quite near, in which case there may be a slight scuffle before either or both disappear, or flies at him over the water from a greater or lesser distance and often very nearly gets hold of him, but never quite. Invariably the other is down in time, if it be only the justest of justs. The third plan, which is the most rusé, is for the attacking bird to dive whilst yet some way off, and, coming up beneath his "objective," to spear up at him with his bill. And so nicely does he judge his distance that he always does come up exactly where the swimming bird was, - not is, for this one is as invariably gone. Yet this plan must sometimes be successful, though I did not see a case in which it was. At least, I judge so by the precipitation with which the bird on the water when he saw the other one dive-as he always did, and divined his intention-flew up and off to some distance. In just the same way have I seen the great crested grebe rise up and fly far over 
the glassy waters of the sun-bathed lake-but still more precipitately, and, indeed, in disorder, for he rose not alone from the surface but also from the

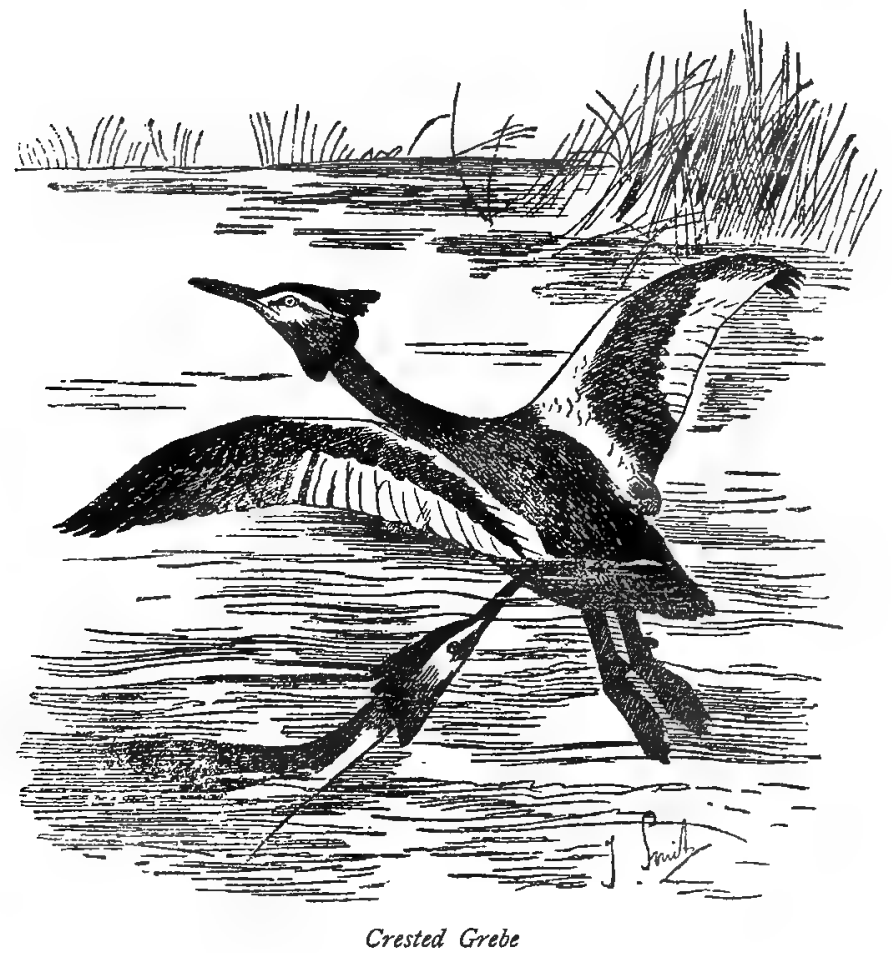

well-aimed spear-point of his successfully-lunging antagonist. Whether the little dabchicks also, as well as the crested grebes, attack each other in this manner, I cannot from observations say, but from the relationship it would seem probable.

Razorbills also dive briskly, opening the wings 
and with a kick up, as it were, of the legs and tail. If one sits on a height and they come sufficiently near inshore to look down on them at an acute angle, one can follow their course under the water, often for a considerable time. One remarks then that the wings are moved both together-flapped or beaten-so that the bird really flies through the water. In flight, however, they are spread straight out without a bend in them, whereas here they are all the while flexed at the joint, being raised from and brought downwards again towards the sides in the same position in which they repose against them when closed. These birds-and, no doubt, the other divers-dive not only to catch fish, but also for the sake of speed. I have seen them when travelling steadily along the shore duck down and swim or fly like this, in a straight line and but just below the surface of the water, always pursuing the same direction, and seeming to have no difficulty in guiding themselves. The speed was very much greater than when they merely paddled on the surface. Thus we may see, perhaps, how such birds as the great auk and the penguins came to lose the power of flight. They could fly in two ways, either through the air or the water. The first-as long as they retained it at all, probablywas much the quicker; but the other was quick enough for their purposes, and the effort required to rise from the water was thus dispensed with. These razorbills dived in order to get more quickly to some point for which they were making. They might have got there still sooner by flying, but the time saved was evidently not worth that effort to them. But the power of flight might be long retained by a bird-though useless to it 
in other respects-owing to its habit of laying its eggs on otherwise inaccessible ledges of the rock.

When three or four razorbills are swimming together, it is common for one of them to dive first, and for the rest to follow in quick succession, sometimes so quick that the order in which they go down, and the succession itself, can only just be followed. They must keep together under the water as well as above it, since they will often emerge so, after some time, and at a considerable distance.

The guillemot dives more or less like the razorbill, but I have not been successful in tracing him under the water.

There remains the puffin. "I have been able to follow the puffin downwards in its dive, and at once noticed that the legs, instead of being used, were trailed behind, as in flight, so that the bird's motion was a genuine flight through water, unassisted by the webbed feet. With the razorbill, I was not able to make this out so clearly, for the legs are black, and the eye cannot detect them under the water, as it can the bright vermilion ones of the puffin (one wonders, by the way, if the latter play any part under water such as the white tail of the rabbit is supposed to do on land), though I could see that just in diving they were brought together and raised, so as to extend backwards in the same way. Penguins also trail the legs like this in diving, only giving an occasional paddle with them, whilst the wings are in constant motion."

It would seem, therefore, that those diving birds which swim with their wings under the water only use their feet in a minor degree, and that they go down with a quick, sudden duck, or bob, and in the 
act of opening their wings. On the other hand, cormorants, shags, and mergansers, birds which do not use their wings in this way, dive in a quite different manner. Instead of the sudden, little, splashy duck, as described, they make a smooth, gliding leap forwards and upwards, rising a little from the water, with the neck stretched out, and wings pressed close to the sides, to enter it again, beak foremost, like a curved arrow, thus describing the segment of a circle. Their shape, as they perform this movement, is that of a bent bow, and there is the same suggestion in it of pent strength and elasticity.

The shag is the greatest exponent of this school of diving, excelling even the cormorant-at least I fancy so-by virtue of his smaller size. He leaps entirely clear of the water, including even, for a moment, his legs and feet. This seems really a surprising feat, for, as I say, the wings are tightly closed, so that, by the force merely of the powerful webbed feet, he is able to throw himself bodily out of the sea. It must be by a single stroke, I think, for the motion is sudden and then continuous. The bird may, of course, have been in ordinary activity just previously, so that some slight degree of impetus may be supposed to have been already gained, but this is unnecessary, and the leap is often from quiescence. The merganser dives like the shag or cormorant-though the curved leap is a little less vigorous-and swims, like them, without using the wings. His food being fish, instead of getting deeper and deeper down till he disappears, like the eider-duck, he usually swims horizontally, sometimes only just beneath the surface, 
and, as he comes right into the shallow inlets, where the water almost laps the shore, he can often be watched thus gliding in rapid pursuit. Though I saw all his turns and efforts, I never could see either the fish or the capture of it-supposing that this took place. If it did, the fish must each time have been swallowed, or at least pouched, beneath the surface, as the bird never emerged with one in his bill. There are, of course, several different species of merganser and goosander. I cannot be quite sure of the identity of the bird which has given rise to these observations-I think it was the red-throated merganserbut, no doubt, the ways and habits of all the species are either identical or nearly so.

It is interesting to find the little dabchick of our ponds and streams diving sometimes in the manner of the shag and cormorant, though, of course, tempered with his own little soft individuality. I have this note of him, taken in the frost and snow of a cold December day whilst he sported in his little creek just a few feet in front of me. "He gives a little leap up in the water, making a graceful curve, a pretty little curl, as he plunges. One sees the curve of his back-which is something-as he spring-glides down. The action is that of the cormorant, but, rendered by himself, made dabchicky. Of course he is in the water all the time; he does not shoot right out of it. There is far less power and energy. It is a star-twinkle to a lightning-flash, a floss ringlet to a bended bow." And again : "He is diving now very prettily, with a graceful little curled arch in the air before going down."

I say that the dabchick sometimes dives like this, 
for he has many ways of doing so, and it is not very often that he will repeat the same thing twice in succession. Sometimes he dips so smoothly and still-ly down that one seems hardly to miss him from where he was; there is just a swirl on the streamwhich seems, now, to represent him-and that all but silent sound, so cool and pleasant, as of water sucked down into water. Or, swimming smoothly down the current, he stops suddenly, brings the neck stiffly and straightly forward, with eye fixed intently, severely on the water-piercing down into it as though making a point-and then down he goes with a click, almost a snap, flirting the water-drops up into the air with his tiny little mite of a tail. I have seen it stated, I think, that the dabchick has no tail, or that he has no tail to speak of. I shall speak of it, for I have seen it enter largely into his deportment. When, as I say, he dives like this, suddenly, it may be flirted up with such vigour that, mite as it is, it will send a little shower of sparkling drops to 20 feet away or more. It may be said that it is not so much the tail as the whole body that does this. I say that the tail has its share, and a good share, too-more, perhaps, than is quite fair. At any rate, I have seen the prettiest little drop of all whisked right off the tip of it, and the sun shining more upon that one than any of the others-and that, I think, is having a tail to speak of. But when swimming along quite quietly, the dabchick's tail, instead of being cocked or flirted up like the moor-hen's, is drawn smoothly down on the water so as not to project and thus interfere with its owner's appearance, which is that of a little, smooth, brown, oiled powder-puff, "smooth as oil, soft as young 
down." The dabchick, therefore, has a tail, and knows how to regulate it.

Between these two extremes of the dabchick's manner of diving, and independently of the little curled leap $\dot{a} l a$ cormorant, there are infinite gradations, as well as all sorts of mannerisms and individualities. But in all these I do not distinctly remember to have seen him throw out his wings in the act of going down.

I should be pretty sure, therefore, that he swims only and does not fly (if this expression is permissible) under water, if I did not seem to remember having once seen him do so, as I lay with my head just over the river's bank and he passed underneath me. But it was years ago; I have no note, and my memory may very likely have deceived me. Possibly both in regard to this, as well as the way in which he dives, the dabchick may be in a transition state. His multifariousness in this latter respect seems to render this likely. The shag, if I mistake not, never dives in any other way than that which I have described, unless he is really alarmed, when he disappears instantaneously and in a dishevelled manner.

The moor-hen, also, may follow no fixed plan in his diving, for I have certainly seen him using his feet only under water, and I believe I have also seen him using his wings. Though this, too, was many years ago I ought not to be mistaken, as the incident made such a deep impression on me at the time. I was standing on the bank of a little creek, or streamlet, running out of a reedy moor-hen-haunted river. The creek itself, however, was clear where I 
stood, and all at once a strange object passed right in front of me, swimming beneath the surface. It was a moor-hen, but the wings used in the way I have been discussing - a thing to me quite unexpected - seemed to give it an entirely unbirdlike appearance, and surprised me into thinking for the moment that it was some kind of turtle. The legs, I believe, were also used, alternately in a kind of long, gliding stride, and may just have touched the mud at the bottom. This, however-and I believe the moor-hen often walks in this way along the bottom rather than swims-would seem to make its use of the wings at the same time all the more unlikely. I have but my memory, which, as evidence after so many years, is of little value. In all such matters what is wanted is a note taken down at the time. As to the actual dive down of the moor-hen, whenever I have seen it it has always been a sudden duck, sometimes in a rather splashy and disordered manner, but whether the wings were ever thrown partly open I am not able to say. I have noted cases, however, where they certainly were not, and this again makes it more likely that the moor-hen in diving does not use the wings at all. I do not know that I have ever seen the moor-hen dive, unless it was in alarm from having seen me; and with regard to this a question arises which, I think, is of interest-to what extent, namely, does diving enter into the moor-hen's ordinary habits, how often does it do so of its own free will? Possibly it may differ as to this in different localities. Jefferies, for instance, writes as though it were always diving. Yet I have watched moor-hens latterly, at all seasons, and for several hours 
at a time, without having once seen them do so; so that from seeing them thus au naturel, and without any suspicion of my proximity, I might have come to the conclusion that they were not diving birds at all. As it is, I am inclined to think that they rarely dive except to avoid danger, and only then when surprised and as a last resource. For instance, if a moor-hen sees one from the smallest distance it flies to the nearest belt of reeds, but if one appears quite suddenly on the bank just above it-as sometimes happens-it will then often dive. Even here, however, according to my own experience, it is more likely to trust to its wings; so that, as it seems to me, the habit under any circumstances is only an occasional one, and may, therefore, be in process either of formation or cessation. If we look at the moor-hen's foot, which shows no special adaptation to swimming, but a very marked one for walking over a network of water-herbage, the former of these two suppositions seems the more probable. The bird from a shore and weed-walker has become aquatic, and is probably becoming more so. If the habit of diving is only becoming established, it is possible that some localities might be more conducive to its quick increase than others, and it would be interesting, I think, if observers in different parts of the country would make and record observations on this point.

The chariness of the moor-hen in diving is the more interesting because the coot, which belongs to the same family, has the same general habits, and has evidently become aquatic by the same gradual process, dives frequently, and is accustomed to feed upon weeds 
which it pulls up from the bottom of the water. Here is an instance, in which it will also be seen that the coot's manner of diving is very much more formed than the moor-hen's, which may be said to be archaic. "It dives down and reappears, shortly, with some dank weediness in its bill, which it proceeds to peck about and swallow on the surface. Then it dives again, comes up with some more, which it likewise eats, and does this several times in succession. After five or six dives it comes up with quite a large quantity, with which it swims a little way to some footing of flag and reed, and on this frail brown raft it stands whilst picking to pieces and eating 'the fat weed' which it has there deposited. Having finished, or selected from it, it swims to the same place again and continues thus to dive and feed, each time coming up with some weeds in its beak, which I see it eat quite plainly. It is charming to see this, and also the way in which the bird dives, which is elaborate, studied, and yet full of ease. Rising, first, from the water in a light, buoyant manner as if about to ascend, balloon-like, into the air, it changes its mind in the instant and plunges beneath the surface, having, as it goes down, a very globular and air-bally appearance. It is like the sometime dive of the dabchick, but with more deportment and less specific gravity. The dabchick is an oiled powder-puff, the coot a balloon, the dabchick a small fluff-ball, the coot an air-ball."

From this it would seem as though the coot belonged to the cormorant school of diving, disagreeing in this with the moor-hen, to whom it is so closely allied, whilst agreeing with the dabchick, as well as 
the great crested grebe and other birds-the cormorant itself-with whom it has no close affinities. But this cannot be said without considerable qualification, for, though the description I have given is from the life and seen over and over again, yet at other times the dive down of this bird is so totally different that no one who had seen only the one could think it capable of the other. In the winter, coots swim about in flocks, and then one may see first one little spray of water thrown up as a bird disappears, and then another. That is all; there is the spray and there is no bird, whereas just before there was one. Indeed, I think it is a quicker dive than any that I have seen a sea-bird make, only equalled, perhaps (or even, perhaps, not quite equalled), by that of a really alarmed dabchick. As for the process of it, it is undiscoverable, the eye catches only the spray-jet, which is pretty and always just the same. But there is no disorder, no higgledypiggledyness. It is something which you can't see, but which you feel is the act of a master. Here again, then, the coot in diving is quite the moor-hen's superior. The dive of the latter bird is, as we have said, archaic. It is unpolished, and greatly wants form and style. Now, the coot is fin-footed-that is to say, the skin of the toes is extended so as to form on the interspace of each joint a thin lobeshaped membrane. In this formation, which likewise distinguishes the grebes, we may, perhaps, see the gradual steps by which the feet of some more purely aquatic birds have become webbed. As the lobes became larger they would have met and overlapped, and from this to an actual fusion does not 
seem an impassable gulf. This, however, is only a supposition. It seems more likely that the web has been, in most cases, gained by the extension of the slight membrane between the toes, at their junction with one another. Possibly the lobes on the toes of the coot were gained before he became a swimmer, and served the purpose of supporting him on mud or floating vegetation, or, as perhaps is more probable, they may have been developed in accordance with the double requirement. At any rate, if we suppose this structural modification to have been effected after the bird became in some degree truly acquatic, then, though this does not prove that the period at which it became so was longer ago than in the case of the moor-hen, which has remained structurally unaffected, yet it, perhaps, renders it likely, and we can, by supposing so, understand why the one bird should dive habitually and the other only occasionally.

The great crested grebe exhibits the same feature of variety in his manner of diving as does his sprightly little relative the dabchick. Sometimes it is quite informal-he just spears the water before disappearing, sinking in it a little before he spears-but at others there is the cormorant leap upwards as well as forwards, before going down. Of course, no more than with the dabchick is there the same tremendous vigour, the wonderful supple virility which lives in the leap of this strong-souled sea robber. I say "of course," for anyone who has watched these birds - the most ornamental, perhaps, of any except swans that swim the water-must have remarked a quiet, easy, one may almost say languid, grace-something suggestive of high birth, of "Lady Clara Vere de 
Vere"-ness-in their every, or almost every, action. Masters of grace indeed they are, and consummate masters of diving. I do them wrong descanting upon them here so scantily, but space, my constant and persistent enemy, will have it so. I have not even sufficient to make them any further apology.

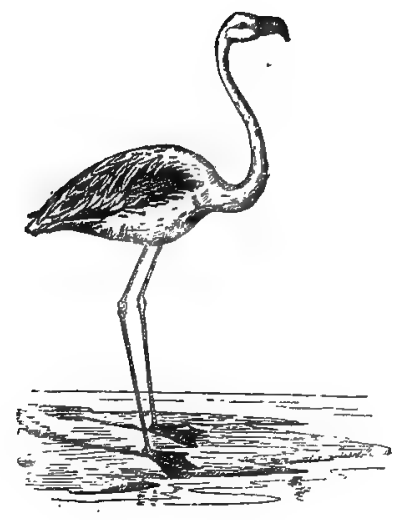




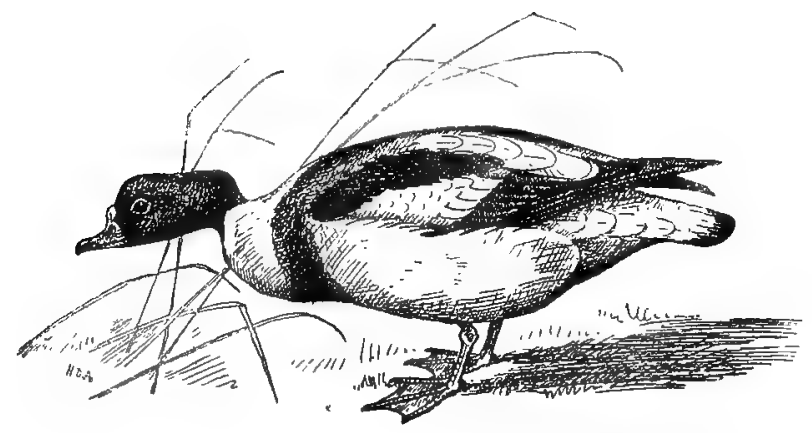

CHAPTER VII

\section{Watching Shags and Guillemots}

I HAVE referred once or twice before to the cormorant (including under this title the shag), and once to the guillemot. In this chapter I shall treat of both these birds a little more at large, for in the first place they are salient amongst sea fowl, giving a distinctive character to the wild places that they haunt, and secondly, I have watched them closely and patiently. Both are interesting, and the cormorant especially has a winning and amiable character, which I shall the more enjoy bringing before the public because I think that up to the present scant justice has been done to it. Something, perhaps, of the wild and fierce attaches to the popular idea of this bird, due, no doubt, both to its appearance, which has in it something dark and evil-looking, and to the stern, wild scenery of rock and sea with which this is in consonance, and by which it is emphasised. Perhaps the mere name even, which has by no means a harmless sound, has something to do with it. 
"As with its wings aslant

Sails the fierce cormorant

Seeking some rocky haunt,"

says Longfellow - lines which, to me at least, call up a graphic picture of the bird, though I do not know that the first contains anything which is specially characteristic of it; and Milton has recorded-as we may, perhaps, assume-the way in which its uncouth shape appealed to him by making it that which his grand angel-devil chooses, on one occasion, to assume. On another one, it may be remembered, Satan takes for his purposes the form of a toad, and on each, no doubt, the poet, who never appears to yield to the strong temptation (as one would imagine) of loving his great creation, has intended to convey a general idea of fitness and symbolical similarity as between the disguised being and the disguise taken.

It has been conjectured that the habit which the cormorant has of standing for a length of time with its wings spread out and loosely drooping, suggested to Milton its appropriateness, and certainly there is an o'er-brooding, possession-taking appearance in this attitude of the bird, in keeping with the ideas which may be supposed to reign in Satan's breast as he looks down from the high tree of life upon the garden of Eden and its two newly created inhabitants. Independently of this, however, the bird, as it stands in its ordinary posture, firmly poised, the body not quite upright but inclined somewhat forward, with the curved neck and strong hooked beak thrown into bold relief-the dark webbed feet grasping firmly on the rock-has in it something suggestive both of 
power and evil, which may well have struck Milton, as it must, I think, anyone who is appreciative and either not an ornithologist or who, if he is one, will suppress for the time being his special scientific knowledge and se laisser prendre aux choses, as did the less (falsely) critical portion of Moliere's audiences.

For, whatever the cormorant may look, he is in reality - except from the fish's point of view, which is, no doubt, a strong one - both a very innocent and, as I have said, a very amiable bird. He shines particularly in scenes of quiet domestic happinessin the home circle both giving and receiving affection -and it is in this light that the following pictures will for the most part reveal him. I must premise that they all refer to that smaller and handsomer species of our two cormorants adorned with a crest, and whose plumage is all of a deep glossy, glancing green, called the shag. If I speak of him sometimes by his family name, it is because he has a clear right to it, and also because it has a more pleasing sound than the one which distinguishes him specifically. The habits of the two birds are almost the same, if not quite identical. They fish together in the sea, stand together on the rocks, and in the earlier stages of its plumage the more ornate one closely resembles the other in its permanent dress. One might think that they were not merely the co-descendants of a common and now extinct ancestor, but the modified form and its actual living progenitor. But I am aware of the arguments which could be used against such a conclusion.

I will now give my observations as taken down 
at the time, and should they be thought minute to the point of tediousness, I can only in extenuation plead the title of this book, whilst assuring the reader, that however it may lie between us two, the bird, at any rate, is in no way to blame.

Courtship, love-making. - "The way in which the male cormorant makes love to the female is as follows:-Either at once from where he stands, or after first waddling a step or two, he makes an impressive jump or hop towards her, and stretching his long neck straight up, or even a little backwards, he at the same time throws back his head so that it is in one line with it, and opens his beak rather widely. In a second or so he closes it, and then he opens and shuts it again several times in succession, rather more quickly. Then he sinks forward with his breast on the rock, so that he lies all along it, and fanning out his small, stiff tail, bends it over his back whilst at the same time stretching his head and neck backwards towards it, till with his beak he sometimes seizes and, apparently, plays with the feathers. In this attitude he may remain for some seconds more or less, having all the while a languishing or ecstatic expression, after which he brings his head forward again, and then repeats the performance some three or four or, perhaps, half-a-dozen times. This would seem to be the full courting display, the complete figure so to speak, but it is not always fully gone through. It may be acted part at a time. The first part, commencing with the hop-the simple aveu as it may be called-is not always followed by the ecstasy in the recumbent posture, and the last is still more often indulged in without this preliminary, 


\section{WATCHING SHAGS AND GUILLEMOTS 167}

whilst the bird is sitting thus upon the rock. Again, a bird whilst standing, but not quite erect, will dart his head forward and upward, and make with his bill as though snapping at insects in the air. Then, after a second or two, he will throw his head back till it touches or almost touches the centre of his back, and whilst at the same time opening and shutting the beak, communicate a quick vibratory motion to the throat. It looks as though he were executing a trill or doing the tremulo so loved of Italian singers, of which, however, there is no vocal evidence.

"When the male bird makes the great pompous hop up to the female, and then, after the preliminaries that I have described, falls prone in front of her, he is, so to speak, at her feet; but by throwing his head backwards he gets practically farther off, nor can he well see her whilst staring up into the sky behind him, which is what he appears to be doing. Thus the first warmth of the situation is a little chilled, and on the stage we should call it an uncomfortable distance. The female shag seems to think so too, for all that she does-that is to say, all that I have then seen her do-is to stand and look about, conduct which, as it is uninteresting, we may perhaps assume to be correct. But when the antics begin, as one may say, from the second figure, the male not rising from his recumbent position (a quite usual one) on the rock to make the first display, the bird towards whom his attentions are directed will often be standing behind him, and it then appears as if he had brought back his head in order to gaze up at her con expressione. In this case she, on her part, will 
sometimes cosset the feathers of his throat or neck with the tip of her hooked bill, a courtesy which you see him acknowledge by sundry little pleased movings of his head to one side and to another. It must, however, be understood that when I say it is the male bird who thus pays his court to the female, I am only inferring that this is the case. There was nothing beyond likelihood and analogy to guide me in what I saw, and from some subsequent observations I have reason to think that these antics are common to both sexes. As a rule, however, one may safely assume that the bird which in such matters both takes the initiative and does so in a very decided manner, is the male."

I will add that the waddling step with which the male bird (as I believe) approaches the female may become quickened and exaggerated into a sort of shuffling dance. But I only use the word "dance," because I can think of no slighter, yet sufficient, one. It is not, I should imagine, intentional, but only the result of nervous excitement.

These seem to be odd antics, but it is in the nature of antics to be odd, and when such a bird as a cormorant indulges in them one may expect something more than ordinarily peculiar. The hop, however, which is very pronounced, is not confined to such occasions, but is made to alternate with the customary waddle when the bird is moving about on the rocks, and especially when getting up on to any low ledge or projection. I do not know of any other British bird which adopts this recumbent position in courtship, but this is just what the male ostrich does, as I have over and over again seen. He first pursues 




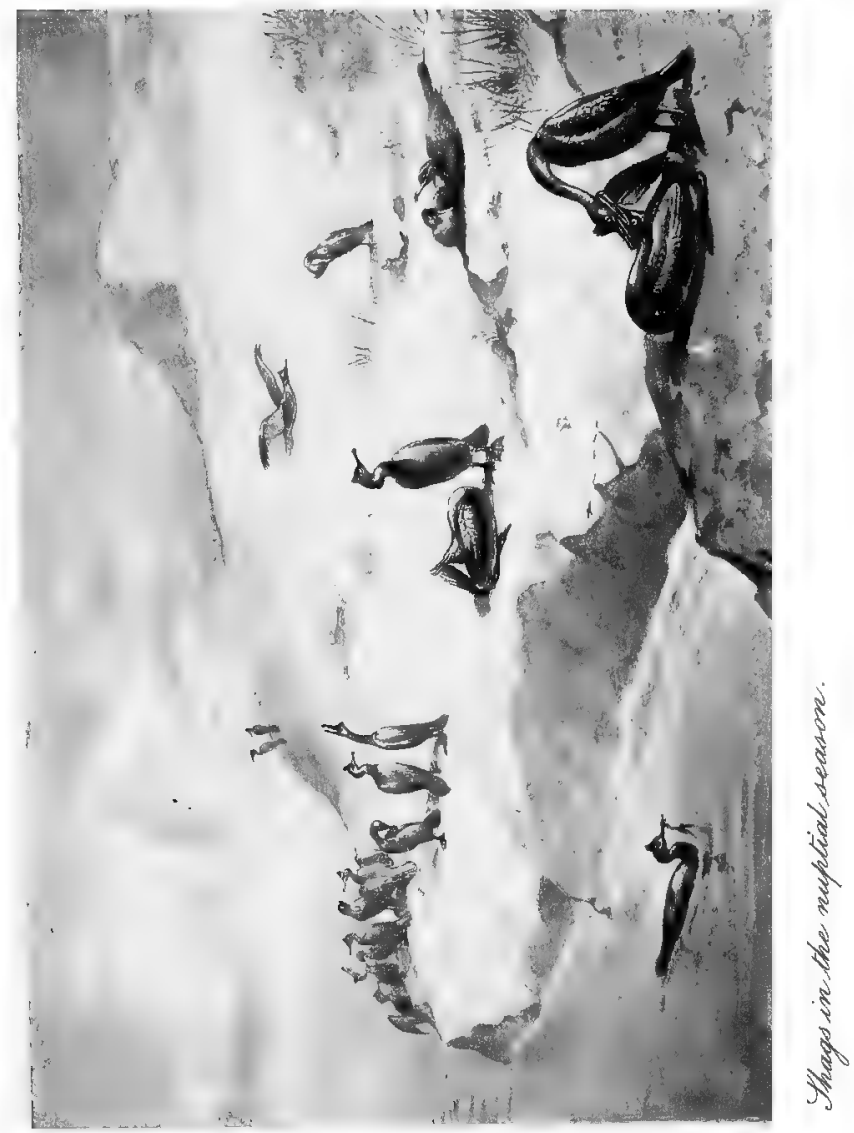



the hen, who flies before him, and then, having followed her for a short distance, flings himself down, throws back his head upon his back and rolls from side to side, each time slowly passing the splendid white feathers of first one and then another wing over the velvet black plumage of his body, by which, of course, they are shown to the very best advantage. The hen commonly stops whilst he is doing this, and may be supposed to pay some attention, but as to the amount, as I write from memory after many years, I will not here express an opinion. After a while the male bird rises, again pursues the hen, again flings himself down, and this is continued for a greater or lesser number of times, till either he gives up the chase, or the two have come to a thorough understanding. When thus rolling with wings spread out and head thrown back upon himself the bird is in a kind of ecstasy, and it is easy to go right up to himas I have myself done-and seize him by the neck before he becomes aware of one's presence.

These antics therefore-though in a bird so different as the ostrich* - bear a considerable resemblance to those of the shag, though the latter does not at any time make use of his wings. This, again, is interesting, for there is nothing specially handsome in the wings of a cormorant. The crest, however, is conspicuous as the head is flung up, and by the opening of the bill, which is a very marked feature,

* Having been led to speak of the ostrich, I will take this opportunity of challenging the statement to be met with in several works of standing, that the male bird alone performs the duties of incubation. I have lived on an ostrich-farm and (unless I am dreaming) ridden round it every afternoon in order to feed the hens, who had till then been sitting on the eggs, and were often still to be seen so doing. 
the brilliant yellow gule which matches in colour the naked outer skin at the base of the mandibles becomes plainly visible. This habit of opening the bill as it were at each other I have remarked in several seabirds, and also that in all or most of these cases the interior part thus disclosed is brightly or, at least, pleasingly coloured.

Bathing. - But whether the following be bathing or a kind of aquatic exercise either of or not of the nature of sexual display, I will leave to the reader to decide. Birds which live habitually in the water do yet bathe, I believe, in the proper sense of the word.

"The cormorant, when bathing, raises himself a little out of the water whilst still maintaining a horizontal position, and in this attitude, supported as it would seem on the feet, he commences violently to beat the sea with his wings, moving also the tail and, I think, treading down with the feet upon the water. The sea is soon beaten all into foam, and when he has accomplished this, desisting, he begins to sport about in the whiteness of it in an odd excited manner, making little turns and darts and often being just submerged, but no more. He does this for a few minutes, stops, and commences again after a short interval, and thus continues alternately sporting and resting for a quarter of an hour or, perhaps, even as long as half-an-hour. I think this must be bathing or washing, for other birds act in the same way, though less markedly, so that it does not occur to one to wonder what they are about. The little black guillemot, for instance, beats the water briskly and rapidly with his wings, but whereas the cormorant 
beats it into foam so that it looks like the wake of a steamer, he raises only a little silvery sprinkling of spray, for he but just flips the surface of it with the tips of his quill feathers. All the while his little, upturned, fanned tail keeps waggle-waggling, but this, too, acts more like a light shuttlecock than a powerfful screw. Nor does he dip so much or make such violent motions as of a mad water-dance. The cormorant's performance is strong-an epic. His is lyrical rather. No lofty genius but a pretty little minor poet is the black guillemot, and after each little water-verselet he rises pleasedly and gives his wings an applausive little shake. You might think he was clapping them-and himself."

Gargoyle idylls. - "Now I have found a nest with the bird on it, to see and watch. It was on a ledge, and just within the mouth of one of those long, narrowing, throat-like caverns into and out of which the sea with all sorts of strange, sullen noises licks like a tongue. The bird, who had seen me, continued for a long time afterwards to crane about its long neck from side to side or up and down over the nest, in doing which it had a very demoniac appearance, suggesting some evil being in its dark abode, or even the principle of evil itself. As it was impossible for me to watch it without my head being visible over the edge of the rock I was on, I collected a number of loose flat stones that lay on the turf above, and, at the cost of a good deal of time and labour, made a kind of wall or sconce with loopholes in it, through which I could look, yet be invisible. Presently the bird's mate came flying into the cavern, and wheeling up as it entered, alighted on a sloping 
slab of the rock just opposite to the nest. For a little both birds uttered low, deep, croaking notes in weird unison with the surroundings and the sad sea-dirges, after which they were silent for a considerable time, the one standing and the other sitting on the nest vis-a-vis to each other. At length the former, which I have no doubt was the male, hopped across the slight space dividing them on to the nest, which was a huge mass of seaweed. There were now some more deep sounds and then, bending over the female bird, the male caressed her by passing the hooked tip of his bill through the feathers of her head and neck, which she held low down the better to permit of this. Afterwards the two sat side by side together on the nest.

"The whole scene was a striking picture of affection between these dark, wild birds in their lonely, wavemade home.

"Here was love unmistakable, between so strange a pair and in so wild a spot. But to them it was the sweetest of bowers. How snug, how cosy they were on that great wet heap of 'the brown seaweed,' just in the dark jaws of that gloom-filled cavern, with the frowning precipice above and the sullen-heaving sea beneath. Here in this gloom, this wildness, this stupendousness of sea and shore, beneath grey skies and in chilling air, here was peace, here was comfort, conjugal love, domestic bliss, the same flame burning in such strange gargoyle-shaped forms amidst all the shagginess of nature. The scene was full of charm, full of poetry, more so, as it struck me, than most love-scenes in most plays and novels-having regard, of course, to the prodigious majority of the bad ones. 
"The male bird now flies out to sea again, and after a time returns carrying a long piece of brown seaweed in his bill. This he delivers to the female, who takes it from him and deposits it on the heap, as she sits. Meanwhile, the male flies off again, and again returns with more seaweed, which he delivers as before, and this he does eight times in the space of one hour and forty minutes, diving each time for the seaweed with the true cormorant leap. Sometimes the sitting bird, when she takes the seaweed from her mate, merely lets it drop on the heap, but at others she places and manipulates it with some care. All takes place in silence for the most part, but on some of the visits the heads are thrown up and there are sounds-hoarse and deeply guttural-as of gratulation between the two.

"Once the male bird, standing on the rock, pulls at some green seaweed growing there, and after a time gets it off.

('It was rather tough work to pull out the cork, But he drew it at last with his teeth.')

"The female is much interested, stretches forward with her neck over the nest and takes the seaweed as soon as it is loose, before the other can pass it to her. Then she arranges it on the nest, the male looking on the while as though she were the bride cutting the cake. Now he hops on to the nest again, and both together (for I think the male joins) arrange or pull the seaweed about with their beaks. One would think that the nest was still a-building and that the eggs were not yet laid. This last, however, is not the case. Several times, whilst waiting alone, 
the female bird rises a little on the nest, and each time there is a gleam like snow and the gloom seems deeper against the cut outline of a pure white egg. How full of poetry and interest it is lying there; how unmeaning and, one may almost say, absurd in a cabinet!"

The nest of the shag is continually added to by the male, not only whilst the eggs are in process of incubation, but after they are hatched, and when the young are being brought up. In a sense, therefore, it may be said to be never finished, though to all practical purposes it is, before the female bird begins to sit. That up to this period the female as well as the male bird takes part in the building of the nest I cannot but think, but from the time of my arrival on the island I never saw the two either diving for or carrying seaweed together. Of course, if all the hen birds were sitting this is accounted for, but from the courting antics which I witnessed, and for some other reasons, I judged that this was not the case. Once I saw a pair of birds together high up on the cliffs, where some tufts of grass grew in the niches. One of these birds, only, pulled out some of the grass, and flew away with it accompanied by the other one. It is not only seaweed that is used by these birds in the construction of the nest. In many that I saw, grass alone was visible (though I have no doubt seaweed was underneath it); and one, in particular, had quite an ornamental appearance, from being covered all over with some land-plant having a number of small blue flowers; and this I have observed in other nests, though not to the same extent. A fact like this is interesting when we remember the bower-birds, and the way in which they 
ornament their runs. I think it was on this same nest that I noticed the picked and partially bleached skeleton-with the head and wings still featheredof a puffin. It had, to be sure, a sorry appearance to the human-at least to the civilised human-eye, but if it had not been brought there for the sake of ornament I can think of no other reason, and brought there or, at least, placed upon the nest by the bird, it must almost certainly have been. The brilliant beak and saliently marked head of the puffin must be here remembered. Again, fair-sized pieces of wood or spar, cast up by the sea and whitened by it, are often to be seen stuck amongst the seaweed, and on one occasion I saw a bird fly with one of these to its nest and place it upon it. In all this, as it seems to me, the beginnings of a tendency to ornament the nest are clearly exhibited. It would be interesting to observe if the common cormorant exhibits the same tendency, or to the same degree. The shag being a handsome and adorned bird, we might, on Darwinian principles, expect to find the rsthetic sense more developed in it than in its plainer and unadorned relative.

Both the sexes share in the duty and pleasure of incubation, and (as in some other species) to see them relieve each other on the nest is to see one of the prettiest things in bird life. The bird that you have been watching has sat patiently the whole morning, and once or twice as it rose in the nest and shifted itself round into another position on the eggs, you have seen the gleam of them as they lay there

"As white

as ocean foam in the moon." 
At last when it is well on in the afternoon, the partner bird flies up and stands for some minutes preening itself, whilst the one on the nest, who is turned away, throws back the head towards it and opens and shuts the bill somewhat widely, as in greeting, several times. The newcomer then jumps and waddles to the further side of the nest, so as to front the sitting bird, and sinking down against it with a manner and action full both of affection and a sense of duty, this one is half pushed, half persuaded to leave, finally doing so with the accustomed grotesque hop. As it comes down on the rock it turns towards the other who is now settling on to the eggs, and, throwing up its head into the air, opens the bill so as to show (or at any rate showing) the brightly coloured space within.

All this it does with the greatest-what shall we say? Not exactly empressement, but character-it is a character part. There is an indescribable expression in the bird-all over it-as of something vastly important having been accomplished, of relief, of satisfaction, of summum bonum, and, also, of a certain grotesque and gargoil-like archness-but as though all these were only half-consciously felt. She then (for I think it is the female), before flying away, picks up a white feather from the ledge and passes it to the male, now established on the nest, who receives and places it. It has all been nearly in silence, only a few low, guttural notes having passed between the birds, whilst they were close together.

Just in the same way the birds relieve each other after the eggs have been hatched and when the young are being fed and attended to. 
"A shag (I think the female bird) is sitting on her nest with the young ones, whilst the male stands on a higher ledge of the rock a yard or so away. He now jumps down and stands for a moment with head somewhat erected and beak slightly open. Then he makes the great pompous hop which I have described before, coming down right in front of the female, who raises her head towards him and opens and closes the mandibles several times in the approved manner. The two birds then nibble, as it were, the feathers of each other's necks with the ends of their bills, and the male takes up a little of the grass of the nest, seeming to toy with it. He then very softly and persuadingly pushes himself against the sitting bird, seeming to say, 'It's my turn now,' and thus gets her to rise, when both stand together on the nest, over the young ones. The male then again takes up a little of the grass of the nest, which he passes towards the female, who also takes it, and they toy with it a little together before allowing it to drop. The insinuating process now continues, the male in the softest and gentlest manner pushing the female away and then sinking down into her place, where he now sits, whilst she stands beside him on the ledge. As soon as the relieving bird has settled itself amidst the young, and whilst the other one is still there -not yet having flown off to sea-it begins to feed them. Their heads-very small, and with beaks not seeming to be much longer in proportion to their size than those of young ducks-are seen moving feebly about, pointing upwards, but with very little precision. Very gently, and seeming to seize the right opportunity, the parent bird takes first one head and then another in the basal part, or gape, of his mandibles, turning his 
own head on one side in order to do so, so that the rest of the long bill projects sideways beyond the chick's head without touching it. In this connection, and whilst the chick's head is quite visible, little, if any more than the beak being within the gape of the parent bird, the latter bends the head down and makes that particular action as of straining so as to bring something up, which one is familiar with in pigeons. This process is gone through several times before the bird standing on the ledge flies away, to return again in a quarter of an hour with a piece of seaweed, which is laid on the nest." Here again, as throughout, the sexes of the birds can only be inferred or merely guessed at. Both share in incubation, both feed the young, both ( $I$ think) bring seaweed to the nest, and both are exactly alike.

As the chicks become older they thrust the head and bill farther and farther down the throat of the parent bird, and at last to an astonishing extent. Always, however, it appeared to me that the parent bird brought up the food into the chick's bills in some state of preparation, and was not a mere passive bag from which the latter pulled out fish in a whole state. There were several nests all in unobstructed view, and so excellent were my glasses that, practically, I saw the whole process as though it had been taking place on a table in front of me. The chicks, on withdrawing their heads from the parental throat, would often slightly open and close the mandibles as though still tasting something, in a manner which one may describe as smacking the bill; but on no occasion did I observe anything projecting from the bill when this was withdrawn, as one would expect 
sometimes to be the case if unmodified fish were pulled up, but not if these were in a soft, porridgey condition. Always, too, the actions of the parent bird suggested that particular process which is known as regurgitation, and which may be observed with pigeons, and also-as I have seen and recordedwith the nightjar.

Cormorants, as they sit on the nest, have a curious habit of twitching or quivering the muscles of the throat, so that the feathers dance about in a very noticeable manner, especially if that rare phenomenon, a glint of sunshine, should happen to fall upon them. Whilst doing so they usually sit quite still, sometimes with the bill closed, but more frequently, perhaps, with the mandibles separated by a finger's breadth or so. I have watched this curious kind of St Vitus's dance going on for a quarter of an hour or more, and it seems as though it might continue indefinitely for any length of time. All at once it will cease for a while, and then as suddenly break out again. It is not only the old birds that twitch the throat in this manner. The chicks do so too in . just as marked a degree, and on account of the skin of their necks being naked it is, perhaps, more noticeable in their case than with the parent birds. I have observed exactly the same thing, though it was not quite so conspicuous, in the nightjar, so that I cannot help asking myself the question whether it stands in any kind of connection with the habit of bringing up food for the young from the crop or stomachthe regurgitatory process. I will not be sure, but I think that the same curious tremulo of the throatal feathers may be observed in pigeons as they sit on the 
nest. It is that portion of the throat which lies just below the bird's gape ( $\mathrm{I}$ am here speaking of the shag), including both the feathered and the naked skin between the cleft of the lower mandible, and extending to the sides of the neck, which is principally twitched or quivered.

The above, perhaps, is a trivial observation, but no one can watch these birds very closely without being struck by the habit.

Young shags are, at first, naked and black-also blind, as I was able to detect through the glasses. Afterwards the body becomes covered with a dusky grey down, and then every day they struggle more and more into the likeness of their parents. They soon begin to imitate the grown-up postures, and it is a pretty thing to see mother and young one sitting together with both their heads held stately upright, or the little woolly chick standing up in the nest and hanging out its thin little featherless wings, just as mother is doing, or just as it has seen her do. At other times they lie sprawling together either flat or on their sides. They are good-tempered and playful, seize playfully hold of each other's bills, and will often bite and play with the feathers of their parent's tail. In fact, they are a good deal like puppies, and the heart goes out both to them and to their loving, careful, assiduous mother and father. As pretty domestic scenes are enacted daily and hourly on this stern old rock, within the very heave and dash of the waves, as ever in Arcadia, or in any neat little elegant bower where the goddess of such things presides-or does not. The sullen sea itself might smile to watch its 
pretty children thus at play, and to me it seemed that it did.

Guarding the nest and affairs of honour.-When both birds are at home, the one that stands on the rock, by or near the nest, is ready to guard it from all intrusion. Should another bird fly on to the rock and alight, in his opinion, too near it, he immediately advances towards him, shaking his wings, and uttering a low, grunting note which is full of intention. Finding itself in a false position, the intruding bird flies off; but it sometimes happens that when two nests are not far apart, the sentinels belonging to each are in too close a proximity, and begin to cast jealous glances upon one another. In such a case, neither bird can retreat without some loss of dignity, and, as a result, there is a fight. I have witnessed a drama of this nature. As in the case of the herring-gulls, the two locked their beaks together, and the one which seemed to be the stronger endeavoured with all his might to pull the other towards him, which the weaker bird, on his part, resisted as desperately, using his wings both as opposing props, and also to push back with. This lasted for some while, but the pulling bird was unable to drag the other up the steeply-sloping rock, and finally lost his hold. Instead of trying to regain it, he turned and shuffled excitedly to the nest, and when he reached it the bird sitting there stretched out her neck towards him, and opened and shut her beak several times in quick succession. It was as if he had said to her, "I hope you observed my prowess. Was it well done?" and she had replied, "I should think I did observe it. It was indeed well done." On 
the worsted bird's ascending the rock to get to his nest, the victorious one ran, or rather waddled, at him, putting him to a short flight up to it. But, though defeated, this bird was cordially received by his own partner, who threw up her head and opened her bill at him in the same way, as though sympathising, and saying, "Don't mind him ; he 's rude." In such affairs, either bird is safe as soon as he gets within close distance of his own nest, for it would be against all precedent, and something monstrous, that he should be followed beyond a certain charmed line drawn around it.

Nothing is more interesting than to look down from the summit of some precipice on to a ledge at no great distance below, which is quite crowded with guillemots. Roughly speaking, the birds form two long rows, but these rows are very irregular in depth and formation, and swell here and there into little knots and clusters, besides often merging into or becoming mixed with each other, so that the idea of symmetry conveyed is of a very modified kind, and may be sometimes broken down altogether. In the first row, a certain number of the birds sit close against and directly fronting the wall of the precipice, into the angle of which with the ledge they often squeeze themselves. Several will be closely pressed together so that the head of one is often resting against the neck or shoulder of another, which other will also be making a pillow of a third, and so on. Others stand here and there behind the seated ones, each being, as a rule, close to his or her partner. There is another irregular row about the centre of the ledge, and equally here it is to be remarked that the 
sitting birds have their beaks pointed towards the cliff, whilst the standing ones are turned indifferently. There are generally several birds on the edge of the parapet, and at intervals one will come pressing to it through the crowd in order to fly down to the sea, whilst from time to time, also, others fly up and alight upon it, often with sand-eels in their beaks. On a ledge of, perhaps, some dozen or so paces in length, there may be from sixty to eighty guillemots, and as often as they are counted the number will be found to be approximately the same.

Most of the sitting birds are either incubating or have young ones under them, which, as long as they are little, they seem to treat very much as though they were eggs. Others, however, when they stand up are seen to have nothing underneath them, for as with other sea-birds, so far as I have been able to observe, there seems to be a great disparity in the time at which different individuals begin to lay. In the case of the puffin, for instance, some birds may be seen collecting grass and taking it to their burrows, whilst others are bringing in a regular supply of fish to their young. Much affection is shown between the paired birds. One that is sitting either on her egg or young one-for no difference in the attitude can be discovered-will often be very much cosseted by the partner who stands close behind or beside her. With the tip of his long, pointed beak he, as it were, nibbles the feathers (or perhaps, rather, scratches and tickles the skin between them) of her head, neck, and throat, whilst she, with her eyes half closed, and an expression as of submitting to an enjoyment-a "Well, I suppose 
I must" look-bends her head backwards, or screws it round sideways towards him, occasionally nibbling with her bill, also, amidst the feathers of his throat, or the thick white plumage of his breast. Presently, she stands up, revealing the small, hairy-looking chick, whose head has from time to time been visible, just peeping out from under its mother's wing. Upon this the other bird bends its head down and cossets in the same way-but very gently, and with the extreme tip of the bill-the little tender young one. The mother does so too, and then both birds, standing together side by side over the chick, pay it divided attentions, seeming as though they could not make enough either of their child or each other. It is a pretty picture, and here is another one. "A bird-we will think her the female, as she performs the most mother-like part -has just flown in with a fish-a sand-eel-in her bill. She makes her way with it to the partner, who rises and shifts the chick that he has been brooding over from himself to her. This is done quite invisibly, as far as the chick is concerned, but you can see that it is being done.

"The bird with the fish, to whom the chick has been shifted, now takes it in hand. Stooping forward her body, and drooping down her wings, so as to make a kind of little tent or awning of them, she sinks her bill with the fish in it towards the rock, then raises it again, and does this several times before either letting the fish drop or placing it in the chick's bill-for which it is I cannot quite see. It is only now that the chick becomes visible, its back turned to the bird standing over it, and its bill and throat moving as though swallowing something down. Then the bird 
that has fed it shifts it again to the other, who receives it with equal care, and bending down over it, appears - for it is now again invisible-to help or assist it in some way. It would be no wonder if the chick had wanted assistance, for the fish was a very big one for so small a thing, and it would seem as if he swallowed it bodily. After this the chick is again treated as an egg by the bird that has before had charge of him -that is to say, he is sat upon, apparently, just as though he were to be incubated-or suppressed, like the guinea-pigs in "Alice in Wonderland."'

On account of the closeness with which the chick is guarded by the parent birds, and the way in which they both stand over it, it is difficult to make out exactly how it is fed; but I think the fish is either dropped at once on the rock or dangled a little, for it to seize hold of. It is in the bringing up and looking after of the chick that one begins to see the meaning of the sitting guillemots being always turned towards the cliff, for from the moment that the egg is hatched, one or other of the parent birds interposes between the chick and the edge of the parapet. Of course I cannot say that the rule is universal, but I never saw a guillemot incubating with its face turned towards the sea, nor did I ever see a chick on the seaward side of the parent bird who was with it. It seems probable that the relative positions of the sitting bird and the egg would be continued from use after the latter had become the young one; and if we suppose that in a certain number of cases where these positions were reversed the chick perished from running suddenly out from under the parent and falling over the edge of the rock, we can understand natural selection 
having gradually eliminated the source of this danger. But natural selection may have acted in another direction, which would have been still more conducive to the safety of the chick. I observed that the latter -even when, as I judged by its tininess, it had only been quite recently hatched-was as alert and as well able to move about as a young chicken or partridge; but whilst possessing all the power, it appeared to have little will to do so. Its lethargy - as shown by the way in which, even when a good deal older, it would sit for hours without moving from under the mother - struck me as excessive; and it would certainly seem that on a bare narrow ledge, to fall from which would be certain death, chicks of a lethargic disposition would have an advantage over others who were fonder of running about. If we suppose that a certain number of chicks perished even amongst those whose parents always stood between them and the sheer edge, we can understand both the one and the other step towards security having been brought about, either successively or side by side with each other.

From the foregoing it would appear that the young guillemot is fed with fish which are brought straight from the sea in the parent's bill, and not-as in the case of the gulls-disgorged for them after having been first swallowed. It is, however, a curious fact that the fish when thus brought in is, sometimes at any rate, headless. The reason of this I do not know, but with the aid of the glasses I have made quite certain of it, and each time it appeared as though the head had been cleanly cut off. Moreover, on alighting on the ledge the bird always has the fish (a 


\section{WATCHING SHAGS AND GUILLEMOTS 187}

sand-eel, whenever I saw it) held lengthways in the beak, with the tail drooping out to one side of it, and the head part more or less within the throat-a position which seems to suggest that it may have been swallowed or partially swallowed-whereas puffins and razorbills carry the fish they catch crosswise, with head and tail depending on either side.

I have also once or twice thought that I saw a bird which just before had had no fish in its bill, all at once carrying one. But I may well have been mistaken; and it does not seem at all likely that the birds should usually carry their fish, and thus, as will appear shortly, subject themselves to persecution, if they could disgorge it without inconvenience. With regard to the occasional absence of the head, perhaps this is sometimes cut off in catching the fish, or before it is swallowed, which may also have been the case with the herrings brought by the great skuas to their young. However, I can but give the facts, as far as I was able to observe them.

Married birds sometimes behave in a pretty manner with the fish that they bring to each other, and if coquetry be not the right word to apply to it, I know of none better. The following is my note made at the time:-

"A bird flies in with a fine sand-eel in his bill, and having run the gauntlet of the whole ledge with it, at last succeeds in bringing it to his partner. For a long time now, these two coquet together with the fish. The one that has brought it keeps biting and nibbling at it, moving his head about with it from side to side, bringing it down upon the ledge between his feet, then raising it again, seeming to rejoice in the 
having it. The other one seems all the while to admire it too, and often makes as though to take it from him -prettily and softly-but he refuses it to her, something as a dog prettily refuses to give up a stick to his master. At last, however, he lets her take itwhich, it is apparent, he has meant to do all the time -and when she has it she behaves in much the same manner with it, whilst he would seem to beg it back of her, and thus they go on together for such a time that at last I weary of watching them. There is a wonderful making much of the fish between the two birds, yet it is not eaten by either of them, and there is no chick, here, in the case. It is quite apparent that the fish is only something for coquetry and affection to gather about-it is a focus, a point d'appui, a peg to hang love upon. Yet the birds-and this is what I constantly notice-seem only to have a kind of half consciousness of what they mean." This particular fish, I may say, was minus the head, which had the appearance of having been neatly and cleanly cut off.

Yet there are harsher notes amidst all this tenderness, and the state of a bird's appetite will sometimes make a vast difference in its conduct under the same or similar circumstances. "A bird," for instance, "that has just come with a fish in its bill for the young one, is violently attacked-and this several times in succession-by the other parent, who is in actual charge of the chick. This one-we will suppose it to be the father, though, I half think, unjustly-makes the greediest dart at the fish, trying to seize it out of his wife's bill, and also pecks her very violently. Once he seizes her by the neck and holds her thus for some seconds, yet all the while in the couched attitude and 
with the chick underneath him. The poor mother yields each time to the storm, scuttles out of the way, seems perplexed and startled, but keeps firm hold of the fish. Driven away over and over again, she always comes back, and at length, by dint of perseverance and right feeling, weathers the storm, insinuates herself into the place of the greedy bird and begins to feed the chick. A new chord of feeling is now struck, and the bird that has been so greedy and ill-tempered cooperates in the most tender and interested manner with the wife whom he has outraged. The 'scene' of a moment ago is forgotten, and there is now a widely different and more accustomed one of family concord, tenderness, and peace."

I cannot think that such conduct as the above is common, and even on this one occasion when I saw it, it is possible (though it does not seem very likely) that the ill-behaving bird did not try to get the fish for its own sake, but only to feed the chick with. But however this may have been, fish are the constant cause of disturbance amongst the birds generally, and the guillemot that flies in with one has to avoid the snaps made at it by all those near to where he alights, and must sometimes run the gauntlet of most of the birds on the ledge before he can get with it to his own domicile. Sometimes he loses the fish, which is then often lost again by the successful bird, and so passed from one to another.

Or it may be tugged at for a long time by two birds that have a firm hold of the head and tail part respectively, and pull it backwards and forwards, not infrequently across the neck of a third bird standing between them. Birds incubating or brooding over 
their young ones are equally ready with those standing, to try and snatch away a fish from another, but in the great majority of cases the bird who has flown in with his booty and has a very firm hold of it, gets it safely through the crowd. Such episodes as these are rather of the nature of assault and robbery than regular fighting, for the bird attacked, though often severely pecked, never does anything but dodge and pull, for he cannot well thrust back again whilst holding a fish in his bill, and his whole endeavour is to avoid losing this. Combats, however, are very frequent amongst guillemots, much more so than I should have thought the condition of living packed closely together on a narrow ledge in the rock would have allowed, for surely one might have expected that this necessity would have been a power making for peace and concord. That it has been so to some extent, I make no doubt, and it may also have played a part in forming the character of the fighting, which is - or, at least, it struck me as being - somewhat peculiar. Though often violent, it is not, as a rule, vindictive, and as it seems to break out for no particular reason, so it generally ceases suddenly by one of the two birds stopping, as it were, in mid-thrust, and commencing to preen itself, after which it may be resumed once or twice before ceasing finally in the same way. The other bird seems only too happy to be left in peace, and instead of pressing the assault whilst his adversary is thus engaged and at a momentary disadvantage, generally stands unconcerned or begins to preen himself also. This sudden passing from the sublime to the ridiculous, from war to the toilette, has a curious and half comic effect. 
Such preening under such circumstances must, one would think, spring from a powerful incentive, and it is, I believe, chiefly when annoyed by insects that the birds preen themselves, though whether their efforts are actually to free themselves of these, or only to allay the irritation by scratching, I am not quite sure. But I noticed that a bird would often bend down its head, and with the extreme tip of its finely-pointed bill appear minutely to explore the surface of its webbed feet-and further, that when the partner of a bird doing this was beside him, it would become most interested, and do its best to assist him in the matter. One may suppose that the ledge-which is, of course, coated with a layer of guano-is covered with these pests, and that they often crawl over the bird's feet, and so ascend on to the body. If the skin of the feet were sensitive, their owner would at once know when this was the case, and with its keen eyesight and stiletto bill might guard itself fairly well, as long as it only stood. As, however, all the birds constantly sit flat on the rock, even when not incubating, the searching of the feet can be of little or no real importance to them. It is very interesting and has a very human appearance (not so much in regard to the particular act as the careful look and manner and the attitudes assumed) to see two birds thus helping to clean each other's feet, as I think must here be the case. When they nibble and preen each other they may, as a rule, I think, be rightly said to cosset and caress, the expression and pose of the bird receiving the benefit being often beatific, and the enjoyment being, no doubt, of the nature of that which a parrot receives 
by having its poll scratched; though, with regard to this, we must not forget the look of supreme satisfaction which a monkey often has whilst a friend is doing his best to make him clean and respectable. With the foot-cleaning there is no such attitude and expression. The bird helped is at the same time an active agent, and both of them are careful, earnest, and investigatory. It struck me, however, that the chick was cosseted in a somewhat more business-like manner, as though, if not actually to clean it, at least to make it spruce and tidy. It seems probable, indeed, that the conferring a practical benefit of the kind indicated may be one origin of the caress throughout nature; but others may be imagined.

The usual cause of guillemots fighting would seem to be one of them moving to a sufficient degree to attract the attention of the one nearest to it, who then-as though the circumstances permitted of no other course-delivers a vigorous thrust with its long, spear-like bill. This is the usual way of fighting, so that a combat has something the appearance of a fencing-match. The two birds stand upright with their bodies turned more sideways towards each other, than actually fronting, so that their heads, which alone do so, are twisted a little round. They stand at such a distance apart, that when the neck is held straight up, with the head flying out at a right angle, the tips of their two long lances just touch, so that the birds form a natural archway. In this position they make quick, repeated thrusts at each other, usually directed at the face or neck, by a motion of which, rather than by parrying with the beak, each endeavours to avoid the lunge of its adversary. But besides 


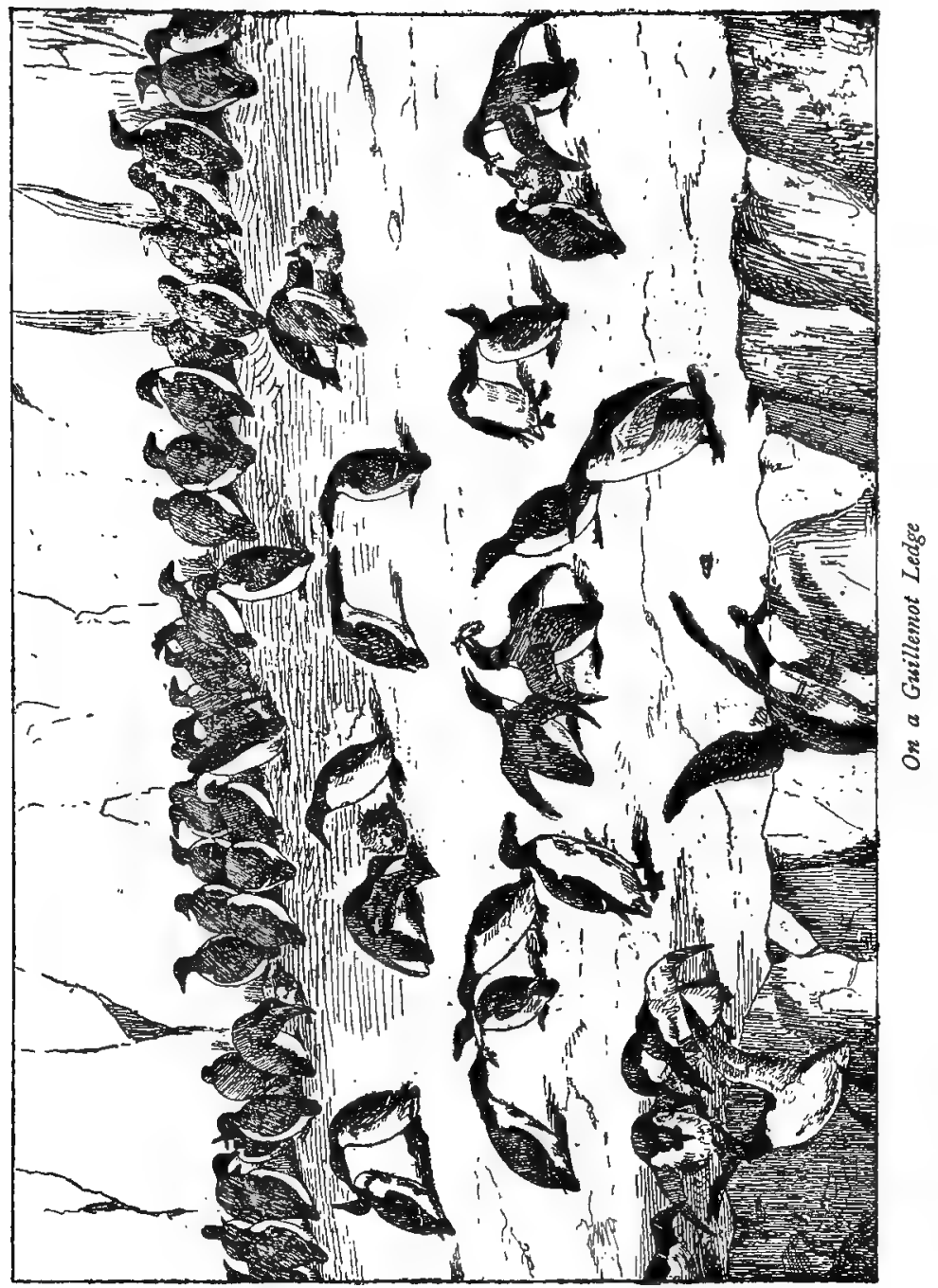





\section{"Tilting,}

Point to point at one another's breasts,"

they are ready to seize hold of each other should the opportunity occur, and when the fight is fierce, and the birds in their eagerness press in upon each other, they then strike smartly with their wings. Sometimes, too, each tries to seize the other's beak, but this is not usual, as I imagine it to be with herringgulls and cormorants. These single combats rarely become mélées, though, if one bird is forced to retreat, those amongst whom he pushes will be ready to peck at him and at each other. Of course, a bird, if really in distress, can always fly down from the ledge into the sea, and this it is often forced to do if it has been standing near the edge when the combat broke out. The better-placed bird seems then to recognise its advantage, and presses boldly forward upon the other. There is a short retreat, a recognition of the danger and vigorous rally, another forced step backwards, an ineffectual whirring of wings on the extreme brink, and, turning in the moment of falling, the discomfited one renounces all further effort and plunges into the abyss. And, no doubt, the little lice who crawl about upon the ledge and see such mighty doings, would, were they poets, write long epics telling of the wars and falls of angels. But only combats on the brink have such dramatic terminations, and farther inland a fight must be of an exceptionally violent kind to make the birds not think of preening themselves, and thus bring it to an end.

Birds that are incubating will fight as well as the others, and no respect seems to be paid to them on this account. Often one thus occupied may be seen 
thrusting up at a standing bird, who, in turn, thrusts down at it, or two recumbent ones will spar vigorously at each other. One wonders that under these circumstances the eggs are not sometimes broken, as may possibly be the case; but with regard to this, I will here quote the following note which I made on the management of the egg during incubation:-

"It appears to me that the guillemot sits with the egg not only between its legs, but resting on the two webbed feet, and pressed slightly by them against the breast. At any rate, I have just distinctly seen the bird rise up, take the egg carefully in this way between its two feet, sliding them underneath it, and then sink gently down upon it again. I believe that the egg was so placed when the bird rose, and that it rose for the purpose of improving its position. It seems likely that if the egg rests upon the bird's feet instead of on the bare rock, it must be less liable to fracture, and could be pressed slightly up by the bird amongst its feathers, so that the two opposed pressures could be combined to advantage, or either of them relaxed when it was to the bird's convenience.

"Have just seen another sitting bird rise, and, in settling down again, she certainly seemed to place her feet under the egg, assisting at the same time to place it with the bill. When she rose the partner bird came forward to her, and, lowering his head, looked at the egg with the tenderest interest, then cosseted her as she stood, and again when she had resettled.

"Another bird has half risen, showing the egg quite plainly. It is certainly resting on the feet."

Guillemots, as is well known, lay their single egg 
on the bare rock, but sometimes they will pick up and play with a feather, and I have seen one carry some fibres of grass or root, which had perhaps fallen or been blown from a kittiwake's nest, to its partner, and lay them down as if showing her. In such acts we may perhaps see a lingering trace of a lost nestbuilding instinct. They walk, as a rule, with the whole shank, as well as the actual foot resting on the surface of the rock, but sometimes they will draw themselves up so that they stand upon the foot, or rather the toes, alone, just in the way in which a penguin does, and in this attitude they can both walk and run. Anatomically speaking, the shank is, I believe, a part of the foot, corresponding to our own heel, and functionally it is so, too, in the guillemot, as well as in the razorbill and puffin. It is interesting, therefore, to see the occasional assumption of an attitude which in the penguins has become habitual. Their ordinary walking attitude is with the head held erect, but they often sink it to or below the breast, at the same time craning the neck right forward, which gives them a grotesque and uncanny appearance, like one of the evil creatures in Retche's outlines of Faust. Again, one of them will sometimes throw the head and neck slightly forward, and at the same time jerking the wings sharply behind the back, will, after remaining with them thus "set" for a moment, run briskly forward, giving them a vigorous shaking. But in spite of wings and beaks, and a few other dissimilarities, it is of men that one has to think when watching these erect, white-waistcoated, funny little bodies. Indeed, they are much like us, for they fight, love, breed, eat, and stand upright, which is most of 
what we do, though we make so much more pother about it. But it has a funny effect to see it all going on-like a "picture in little"-on a ledge of the bare rock.

If guillemots are watched closely, one may be noticed now and again to scrape with its beak for some time at the ledge where it is lying, opening and closing its mandibles upon it. Every now and thenas I make it out-it encloses a small object between them, which must, I think, be a piece of the rock, and with a quick jerk of the head sideways and upwards, swallows this. This, then, is how guillemots procure the small stones which are, no doubt, necessary to them for digestive purposes. The great mass of the rock forming the island is sedimentary, and in a more or less crumbling state, much of it, indeed, quite rotten and dangerous to trust to.

I will conclude this slight picture of life on a ledge with a few lines from my notes, as taken during that short period which, in summer, best answers to the coming on of night and dawn of morning here in England.

"IO.4O P.M. Some dozen birds out of about thirty that I can see appear to be roosting. The kittiwakes are more silent than in broad day, though there is a burst of clamour now and again.

"I0.56. There is less activity now, but few birds seem thoroughly asleep. Many stand, and some occasionally walk about and flap their wings. One has just flown off the ledge, but no others are doing so, nor are any arriving upon it. The general scene is much quieter, and so with the kittiwakes. The ledge now, at past eleven, is very quiet, though the 
majority of the birds still stand, and some preen themselves. The glasses have become inferior to the naked eye, though one can read anything with perfect ease. The birds, it is evident, judge of night by the light. They do not make a factitious night according to the duration of time. They sleep, indeed, in patches, but, on the whole, would seem to do so very little in the twenty-four hours.

"I I.I7. The majority of the birds are now roosting, perhaps almost all. I can see no puffins. They must, therefore, it seems, lie roosting too, in holes or crevices of the rocks.

"I I.30. All quiet at Shipka.

"I 1.35. A bird flies in duskily from the sea, and now no fighting ensues. All is quiet at Shipka.

"I I.5O. All quiet at Shipka - a little more so perhaps.

"I I.55. As before.

"I2 o'clock. Much as before, but two birds are, I think, cosseting. Though one can read and write with ease, and see all objects-even birds sitting or flying a long way off-still it is all gloom and yellow murkiness. Light seems gone, though there be light. It is 'darkness visible,' indeed, neither true night nor true day, but more like night than day. The great shapes of cliff and hill seem drawn in gloom clearly, the sea gleams dimly and duskily, all is weird, strange, and portentous. It is the marriage of opposite kingdoms, or rather, the monstrous child of light and darkness.

"1 2.I5. All roosting, I think.

"I 2.30. Quiet now. All quiet at Shipka.

"I 2.43. Much as before. On the steep side of 
one of the great 'stacks' opposite, kittiwakes are roosting in the most extraordinary numbers, and so close together that they look not like birds, but some outcrop on the surface of the rock. They consist, no doubt, of the partners of all the sitting birds on the ledges.

"I.5 A.M. The ledge is now stirring into life again, and so, too, the great block of kittiwakes on the 'stack,' from which birds keep dashing out, whirling and circling, settling again or visiting their sitting partners on the nests, before flying back to it. But the clamour of voices is, as yet, slight.

"Now, at 1.25, it is beginning to be greater.

"I.50. A general preening amongst the guillemots, though a good many still lie asleep. But soon they wake, too, and begin, for now it is light, bright, and morning."

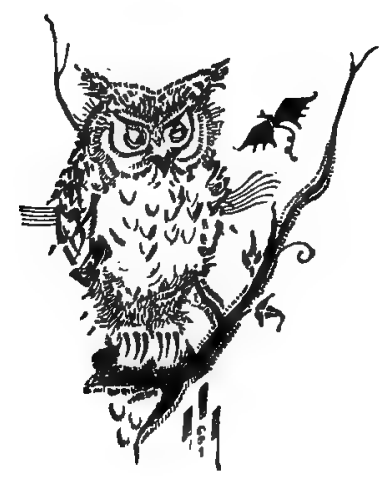




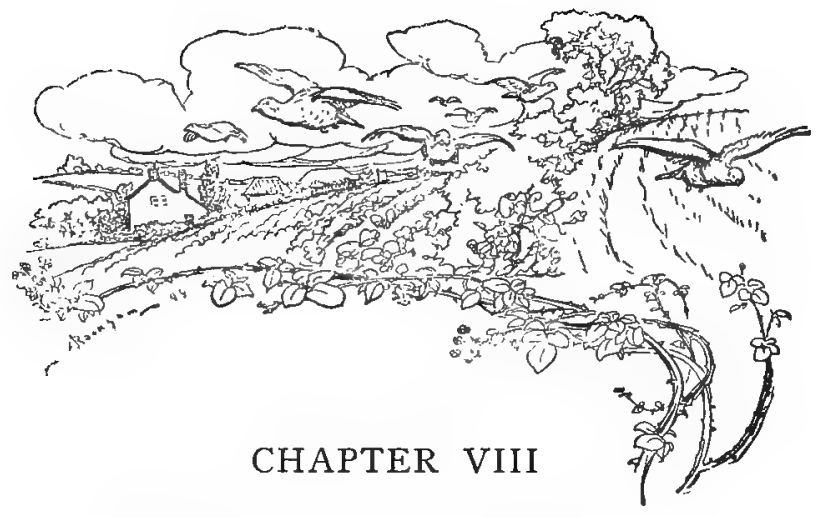

Watching Birds at a Straw-Stack

ONE of the most interesting ways of watching birds at very close quarters is to conceal oneself in one of the corn-stacks or wheat-ricks that in the autumn begin to spring up like mushrooms all over the country-side. This is a winter pastime, and the harder the weather the greater will be the results yielded. To have chaffinches, greenfinches, bramblings, tree-sparrows, buntings, yellow hammers, blue - tits, starlings, perhaps a blackbird or two, pheasants and partridges, all about one and quite near, one should choose a bitterly cold day with a biting wind driving the snowflakes before it, and the snow itself whitening the landscape, but not so deeply as to cover things beyond a bird's power of scratching. Rising early, one gets to the stack whilst it is still dark. At one side there is always a great heap of refuse material of the stack, threshed ears of corn, chopped and winnowed straw, as well as-at least where picturesque farming prevails (and may it long prevail)199 
a vast quantity of thistle-heads, poppy-pods, campion, columbine, and all sorts of other plants and flowers that have been garnered in with the harvest. Small birds come down on this in flocks, and where the slope of the heap on one side joins the stack, one should make in the latter, by a process of pulling out and pressing in, a nice cosy cavern just big enough to squeeze into. On the floor of this one should lay a shawl or plaid, and then, eriveloping oneself in another, enter it backwards, and, kicking one's legs farther into the body of the stack so as to be out of the way, pull down the straw over the aperture, arranging it thinly just in front of one's face so as to have a good outlook. Even on the coldest morning one is warm and comfortable under such circumstances, and the snow without and frosted stalks that one's near breath is thawing, make one feel all the warmer. It is for warmth, indeed, that such an ensconcement is principally needed, for on days like this small birds, at any rate, will come within a few paces of one, if only one sits still. Even when one walks up to the stack in broad daylight, they only fly round to another side of it, and one has scarcely settled oneself before they begin to come again. But hidden thus before "black night" has ceased to "steal the colours from things," one may have stragglers from the main crowd within the length of one's arm, and I have even tried catching one-for the bizarrerie of the thing-by gliding my hand stealthily through the loose straw underneath it. The attempt failed, but I believe such a feat would be quite possible.

As the light begins to creep upon the darkness and the world to grow more and more white, the arrivals 
commence. First a few greenfinches - principally hens-fly down upon the heap, then chaffinches, both cocks and hens, but hens predominating, with a few yellow-hammers, mostly of immature plumage, and a hedge-sparrow or two. These birds come and go independently for some little time, and it is not till the morning has grown lighter that they begin to form a band, in the sense not of their numbers only, but also of their actions. It is only gradually, for instance, that their habit of all flying away together into the neighbouring trees and returning quickly again in the same way becomes at all marked. They are at first independent units, but as the day brightens and the numbers increase they become more and more interdependent. Now, too, there is more equality in the numbers of the sexes. The females still predominate, but one would not always think that this was the case, for as they all whirr into a large oak tree that is beginning now to be gilded by the beams of the tardily-rising sun, its bare boughs and twigs, as well as the surrounding bushes, are made suddenly lovely with bright, soft green and mauvy-purplish red. A glorious winter foliage this, that might make an old tree feel young again!

All the time the birds are down on the heap they are busily feeding, seeming to put their whole soul into each peck (like the single jest at the Mermaid) and all in a kind of sociable, yet but half friendly, competition with each other. Gradually they spread out a little from the heap, half-a-dozen greenfinches are amongst the straw that one has oneself pulled out from the stack, and one of them is feeding positively within three feet. To see them so near, and to think 
that they think you anywhere rather than where you are! It is like eavesdropping, it hardly seems right. Now the nearest greenfinch picks out an ear of the corn and, as if to show you just how he does it, comes even a thought nearer. He turns it till it is crosswise in his beak, snips off the stalk, rapidly divests it of what remains of the outer huskiness-in doing which you see him work his mandibles in a delicate, tactile manner-and swallows the inner essence. Throughout he does not help himself with his claws at all. It is pleasant to see this, but still more so to have so many little dicky birds just within a pace or two, all free and unconstrained and knowing nothing whatever about it. It is as if you had somehow got into a bird-cage without alarming the inmates, but even as this occurs to you you recognise the poverty of the simile, and rejoice to be in nature's aviary-at least one may say this of the birds if not of the strawstack.

There is now, besides chaffinches and greenfinches, which form the great bulk of the numbers, quite a little crowd of bramblings-twenty or more-their beautiful gold-russet plumage gleaming out in an easy pre-eminence of colour ; for they are, indeed, much handsomer than the handsomest cock chaffinch or greenfinch, and as both the sexes are alike, nothing of them is lost, there are no dead-weights. Even the yellow-hammers when at their yellowest cannot compete with these chestnut beauties, and the pretty little blue-tits who feed softly-two or three together-on the poppy seeds are beaten, whether they confess it or not. A hedge-sparrow or two hopping very quietly and unobtrusively about on the outskirts of the great 
central crowd have, of course, no pretensions to anything like distinguished beauty, but there is one bird -one, unfortunately, not only as a species but individually-that may, perhaps, stand up in rivalry even with the brambling.

This is a solitary male goldfinch who, as though knowing the sad and waning state of his clan, feeds all by himself and-as one seems to fancy-in a melancholy manner. Be this as it may, his mode of feeding is quite different to that of the other birds. Whilst all, or nearly all, of these are pecking odds and ends from amongst the straw and draff of the heap, using their beaks only and seeming to swallow something at each little peck, like chickens with grain, he makes successive little excursions to the stack itself, from which he extracts a blade of corn, a campion, or a thistle-head, and then, standing with the claws of both his feet grasping it (like a crow with a piece of carrion), picks it to pieces and devours it, or the seeds it contains, in a leisurely, almost a phlegmatic, way. This is quite different from the greenfinch, which-as just seen-in extracting the grain from an ear of corn, uses only its bill, standing the while in an ordinary upright attitude, and not pick-axeing down upon it as it lies along the ground. Perhaps the goldfinch can do this too, but as this particular one did not on any morning employ a different method to that which I have described, it must, I should think, be the usual one; nor did I ever see it pecking up anything from the ground in a careless haphazard fashion, like the other birds.

One can feed the birds with bread if one likes, and, when found and tasted, this is appreciated. But the 
pieces that one throws are not noticed, as they lie amongst the straw, so readily as one would have supposed, and often birds will pass quite near to, or even almost touch them, without seeing them or, at least, discovering what they are. A whole Osborne biscuit, upon one occasion, was an object of suspicion. Several chaffinches came up as though to peck at it, but their courage failed them at the last moment, and it was never touched the whole time I was there. Of course, when larger and more wary birds come to the stack, one must keep quite still and not play any tricks like these, if one wishes them to stay. A hen blackbird is now feeding on the outskirts of the heap. She will not permit any small birds to be near her, but drives them all off if they come within a certain distance, so that she is soon in the centre of a little space which she has all to herself. Into this a starling flies down and seems at first inclined to meet the blackbird on equal terms, for, of course, the two instantly recognise each other as rivals, and cross swords as by mutual desire. But even in the first encounter the starling has to give way, and then beats a series of retreats before the other's sprightly little rushes, till at length, being left no peace, he has to fly away. Later, some half-dozen starlings come down together almost on the top of the heap, and feed in just the same way as the small birds they alight amongst. Soon there is a combat between two of these. Both keep springing from the ground, going up again the instant they alight, and each trying, as it seems, to jump above the other, whether to avoid pecks delivered or the better to deliver them. They never jump quite at the same time, but always one goes up as the other 
comes down, which has a funny effect. They never close or grapple, they do not even seem to do much pecking, and when it is all over, neither of them "seems one penny the worse." The great thing, evidently, is to jump, and as long as a bird can do it he has no cause to be dissatisfied. It is delightful to watch them from so close. One can see the gleam of each feather, catch their very expressions, and sympathise with every spring. They look very thin and elegant, and their plumage is all gloss and sheen. All the while they keep uttering a sort of squealing note which it is quite enchanting to hear.

A few partridges now come down over the thin snow towards the stack, at first fast, with a pause between each run, during which they draw themselves up and throw the head and neck a little back. Then they seem to waver in their intention; and, whilst one pecks at the body of a frosted swede, another bends above it and sips with a delicate bill a little of the rime upon its leaves. Then they come on again, but, as they near the stack, with slower and more hesitating steps, and no longer uttering their curious, grating cry "ker-wee, ker-wee." Instead, one hears now-for now they are in close proximity-all sorts of pretty, little, soft, croodling sounds, seeming to express contentment and happiness with a quiet under-current of affection. Then they feed quietly on the frontiers of their winter oasis.

All at once something gorgeous and burnished steals and then flashes into sight. It is a pheasant. $\mathrm{He}$ has come invisibly from another direction, and ascending the opposite slope of the great chaffheap, rises over it like a second sun. Surely such 
splendour should come striding in majesty, but he is very nervous, full of apprehension, open to the very smallest ground of fear or suspicion. Often he stops and looks anxiously about, half crouches, then makes a little start forward with the body as though on the point of running, but checks himself each time and begins to peck instead. Sometimes he draws himself up to his full height, and looks all round as from a watch-tower, but after each fit of fear he decides that all is well and goes on feeding again. And now another sun rises and immediately afterwards three - no, four ("dazzle my eyes, or do I see four suns?") advance together over the crest of the hill which, though of straw and all inflammable materials, does not-a miracle!-take fire and burn. But the snow and the dampness must be taken into consideration. All of them are now feeding quietly, but not all together or in view. Two have set again, but three and the tail of another, in partial eclipse from behind, is a sight of sufficient magnificence. Looking at them, at their splendid body-plumage of burnished orange gold, gleaming even in the dull morning without any sun but themselves - for the great one is now "over-canopied"-at their glossy blue heads, rich scarlet wattles, and long graceful tails, one cannot help wondering how beautiful a bird would have to be before compunction would be felt in killing it. Would the golden or Amherst pheasant produce the sensation? Idle thought! Peacocks are shot in India, trogons in Mexico, humming-birds both there and in the Brazils, and birds of paradise in the islands of the east. Of paradise-2. Then are there birds in heaven, and 
do our sainted women wear their feathers? But such speculations are beyond the province of this work.

Now the feeding goes on apace. All the splendid birds keep scratching backwards in the chaff-heap as do fowls, sending up clouds of it into the air. Like the partridges, too, they utter, from time to time, a variety of curious, low notes, which, unless one were quite near, one would never hear, and once they make a quick little piping sound, all together, standing and lifting up their heads to do it, as though filled with mutual satisfaction and a friendly feeling. The low sounds are of a croodling or clucking character. They are not quite so soft as those of the partridges, and, low as they are, one still catches in them that quality of tone whereof the loud, trumpety notes are made.

I have spoken of the extreme nervousness of the first pheasant. The later arrivals, just as would be the case with men, were not nearly so nervous, though all were wary and circumspect. But now it is most interesting to watch them, and to remark how, in these cautious birds, timidity-or say, rather, a proper and most necessary prudence-is tempered with judgment, and modified by individual character or temperament. They are capable of withstanding the first sudden impulse to flight, and of subjecting it to reason and a more prolonged observation. Thus, when the small birds fly, suddenly, off in a cloud, as they do every few minutes, and with a great whirr of wings, the pheasants all stop feeding, look about, pause a little, seeming to consider, and then recommence, as though they had decided that such panic 
fear was uncalled for, and that there was no rational ground for alarm. An hour or two later three out of the four birds - for two have got gradually to the other side of the stack-see enough of me in the straw to make them suspicious, and go off at half pace. The fourth bird notes their retreat, looks all about, can see nothing to account for it, and instead of following them, as might have been expected, goes on feeding. This, though it may seem to show a defect in the reasoning power (the power itself it certainly does show), at least argues strength of character and independence of judgment. A certain line of conduct is suggested by the action of a bird's three companions, but this suggestion this powerful stimulus, one would think - is resisted by the one bird, put to the test of its own powers of observation, and the line of conduct dictated by it, rejected. This self-reliant quality and power of not being swayed by others, I have constantly observed in birds.

As will have been gathered, these six pheasants that came and fed together at the stack were all males, and this has been my usual experience. Under such circumstances I have always found them agree together perfectly well, but there is generally some fighting to be seen amongst the small birds, though, perhaps, not much, if one takes their numbers into consideration. Chaffinches are the most pugnacious, though, here again, a similar allowance must be made, for they largely predominate, even over greenfinches, whilst, compared to these two, the others-excepting sometimes bramblings-are only scantily represented. Chaffinches fight by springing up from the ground 
against each other, breast to breast (as do so many birds), and they may rise thus to a considerable height, each trying to get above the other, and claw or peck down upon it - at least, it would seem so. Their position in the air is thus perpendicular, and as they mutually impede each other, they are more fluttering than flying. Sometimes, however-generally after they have got to a little height-they will disengage, and then there will be between them a series of alternate little flights up and above, and swoops down upon each other, very inspiriting to see. Sometimes they will commence the fight with these swoopings, but it is more common for them to flutter perpendicularly up as described, and then down again. Often, too, they will rise beak to beak only, the position being then between perpendicular and horizontal, but more the latter, the tail part of them giving constant little flirts upwards-as when a volatile Italian in an umbrella shop leans his whole weight on the stick of one of the umbrellas and leaps, or, rather, swings himself from the ground, kicking his heels into the air, to demonstrate its strength. Imagine two volatile Italians thus testing two umbrellas whose handles touch, continually throwing up their heels, rising a little as they do so, never coming quite down again, and so getting a little higher each time, and you have the two chaffinches. Or there will be a series of alternate flying jumps from the ground like the starling's, but more aerial. These are the more usual ways, but if one bird can, whilst on the ground, suddenly seize another by the nape of the neck, and then, getting on his back, twist his beak about in the skin and feathers, it is all the 
better-for that one. Such fights as these are usually between two male birds, but hen chaffinches sometimes fight, whilst scuffles between a cock and a hen over food may also be witnessed.

Greenfinches fight in much the same manner, but they are more stoutly built, and their motions are not quite so brisk and airy, though chaffinches themselves are but clumsy birds in this respect compared to many others-larks, for example. They, too, fight tenaciously. After a brisk partie in the air, I have seen one, on their falling together, seize the other by the nape and be dragged about by it over the snow.

But what has interested me more than anything else in my frequent watchings of small birds congregated together at the stacks, is the way in which every few minutes or so-sometimes at longer, and sometimes at shorter intervals - they take instant and simultaneous flight, rising all together* with a sudden whirr of wings, and flurrying away to some near tree or trees, or into the hedgerow, to return in a much more scattered and gradual manner very soon-sometimes almost directly afterwards. These sudden spontaneous flights, where one and the same thought seems suddenly to take possession of a whole assembly of beings, I had before, and have often afterwards, observed in rooks, starlings, wood-pigeons, etc., and I have been equally puzzled to account for it in all of them. I do not remember that this habit, which is, indeed, common in a greater or less degree to a very great number of birds, has ever been brought

* This is the effect produced, but for greater accuracy see p. 245. 
forward as something difficult of explanation, and many, perhaps, will doubt there being any such difficulty in regard to a thing so ordinary and commonplace. As to this, I can only say that I have arrived at a different conclusion.

What would be the ordinary way of accounting for such sudden and simultaneous taking to flight of a number of birds? One may suppose, in the first place, that a particular note is uttered by one or more of them on the espial of danger, and that this acts as a sauve qui peut to the rest. This seems a satisfactory explanation, but as against it, no such note is, as a rule, uttered, and even if it were, it would not account for all the facts as I have often observed them.

Day after day, and for hours at a time, I have watched these crowds of little birds under the circumstances described, and only on one single occasion was the sudden rising into the air in flight preceded by any note at all, nor did I observe anything-I do not believe there was anything to be observed-which could have frightened them.

In the one case referred to, which was different, "the flight was certainly preceded by a note-a very peculiar one, single, long, and remarkably loud, taking the size of the birds into consideration. It suggested somewhat the sudden blowing of a horn-though, of course, a small one. I could not tell which bird uttered it, but feel sure, from the quality of the tone, that it was a greenfinch. To the best of my observation, the note was uttered before the flight commenced, and the flight followed before it had ceased. Almost immediately afterwards I heard, for the first time, the caw of rooks, and my theory is (or was) that one of these, 
appearing suddenly in the air from the back of the hay-stack, had been mistaken for a hawk, and that the bird so mistaking it had immediately uttered the appropriate warning note. Unfortunately for my little mouse" ("theories," says Voltaire, "are like mice; they run through nineteen holes, but are stopped by the twentieth"), "only the other day, when I was at the same place and equally near, a genuine hawk (a sparrow one) had flown by, when, instead of a warning note, there had been a sudden hush and silence, followed by a flight which, as it seemed to me, was not so close and compact as usual. Difficulties of this sort are always occurring in observation-at least in my observation - and show how cautious one should be in translating the particular into the general. For instance, with moor-hens, I have noted that in one or two of their many timorous flights to the river a peculiar cry was uttered by a single bird, which had all the appearance and seemed to have all the probability of being a warning note; but this was not the case on other occasions." Even here, then, there is some difficulty in accepting the theory of a dangersignal uttered by one bird, and causing the simultaneous flight of all, whilst in all other instances (I am speaking now of small birds at the stacks) either no note at all or none distinguishable from a general chirping was uttered. Manifestly, ${ }^{*}$ then, this explanation will not serve. But it may be said, either that there is a leader whose movements all the birds follow, or that when one bird flies, for whatever reason, the rest take alarm and fly also. But where different species of birds are all banded together, it seems very

* My very close proximity must be taken into account. 
unlikely that there should be a leader, and both this and the other explanation, which at first sight seems satisfactory, are destroyed by the salient fact that in hardly any case do all the birds rise and fly away together, but only the great majority. Almost invariably a certain number of them, though sometimes only half-a-dozen or so, or even less, remain, nor has this anything to do with the particular species of bird. Moreover, the flying up of any bird from the crowd does not, of itself, communicate alarm to the others, for first one and then another and often several at a time may constantly be doing so, whilst the rest feed quietly and take no notice. It may be said that it is only when a bird flies off in alarm that its flight communicates alarm to its companions. That it does so necessarily, even in such a case, I, from general observation, very much doubt, and also, if the facts as I have given them be a little considered, it will be seen that the difficulties are not met by this view of the case.

The theory of a leader seems more applicable to birds like rooks, which are gregarious, and may be constantly watched in large numbers together, without the intermixture of any other species. The same difficulties, however, apply here, and even to a greater extent, for the movements of rooks are more complicated, whilst alarm or any such primary impulse as the origin (I do not say the explanation) of them, is in most cases quite out of the question. An instance or two of these sudden and quite simultaneous movements of bodies of rooks I have noted down directly after observing them. They would be much in place here, but as I have two chapters devoted to these birds, and, more- 
over, as they but make a part in general scenes and pictures, I will not separate them from their context nor any bird from its companions.

Starlings, again, furnish striking examples of the same phenomenon. Their aerial evolutions before roosting are sufficiently remarkable, but, perhaps, still more so from this point of view is the manner in which they leave the roosting-place in the morning. This is not in one great body, as might have been expected, but in successive flights at intervals of some three or four to ten or twelve minutes, each flight comprising, sometimes, hundreds of thousands of birds-the numbers, of course, will vary in different localities-and the whole exodus occupying about half-an-hour. Each of these great flights or uprushes from the dense brake of bush and undergrowth where the birds are congregated, takes place with startling suddenness, and it seems as though every individual bird composing it were linked to every other by some invisible material, as are knots on the meshes of a net by the visible twine connecting them. There is no preliminary,* nor does it seem as though a certain number of more restless individuals gradually affected others, but at once a huge mass roars up from the still more immense multitude, as does a wave from the sea, or as a sudden cloud of dust is puffed by the wind from a dust-heap. I am speaking here of the great main flights, which are, in most cases, of this character. The fact that quite small bands of birds will sometimes fly

* As far, at least, as observable from just outside the plantation, and to judge from the sound. But previous movements within the plantationunless we assume a quite human organisation-would not explain what is here assumed to require explanation. 
off between the intervals of these, does not detract from the more striking phenomenon or lessen the difficulty of explaining it. For, surely, there is a difficulty in explaining how the example of one vast body of birds, soaring forth on the morning flight, should not affect every individual of the still vaster body of which they form a part-the whole occupying, it must be remembered, a small and densely packed area-and why the impulse of the flying birds to fly should, apparently, become uncontrollable in each individual of them at the same instant of time. If we saw soldiers issuing in this manner from an encampment, or performing all sorts of collective movements and evolutions before entering it in the evening (as do the starlings before descending on their roosting place), and yet satisfied ourselves that there were neither captains nor officers, signals nor words of command amongst them, we should probably wonder, and might think the phenomenon sufficiently curious to make it worth study and investigation.

I will take one more example from my notes on wood-pigeons before returning to the flocks of small birds at the stacks.

"A number of wood - pigeons" (this was early on a very cold winter's morning) "have now settled on the elms near me. I am quite still, and they have sat there quietly for some little time. All at once the whole band fly out, to all appearance at one and the same moment, and in a peculiar way, with sudden sweeps and rushes through the air in a downward direction, shooting and zig-zagging across each other with a whizzing whirr of the wings, in much the same manner as do rooks. On account of this peculiar 
flight, which seems to be joyous and sportive, I do not believe they have seen me. But whether they have or not, the absolutely simultaneous flight of the whole body is, to me, equally hard to account for. Supposing - what would be most likely-that only one bird has seen me, how has this knowledge been communicated, instantaneously, to all the rest? There was no note uttered of any kind. I must have heard it, I think, if it had been, so near as I was, nor are pigeons supposed to have an alarm-note. It may be said that the sudden abrupt flight of one alarmed the rest, but all cannot have been looking at this one at the same time, and it is difficult to suppose that there was anything to discriminate in the actual sound of the wings-for one or more than one bird may, at any time, fly eagerly off without affecting the others. Moreover, if this were the explanation, there would have been an appreciable interval of time between the flight of the alarmed bird and the others, which, to my sense, there was not. But, as I say, I do not believe that the birds saw me, and, if not, the collective, instantaneous impulse of flight seems still harder to account for on ordinary known principles. It is, of course, easy to give a plausible explanation of a thing and take for granted that all the facts are in accordance. But the facts, when one watches them, are apt to discredit the theory. Observation and difficulties begin, often, at the same time."

Returning now to the little winter collections of chaffinches, greenfinches, bramblings, etc., which come and feed at the corn-stacks during the winter, in general they whirr up every three or four minutes, but the intervals vary, and may be much longer. 
Sometimes only about half the flock flies off, the rest not appearing to care much about it; usually a much greater number does, and this often appears to be the whole number, but almost always - unless, of course, on the approach of a man or some other such alarming occurrence-some few, at least, remain. As with the starlings, these flights seem often to be absolutely instantaneous, the birds all rising together in a solid block, but this is not always the case, and the cloud may be preceded by a little half-hopping, halfchasséeing about of three or four individuals, whilst sometimes there is, for a second or two, a very quick following of one another. If this were always so, and if one bird could not fly off without others following it, there would be little or nothing to explain, but, as we have seen, this is very far from being the case. In nine cases out of ten the birds begin to come back almost as soon as they are gone; but, in spite of this, I came to the conclusion that the cause of flight was almost always a nervous apprehension, such as actuates schoolboys when they are doing something of a forbidden nature and half expect to see the master appear at any moment round the corner. Though there might be no discernible ground for apprehension, yet after some three or four minutes it seemed to strike the assembly that it could not be quite safe to remain any longer, and presto! they were gone. Afterwards it was recognised that there had been no real reason for alarm, and they came back, but this seemed to strike them individually rather than collectively. Now it was by stacks in the open fields under no more cover, as a rule, than the neighbouring hedgerow, that I had noticed 
these phenomena, and, coming one day upon such a heap of chaff or draff-though without any stackin the centre of a small plantation of fir and pine trees, I determined to watch here, a number of small birds having flown up as I approached. I was able to conceal myself very well amidst some bushes that grew quite near, and very shortly the birds-chaffinches, bramblings, hedge and tree-sparrows, etc., but not greenfinches-were down again. I stayed a considerable while, but, except once or twice when I moved a little so as to alarm them, they remained feeding all or most of the time. Sometimes, indeed, some or other of them would fly into the surrounding trees or bushes, but this they did at their leisure, without alarm or hurry, and only as desiring a change. The simultaneousness was wanting - there were none of those nervous flights at short intervals that I had observed when watching at the open corn-stacks. Here, amongst the pines, and protected on every side, the birds felt, apparently, quite secure, though whether it was altogether a rational security may be questioned. This observation strengthened me in my conclusion as to these flights being caused by a feeling of nervous apprehension or alarm, but I am bound to add (another case of the mouse) that I subsequently watched by stacks in the open, where, also, a considerable sense of security seemed to prevail. Temperature may perhaps have something to do with the explanation, but I have as yet taken no steps to test this theory.

But whatever may be the motive (which, of course, may vary) of such sudden flights-and here I am thinking of all the examples which $I$ have brought 


\section{WATCHING BIRDS AT A STRAW-STACK 219}

forward, as well as others, in fact, the whole range of the phenomena-how are we to account for their simultaneousness, and the other special features belonging to them?

It would seem as though either one and the same idea were flashed suddenly into the minds of a number of birds in close proximity to each other at one and the same instant of time, or that this same idea, having originated or attained a certain degree of vehemence, at some one point or points - representing some individual bird or birds-spread from thence, as from one or more centres, with inconceivable rapidity, so as to embrace either the whole group or a portion of it, according to the strength of the original outleap. In other words, I suppose (or, at least, I suggest it) that birds when gathered together in large numbers think and act, not individually, but collectively; or, rather, that they do both the one and the other, for that individual birds are capable of withstanding the collective influence of the flock of which they form a part, I have ample evidence. The old Athenians-though slave-holders, wherein they may be compared to the Americans at one period-were a very democratic people, and lived a more public life than any other civilised community either before or after them, of which we have any record. They were also of a very emotional temperament, and it is curious to find amongst them the idea (at any rate) of the $\phi \eta \mu \eta-\mathrm{a}$ sudden wave or current of thought which swept through an assembly, causing it to think and act as one man.* When watching numbers of birds together, this

\footnotetext{
* In the wilderness of Grote's twelve volumes I cannot, now, find the
} 
$\phi \eta \mu \eta$ idea has constantly been brought to my mind, nor do I see how the whole of the facts are to be explained except upon some such hypothesis. If we suppose that the sudden flurryings away of a band of small birds from the chaff-heap where they have been quietly feeding, are caused by the apprehension of danger, we may well credit the birds with having sharper senses than our own, though that they are often mistaken is shown by their almost immediate return, and also by as many of them (sometimes) remaining as fly away. But it is impossible to imagine that every individual bird of a large number, crowded together and busily feeding, can at the same instant of time see the same object, or even hear the same sound of alarm, unless very loud or conspicuous, nor can it be supposed that the same thought, producing the same action, can flash independently into all their minds at once, by mere chance. But if we suppose thought to be like a wind, sweeping amongst them and producing, each time that it rises to a certain degree of strength, its appropriate act, then we can understand fifty, seventy, or a hundred birds rising in this thought-wind, like leaves or straws blown up in a sudden gust, and, in the same way as when a blizzard or tornado bursts on a town, some frail objects in a room through which it has torn may be left standing, whilst everything else is strewed about in ruin, so may the thought-wave (to use the more familiar term) moving with inconceivable

passage which I seem to remember so well, nor can anyone (including the whole of the Psychical Research Society) help me to. My Greek word, $\mathrm{I}$ am told, too, is wrong. But let it stand till someone can give me the right one. 
rapidity amidst the flock, miss out some individuals, though right in the midst of those that are affected, in a manner which is hard to account for. Again, if we suppose two centres from which two opposite thought-waves or impulses spread, we can understand two groups of birds, which, together, have made one band, acting in different ways or going in different directions (as one may constantly see with rooks and starlings), whilst, by supposing that the wave, or energy, tends to exhaust itself after spreading to a certain distance around any point or centre where it may have originated or become focussed, we account for such facts as many thousands of starlings, say, rising from, perhaps, a million without the others being affected. But, no doubt, even in an Athenian assembly there were some men capable of withstanding the force of the $\phi \eta \mu \eta$, and if we give to birds, even when thus assembled together, a power of individual as well as collective action, varying in each unit so that the one power is now more and now less under the control of the other-but with, on the whole, a preponderance in favour of the latterwe then, as it appears to me, come near to explaining what I must regard as the often very puzzling problem of the movements of such assembled bodies.

This, of course, is the theory of thought-transference, and if this power does really exist in the case of any one species we might expect it to exist also in the case of others. With the evidence of its existence amongst ourselves I am not unacquainted, but I need say nothing of this or of my humble opinion concerning it, here. I have suggested it as a possible explanation of some of the actions of birds, 
because I have found it difficult to account for them in any other way. If it could be made out that animals did really, in some degree, possess this power, it might throw a new light upon many things, and, possibly, explain some difficulties of a larger kind than those which I have called it in to do. To me, at least, it has always seemed a little curious that language of a more perfect kind than animals use has been so late in developing itself; but animals would feel less the want of a language if thought-transference existed amongst them to any appreciable extent.

Assuming its existence, it is amongst gregarious animals that we might expect to find it most developed, and gregariousness has, probably, preceded any great mental advance. Therefore, before an animal reached a grade of intelligence such as might render the growth of a language possible, it would have become gregarious; and, assuming it then to have a certain power of feeling, and being influenced by the thought of its fellows, without the aid of sound or gesture, it is obvious that here would be a power tending to dull and weaken that struggle to express thought by sound, which may be supposed to have slowly and unconsciously led to the formation of a language. Here, then, would be a retarding influence. Still, as ideas communicated in this way would probably be of a general and simple kind, corresponding, perhaps, more to emotions and sensations than definite ideas, the need for more precise impartment would gradually, as mental power became more and more developed, become more and more felt. Then would come language (as spoken), and spoken language, 
once established, would tend to weaken the old primitive power, as an improvement on which it had arisen. Thus if thought-transference exist in man, it may, perhaps, represent a reversion to a more primitive and generalised means of mental intercommunion, or the older power may exist, and still occasionally act, or even do so habitually to some extent; in fact, it may not yet have entirely died out. Possibly, also, it might tend to survive, and even to some extent increase, as being, in certain ways and directions, superior to the more precise medium. But if so, it would become-unless specially cultivated-more and more limited to these directions. Certain it is that people seem often to approach each other mentally much more by feeling than by words, and in a wonderfully short space of time. We call this insight, intuitive perception, affinity, etc.,_-but such words do not explain the process.

Is it not possible that birds living habitually together, as part of a crowd, may have acquired the faculty of thinking and acting all together, or in masses, each one's mind being a part of the general mind of the whole band, but each possessing, also, its individual mind and will, by virtue of which it is enabled to suspend its general crowd-acting, and act individually?

Perhaps a careful observation of gregarious animals in a wild state, or even (if a more special definition be wanted) of large crowds or masses of men, might throw some light upon this subject, and it would, at any rate, be approaching it upon a broader basis, and by methods less tainted with our silly prejudices, than has hitherto been done.

But when I speak of gregarious animals in a wild 
state, I am forgetting that such hardly any longer exist. The great herds of bisons, zebras, antelopes, giraffes, etc., that once roamed over places now given over to humanity (and inhumanity) have disappeared, and what have we learnt from them? Who has watched them-at least very carefully or patientlywith thoughts other than of their slaughter? I know of no careful record of their movements, taken from hour to hour and from day to day. A few generalities, conveying some of the more obvious and striking facts-or what seemed to be so-will alone survive their extinction. Enlightened curiosity has been drowned in bloodthirstiness, and the coarse pleasure of killing has over-ridden in us the higher ones of observation and inference. We have studied animals only to kill them, or killed them in order to study them. Our "zoologists" have been thanatologists. Thus the knowledge gleaned even by the sportsmannaturalist has been scant and bare, for-besides that the proportions of the mixture are generally as Falstaff and Falstaff's page-there is little to be seen between the sighting of the quarry and the crack of the rifle. Observation has commonly left off just where it should have begun.

Had we as often stalked animals in order to observe them, as we have in order to kill them, how much richer might be our knowledge! 


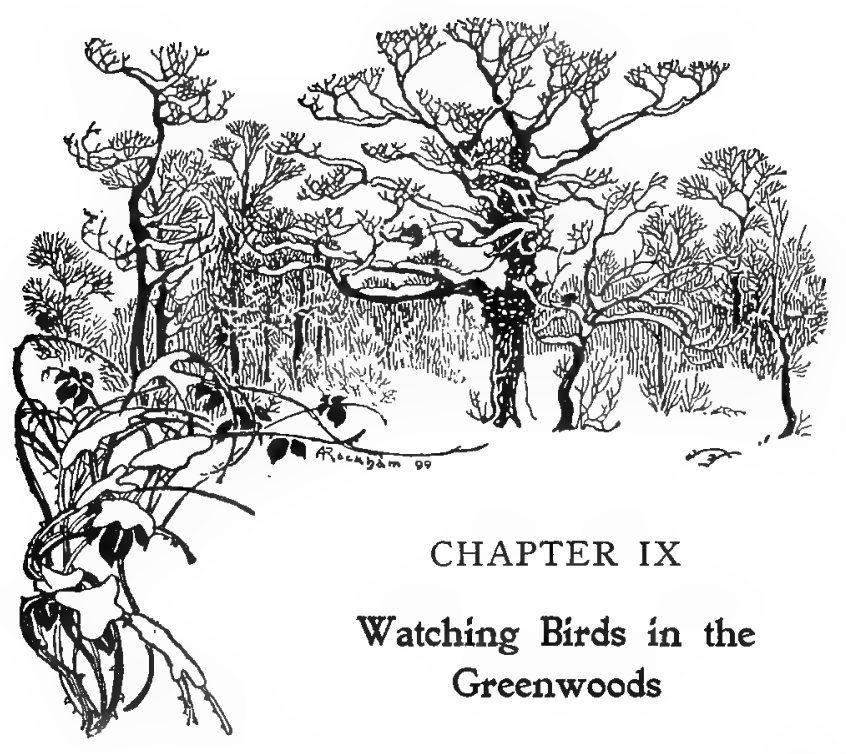

I HAVE called attention in the last chapter to that independent or self-reliant quality which so many birds possess, and by virtue of which they often act differently to their fellows, even when there is a strong inducement to them to act as they do. This seems to me an important point, for it must be as the foundation-stone upon which change of habit would be built, and change of habit points out a certain path along which change of structure, were it to occur, would be preserved, and a new species be thus formed.

One might think that the most timid birds would, under ordinary circumstances, be the ones least liable to change their habits, for such change would often mean a penetrating into "fresh fields and pastures 
new," where they might be expected to fear and distrust in a higher degree than amidst surroundings with which they were familiar. This, perhaps, may be the case, but one must distinguish between timidity and a wary caution or prudence, which may be combined with an independent, perhaps one may even say a bold, spirit.

The moor-hen is an example of such a combination. I have watched these birds for hours browsing over some meadow-land, bordering a small and very quiet stream, near where I live. Sometimes there would be a dozen or twenty scattered over a wide space, and every now and again, when something had alarmed them, the whole troop, one taking the cue from another, would run or fly pell-mell to the water, most of them swimming across and taking refuge in a belt of reeds skirting the opposite bank, whilst some few would remain floating in midstream, ready to follow their companions if necessary. In two or three minutes, or sometimes less, they would all be back browsing again, and so continue till, all at once, there was another panic rush and flight. The cause of these stampedes was generally undiscoverable; but sometimes, when the birds stayed some time down on the water, the figure of a rustic would at length appear, walking behind a hedge, along a path bounding the little meadow. Of such a figure rooks and many other birds would have taken no notice, even when considerably nearer. One cause of alarm I frequently noted, and this was where another moorhen would come flying over the meadow, either to alight amongst those upon it, or making for a more 
distant point of the stream. Such birds, though not alarmed themselves-for I frequently saw the commencement and spontaneous nature of their flightsyet always brought alarm to the others: a fact which seems to me interesting, for it cannot be supposed that these would have been disquieted at the mere sight of one of their kind, and if they judged from the flying bird's manner that it was seeking safety, then they judged wrongly. This, again, does not seem likely, and the only remaining explanation is that they drew an inference- " This bird may be flying from danger" - which, I think, must have been the case. At any rate, each time it was a sauve qui peut, one of themselves sent them all in a race to the water, just as a dog or a man would have done. But I must qualify the word "all." Often-perhaps each time--one or two birds might be seen (like the pheasant) to glance warily about, as though to assure themselves whether there was danger or not, standing, the while, in a hesitating attitude, and ready, on the slightest indication, to follow their companions. Then, having satisfied themselves, they would continue quietly to browse-for moor-hens browse the grass of meadows as do geese.

Coming, now, to the opposite side of the bird's character-its boldness and enterprise-I remember one afternoon, when I had been watching the stone curlews, seeing, just as evening was falling, a moorhen walking along the piece of wire netting which skirted a wheat-field, or rather an arid waste of sand where some wheat was feebly attempting to grow. The whole country around was the chosen haunt of the former birds, as opposed, therefore, to anything 
damp, moist, or marshy, as can well be imagined. The moor-hen went steadily on, with a composed and mind-made-up step, never deviating from the straight line of the netting till, upon coming to where this was continued at a right angle in another direction, it found its way through, and proceeded to cross a green road skirted with fir-trees into another Saharalike waste, where I lost it, at least a quarter of a mile from the nearest little pond or pool. Possibly it was walking from one of these to another, but quite as probably-in my experience-it was leaving its ordinary haunts for some inland part it had discovered, where it could get food to its liking. For the moor-hens living in the little creek or stream that I used to watch would range over the adjacent meadow-land, and a few of them, having come to the limit of this, would climb up a steep bank and through a hedge at its top, down again into a little bush and bramble-grown patch on the other side. One bird, indeed, that I startled, actually climbed this bank and scrambled through the hedge into the patch, instead of flying to the water; which is as though a lady were to take up Shakespeare rather than a novel, or a servant-maid to act by reason instead of by rote. Again, I have startled a moor-hen out of a large tree standing in a thicket, and a good way back from the ditch surrounding it-such a tree as one might have expected to see a wood-pigeon fly out of, but certainly not a moor-hen.

Such variations of habit are to me more interesting than those of structure, for they represent the mind, as do the latter-which they have probably in most 
cases preceded-the body. Changes of structure, too, if slight, are not easy to see, and as soon as they become observable the varying animal is dubbed another species, or, at least, a variety of the old one, so that one is not allowed, as it were, to see the actual passage from form to form;-one is always either at one end of the bridge or the other end. But changed habits may be marked in transitu, and there is hardly, perhaps, a bird or a beast which, if closely watched, will not be seen to act sometimes in a manner which, if persisted in to the neglect of its more usual circle of activities, would make it, in effect, a new being, though dressed in an old suit of clothes. Thus, in such a bird as the robin, which is associated - and rightly - in the popular mind with the cottage, the little rustic garden, and with woodlands wild-such scenes and surroundings, in fact, as are represented, or used to be, on Christmas cards-one may get a hint of some future little redbreasted, water-loving bird, at first no more aquatic than the water-wagtail, but becoming, perhaps, as time goes on, as accomplished a diver and clinger to stones at the bottom of running streams as is the water-ouzel - a bird as to which, Darwin says, "the acutest observer by examining its dead body would never have suspected its sub-aquatic habits."

To illustrate this, I take from my notes the following :- "A robin"-it is in December-"flies on to the trunk of a fallen tree spanning the little stream, from thence on to some weedy scum lying against it on the water, from which he picks something off and returns again to the trunk. Two or three times again he flies down and hops about. on the weeds, 
and sometimes, whilst doing so, pecks at the great black trunk. Now he is standing on them contentedly, with the water touching his crimson breastfeathers. $\mathrm{He}$ is in his first or more primitive figure, for the robin has two. Either he is a little round globe with a sunset in him-his rotundity being broken only by a beak and a tail-or else very elegant, dapper, and well set up. In the first he is fluffy, for he has ruffled out his feathers, but in the last he has pressed them down and is smooth and glossy-has almost a polish on him." Again, whilst walking by the river in the early morning, the water being very low, "a robin hops down over the exposed shingle, to near the water's edge, then flies across to the opposite more muddy surface, and hops along it, pecking here and there. He again flies across and proceeds in the same way, always going up the stream, crosses again, and so on. Each time he is farther away from me, and now I lose sight of him; but this is evidently his system. How out of character he seems amidst the mud and ooze of the dank river-bed on this chill winter's morning, how little like the robin of poetry and Christmas-card, how much more in the style of some little mud-loving, stilt-walking bird: for this is often their manner of zig-zagging from shore to shore up or down the stream. I have noticed it but now in the redshank. Yet the old associations are with him, for this is home, and the thatched cottage peeps over the familiar hedge."

And here I will chronicle an experience-my own, if it be not that of others. Provided there be shrubbery about, there are but few places here in England 
where one can sit quietly for very long, without a robin stealing softly out and, as it were, sliding himself into the landscape. Then-however bleak or chill it may be-his presence seems to bring home comforts with it. But this is only when one is near home and home comforts-not when one is far, far away from them. I remember in the great pineforests of Norway-so lovely yet so stern in their loveliness-the robin seemed to have lost all his character. He did not suggest home and all its pleasures when home was no longer near. It was not (or perhaps it was) that by suggestion he made these seem farther off, but that his character seemed gone. Surely, things are to us as a part of what they move in with us, and, out of this, seem changed and to be something else.

I am not quite sure if the following represents any change of habits in regard to food, induced by the presence of a foreign tree, in any of the three birds that it concerns. I have occasionally watched the great-tit in our own fir-plantations, but have not yet seen him attacking the cones, though the coal-tit, as I believe, does so. For the greenfinch I can only say that I should not have thought it of him, nor is he often to be seen in such places. The nut-hatch is not common where I live.

"Standing this Christmas Eve under a large exotic conifer on the lawn of the garden here in Gloucestershire, I became aware that various birds were busy amongst its branches, and I kept hearing a curious grating noise with a strong vibration in it, which seemed to be made by them with the beak upon the large fir-cones, but as the branches were very close 
together, and the birds high up, I could not observe the manner of it-the sound (as I said before) being very peculiar. I therefore climbed the tree (which was easy), and the birds being now often quite nearthough the branches and great clusters of needle-tufts were much in the way-I ascertained that it was the greenfinch alone which was producing the peculiar, vibratory noise, but how, exactly, he did it I could not make out. He appeared to be tearing at the woody sheaths or clubs (which stood wide apart) of the large fir-cones, and it seemed as though, to give the vibration in the sound, either the mandibles must work against each other with extraordinary swiftness, or the clubs of the cone itself vibrate in some manner against the beak, thus causing the sound in question to mingle with the scratching made by the latter against the hard surface.

"The great-tit and the nut-hatch are also busy at the cones. The former strikes them repeatedly with his bill, making a quick ' rat-tat-tat.' He attacks them either from the branch or twigs from which they hang, striking downwards, or clinging to the side of one and striking sideway-downwards, or even hanging at their tips, in which case he hammers up at them. Whilst hammering, or rather pick-axeing, he often bends his head very sharply from the body-almost at a right angle-towards the point at which his blow is aimed, and he then becomes, as it were, a natural, live pickaxe, of which his body is the handle and his head and beak the pick. After hammering a little on one of two cones that hang together, he perches on the other one, and, in the intervals of hammering it, shifts his head to the first and gives it, as 
it seems, a sharp investigatory glance. $\mathrm{He}$ then flies away.

"A nut-hatch, also, I twice see hammering at the cones, in much the same manner as the tit, and, having loosened a thin brown flake from one of them, he flies off with it in his beak. I have not yet seen the tit do this, nor did I ever see him get an insect. If he got anything at all, it must have been in one of the actual blows, become a peck, as when he hammers at a cocoa-nut hung in the garden. The greenfinches never hammered, but only bit and tugged at the clubs of the cones. Brown flakes often fell down from them, but I never saw the birds fly off with these, as the nuthatch has done. I had seen one with a flake in his bill which, however, he soon let fall to the ground.

"One of the greenfinches is again attacking the cones, and I can now see the way he does it more plainly. He places his beak between the clubs of the cones at their tips (I mean their outer ends), and then moves his head and beak rapidly, seeming, as it were, to flutter with his head, and as he does this you hear the grating, vibratory sound. All the time, he is clinging head downwards to the side of the cone, quite a feat for so large, at least for such a stout-built bird. I will not, however, be quite sure that it is to the cone itself that he clings. The fir-needles hang in bunches near them, and his claws may be fixed amongst these, though I do not think so, or, at least, not always. Besides this sound made with the beak on the fircones, there is another, which one often hears, and which is usually, I think, made by the greenfinch. To get at the cones, he often flies up underneath them, and hangs a little, thus, before clinging, on fluttering 
wings. When the tips of these strike amongst the bunches of needles, a sharp, thin, vibratory rattle is produced - also a very noticeable sound.

"The nut-hatch-or another one-now flies in again, uttering, as he arrives, a curious, high, sharp note'zitch, zitch, zitch' - and again flies away with a thin brown flake in his bill, a very woody morsel it would seem. And now, later in the afternoon, I see a greattit probing the cones with his bill, and he also pulls out a brown flake and flies away with it. Another does the same, hanging from the tip of a cone, on which he afterwards perches for a moment, before flying with it to another tree. Whilst standing, all this time, in the tree, I had noticed little hard brown seeds about the size of apple-pips, and which had all been cracked, lying in the forks formed by the junction of the branches with the trunk. There was hardly one such resting-place in which there were not a few of these cracked seeds. Pulling off a fir-cone, I began to pull it to pieces, and at once saw, at the base of every club where it had joined and helped to form the central pillar, the double indentation, one on either side of the median line-or mid-rib as it would be called in a true leaf - in which the two seeds had been lying. Soon I came upon a seed itself, and, attached to the outer end of it-that farthest from the base of the club-I at once recognised the little brown flaky leaf that I had seen in the bills of all three birds, but which none of them seemed to eat.

"Here, then, the whole mystery-for to my ignorance it had been such-was explained. The birds were picking out the seeds from the cone, and the way to do this was to seize the thin brown flake to which the 
seed was attached, and which lay all along inside each club or leaf of the cone, whereas the seed itself was right at the base, and the beak of the birds could not, perhaps (or not so easily), be pushed up so far between the stiff clubs, the hard edges of which would catch their foreheads uncomfortably. At least with the tit and greenfinch, whose bills are not long, this would seem to be likely. When the birds-as was evidently often the case-pulled out only the thin flakeleaf which had become detached from the seed, they let it fall negligently, thus conveying the impression that they had been taking trouble to no end. When, however, they flew away with it, it is to be presumed the seed was attached.

"Here, then, are three quite different birds, all busily occupied in extracting the seeds from the large cones of an exotic species of fir, but whilst two of themthe great-tit and the nut-hatch-effect this by first hammering on the cone, so as to loosen the seeds, or, rather, the woody flake to which they are attached, from the basal part of the club (if we may assume this to be the object) before pulling them out, the greenfinch procures them without any previous hammering, which is an action, perhaps, to which it is not accustomed. One should not, however, assume too hastily that the latter bird has no plan of his own for first loosening the seeds. Remembering the rapid, almost fluttering, motion - not at all like pecking or hammering-which he communicates to his head and bill, with the curious, vibratory sound-which again does not suggest an ordinary blow-that accompanies it, and how often when I could get a fairly good view of him, he seemed to be repeatedly seizing and letting 
his bill slip over the outer edges of the fir-clubs, I am inclined to think that he was making the stiff clubs vibrate on their stalks-their hinges, so to speakin a manner that would tend to loosen the seeds as effectually, perhaps, as would tapping them.

"Judging by these limited observations, I should say that the nut-hatch was the most skilful of the three in extracting the seeds, as, on the two occasions when I saw him plainly, he flew away with a flake, soon (once almost immediately) after he had come. He looked more like a connoisseur, too, and his bill is much longer. He alone, as I should think, might possibly be able to drive it right down, so as to seize the actual seed. Yet he tapped the cone in the same quick manner as did the tit, nor did he appear to me to be probing it at such times. Moreover, I never observed him-any more than the others--to extract the seed independently of the flake."

Birds that are not tree-creepers will often behave very much as if they were so, and show different degrees of expertness in the art. It seems quite natural that a small bird, which habitually frequents trees, should sometimes cling to the trunk; but what surprises me is, that with so much raw material to have worked upon, nature should not have developed some of our small perching birds into actual treecreepers. My observations on the blue-tit and the wren show, at least, that should anything occur to make it difficult for them to procure food in other ways, or should they (and this is easier to imagine) develop a partiality for some particular kind of insect or other creatures living in the chinks or under the bark of trees-say spiders, for instance, which are 
often to be found there in colonies-they would be all ready to become specialised experts. At least it appears to me so, and I think it the more curious because they do not seem often to practise what they can do so well. Here is my note, taken in October, when, perhaps, there would be a little more scarcity of the ordinary food of such birds, than in the spring and summer of the year.

"In a grove of Scotch firs this morning I noted, first a blue-tit, clinging to the trunk of one in the same manner as a nut-hatch or tree-creeper. Hardly had he flown off it when a wren flew to and commenced to ascend perpendicularly the trunk of a tree quite near me, flying thence to another which it also ascended, and so on from tree to tree. Afterwards, however, I was able to watch blue-tits acting in this manner for some little time, as well as quite closely, and I decided that they were the greater adepts of the two. They climbed the perpendicular or overhanging trunk with ease and swiftness, clinging to the roughnesses of the bark, at which they pecked from time to time, I imagine for insects. Usually they went straight upwards, but sometimes more or less slantingly. I also noted - and this I had not been able to do for certain in the wrenthat they descended as well as ascended the trunks of the trees; but here the manner of progressing was not quite so scansorial, for it was with a little flutter. Whether they used the feet as well as the wings in the descent I could not actually see, but they kept quite near enough to the trunk to have done so. These little fluttering drops or drop-runs interested me very much. The bird never made 
them except whilst hanging on the trunk of the tree perpendicularly and head downwards, and when he stopped and clung to it again he was in precisely the same position. The drop each time might have been from four to six or seven inches. It never appeared to me to be more. Both the blue-tit, therefore, and the wren have acquired the habit of creeping about the trunks of trees, in search, presumably, of insects or spiders, as do the tree-creepers, woodpeckers, and nut-hatch. The former of them can descend the trunk, but not, it would appear, without the aid of its wings, either wholly or in part. For the wren, I saw him descend once, as I think, in a quick side-eye-shot; but some nettles intervened, and I cannot be sure."

"On the next morning I am at the same grove, and, about seven, a good many blue-tits fly into it, one of which is soon busily occupied on the trunk of a fir-tree. I now observe that this bird uses his wings even in ascending the trunk, for though he certainly crawls up it, yet he accompanies each fresh advance, after a pause, with a little flutter, and advance and flutter end commonly together, taking him but a very little way. A tree-creeper on the same tree, who moves deftly about, pressed much flatter to the trunk and never using his wings, gives a good opportunity of comparing the two birdsthe professional and the amateur. Now, both according to my memory and my notes, the tits I saw yesterday did not flutter at all while ascending the tree-at any rate, that one which I saw quite close both ascending and descending, on which my note was principally based, did not; for though I saw 
others, this one gave me the best and longest view, and the only one of the descent. Had he fluttered in the ascent also, I must certainly have noted it, and I should not, then, have placed the two in such contradistinction. If an inference may be drawn from such limited observation, it, perhaps, is that this bird is in process of acquiring, or, at any rate, of perfecting, a habit, and that, therefore, all the individuals do not excel in it to an equal degree. The fact that I often watched and waited to see them practising the art again, but without success, may lend some colour to this. There was clinging sometimes, but not climbing."

In this competition, therefore, between the wren and the tit as tree-creepers, the tit bears off the bell; but later I had a better opportunity of observing the prowess of the latter bird, and, though I did not see it descend, yet in ease and deftness, length of time during which the part was assumed, and general fidelity of the understudy to the original, it must, I think, be pronounced the superior. It was early on a cold, rainy, cheerless morning towards the end of February, that I was so lucky as not to be in bed. I say-"Have, this morning, watched closely, and from quite near, a wren behaving just like a professional tree-creeper. It ascended the trunk of an alder, quickly and easily, and sometimes to a considerable height-twenty or thirty feet perhaps-beginning from the roots, and then flew down to the roots or base of the next one, and so on along a whole line of them. $\mathrm{Up}$ the sloping roots, or anywhere at all horizontal, it hopped along in the usual manner, but, when the trunk became perpendicular, it crept or crawled, just 
like a true tree-creeper.* I was, as I say, quite close, and watched it most attentively. It certainly-as far as good looking can settle it-did not assist itself with the wings. They remained close against the sides, or, if they moved at all, it was imperceptible to my eyes (which, by the way, are non-pareils). Nevertheless, at a later period-for I followed along the trees-when I watched it at only a few paces off, it as certainly appeared that it did use the wings, advancing up the trunk by flutterings, but these were so small and slight, and raised the bird so imperceptibly from the surface of the trunk, that it had all the while the appearance of creeping. As I was still closer to the bird during the latter part of my watching, it may be thought that this alone represents the actual fact; but, for my part, I cannot help thinking that my eyesight served me upon each occasion. If so, then here is more 'richness,' from a Darwinian point of view. The tits, it will be remembered, differed individually, but in this wren there was a personal variation. He could creep, in ascending, without using his wings, and generally did so; still he sometimes broke into a little flutter, which, in a more pronounced form, had been prevalent in his youth. His father always did it in this way, and there were very old wrens still living who only flew up a trunk. But this was thought very oldfashioned."

It will not be forgotten how this bird flew from the point which it had reached on one tree, right down to the roots of another, and ascended from these.

* I allude to the apparent motion. The tree-creeper itself, I believe, really hops. 
The tree-creeper, when it flits from tree to tree, generally does so in a downward direction. If trees were of a uniform height, and if the bird usually ascended to the top, or nearly to the top, of each one in succession, one could see the rationale, or even the necessity, of this practice, for the tree-creeper does not-at least not usually-descend the trunk. But in a wood, the top of one tree may not represent half the height of another, and, moreover, a tree will often be abandoned by the bird when it has reached only a moderate height, or is still quite near to the ground; and it is not so easy to see how, under these circumstances, the abovementioned habit should have arisen. But, now, if the forerunners of the tree-creeper had been birds accustomed to hop about on the ground, and to peer and pry amongst the projecting roots of trees, and if they had, from these, gradually ascended the trunk, getting back to them at first quite soon, but making longer and longer and more and more accustomed excursions, then we can understand how this habit might have become-as one may say-rooted, so as to continue after there was no longer any particular advantage in it. Now, however, it is beginning to weaken. I have on several occasions-which I duly noted down at the time-seen a tree-creeper fly from one tree to another, upon which it clung, in an upward direction. I have little doubt that what is now still a habit will come to be a preference merely, and that, in time, even this will cease to be discernible, and the bird be guided simply by circumstances.

It is said that the tree-creeper never descends the tree it is on, and, also, that it generally proceeds in a spiral direction, by which, I suppose, is meant that 
the line of its course winds round and around the trunk of the tree. This last, however, has not been quite my experience. I have watched the bird often and carefully, and I should say that a true spiral ascent by it is decidedly exceptional. Often one has alighted upon the tall stem of a Scotch fir, on the side away from me, and never come round into view at all. On other occasions, after some time, I have seen its tiny form outlined against the sky on one or other side of the trunk, considerably, higher up, and then, again, it has disappeared back, or flown to another tree. This can hardly be called a spiral ascent, and I have seen no nearer approach to one. Often, too, I have seen it mount quite perpendicularly for a considerable distance. To me it appears that the tree-creeper recollects, occasionally, that he ought to ascend a tree spirally, and begins to do so, but the next moment he forgets this tradition in his family, and creeps individually. One might expect, indeed, that insects or likely chinks for them would act as so many deflections from the path of spiral progress, which, as it seems likely, may have been originally adopted for the same reason and upon the same principle that a road is made to wind round a mountain instead of being carried up the face of it. But how is it, then, that the wren and the blue-tit ascend tree-trunks perpendicularly? for one would have thought that the less au fait a bird was, the more would the advantages of an easy gradient have forced themselves upon it. But these birds are stillsometimes, at any rate-aided by their wings, so that it would seem as though their tree-creeping had been developed, or was being developed, as an adjunct to 
tree-fluttering. Now, as it appears to me, though it might be easier for a bird to creep up a tree by going round it, it could more easily flutter up it perpendicularly,* in the way I have described, and, if so, we can understand a bird that is only in process of becoming a tree-creeper, commencing, as it were, at the most advanced end. For it would first have fluttered up perpendicularly, then have both crept and fluttered so, and finally, when it could creep without fluttering, it would do so at first on the old fluttering lines. Then it might begin to adopt the spiral method, but as the effort required became less and less, and structural modification - as seen, for example, in the shape and stiffness of the tail-feathers of the tree-creeper-came to its assistance, this would cease to be a help, and become a habit merely, and when once a habit has lost its rationale, it is in the way of being broken, even in good society. Thus the perpendicular ascents of the tree-creeper may be the final stage in a long process, and the return in ease to what was before done in toil.

The tree-creeper is assisted in its climbing by the stiff, pointed feathers of the tail, which act as a prop, and also by its small size, which may possibly have been partly gained by natural selection. The great green woodpecker is possessed of the first of these advantages, but not of the second, and it is, I believe, the case that he much more adheres to the spiral mode of ascent than does the tree-creeper, who, as it seems to me, has almost discarded it. It would be interesting, therefore, to observe if the smaller spotted

* Or rather no particular difficulty would be experienced, so that the shortest course would be the best one. 
woodpecker shows a greater tendency to deviate in this direction; but I have had no opportunity of doing this.

With regard to the other assertion-namely, that the tree-creeper never descends the trunk of the tree-this is at least not true without qualification, for I have seen it do so backwards, with a curious and, as it seemed to me, a quite special motion. It was quick and sudden, carrying the bird an inch or so down the trunk, when it ceased and was not repeated : a jerk, in fact, but of a much more pronounced character, made thus backwards, than any of the little forward jerks, in a toned-one might almost sometimes say a glidingsuccession, of which the ordinary "creeping" consists. The first time I saw this action (to dwell upon) it constituted a perpendicular descent, but my eye was not full on the bird at the moment, so that I only observed it imperfectly. On the second occasion I saw it quite plainly, and this time the bird jerked itself sideways as well as downwards, stopping in the same abrupt manner, though whether it made two short quick jerks or only one, I could not be quite sure of. I think it was two, but that only the last one gave the jerky effect. It would thus seem that the tree-creeper might really progress in this way, for some little while, if it wished to. The tail must almost of necessity be raised, or the stiff, pointed feathers would catch in the roughnesses of the bark; but, either from the quickness of the action, or the slight extent to which it was lifted, I did not notice this.

I have also seen the great green woodpecker make exactly this same motion, downwards and backwards, on the trunk to which he was clinging, so 
perhaps all true tree-creeping birds may be able to descend in this fashion, should they wish it, though to do so head first may be beyond the power, or rather the habit, of most of them. This, certainly, I have never seen the tree-creeper do, but I should not be at all surprised were I to, some day, and in describing the habits of any bird, "never"-excepting in extreme cases-is, in my opinion, a word that should never be used.

The tit, however, though only an amateur treecreeper, does, as we have seen, descend the trunk head downwards, showing, to this extent at least, a superiority over a much greater master of the art. But here we have the flutter, whether helped out by the use of the feet or not, and we can imagine that, as the bird became more and more a true creeper, and used the wings less and less, he might cease to descend, and only creep upwards. It must, however, be remembered that all the tits are accustomed to hang head downwards from twigs and branches in an uncommon degree, so that a member of the family, developing along these lines, might find it easier to descend the trunk, or make greater efforts to overcome the difficulty of doing so, than a bird whose habits in this respect were less pronounced. Tits perch more generally amongst the higher branches of trees, and have no particular habit of hopping about the ground or creeping over and about the tangle of a tree's projecting roots, which I have often watched wrens doing. Those which I saw tree-creeping did not fly-or at any rate I did not notice that they did-from the tree they were on, so as to alight upon another at a lower elevation, 
but they were hardly systematic enough to let one judge properly as to this. The wren, however, both in this respect and in its general façons d'agir, had a striking resemblance to the tree-creeper, with which bird-if I read the systematic tangle (I mean in print) aright-he is more closely related than are the tits.

"Howsoever these things be"-I fear I have dwelt too long upon them, but whole books are written upon a war or even a battle-the little tree-creeper is a very delightful bird to watch. Sometimes, on inclement winter days, one can come very near him, very near indeed, and almost forget the cold, the rain, the sleet, in his active busy little comfort. To see him then creeping like a feathered mouse over some stunted tree-trunk, and insinuating his slender, delicately-curved little bill into every chink and crevice of the bark-so busy, so happy, so daintily and innocently destructive! His head, which is as the sentient handle to a very delicate instrument, is moved with such science, such dentistry, that one feels and appreciates each turn of it, and, by sympathy, seems working oneself with a little probing sickle that is seen even when invisible, as is the fine wire or revolving horror in one's tooth, whilst sitting in the dreadful chair. After watching him thus almost, sometimes, bending over him-I have broken off some pieces of bark, to form an idea of what he might be getting. A minute spider and a small chrysalis or two would be revealed, but there were, generally, many cocoon-webs of larger hybernating spiders, whilst empty pupa shells and other such debris suggested "pasture" sufficient to "lard" many 
"rother's sides." And again I wonder why there are not more professional tree-creepers, why countries so rich and defenceless are not more invaded, in the name of something or other high-sounding-evolution will here serve the turn. But, in spite of this abundance, the tree-creeper does not quite confine himself to searching the bark of trees, for I have seen him, on one occasion, dart suddenly out and catch a fly, or other insect, in the air, returning immediately afterwards to his tree again. To my surprise, I cannot find this in my notes, but, as my memory is quite clear upon the point, I mention it. This is another method of procuring food, which, as an occasional practice, is widely disseminated amongst our smaller birds, and here again one wonders why it has only become a fixed habit with the fly-catcher. However, I have seen a male chaffinch dash from the bank of a river and catch may-flies in mid-stream, sometimes a little and sometimes only just above the surface of the water, several times in succession, so that, in this case also, we see the possible beginnings of another species.

I have forgotten to admire the tree-creeper - I mean as a thing of beauty. To do so is a very refined sensation, he is so neutral-tinted and halfshady. One is an æsthete for the time, but the next blue-tit dethrones one, for one has to admire him too, and he, with his briskness and his Christian name of Tom, is hardly zsthetic. The hardiness of these little creatures - I am speaking here of the tits, but to both it would apply-is wonderful-quite wonderful. They are downy iron, soft little colour-flakes of nature's very hardest material. It is now - for 
I select a striking example-the most atrocious weather, a howling wind, and sleet or sleety snow that seems, as it falls, to thaw and freeze upon one's hands, both at the same time. Later it becomes almost a storm, with more snow. It is, indeed, a day terrible to bird and beast in the general, as well as to man, yet, through it all, these tiny little bits of natural feather-work are feeding on the small February buds of some elms that roar in the wind. Wonderful it is to see them blown and swayed about, with the snow-flakes whirling about them, as they hang high up from the extremities of slender twigs, playing their little life-part (as important in the sum of things as Napoleon's) with absolute ease and wellbeing, whilst one is almost frozen to look at them. One must think of Shakespeare's lines about "the wet shipboy in a night so rude," but what a poor mollycoddle was he by comparison! Later they will sleep - these robust little feathered Ariels - to the tempest's lullaby, above a world all snow, and with frozen snow the whole way up the trunk of every unprotected tree, on the windward side. Now it is dinner, with appetite and entire comfort "in the cauld blast."

What insects are in these tiny little new buds, or are there insects in each one?-for these tits browse from one to another and seem equally satisfied with all. Yet it is authoritatively stated that they eat only the insects in buds, and not the buds themselves. In watching birds, however, as in other things, one should be guided by a few simple rules, and one of the most important of these is absolutely to ignore all statements whatever, without the smallest regard 
to authority. Everything should be new to you; there should be no such thing as a fact till you have discovered it. Note down everything as a discovery, and never mind who knew it-or knew that it was not so-before. You may be wrong, of course. So may the authority. But what makes authority in a matter of observation?

To me it certainly seemed that these tits ate the elm-buds. At any rate, I have broken a spray off a low bough where I had seen one feeding, and taken it home. On examining it I found many a little bare stalk where buds had been, which suggests that they had been eaten and not merely pecked at. I tried several of these little buds (it was in February) myself, and found them very nice and delicate. Later, in April, I have noted down:

"The buds being now larger, I can see the birds pecking and tugging at them more plainly, and now and then a minute bud-leaf flutters to the ground. I certainly think it is the buds themselves they are attacking, for their own sake." As blue-tits feed at the stacks-certainly not on insects-and eat cocoanuts, Brazil-nuts, horse-chestnuts (I believe), meat, and, in fact, almost everything, it would be strange indeed if they neglected such a rich pasture-ground as the buds of trees would yield them, or if they did not care about them. On such a day as I have described, one can understand them feeding hour after hour, and making themselves rotund on the tiny little buds themselves, but hardly on insects contained in them.

The bullinch, at any rate, is known to be a budeater, and he may often be seen feeding on the elms, in company with the blue-tit, and, to all appearance 
in just the same way. It is marvellous what slender little twigs this bird will perch on, without their giving way beneath his round burly form. Sometimes they do give way, and then he swings about on them like a ball at the end of a piece of string, nor does he get off on to another one without a good deal of turmoil, and some climbing, which cannot be called quite fairylike. In fact, he is awkward-but in the most graceful manner imaginable. Harpagon, as we know, "avait grace a tousser," and when a bird like the bullfinch condescends, for a moment, to be awkward, his charm is merely enhanced. Yet I cannot call him deft in the procurement of buds, as the blue-tit is, with whom he comes into competition, and whom he will drive away. He does not hang nibbling at them head downwards, as though to the manner born, and then swing up again on a twig-trapeze. These things, if not beyond him, are, at least, alien to his disposition, which is straightforward, and to his deportment, which has a certain sobriety. His plan, therefore, is to advance along the twig as far as it seems to him advisable to go, and then, stretching forward and elongating his neck, take a sharp bite at the bud, which, with his powerful bill, secures it at onceunless he fails. In the same way, he will stretch out from the twig he is on, to secure the bud on another, but this he does still more cautiously. At the bluetit, when feeding on the same tree, he will sometimes make little dashes, driving him away. He has, in fact, just done so (only in this instance it was the hen bird) three times in succession. And now a fourth time has this hen bullfinch made a dash at the blue-tit. The tit, each time, flutters away easily, and without 
making any fuss about it. He is insulted, but he does not wish to make a scene. Besides, he is smaller.

The catkins, too, are now hanging on the alders, and on these also, or-if any one prefers it-on the insects in them, the blue-tits feed. They, I think, prefer the catkins, but I will not be sure.

Whenever practicable they grasp a catkin with one claw, and the twig from which it hangs, and which is their main support, with the other. Often, however, they grasp catkin and twig together with both claws, and, standing thus, peck down upon them like ("parva si magnis licet comparare") a crow or hawk upon some dead or living creature. Or, again, they will hang head downwards from, and pecking at, a bunch of the catkins, without any more substantial support, or, with one claw grasping one twig, will, with the other, hold a catkin belonging to another twig up to the beak, like a parrot. The claws of tits are evidently of high value as seizers and holders, if not quite as "pickers and stealers." They are much more than mere rivets for fixing themselves on a perch. To see one of these little birds, whilst straddled in this way, pull the catkin towards it, is most interesting and very pretty. The little legs are so thin and delicate that one must be very close or get a very steady look through the glasses, both to see, and, at the same time, distinguish them from the twigs.

The coal-tit is even more parrot or, rather, squirrellike, and one can make out his actions better, for he sits upright - one may almost say - on the ground beneath a fir-tree, supporting himself with his tail and one claw, whilst the other grasps a fir-cone at which he pecks. At least I think it was a fir-cone, and I 
afterwards picked up several which were marked with little pits round the base, where it had joined the stalk, difficult to attribute to squirrels, and suggesting that the birds had severed them in this way, and not yet proceeded farther.

If the coal-tit does this, then it seems likely that the great-tit does so also, in which case his extracting the seeds from the larger cones of exotic firs would be only what one might expect. The coal-tit, too, ascends the trunks of trees - Scotch fir-trees especially - in the same fluttering way as does the blue-tit, but perhaps still more deftly, in search of insects, and often, as one watches him, a flake of the bark that he has detached comes fluttering down. The golden-crested wren may do the same, but I have been more struck by the way in which this little bird flies about amidst the pine-trees, from one needle-bunch to another. He hangs from them head downwards, but often, before clinging amongst them, flutters just above or, sometimes, just below them. In the latter case it seems as though the needles were flowers, and that he was probing them with his bill, whilst hanging in the air like a hummingbird; and this, amidst the dark pines and, especially, on a gloomy winter's day, is odd to see. Often he flits down from his pine-needles into the coarse, tufty grass just bounding the plantation, bustles and fairyfusses there for a little, then is up again amongst his needles, pecking the frost from them. For this is what it looks like, that seems to be the meal he is making, though, surely, it must really be something more substantial-if "meal" and "substantial" are words that can be properly used in respect of a 
being so tiny and delicate. However, he seems busily examining the pine-needles, and this may be either for minute insects upon them, or for the very small buds which they bear. It is pleasant to watch these little birds, and to hear their little needley note of "tzee, tzee, tzee." Sometimes, however-but this is more as spring comes on-they will fly excitedly about amidst the trees and bushes, uttering quite a loud, chattering note-far louder than one could have expected from the size of the bird.

Returning to our blue-tits on their alder-tree; they have all flown into it-being a band of about twenty -from a small hawthorn-tree a few paces off. Excepting for some lichen here and there on its branches, this hawthorn-tree is bare, and the birds seem far more occupied in preening themselves, and in giving every now and again the little birdy wipe of the bill first on one side and then another of a twig or bough, than in any serious "guttling." For this they fly to the alder, where, at once, they are feeding busily. But I notice that every now and again some few of them fly back into the hawthorn, where they sit, a little, preening themselves as before, before returning. In fact, they use the hawthorn-tree as their tiringroom, whilst the alder is the great banqueting-hall. Once or twice-I think it was twice-I saw one dart at another and drive it from its particular catkin. As they had a whole large tree to themselves, this, I think, was pretty good.

But I have never seen the blue-tit behave so prettily and airily with its catkins, as I have the little willow-warbler in April. These little birds are then constantly pursuing each other about through 
the trees, and especially the birch-trees, for which they seem to have a decided preference, perhaps

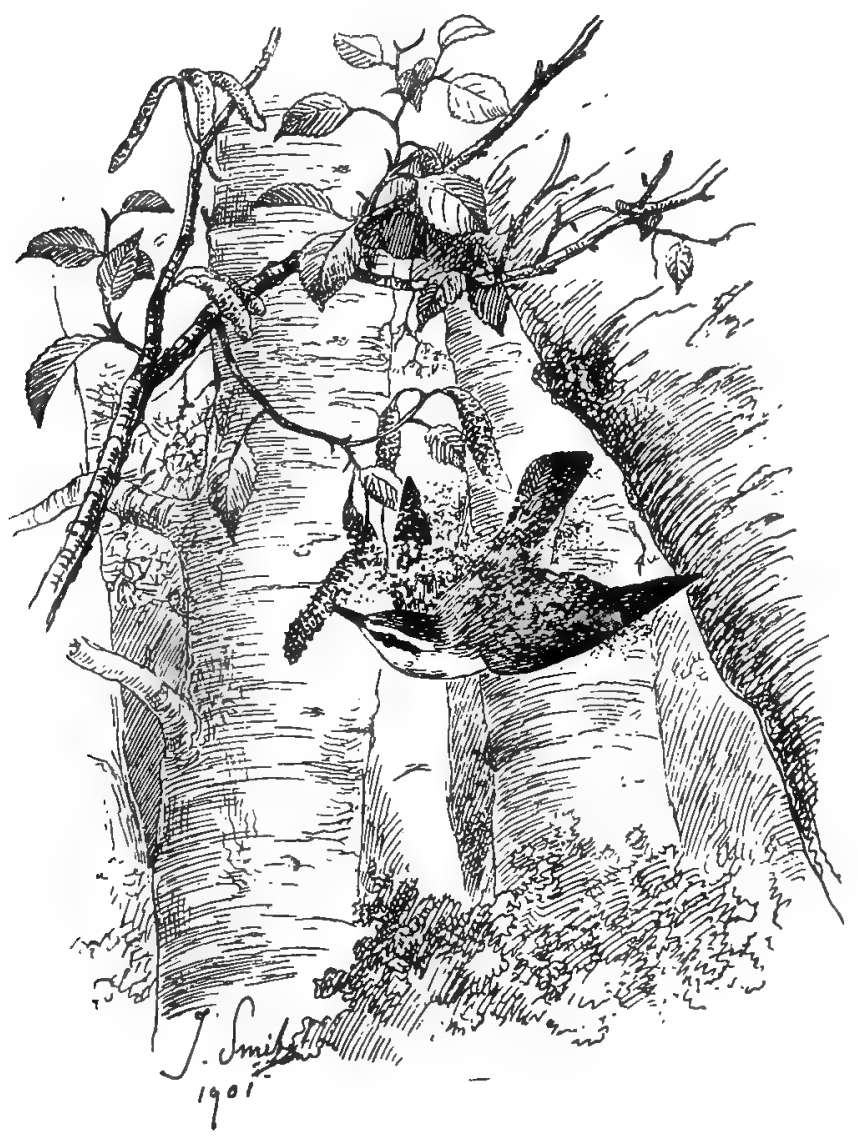

Fairy Artillery

because they make a fairy setting for their fairy selves. They affect its catkins, and one of the most 
pleasing of things is to see them shoot through the yet thin veil of green, give a flying peck at one, and become immediately enveloped in a little yellow cloud of the pollen. It looks, indeed, as if the bird had shaken it from its own feathers, for its intimate actions are too quick and small to be followed, and the pollen is all around it. But as the eye marks the tiny explosion with delight, reason, quickly following, as delightedly tells you the why of it, and a plucked catkin illustrates.

This is all in the early fresh morning, when the earth is like a dew-bath and all the influences so lovely that one wonders how $\sin$ and sorrow can have entered into such a world. It seems as though nature must be at her fairest for so fairy a thing to be done. I, at least, have not seen it take place later, and I cannot help hoping that no one else will.

But why do the little birds explode their catkins? Do their sharp eyes, each time, see an insect upon them, or do they really enjoy the thing for its own sake? I can see no reason why this latter should not be the case, or, even if it is not so to any great degree now, why it should not come to be so in time. It must be exciting, surely, this sudden little puff of yellow pollen-smoke, and then there is the fairy-like beauty of it. There was much laughter, naturally, when Darwin propounded the theory that birds could admire, and when he instanced the bowerbirds, and, particularly, one that makes itself an attractive little flower-garden, removing the blossoms as soon as they fade, and replacing them with fresh ones, it was held that such cases as these were decisive 
against his views. Gradually, however, it began to be seen that they pointed rather in the opposite direction, and now it is recognised that Darwin was right. This being so, it does not appear to me absolutely necessary to suppose that when the little wood-warbler flies at his catkin and produces one of the prettiest little effects imaginable, he does so always merely to get a fly or a gnat. There are other possibilities, and I think that if our common birds were minutely and patiently watched, we might trace here and there in their actions the beginnings of some of those more wonderful ones, which obtain amongst birds far away.

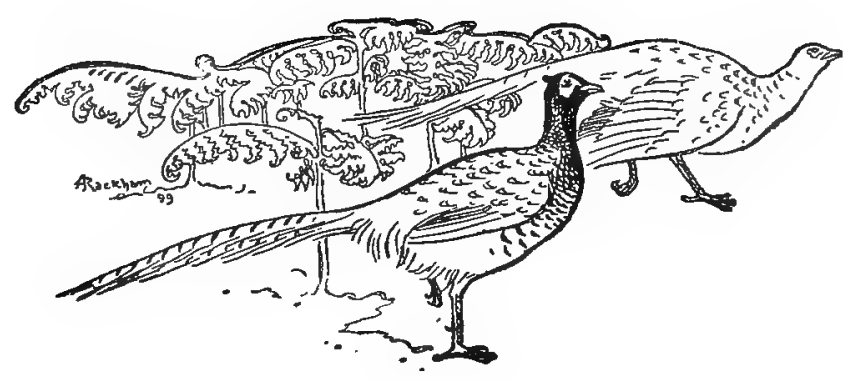




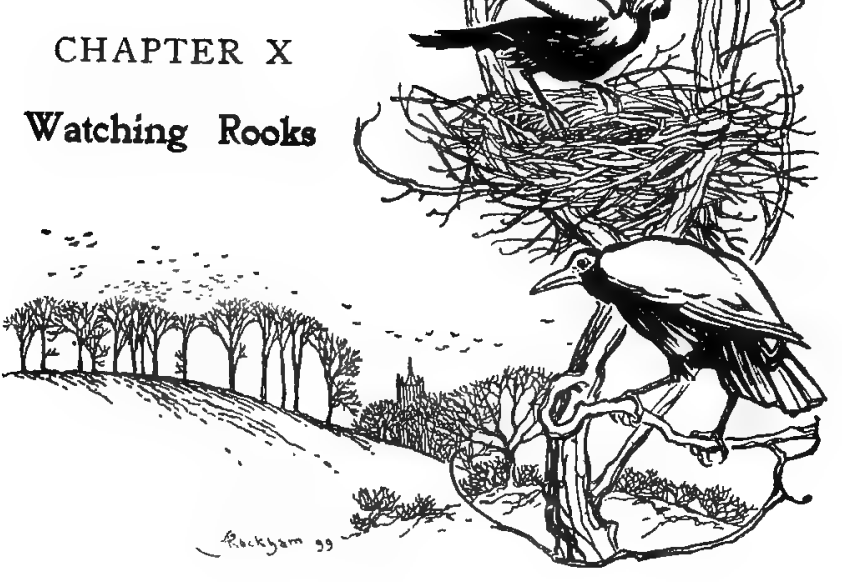

IN this chapter I will give a few scenes from rook life, as I have watched it from late autumn to early spring, linking them together by a remark now and again of a general nature, or, possibly, some theory which my observations may have suggested to me, and seemed to illustrate. Were I to put into general terms what I have jotted down at all times and in all places, in the darkness before morning when the rookery slept about me, in the dim dawn whilst it woke into life, to stream forth, later, on wings of joy and sound, in the long day by field and moor and waste, and at evening again, or night, when the birds swept home and sank to sleep amidst their own sinking lullaby, I might make a smoother narrative, but the picture would be gone. I think it better, therefore, to make a preliminary general apology for all roughnesses and repetitions, triviality of matter, $\mathbf{R}$ 
minuteness of detail and so forth, in fact for all shortcomings, and then to go on in faith, not in myself, indeed, but in the rooks, believing that they will be interesting, however much I may stand in their way.

When I speak of the rookery I do not mean the trees where the birds build - unfortunately there are none very near me-but those where they come to roost during the autumn and winter-true rookeries indeed if numbers count for anything. Here, their chosen resting-place is a silent, lonely plantation of tall funereal firs, standing shaggily tangled together, mournful and sombre, making, when the snow has fallen but lightly-before they are covered-a blotch of very ink upon the surrounding white. Who could think, seeing them during the daytime, so sad and abandoned, so utterly still, tenanted only by a few silentcreeping tits, or some squirrel, whose pertness amidst their gloomy aisles and avenues seems almost an affectation - who could think that each night they were so clothed and mantled with life, that their sadness was all covered up in joy, their silence made a babel of sound? In every one of those dark, swaying, sighing trees, there will be a very crowd of black, noisy, joyous birds, and strange it is that there should be more poetry in all this noise and clamour and bustle than in their sad sombreness, deeply as that speaks to one. The poetry of life is beyond that of death, and when the rooks have gone the dark plantation seems to want its soul. It is Cupid and Psyche, but under dreary, northern skies. Every evening the black, rushing wings come in love and seem to kiss the dark branches, every morn- 
ing they kiss and part, and, between whiles, the poor longing grove stands lifeless, dreams and waits. But how different would it seem if the rooks were a crowd of men - nice, cheery, jovial, picturesque, civilised men! Thank heaven, they are a crowd of rooks!

I will now quote from my journal :

"Walking over some arable land that rises gently into a slight hill, my attention is attracted by a number of rooks hanging in the air, just above a small clump of elm-trees on its crest. They keep alternately rising and falling as they circle over the trees, often perching amongst them, but soon gliding upwards from them again. A very common action is for two to hover, one above another, getting gradually quite close together, when both sinking, one may almost say falling, rapidly, the upper pursues the under one, striking at it-either in jest or earnest, but probably the former -both with beak and claws. The downward plunge would end in a long swoop, first to right or left, and then again upwards, during which the two would become separated and mingled with the general troop. This action, more or less defined and perfect, was continued again and again, and there were generally one or more pairs of birds engaged in it. The rest rose and fell, many together, and obviously enjoying each other's society, but without any special conjunction of two or more in a joint mancuvre. Their descents were often of a rushing nature, and accompanied with such sudden twists and turns as, sometimes, seemed to amount to a complete somersault in the air-though as to this I will not be too certain. The whole seemed the outcome of pure enjoyment, and seen in the clear 
blue sky of this fine bright October morning-the last one of the month-had a charming effect.

"A fortnight later I happened to be near some woods to which rooks were flying from all directions, to roost, as I thought then, but afterwards I found it was only one of their halting places. They were in countless numbers, one great troop after another flying up from far away over the country. The air was full of their voices, which were of a great variety and modulation, the ordinary harsh (though pleasant) 'caw' being perhaps the least noticeable of all. Each troop flew high, and, on coming within a certain distance of the wood-a fair-sized field away-they suddenly began to swoop down upon it in long sweeping curves or slants, at the same time uttering a very peculiar burring note, which, though much deeper and essentially rook-like in tone, at once reminded me of the well-known sound made by the nightjar. Imagine a rook trying to 'burr' or 'churr' like a nightjar, and doing it like a rook, and you have it. Whilst making these long downward-slanting swoops the birds would often twist and turn in the air in an astonishing manner, sometimes even, as it seemed to me, turning right over as a peewit does, in fact, exhibiting powers of flight far beyond what anyone would imagine rooks to possess, who had only seen or noticed them on ordinary occasions.

"Whilst these birds sweep down into the trees others of them settle on the adjoining meadow-land, but they do not descend upon it in the same way, but more steadily, though still with many a twist and turn and whirring, whizzing evolution. Neither do they utter the strange burring note to which I have called atten- 
tion, and which is a very striking sound. Starlings are mingled with these latter birds, flying amongst them, yet in their own bands, and alighting with them on the meadow, where they continue to form an imperium in imperio. Both they and the rooks descend at one point, in a black or brown patch, but soon spread out over the whole meadow, from which they often rise up in a cloud, and, after flying about over it for a little, come down upon it again. At last a vast flock of starlings-numbering, I should think, many thousands-flies up, and, being joined by all those that were on the field, the whole descend upon the woods, through which they disseminate themselves. Almost immediately afterwards, the rooks, as though taking the starlings for their guide, rise too, and fly all together to the woods. Now comes a troop of some eighty rooks, and, shortly afterwards, another much larger one - two or three hundred at the least - all flying high, and going steadily onwards in one uniform direction. They are all uttering a note which is difficult to describe, and does not at all resemble the ordinary 'caw.' It has more the character of a chirrup, loud in proportion to the size of the bird, but still a chirrup-or chirruppy. There is great flexibility in the sound, which has a curious rise at the end. It seems to express satisfaction and enjoyable social feeling, and, if so, is very expressive. One feels, indeed, that every note uttered by rooks is expressive, and if one does not always quite know what it expresses that is one's own fault, or, at any rate, not theirs.

"Twenty more now pass, then twenty-seven, and, finally, another large body of some two to three hundred-all flying in the same direction. It is the last 
flight, and, shortly afterwards, the loud harsh trumpeting of pheasants is heard in all the woods and coverts around, as they prepare to fly up into their own roosting trees. This dove-tailing of two accustomed things in the daily life of rooks and pheasants I have often noticed, but it must be mere coincidence, for pheasants vary in their hours of retirement, whilst the leisurely homeward journeying of rooks, with pauses longer or shorter at one place or another, occupies, in winter, most of the afternoon.

"November 27th.-By the river, this afternoon, I noticed two great assemblages of rooks down on the meadow-land, whilst others, in large numbers, were flying en route homewards. Of these, two would often act in the way $I$ have before described - that is to say, whilst flying the one just over the other with very little space between them, both would sink suddenly and swiftly down, the upper following the under one, and both keeping for some time the same relative position. But besides this, two birds would often pursue each other downwards in a different way, descending with wide sideway sweeps through the air, from one side to another, after the manner of a parachute, the wings being all the while outstretched and motionless. In either case the pursuit was never persisted in for long, and obviously it was no more than a sport or an evolution requiring the concurrence of two birds.

"Again, two will sweep along near together, at slightly different altitudes, with the wings outspread in the same way-that is to say, not flapping. Then first one and afterwards the other gives a sharp wriggling twist, seeming to lose its balance for a moment, rights itself 
again, and continues to sweep on as before. Then another wriggle, a further sweep, and so on."

Since seeing the curious manner in which ravens roll over in the air-as described by me-I have watched the aerial gambols, as one may almost call them, of rooks more closely. There is a certain place, not far from where I live, where these birds make an aerial pause in their homeward flight; for, whilst many are to be seen settled in some lofty trees of a fine open park, others sail round and round in wide circles and high in the air, over a wide expanse of water in the midst of it. After wheeling thus for some time, first one and then another will descend on spread wings, very swiftly, and with all sorts of whizzes, half-turns or tumbles, and parachute-like motions. When watched closely through the glasses, however, it may be seen that, very often, these rushing descents have their origin in an action, or, rather, an attempted action, very much like that of the raven. The idea of the latter bird is to roll over, so as to be on its back in the air, and, by closing its wings, it is able to achieve this without, or with hardly, any drop from the elevation at which it has been flying. The rooks seem to try to do this too, but instead of closing the wings, they keep them spread, as open, or almost so, as before. Consequently, instead of just rolling over, their turn or roll to either side sends them skimming sideways, down through the air, like a kitea paper one, I mean. Peewits close the wings and roll over in much the same way as does the raven, but this is generally either preceded, or followed, by a tremendous drop through the air, with wings more or less extended, so that the whole has quite a different effect. 
"Of the two assemblies on the ground, one is in perpetual motion, birds constantly rising-either singly, in twos or threes, or in small parties-from where they were, flying a little way just above the heads of their fellows, and re-settling amongst them again. Thus no individual bird, as it seems to me, remains where it was for long, though those in the air, at any given moment, form but a small minority, compared with the main body on the ground.

"But the birds composing the other great assemblage keep their places, or, if some few rise to change them, these are not enough to give character to the whole, or even to attract attention. It is curious to see two such great bodies of birds close to each other, and on the same uniform pasture-land, yet behaving so differently, the one so still, the other in such constant activity.

"About 4 P.M. a great number of rooks rise from some trees in a small covert near by, and fly towards those on the ground. As they approach the first great body-which is the lively one-the birds composing it rise up, as with one accord, and fly, not to meet them, as one might have expected, but in the same direction as they are flying. So nicely timed, however, is the movement, that the rising body become, in a moment, the vanguard of the now combined troop.

"All these birds then fly together to the other assembly, and whilst about half of their number sweep down to reinforce it, the other half continue to fly on. The flying rooks, however, are not joined by any of those on the ground. How curious it is that, in the first instance, the one whole body of birds 
does the same thing instantaneously, and as by a common impulse, whilst in the second, half acts in one way, and half in another, each appearing to have no doubt or hesitation as to what it ought to do! Again, how different is the conduct of the two fieldassemblages. One rises, as with one thought, to join the flying birds. The other, as with one thought, remains standing. Unless, in each case, some signal of command has been given, then what a strange community of feeling in opposite directions is here shown. Where is the individuality that one would expect, and what is the power that binds all the units together?

"Are rooks led by an old and experienced bird? -which is, I believe, the popular impression, as embodied in a famous line of Tennyson, for which one feels inclined to fight. At first sight, the rising of a whole body of rooks (or any other birds) simultaneously, either from the ground or a tree, might seem to be most easily explained on the theory of one bird, recognised as the chief of the band, having in some manner-either by a cry or by its own flight - given a signal, which was instantly obeyed by the rest. But how-in the case of rooks-can any one note be heard by all amidst such a babel as there often is, and how can every bird in a band of some hundreds (or even some scores) have its eyes constantly fixed on some particular one amongst them, that ought, indeed, on ordinary physical and mechanical principles, to be invisible to the greater number? If, however, to meet this latter difficulty, we suppose that only a certain number of birds, who are in close proximity to the leader, see and obey the 
signal, and that these are followed by those nearest to them, and so on till the whole are in motion, then two other difficulties arise, neither of which seems easy to get over. For, in the first place, the birds do not, in many cases, appear to rise in this manner, but, as in the instances here given, simultaneously, or, at least, with a nearer approach to it than any process of spreading, such as here supposed, would seem to admit of; and secondly, it is difficult to understand how, if this were the case, any bird-or, at least, any few birds-could fly up without putting all the others in motion. Yet, as I have mentioned, birds in twos or threes, or in small parties, were constantly rising and flying from one place to another in the assemblage of which they formed a part, whilst the vast majority remained where they were, on the ground. This fact offers an equal or a still greater difficulty, if, dismissing the idea of there being a recognised leader, we suppose that any bird may, for the moment, become one by taking the initiative of flight, or otherwise. And even if we assume that any of these explanations is the correct one, in the case of a whole body of rooks taking sudden flight, or directing their flight to any particular place, or with any special purpose, what are we to think when half, or a certain number of the band does one thing, and the other half another, each, apparently, with equal spontaneity? We are met here with the same difficulties-and perhaps in a still higher degree-as in the case of the flocks of small birds at the stacks in winter.

"If rooks follow and obey a leader, one might expect them to do so habitually, at least in their 
more important matters. The flight out from the roosting-trees in the morning, and the flight into them again at night are-when it is not the breedingseason - the two daily 'events' of a rook's life. Here, then, are two subjects for special observation.

"November 30 th. -At 3 P.M. I take up my position on the edge of a little fir-plantation, a short distance from where I watched yesterday and the last few days. My object is to watch the flights of rooks as they pass, and try to settle if each band has a recognised leader or not. Of course it is obvious that no one bird can lead the various bands, for these come from over a large tract of country, whilst even those that seem most to make one general army, fly, often at considerable intervals of time, and quite out of sight of each other.

"A good many are already flying in the accustomed direction, but singly, or wide apart. Each bird seems to be entirely independent.

"The first band now approaches. One rook is much in advance for some distance. He then deviates, and is passed by the greater number of the others, who continue on their way without regard to him.

"Another great, irregular, straggling body in which I can discern no sign whatever of leadership. Then comes another, more compact. A rook that at first leads by a long interval is passed by first one and then another, so that he becomes one of the general body.

"A large band, flying very high. Two birds fly nearly parallel, at some distance ahead.

"Two large bands, also very high. In each, one bird is a good way ahead. The apparent leader of 
the second band increases his distance, curves a good deal out of the line originally pursued, nor do the others alter their course in accordance.

"Two other bands. In each the leader theory seems untenable. The birds have a broadly extended front, and fly at different elevations. There is nothing that suggests concerted movement, but, on the contrary, great irregularity.

"In another band the apparent leader swoops down to the ground, and, whilst only half-a-dozen or so follow him, the main body proceeds on its way.

"Hitherto there has been a good deal of the familiar cawing noise, but, now, a number of birds fly joyously up, hang floating in the air, make twists and tumbles, perform antics and evolutions, and descend upon the ground with wide parachute-like swoops from side to side, the wings outspread and without a flap. I am first made aware of their approach by the complete change of note. It is now the flexible, croodling, upturned note - rising at the end, I mean - that I know not how to describe, totally different from the 'caw, nor do I hear a 'caw' from any of these descending birds. It is the note of joy and sport, of joyous sport in the air, of antics there as they sweep joyously down through it, that I now hear. The birds that caw are flying steadily and soberly by. The 'caw' is the steady jog-trot note of the day's daily toil and business-'Jog on, jog on, the footpath way.'

"Another great band, of such length and straggling formation that the birds in the latter part of it could not possibly see the leader if there were one-or indeed, I should think, the vanguard at all. The 
first bird is passed by two others, then passes one of these again, and remains the second as long as I can see them.

"Another long flight that seems leaderless. With the 'caw' comes a note like ' chug-a, chug-a, chug-a' (but the $u$ more as in Spanish), and others that I cannot transcribe. This flight goes on almost continuously-I mean without a distinct gap dividing it from another band-for about ten minutes, when another great multitude appears, flying at an immense height and all abreast, as it were - that is to say, a hundred or so in a long line of only a few birds deep. This, perhaps, would be the formation best adapted for observing and following one bird that flew well in front, but I can see no such one. All these birds are sailing calmly and serenely along, giving only now and again an occasional stroke or two with the wings. Now comes a further great assembly, in loose order, all flying in the same direction. A characteristic of these large flights of rooks is that their van will often pause in the air and then wheel back, circling out to either side. The rearguard is thus checked in its advance, the birds of either section streaming through each other, till the whole body, after circling and hanging in the air for a little, like a black eddying snowstorm (all at a great height), wend on again in the same direction, towards their distant roosting-place. With the air full of the voice of the birds, there is no cawonly the flexible, croodling, chirruppy note that has a good deal of music in it, as well as of expression. This note, I think, is what I have put down as ' chug-a, chug-a, chug-a.' 
"There is now a continuous straggling stream, forming ever so many little troops. The first bird of one troop tends to become the last of the one preceding it, and the last one the leader of the troop following. Then come numbers, flying in a very irregular and widely disseminated formation, yet together in a certain sense. There is much of rising and sinking and again floating upwards, of twists and twirls and sudden, dashing swoops downwards, from side to side, like the car of a falling balloon; two birds often pursuing each other in this way.

"And now come two great bands, one flying all abreast, as before described, the other forming a great, irregular, quasi-circular rook-storm. Leadership in the latter case would be an impossibility; in the former I see no sign of it. All these birds, though at a fair height, are flapping steadily along in the usual prosaical manner; through them, and far above -at a very great height indeed, the highest I have yet seen, and far beyond anything I should have imagined - I see another band gliding smoothly, majestically on, with scarce an occasional stroke of the eagle-spread pinions. The one black band of birds seen through the others, far, far above them, has a curious, an inspiring effect."

Rooks, when in continued progress, either fly with a constant, steady flapping of the wings, in a somewhat laboured way, though often fairly fast, or they sail along with wings outspread, and flapping only from time to time - this last, however, only when they are at a considerable height. A crowd of rooks, indeed, in the higher regions of air present a very different appearance to what they do when they fly 
about the fields, even though at a fair height above the trees; their powers of flight in each case seem of a very different kind. They can also soar to some extent, rising higher and higher on outspread wings as they sweep round and round in irregular circles - like gulls, but far less perfectly, and they have to flap the wings more often. Add to this their downward-rushing swoops, their twists, turns, tumbles, zig-zaggings, and all manner of erratic aerial evolutions, and it must be conceded that the powers of flight which they possess are beyond those with which we generally associate them in our mind.

Seen thus, trooping homewards, in all their many moods and veins,

"Whether they take Cervantes' serious air,

Or laugh and shake in Rabelais' easy-chair,"

their flight, combined with their multitude, is full of effects. To-day their widely extended bands were often, like so many black snowstorms filling a great part of the sky. But at no time did I see anything resembling leadership. "The many wintered crow that leads the clanging rookery home" is-a lovely line. On no other occasion could I make out that rooks obeyed or followed any recognised leader, and I came to a similar negative conclusion in regard to the question of their employment of sentinels. It is asserted in various works - for instance, in the latest edition of Chambers's "Encyclopedia"-that they do post sentinels. I will give two instances of their not doing so-as I concluded-and my experience was the same on other occasions, which I did not think it worth while to note. 
"December 22nd.-To-day, I saw a number of rooks blackening a heap of straw by a stack, whilst some were on the stack itself. Many were sitting in some elms near about, but they did not appear to me to be acting the part of sentinels. When I tried to get up to the hedge in order to watch the rooks at the stack, through it, they flew off, a good deal later than their friends in the trees must have seen me, and not till I was quite near. If these had really been sentinels, they should have warned the rest, either the instant they saw me, or at any rate, when I was obviously approaching, but this they did not do. They were, therefore, either not sentinels or inefficient ones." The second case, however, is more conclusive.

"January 8th.-To-day, on my way down to the roosting-place, I pass a number of rooks feeding in a field, and not far from the road. They are all more or less together, there are no outposts, though of course there is, of necessity, an outer edge to the flock. But neither on the hedge or in any of the trees near, are there any birds to be seen. On the other side of the field, however, and a very considerable way off, a few are sitting in some trees. It hardly seems possible that these can act the part of sentinels at such a distance, and even if they were much nearer, the feeding rooks would have either to be looking at them, to see when they flew, or else, the alarm must be given by a very loud warning note. Bearing this in mind, I alight from my cycle, and walk along the road. The rooks, without any dependence on sentinels far or near, note the fact, bear a wary eye, but continue feeding. I then stop-always an alarming measure with birds. The feeding rooks fly off to a safer distance, the ones 
in the trees remain there as silent as ever, nor is there any special note uttered by any one bird of the flock, nor anything else whatever to suggest that any particular bird or birds is acting the part of sentinel." There is certainly no sentinel in this case, and in matters directly affecting their safety one might suppose that rooks, as well as other birds and beasts, would act in a uniform manner. This, however, we can clearly see, that when there happen to be trees, near where they are feeding, some of them will usually, and quite naturally, be perched in them, and average human observation and inference may have done the rest.

Rooks, I am inclined to think, are not birds that give their conscience into keeping. Each one of them is his own sentinel.

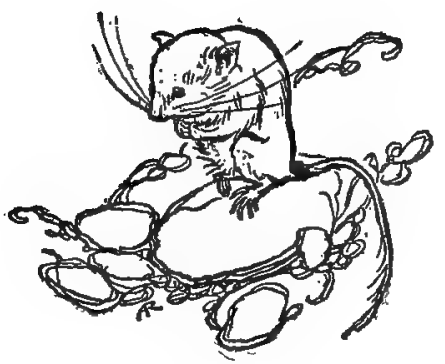




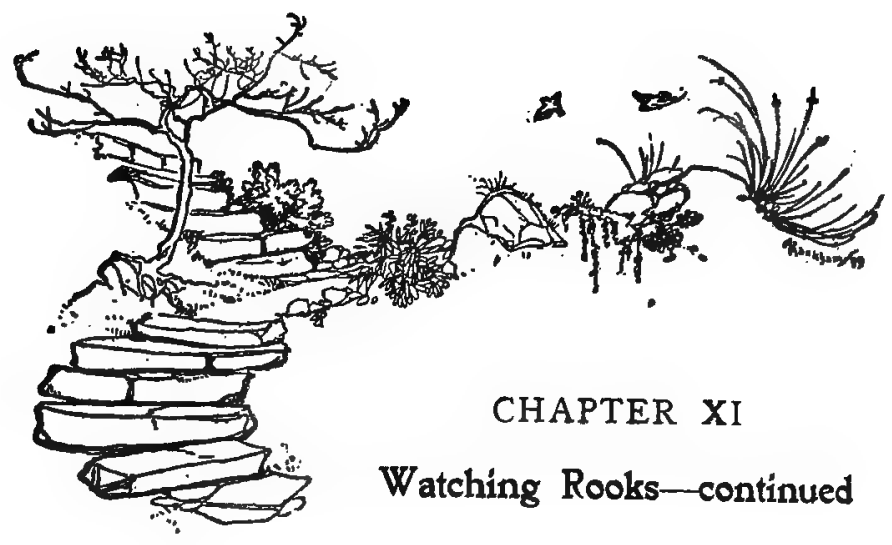

CONTINUING my journal, I will now give extracts which illustrate, principally, the return home of the rooks at night and their flying forth in the morningthose two aspects of their daily winter life which are the most full, perhaps, both of interest and of poetry.

"December 9 th. - This afternoon at about $3.30 \mathrm{I}$ find vast numbers of rooks gathered together on a wide sweep of land, close to their roosting-place.

"Even now-and they are being constantly reinforced-they must amount to very many thousands, and cover several acres, in some parts standing thickly together, in others being more spread out. There is an extraordinary babble of sound, a chattering note and the flexible, croodling one being conspicuous. Combats are frequent-any two birds seem ready to enter into one at any moment-and they commence either, apparently, by sudden mutual desire, or else by one bird fixing a quarrel on another, which he does by walking aggressively up to him and daring him, so to speak. In fighting they stand front to front, and then 
spring up at each other-like pheasants, but grappling and pecking in the air as do blackbirds and small birds generally. Sometimes one bird will be worsted in the tussle, and you instantly see it on its back, striking up with claws and beak at the other, who now bestrides it. It is easier to see this result than to be sure as to the process by which it is arrived at-whether, for instance, the overmatched bird falls, willy-nilly, on its back, or purposely throws itself into that position, so as to strike up like a hawk or owl. I think that this last may sometimes be the case, from the very accustomed way in which rooks fight under such circumstances; but, no doubt, it would only be done as a last resource. The rooks, however, do not seem vindictive, and their quarrels, though spirited, are usually soon over. They may end either by the weaker or the less acharné bird retiring, in which case the pursuit is not very sustained or vigorous, or else by both birds, after a short and not very rancorous bout, pausing, appearing to wonder what they could have been thinking about, and so walking away with mutual indifference, real or assumed. Often one bird will decline the combat, and in this case, as far as I can see, it is not molested by the challenger, however bullying and aggressive this one's manner may have been. A rook coming up to another with the curious sideway swing of the body and a general manner which seems to indicate that he thinks himself the stronger of the two, looks a true bully.

"One rook has just found something, and, whilst standing with it in his bill, another comes forward to dispute it with him, but the attack is half-hearted, and seems more like a mere matter of form. After- 
wards, when the same bird has the morsel on the ground in good pick-axeing position, a second rook advances upon him with a quick, sideway hop, looking cunning, sardonic, diabolic, and much for which words seem totally wanting. But this attack, though swift and vigorous, is not more successful than the former one. The lucky rook gets off with his booty, and has soon swallowed it. Amongst rooks, the finding of anything by any one of them is a recognised cause of attack by any other. This is taken as a matter of course by the bird attacked, and if he holds (and swallows) his own, which, as he has a clear advantage, he generally does, no resentment is manifested by him-there is not even a slight coolness after the incident is over. If however, the attack should be successful, then it is very different. The annoyance is too great for the robbed bird, and he becomes very warm indeed. He makes persistent violent rushes after the robber, is most pertinacious, and clearly shows that kind of exasperation which would be felt by a man under similar circumstances. It seems not so much his own loss, as the success and triumphant bearing of the other bird, that upsets him. He has failed where he ought to have been successful, and of this he seems conscious.

"When one rook makes his spring into the air at another, this one will sometimes duck down instead of also springing. The springer, then, like 'vaulting ambition,' 'o'erleaps himself and falls on the other side.' I have just seen this. The rook that bobbed seemed to have scored a point, and to know it, which the other one confessed shamefacedly-no, indescribably, a rook cannot look shame- 
faced. The advantage was not followed up by the successful bird, but the combat ceased, I think, in consequence.

"I now notice a hare a little on the outside of the phalanx of rooks, at the part of it nearest to myself. All at once he makes a little run towards them as if charging them, and sits down, making one of their first line, and almost, as it seems, touching two or three. After sitting here for some while the hare makes another little run, this time right in amongst the rooks, several of which he puts up as though on purpose-each of the birds giving a little jump into the air with raised wings, and coming down again. He then sits down as before, but this time all amongst them. This he repeats several times, making little erratic gallops through the black crowd, in curves to one side and another, and appearing to enjoy the fun of causing rook after rook to jump up from the ground. Half-a-dozen times he runs right at a rook that he might easily have avoided, and sits down amongst them two or three times, again. At last, in a final gallop, he pierces the squadron and continues on, over the land. This certainly appeared to me to show a sense of fun, if not of humour, on the hare's part, and as-with a few noted exceptions -it is the rarest thing to see one species of animal take any notice of another, I was proportionately interested.

"It is now half-past four, and for about an hour the great assemblage has been increased by a perpetual stream of rooks, that sail up and descend into it with joyous wheels and sweeps. For some time, too, flocks of the birds have been flying from the ground into 
trees near. They fly by relays, and from the farthest part of the troop-that is to say, from that part which is farthest distant from the woods where they are to roost. First one band of birds and then another rises from the outer extremity, flies over the rest, ascending gradually, and wings its way to the trees. By these successive flights the assemblage is a good deal shrunk, and does not cover nearly so much ground, when the remainder-still an enormous number-rise like a black snowdrift whirled by the wind into the air, and circle in a dark cloud, now hardly visible in the darkening sky, above the roosting-trees, with a wonderful babel of cries and noise of wings.

"At 4.40 this deep musical sound of innumerable crying, cawing, clamouring throats is still continuing, and once, I think, the birds rise from the trees into which they have sunk, and circle round them again. Now they are in the trees once more, but the lovely cawing murmur - the hum, as though rooks were rooky bees-still goes on.

"4.47.-It is sinking now. Much more subdued and slumberous, deliciously soothing, a rook lullaby.

"December I Ith.-A stern winter's day, the earth lightly snow - covered, but bright and fine in the morning. At 3 P.M. I am where the rooks roost, a plantation of fir-trees-larches-dark, gloomy and sombre, with a path, piercing them like a shaft of light, over-arched with their boughs, silvered now with light snow-wreaths. Just in this gloomy patch they sleep, but with a light belt of smaller firs opposite, or with adjoining woods of oak and beech they will have nothing to do, leaving these latter to the woodpigeons. 


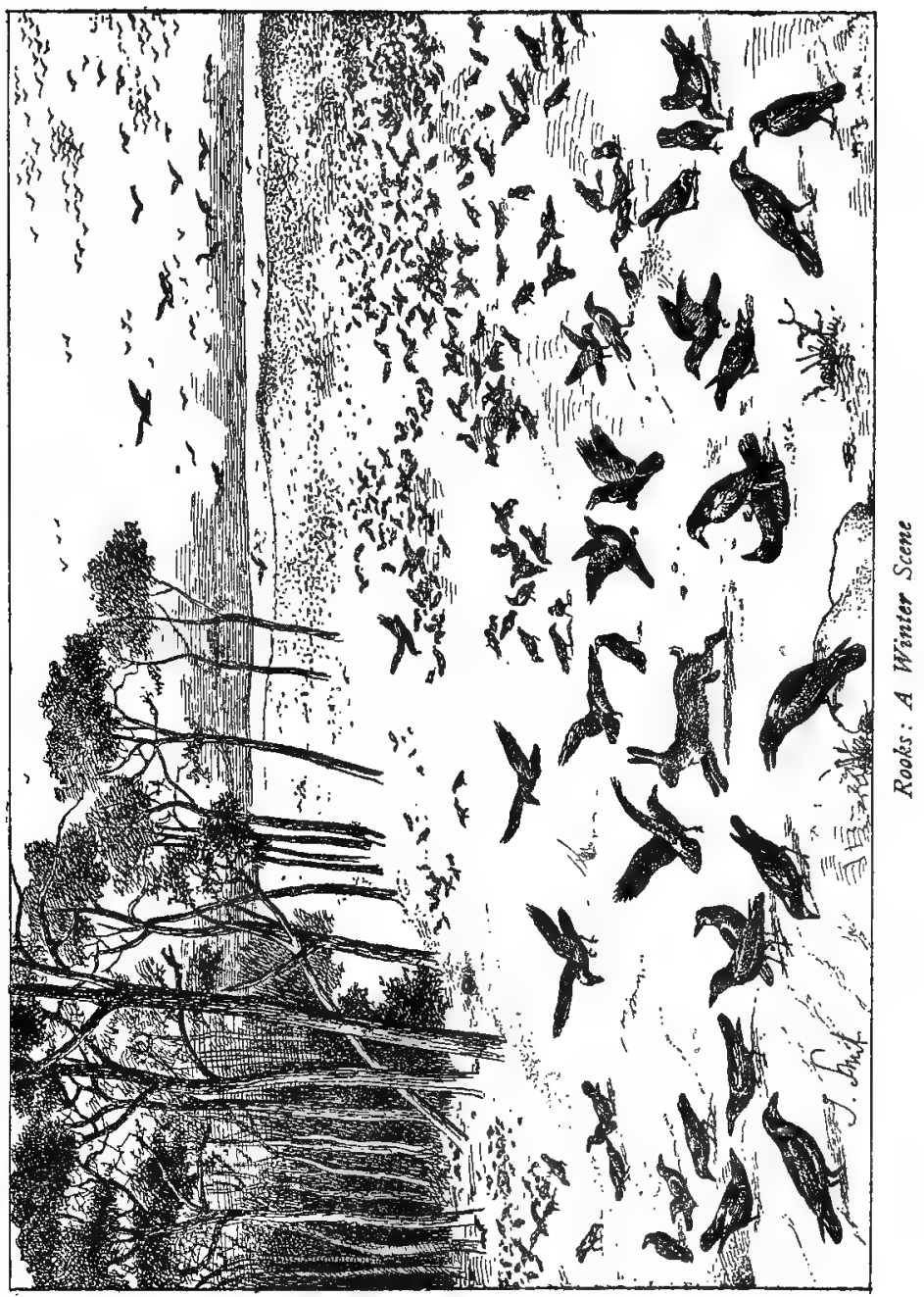


"At 4.30 I leave the woods and find the rooks gathered in the same place as yesterday, but in far less numbers. Shortly, a large band flies up and swoops down with all sorts of turns and twists, and turns right over in the air-a striking sight, the air full of the rushing sound of their wings-a birdstorm, a black descending whirlwind. At 4.35 the rooks all fly from the ground into a small clump of fir-trees near. Great numbers of other ones are flying up and settling in a plantation of small firs, fringing another part of the field, quite filling it. The snow seems to drive them from the ground, their conclave to-day must be held in the trees.

"They are gathering, now, from all parts, filling the trees round about the ploughed land-now all whiteflying in flocks about them, then descending into them again.

"Still coming and coming out of the sunset, specks growing into birds. The stern, snow-covered landscape, the red glow of the sunset, and the black, labouring pinions against it make a fine winter scene.

"4.37.-Back at the larches, and only just in time to stand concealed within them, before the rooks are there. All seem coming, a black, flying multitude. They have reached the larches and fly about over them in wide, sedate circles, coming in relays, as last night. Joyous voices-innumerable multitudesa torrent of wings! All in a broad, rapid, streaming flight to the larches. They sweep, dash, circle and eddy over them, black flashes in the deepening gloom. They sweep into them, and the snow, swept by their 
wings, falls in a drizzle from the branches. Joyous, excited cries, 'chu, chu, chac, chac.' The whole dark grove is a cry, a music. Still other bands, they burden the air. Band after band-now with a pause between each. They fly swiftly and steadily up, at a not much greater height than the trees, not descending into them out of the sky.

"A longer pause, followed by another hurrying band. And now the moon is shining through the larches, and the black, ceaseless pinions go hurrying across its face. Groans, moans, shrieks almost, yells amongst the larches, all mingled and blending-but sinking now. A marvellous medley, a wonderful hoarse harmony! Here are shoutings of triumph, chatterings of joy, deep trills of contentment, hoarse yells of derision, deep guttural indignations, moanings, groanings, tauntings, remonstrances, clicks, squeaks, sobs, cachinnations, and the whole a most musical murmur. Loud, but a murmur, a wild, noisy, clamorous murmur; but sinking now, softening-a lullaby.

\section{'I never heard}

So musical a discord, such sweet thunder."

When the rooks sweep down, thus, into their roosting-trees they frequently do so with a peculiar whirring or whizzing noise of the wings, but although this sound is in perfect consonance with the motion which it accompanies-insomuch that one has to use the same words to describe each-yet it does not seem to be produced by it. At least, it bears no relation to the height from which the birds swoop, nor-as would seem to follow from this-with the 
impetus of the descent. It may be a matter of impetus, but to me it has often seemed more as though the sound gave the idea of impetus, or added to it, and that the sweeps were, sometimes, just as impetuous, or even more so, when made without it. As I observed, the birds flew to their trees at a very moderate height-not very much, indeed, above the trees themselves-and, whilst many made the whizzing sound, the great majority swooped down without it. It seems, therefore, to be a special sound produced by the rooks at pleasure, and always accompanying an excited frame of mind. First one bird and then another gets excited, and dashes suddenly down with the whirring or whizzing noise, so that, as the sound is not vocal, and is only heard upon such occasions, it has all the appearance of being caused by the quick, sudden motions of the wings. But it is possible that some particular way of holding the quill-feathers of the wing or even tail is required to produce it, in combination with the general movements, and this would account for its being sometimes heard and sometimes not heard, when these latter are identical.* The curious burring note is likewise, but far less frequently, an accompaniment of these wild excited sweepings, and this is most often the case when they are from a considerable height. Here, again, the note bears a clear relation to the bird's mental state, so that it would appear that the degrees of pleasurable excitement cannot be estimated by the motions alone.

* With regard to the above, however, I am now no longer so sure. Je me'en doute. When the rooks descend from a height, the sound made is often most remarkable, being that of a mighty rushing wind filling the air. 
The "burr," in my opinion, when well and loudly uttered-for here, again, there is much variety-marks the maximum of a rook's content, at any rate in a certain direction.

"December 15th.-At 7 A.M. I am at the point of the road nearest to the rookery, and I hear the sweet jangle, 'the musical confusion,' already beginning. Not much, however - subdued and occasional - influenced, perhaps, by the heavy morning mist that hangs over trees and earth. After a time I walk to an oak just outside the plantation, and sit listening to the rising hubbub-now rising, now falling. A sad, mist-hung morning, the earth lightly snow-decked; raw and chill, but not so frostily, bitingly cold as yesterday and before. The general intonation of the rook voice is pleasing and musical-how much more so than the roar of an at-home as the door is flung open, even though one has not to go through that door! There is very great modulation and flexibility -more expression, more of a real voice than other birds. One feels that beings producing such sounds must be intelligent and have amiable qualities. One of the prettiest babbles in nature!

"One catches 'qnook, qnook,' ' chuggerrer,' 'choooo-oo.' At intervals the single, sudden squawk, or continued trumpeting, of a pheasant, breaks abruptly into the sea of sound, then mingles with it. Every now and again, too, there is a sudden increase of sound, which again sinks.

"At 7.50 the rooks are still in bed, but a pheasant -a fine cavalier - comes running towards me over the snow. $\mathrm{He}$ makes a long and very fast run for some fifty yards or so, then stops and draws himself 
bolt upright, seeming to stand on tip-toe. More than upright he is-bent back, trying to look like a soldier, but obliged to be graceful and elegant. Standing thus, he seems on the very point of trumpeting, yet does not, and then runs on again. He repeats this, several times, each time thinking of trumpeting, but desisting and going on.

"At 7.58 the flight out commences. Two or three birds are a little in front, none very prominently so, and others are catching them up and seem just on the point of passing them when they are lost to me in the mist. There is nothing suggesting a leader. If they were led it was not by one of themselves, for with them and in their very fore-front two little birds were flying, who passed with them out of sight. They were tits, I think, and in another flight out, after one of the pauses-for the rooks fly out by relays, like the starlings-I noticed one other, all three, I believe, being parus cceruleus. There are quite a number of tits in the plantation and woods adjoining, but why just three should leave it and go flying with the rooks through the mist, over the open country, if not for the mere joy and fun of the thing, I know not. All at once a number of the out-flying birds turn in their flight, and swoop back, with a great rush of wings, to the plantation. Afterwards, at intervals, there are other such returns, little bands of the birds seeming to say, 'Oh, let's go back to bed. It's much nicer,' and doing so. This, too, is exactly what the starlings do. The birds, as they fly, are all vociferous, and the air is laden with a pleasant burden of 'chug-chow, chugchow, chug-chow. Chugger-chugger-chow. How-chow, how-chow.' The rooks talk a kind of Chinese. 
"At 8.20 the principal flight is over, but still there is a stream of birds issuing out, and most of these are now going down on to the land. All at once, thesethat is to say, all the rooks on the ground-rise and fly to the trees, the birds who have been sitting in them join them in the air, they all fly about together over the trees, and then go off in two or more bodies, and in different directions. There has been no sign of a leader, or of leadership, in any of the flights out, or in any of the birds' actions.

"At 8.45 , when no more rooks are to be seen, either flying or on the ground, I walk through the larches, and put up a good many birds who have remained sitting in them, instead of going out with the rest. I, then, walk all round the plantation, and find numbers of rooks sitting in the beech-trees that edge it on one side. Though the numbers seem small, after watching the innumerable flights out, they may yet amount to some hundreds. Thus, some small bodies of birds, and even some individuals, have not been influenced by the action of the vast majority, but have sat still whilst the rest flew forth -unless, indeed, all of them have first flown out, and then back again; but this I do not think is the case. Two great leading principles seem to govern all the actions of rooks-independence and interdependence. All are influenced by all, yet all can, on any and every occasion, withstand that influence, and think and act for themselves.

"Sometimes the sweepsback of the birds into the trees are very curious, seeming to indicate some unknown force at work. There is a sort of commotion-a turmoil of some sort-causing a cessation 
of the regular, orderly flight, the voice varies, there is a rush of wings, and out of this trouble, as it were, the backward swoop is born. Then the wavering stream-or rather a certain wavering eddy in itflies on, and again the voice becomes the musical 'har-char, har-char' (a better rendering than 'howchow'), which characterises the flight out.

"It is as though a sudden surge of thought said 'Back!' and swept some back, but a deeper, stronger surge said 'On!' and on the greater number streamed.

"Again, the stream of flight will sometimes be interrupted by a sort of sweeping or drifting together of a number of the birds, making an eddy in it, as it were-an interruption and perturbation in the current, difficult to describe, and over before one can fix the proper words to it; but indicating some sort of emotion in the birds, a rush of feeling of some kind, something tiresome to note, but which ought to be noted. Once, too, I have seen a single rook flying straight back against the general current of the stream, meeting and passing all the rest on his way to the trees, seeming the very emblem of a fixed intent.

"These curious, pausing, and hesitating movements, in which an idea that seems at first vague becomes, all at once, definite, seem to me to have their origin in what may be termed collective thinking-for this gives a better idea of the appearance of the thing than does the term thought-transference, though that may more correctly indicate the process. The birds do not appear to be influenced by the actions-the external signs of thought_-of each other, but numbers 
of them seem similarly influenced at or about the same moment of time. In fact, they often act as though an actual wind had swept them in this or that direction-when this cannot have been the case, I hasten to add.

"February Ioth.-A hard black frost, bitterly, bitingly cold. At 5.30 A.M. I steal into the dark plantation, and silently take my place at the foot of one of the tall, sighing trees. Softly as I try to move, I disturb some of the sleeping birds, who make heavy plunges amongst the trees, or beat about, for a little, through 'the palpable obscure' above them. But, leaning against the trunk, I am now rock-still, and soon they settle down again, though 'talking'some nervous inquiry-continues a little, breaking out first here and then there, around where I sit. I soon notice, however, that these outbursts have no relation to my whereabouts, but take place over the whole plantation, and I come to the conclusion that they have nothing to do with the late disturbance, which is now, evidently, forgotten. The night, in fact, is passing, and the rooks are beginning to be rooks. Such noises in the utter darkness, amidst the shroudblack firs, sound ghostly, and may, perhaps, have given rise to the idea of the night-raven. In the winter, it must be remembered, it is night, practically, for some time after the peasantry of any country are up and about; nor can I conceive of any sounds more calculated to give rise to superstitious ideas than some of those I hear about me. In the real night, too, a belated peasant might easily get a note or two from some awakening rook, and, both by virtue of time and place, and the actual quality of the 
sound-as I can testify-it would sound very different to what he was accustomed to in the daytime. It is probable that, in a country where ravens were known, and inspired those superstitious feelings which they always have inspired, such sounds, issuing out of the darkness, would be ascribed to them, rather than to the homely rook; and here we should have the nightraven - a bird 'frequently met with in fiction, but, apparently, nowhere else.' Possibly, however, the raven itself may sometimes utter its boding croak through the darkness, and ravens have been, and, in some parts, still are, numerous.

"Gradually the plantation becomes quite a wonderful study of sounds, there being an extraordinary variety, and some of them most remarkable. One, that seems deep down in the throat, suggests castanets being played there, but castanets of a very liquid kind, water-castanets, if such there could be, but, if not, it gives the idea. This curious sound is only uttered occasionally by some particular rook, and it recalls -perhaps is - the well-known burring note that I have heard under such different circumstances. If so, it can only be as a recollection that the bird utters it. I have not the space to reason this, but, assuming it to be so, may we not see, here, one of the alleys leading up to language? A certain sound is uttered during the doing of a certain thing. It becomes associated in the mind with that thing, with the doing of it, and with the state of mind under the influence of which it is done. At first, perhaps, unconsciously, then consciously, it is uttered when such action is recalled, and the utterance recalls it, also, to the mind of whoever hears. Here, then, is a 
certain well-understood sound conveying a certain idea or ideas-as, first, 'burr,' a particular kind of joyous flight: then, 'burr,' something as joyous as such flight, and so, joy: and lastly, 'burr,' the actual joyous flying, the root, therefore, of the verb 'burr,' to fly joyously, and, so, to fly. Darwin supposes language to owe its origin 'to the imitation and modification of various natural sounds, the voices of other animals and man's own instinctive cries, aided by signs and gestures.' To repeat a certain sound, that had been at first the mere mechanical adjunct of a certain act or state, when one recalled that act or state, would be, as it seems to me, an extremely early-perhaps the earliest—step, passing imperceptibly from feeling into thought, and leading on to imitation. Such speculations may be permitted one, in a dark fir-plantation, surrounded by rooks and waiting for the morning.

"One thing, however, I record as a fact, which appears to me somewhat curious. Though the plantation is continuous, without any break other than the narrow path that runs through its centre, and though it is simply crowded with rooks, every tree holding a great many, yet I notice that an outbreak of sound in any particular part of it does not spread over the whole, as one might have supposed that it would, but dies gradually out, as it radiates from the point where it arose. Thus, there are zones of sound, isolated from each other by intervening areas of silence. Just at this moment, after I have sat, for some time, silent, and all alarm has subsided, there is a great clamorous outburst some little way off. It must have some special cause which I cannot divine, but this com- 
motion does not, any more than the lesser ones, spread itself through the packed community, but is strictly isolated. How strange this seems! A parliament (though I heard no nonsense talked) of lively, eminently gregarious birds, all of which are noisy at one time or another, and from the thick of them a storm of clamour bursts: would not one think that the birds sitting cheek by jowl with the stormers would storm too, and so 'pass it on'? Why should there be a periphery, and what should limit the chorus except the bound of the plantation itself? Do crowds shout in patches? That the clamour should cease, after a time, is, of course, natural, but why, though it died along the road by which it travelled, should it not keep travelling on, through all the black, serried ranks? If rooks were influenced only by the outward manifestations of each other's emotions, one might, surely, expect this. But now, if they were influenced more by the thought itself, rapidly transmitted from one to another of them, then, whenever this factor ceased, for whatever reason, to act, the birds beyond the limits of its action might be unaffected by the cries of those who had felt its influence, for they would have been accustomed to look for a sign from within, and not from without. They might then hear, on some occasions, without being impelled, though on other occasions they might choose, to join. It may be difficult to realise such a psychical state, but that does not, of itself, make the state impossible. Its possibility would depend upon the reality or not of collective thinking, or thought-transference, and observation is (or should be) our only means of deciding as to this. 
"As light struggles out of the darkness, the silence is broken more and more frequently, at some point or other of the plantation, so that the sound is disseminated over a larger and larger space, till, for some little while before the flight, the whole rookery seems to be talking at one and the same time. In reality, however, there is a constant cessation and renewal on the part of each individual bird.

"At 6.30 the sounds take a deeper and more emphatic tone. There is more solemnity, more meaning, and the meaning grows plainer and plainer as the asseveration becomes more and more emphatic, that 'it is, yes is, is really, positively is, is, is, is, is the morning.'

"At 6.35 there is the light, joyous 'chug-a, chug-a, chug-a,' besides which one catches-if one has a good ear-'hook, chook, — hook, took-hook-a-hoo-loochuck, chuck, chuck, chuck, chuck, chuck,-polyglot, polyglot.'

"Then there is a question-a serious and solemnly propounded question- 'Quow-yow?' The answerfrom another rook - is immediate and undoubted'Yow-quow.'

"There are sounds which just miss being articulate and just evade one's efforts to write them down. It is significant that I have to use the word 'talking' to describe the rook's utterances. It is the one word; another would sound forced and strained.

"Throughout the babel, there is a tendency for it to sink and rise in sudden accentuations and diminishments. Now there is a diminishment, and a bird in the tree next to mine gives a sleepy stretch out of one wing, which has all the appearance of a yawn. 
But I see no other bird yawning, nor do I notice any toilette, any preening of the feathers.

"Now, at close on 7, the flight out is preceded by a flight of the birds inside the plantation, from one tree to another, and this passes, gradually, into the full forth-streaming. Just above the trees, now, they pass in endless flakes of a black and living snowstorm. Their flight is swift, hurrying, joyous. They flap, but there are, often, long sweeps on outspread wings, between the flaps. And ever, as they fly, they greet the cold, stern morning with their joy-song of 'chowhow, a-chuck, a-chuck, a-chuck, a-chuck, a-chuck-a.'

"Nearly a month later, a smaller, but still numerous, body of the birds had chosen a new roosting-place-a clump of Scotch firs on a lonely heath, which had stood vacant all the winter, a point interesting in itself, but which-for the old reason-I am unable to discuss.

"March 4th.-I got to the plantation towards the end of the afternoon, and resolved to wait there, in order to see wood-pigeons fly into it in the evening. Not many came, but at six o'clock I saw what I thought was a large band of them fly into an oak-tree which I had noticed just outside the plantation, where they remained for a minute or two. They then flew on to the plantation, sweeping over it once or twice before settling, and I saw that they were rooks. As will be seen from this, they had hitherto been silent. When they had settled in the trees there was some talking, but strangely little, I thought, for rooks, and very soon afterwards there was hardly a sound. They remained thus, for some little time. All at once, with extraordinary suddenness, with a sound of wings so compact and instantaneous that it was almost like the 
report of a gun, the whole troop burst suddenly out of the trees, which were on the outer edge of the plantation, flew a little way over the heath (I caught them against the fading red of the sky), wheeled round, returned, and shot into them again. There was a little cawing as they got back, but this soon sank, and again there was silence. Then, in a moment, there was the same sudden rush of wings, and the whole black cloud shot, like one bird, into the open sky, wheeled again, and shot back, as before. This occurred nine times in succession, at intervals of not longer, I should think, than three or four minutes. In the later rushes the birds circled several times-flying out again, each time, over the moor-before resettling in the trees. After the last time they settled in a different part of the plantation. Immediately before two of the rushes out, I heard a loud 'caw,' in rather a high-pitched tone, from a single rook, which seemed to be the signal for the exodus, whilst, almost immediately afterwards, there was another single note of quite a different character-deeper and more guttural-from either the same or another bird still in the trees, which seemed to call the rest back again. A well understood signalnote indeed, would be the easiest way of accounting for these sudden and extraordinarily simultaneous flights and returns, but it was only twice out of the nine times, that this explanation seemed tenable. On other occasions, the caw, at starting, seemed only one of many, or did not correspond so exactly, in point of time, with the sudden flight out, as the theory seemed to require, whilst the deep 'quaw,' which seemed to be made by one particular rook, who always stayed behind, and which I had at first thought called the 
others back, would be heard directly after they had flown, as well as after they had returned. Several times, too, the black cloud and thunder-storm of wings seemed to burst out of silence itself. I came to the conclusion that a signal-note was not the explanation. All I can say is, that-from what cause or actuated by what impulse, I know not-some fifty to a hundred rooks shot, as though they shared one soul, nine times in succession, from those dark pines, circled a little over the dusky moor, and then shot back into them again. No one, except myself, was near. It was one of those very lonely places where, at almost any time, one can count upon seeing no one, and, altogether, it struck me as an extraordinary phenomenon.

"Once more, the old Greek idea of the $\phi \eta \mu \eta-a$ sudden thought, sweeping through a crowd as a wind sweeps through a grove of trees - seemed to me to be the only view which met the facts. But what, then, is the $\phi \eta \mu \eta$, and whence, or why, the impulse?

"All this time, I should say, though quite near, I was perfectly concealed, standing against a tall pinetree, around the trunk of which I had helped to make a wigwam-already partly formed-of some of its own fallen and bending branches. This, with the gloom of the plantation itself, and the falling night, was a perfect concealment, even at a foot's pace, as will shortly appear.

"It was just after the last return of the out-shooting birds that, looking up, I saw what I at first supposed was they, but soon found to be another, and a very much more numerous, band of rooks, who, as they came up, were joined by the other ones, in the air. Now, for the first time-for the cloud came up in 
silence, and, since the last flight out, there had been silence in the plantation too-there was a tremendous clamour of voices, filling the whole place, and then a black, whirling snowstorm of rooks began to shoot, whirr and whizz about, over, into, through, and amongst the fir-trees, in a most extraordinary manner. The rapidity with which they shot about, their hurtlings, their sideway-rushing sweeps and swoops, their quick, smooth turns and gliding zig-zags, avoiding, by miracle, each other and the trunks of trees, was most extraordinary, whilst the whishing noise of their wings through the air was almost frightening. The plantation seemed to be a huge disturbed bee-hive, with great black bees dashing angrily about it. It was a snowstorm with the flakes gone mad; but black, a black, living bird-storm, and it produced in me a feeling of excitement, a peculiar, almost a new, sensation, analogous, perhaps, to what the birds themselves were feeling. What struck me and made it more interesting, was that it was a special exhibition, a 'set thing,' something indulged in by the birds with a peculiar pleasure in the indulgence, something appertaining to the home-coming-the 'heimkehr' emanating from and requiring a particular, psychical state. This is by far the finest display of the kind I have yet seen, and I was in the very midst of it. Considering the number of birds-there must, I think, have been several hundreds-the speed at which they dashed about and the smallness of the space in which so many were moving with such violence, and so erratically, it seems wonderful that they never came into collision, either with one another or the trunks or branches of the fir-trees. In the plantation, when 
I came into it, two dead rooks were lying, and I had also picked up a dead one in the larger roostingplace. The keeper said it had been 'turned out,' which was vague, and then, more definitely, that rooks sometimes died of old age. It seems not impossible, or even improbable, that in these violent whizzings of a great number of rooks together, amongst closely growing trees, and in the gloom of evening fading slowly into night, accidents may, sometimes, occur. The rooks, I should say, in their violent whizzing darts and dashes, shot down, sometimes, to about half the height of the trees, and were, in general, right in amongst them. This wonderful scene of bird excitement, lasted, I should think, about ten minutes, in full action, but grew fainter as the trees became more and more packed with birds, till, at length, all were settled. Every tree held several. On two slender ones-not pines but birches-just in front of me, and but'a step or two off, there must have been more than twenty. The noise and clamour, during the whole time, was tremendous."

It is not always that rooks dash thus madly to rest. Here-on the very next evening and at the same place-is another type of the home-coming.

"March 5th. - A little after 5.30, a hooded crow flies into the clump of pines. Whether it stays there for the night, with the rooks, I cannot tell, but it does not seem to me improbable. I have seen single birds of the former species flying amidst large bands of the latter, and they are constantly together in the fields, where they behave, in regard to each other, very much as though they were of the same species.

"At 6.10, which is later than the first batch of rooks 
came yesterday, five birds fly over the plantation but do not go down into it.

"At 6.I 5 a large, united flock of, perhaps, six or seven hundred fly up from over the ploughed land skirting the moor. They utter the 'chug-a, chug-a' note, characteristic of the homeward flight, but quietly; there is very little noise. Just before reaching the plantation they make a sort of circling eddy in the air - becoming, as it were, two streams that drift through each other-then sail on together and circle some three or four times exactly over it, before descending into its midst. This they do without any of the excited sweeping about of yesterday, and though, of course, the voice of so many birds is considerable, yet, comparatively, it is very subdued, and in a very short time - about five minutes - they all seem settled. Before long, however, some of them, but quite an inconsiderable number, rise and fly about over the trees again, but soon resettle, and there is, now, a deepening silence. No one could imagine that that little lonely clump of trees held all that great army of birds. All, to-night, has been wonderfully decorous. There was something majestic in the way the rooks flew up-slow-seeming yet swiftly-moving. Their flight round, over the trees, before sinking, like night and with the night, upon them, was a fine sombre scene-the thickening light ("light thickens and the crow_' '), the silent, lonely-spreading moor, the gloomy trees, and, above them, slow-circling in the dusky air, that inky cloud of life. It was gloomy, the effect-saddening, yet with the joy of nature's sadness. The spirit of Macbeth was in it-'Here on this blasted heath'- 
'Good things of day begin to droop and drowse, Whilst night's black agents to their prey do rouse.'

"But they sank peacefully down, and all of evil seemed to go, with their sweet, joyous, innocent, and well-loved voices."

Here is one last picture, and I would point out that, on all these three occasions, when the rooks slept in changed quarters, at a later time of the year, the way in which they approached or entered the trees, and the height at which they flew, varied, in a greater or less degree, from what it had been before.

"March I I th.-At 6.20 a small band of rooks comes flapping along in the usual jog-trot way, and enters the plantation. Some five minutes afterwards a very large number sail up, flying at a great height, and gather like a storm-cloud above it. They hang over it, then drift, circling, a little, descending gradually on outspread wings, till, when at a moderate height above the tree-tops, they begin to shoot down into them in the rapid, whizzing manner before described. But they do not all do this at the same time. It is a slow and gradual - in its first stages almost a solemn - entry, and the shooting down itself becomes, gradually, less rapid. How grand is this to witness! It is a living storm-cloud discharging its black winged rain-a simile, indeed, which can hardly fail to suggest itself, so apparent is the resemblance. At a distance, I think, the two might be really confounded. The gradual sinking of the birds, by fine gradations and almost imperceptibly, from their vast height, is more like an atmospheric than an organic phenomenon. The effect is heightened by the loneliness and utter silence, by the deepening shadows. Night sinks as 
they sink, but the moon is now becoming luminous, and the swish and 'coo-ee, hook-a-coo-ee' of peewits is about one on one's way back, over the heath."

I will conclude this fragment of my rook diary by giving a list of some of the distinct notes or sounds which I have, at different times, heard the birds utter. It is but a small page out of their vocabulary, but it may, perhaps, serve to draw attention to the great powers of modulation and inflexion which these birds possess. I must confess that the way in which the voice of the rook is usually spoken of makes me wonder. To me it has often seemed as though these birds were really in process of evolving a language. In only a few cases, however, have I been able-or have I thought myself able-to connect a note with any particular act or state of mind. Here is the list :

Caw (the ordinary "caw" more or less).

Chĭ-choo, chĭ-choo, chĭ-choo.

Cha.

Chug-a, chug-a, chug-a.

Chug-chaw.

Chack-a, chack-a.

Choo (very prolonged).

Chuck (loud, clear, and distinct).

Chee-ow (very lengthened).

Hă-chă ("a" as in "hat").

Har-char.

How-chow, or chow-how.

Hoo, hoo.

Hook-a-hoo.

Hook-a-hoo-loo. 
Kwubba-wubba.

Ow (prolonged, a peculiar musical piping note). Polyglot (or something remarkably like it).

Quar-r-r-r.

Quor-r-r-r-r-r (very prolonged, and deep, as in remonstrance).

Quow-yow, or yow-quow.

Shook, shook, shook (soft and quickly repeated. Have heard it uttered by rooks when flying home belated, after the great majority had settled in the roosting-trees).

Tchar.

Tchar-r-r (with a little roll in it).

Tchu or tew.

Tchoo-oo (very deep and guttural).

The peculiar "burring" note (uttered, but by no means always, when the birds swoop down on to trees, especially the roosting-trees. It is not heard very frequently).

A peculiar sound like a kind of bleat, with a very complaining tone in it.

A short, sharp, single note, much higher than the ordinary caw.

A kind of grating scream, much higher than the usual tone.

A hoarse "mew," or "miaul" almost, as though a rook were trying to imitate a cat, or a cat a rook.

The liquid castanet-note in the throat, suggesting the "burr," but not quite it.

Various other curious little sounds in the throat, some of them clicks. 


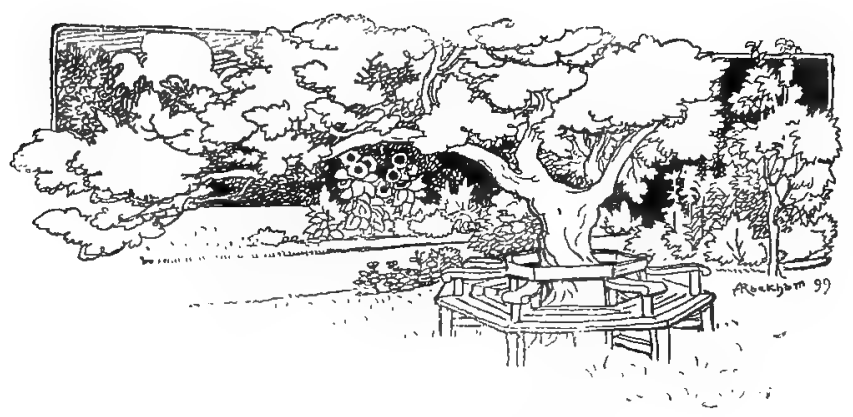

CHAPTER XII

\section{Watching Blackbirds, Nightingales, Sand-martins, etc.}

BIRDS are never more charming to watch than when they are building their nests, and, of all our British nest-builders, few, perhaps, build more charmingly than the blackbird. It is the hen alone that collects and shapes the materials, but the male bird accompanies her in every excursion either to or from the nest. When she is busied in its construction he sits in a tree or a bush near by, and, on her leaving it for fresh leaves or moss, follows her in a series of flights from tree to tree, and, finally, down on to the ground, where the two hop about, closely in each other's company. It is seldom that the hen flies at once to where she means to collect her materials, though time after time it may be at the same place. Usually she flies past the tree-all beautiful in spring and early morningwhere the cock sits, and perches in another at some little distance beyond it. There you may lose sight of her, but as soon as you see her handsome goldbilled mate leave his bower and fly to hers, you know 
that she has flown on, and is now perched somewhere else. Thus you may see them glancing through the greenwood, she usually leading, but sometimes each alternately passing the other. Coming to the collecting ground - for there is usually some spot more liked by the birds than any other-the hen flies down and begins to hop about, making, at intervals, little dives forward with her bill, till she has collected some moss, dry grass, or quite a little bundle of dead brown leaves. The male bird follows her all about, hopping where she hops, prying where she pries, and seeming to make a point of doing all that she does except actually collect material for the nest, and this, in my experience, he never does do. Then, the one laden, the other empty-billed, they both fly back in just the same way, and the cock will sit again, often in the same tree, whilst the hen adds her store to the growing bulk of the nest. I have watched a pair make thirty-one excursions to and from the nest between five and eight o'clock in the morning. By half-past eight or nine the building would cease, nor would it be commenced again during the rest of the day.*

Anything lovelier than the picture presented by the two birds thus busied together in the early, dewy morning, it would be difficult to imagine. It would arouse the enthusiasm of all except very dull people, and is even a prettier thing to see, I think, than when both male and female work jointly. In the latter case the straightforward business element predominates, but here, the attendance of the male bird upon the female, and his evident pleasure in such attendance, his anxious interest in what she is doing, and joy in seeing her do it, throws a more romantic

* As far as I could ascertain this by coming a few times at intervals. 
element into the picture. It is that which makes me extend the word "busy" to both the birds, for the cock is as busy in escorting and observing the hen as she is in collecting the materials for and building the nest; whilst that she loves him and is cheered by his society, his presence making "the labour she delights in" still more a joy, is also apparent. These are sweet and lovely things to see, and the joy of them is the greater that the emotions concerned are so direct and simple, without those windings and ambiguities, those side-issues and counter-currents which, with us, lead direct to grey hairs, and novels not by Scott or Jane Austen. Here are no troublesome entanglements, no tiresome perplexities, no conscientious sacrificings of the best beloved to every other possible person and consideration. All is sweet simplicity and giving up to-not giving up. These blackbirds love each other and carry it through. They do not think of twenty other blackbirds and fail or come in draggle-tail at the end - as in the novels. Nor are they bothered with "questions." It is refreshing-most refreshing-to see them-like a sparkle of Gilbert after some very "serious" dulness.

Roughly speaking, there are three stages in the building of a blackbird's nest. The first or foundation stage consists of moss, sticks, and leaves; the second is the mud stage; and the third, that of dry grass and fibre, with which the interior is finally lined. The nest of the blackbird differs, in this respect; from that of the thrush. The latter bird, as is well known, lays its eggs in a smooth plastered cup formed, not of mud, as one would think, but of rotten wood and cow-dung. The blackbird, after having collected all 
the moss and leaves that it deems necessary and made therewith the mass and bulk of the nest, resorts to some little ditch or sluggish stream and trowels up from its margin mud indeed, but not mud alone, for there is amidst it-generally, if not always-a certain proportion of the fibrous roots or rootlets of mudloving aquatic plants. Of these, the bird can take a firm hold with its bill, and as the mud adheres to the fibrous network, it is enabled to carry a considerable quantity of it at a time, though a greater or less amount often falls off during the passage. It is in this circumstance, as I believe, that one can read the origin of the "extraordinary habit," as Darwin calls it, of a bird's plastering the inside of its nest with mud. It is the thrush to which he alludes, but the description applies equally, and, in respect of the material employed, still more accurately, to the blackbird. At a certain point in its construction, the nest of the latter would be mistaken by anyone without previous experience, for that of a thrush, the cup being as deep and perfect in form and the workmanship not noticeably inferior. It is, however, of a darker colour -black, or approaching to black-though this may vary, according to locality. Over the whole surface are seen the scorings of the bird's beak, which seems to have been used as a trowel. But now, if the nest had been examined a day or two before, its interior, and, especially, the bottom of it, would have been found to be composed of a dank moist mass of vegetation, largely consisting of small water-plants, both the green part and the roots, to the many fibres of which latter a quantity of mud was adhering. Here, then, we read the whole story. Fibrous material was needed on 
general principles by the female blackbird, and she found it in the spreading network of rootlets, belonging to water-loving plants that grew in little rills and ditches, near about her bosky brakes. But to this, mud clung, and, in consequence, there came to be a good deal of the latter in the cup of the nest. Something must be done with it. She began to daub and press it, and, as she became, gradually, more and more a plasterer, mud seemed more and more the proper sort of material to use, till, at last, she sought it for itself alone, utilising the fibres which bound it together, and which had, at first, been what, alone, she sought, as a means of conveying it. But when the mud, thus brought, had been thoroughly smoothed and plastered, so that the nest seemed perfect and "a thing complete," like the thrush's, there would still be something more to be done, for she-our hen blackbird-had always been accustomed to work in stages, and the final or grassthatching stage had not yet been entered upon. Therefore, she would cover up and entirely conceal all her fine plaster-work, so that no one, seeing the finished nest, would imagine that it existed in any part of it. But will she always do this? I cannot think it, for she is a bird of sprightly intelligence, and I believe that, like the thrush, she will some day find out that the neatly-plastered cup of mud does quite well enough to lay her eggs in, and that the further labour of thatching it with grass can be very well dispensed with. Any saving of time or of labour must be of advantage to a species in the struggle for existence, and those birds who thatched their nests more thinly would be enabled to lay their eggs sooner, and thus rear more offspring. In this way, as well as on the "least action" 
principle, and the exercise of ordinary intelligence, the last stage of lining the cup with grass may finally cease. It has ceased with the thrush, but, with the thrush, there has been a still further process of change, for it no longer plasters its nest with mud, but with decaying wood and with cow-dung. Assuming the ancestors of the bird to have once used mud, and lined the interior, as does the blackbird, there does not seem to me to be any great difficulty in explaining this change. The blackbirds that I watched building their nest, always, when the proper period arrived, flew to a certain part of a little muddy dyke (it is in a land of dykes that I reside) some little way from the plantation in which the nest was situated, and there, lying flat behind tufts and tussocks of reeds and grass, I watched them take their mud as I have described-the female, that is to say, but a husband much interested in seeing a baby carried would deserve half the credit of carrying it. Now, much nearer, probably, than this specially-resorted-to dyke was some decayed tree or tree-trunk, whilst over the fields which it intersected and which adjoined the plantation, cows or oxen sometimes grazed. Here, again, a change in the working material might prove of advantage, and when once a bird had become a plasterer, intelligence, and also haste, might lead it to use whatever came first to hand. Bees will carry oatmeal instead of pollen if the former be put in their way, and birds may be credited with equal adaptability.

After watching blackbirds building, and examining the nest in its various stages of construction, I think it much more likely that the thrush has passed through, and then discarded, a final stage of thatching the nest, than that it has stopped short at the stage of plaster- 
ing, and not yet got to the one of thatching or lining. Numberless birds, including other members of this family, line their nests with grass or other soft materials, whereas plastering is a comparatively rare habit. It is legitimate to assume that that which is common has preceded that which is rare. I would here point out that whilst, in works of ornithology, reference is always made to the strange habit which the thrush has of daubing its nest, nothing, as a rule, is said in regard to the similar habit of the blackbird, or, if anything is, we are told merely that mud is used to bind the materials together. The facts, however, are as I state, and, did the blackbird not line its nest with grass after it had so carefully plastered it with mud brought from the waterside, it would be as noted in this respect as is the thrush, its near relative.

I have never heard the male blackbird sing whilst thus attending the female as she built her nest, not even when he waited for her in a tree, during the actual time of its fashioning, though here was a fine poetical opportunity for him. Song, it seemed, had ended when once his bride had been won, and his rivals vanquished by it. It was the same, to a considerable extent, with a pair of nightingales that I watched under similar circumstances. I did, indeed, sometimes hear the song when the bird singing was invisible, and, therefore, I cannot say that it was not this particular one, which, for other reasons I am inclined to think that it was. But during far the greater part of the time, and always when I could see him, he was as silent as his mate. It was in the early morning and not the night-time, but nightingales sing at all hours, both of the day and night. The early 
morning is, indeed, a favourite time with them, and it is then, in the beginning of spring, when nests have yet to be built and before the birds are properly married, that one can best observe how powerful a vehicle of hatred and rivalry their melodious strains are. I have closely watched two rival males for nearly an hour. Let anyone refer to my account of the rival wheatears, substitute a plantation with bush and tangle, and the turf-bordered roadside adjoining, for the open, sandy warrens, and song-but much more frequently indulged in-for the little frenzied dancings, * and the two pictures will be identical, or nearly so. There was the same keeping close to, yet not appearing to follow, each other, the attending to each other's motions without seeming specially to watch them, the drawing near and, then, getting apart, only to approach again, the little bursts of fury - but here, mostly, harmonious - preceding each engagement, and surmounting, each time, that discretionary part of valour, which, in either case, both the birds seemed largely to possess. There were three engagements, one bird, each time, making, as though no longer able to control itself, a sudden little frenzied dash at the other. In no case, however, was the conflict very severe, and the attacked bird soon flew away, with which result the attacker seemed well satisfied. It looked more like a little furious play than a real fight, and so, no doubt, it would, were Moth or Cobweb to have a tussle with Peaseblossom or Mustardseed. Oberon and Titania, indeed, "squared" so, that-

"All their elves, for fear,

Crept into acorn-cups, and hid them there."

* The wheatears, however, sang as well as danced. 
But, here, the audience were themselves fairies, so that it was all in proportion. Besides, the war was but of words, and, in these, we see how the prettiness of being fairies prevails, even over the relationship in which the two stood to each other. So it was with these warriors; they were rivals, and stuffed full of dislike, nay hatred, but, also, they were birds-and nightingales.

Jealousy, however, did not seem to blind them to the merit of each other's performance. Though, often, one, upon hearing the sweet, hostile strains, would burst forth instantly itself-and here there was no certain mark of appreciation - yet sometimes, perhaps quite as often, it would put its head on one side and listen with exactly the appearance of a musical connoisseur weighing, testing, and appraising each note as it issued from the rival bill. A curious, half-surprised expression would steal, or seem to steal (for fancy may play her part in such matters) over the listening bird, and the idea appeared to be, "How exquisite would be those strains, were they not sung by —_, and yet, I must admit that they are exquisite." Sometimes, however, there would be no special response on the part of the one bird, either by voice or attitude, whilst the other was singing. During these musical combats I often saw a third and silent bird, hopping with demure, modest look -by virtue of which it seemed rather to creep than to hop-just within, or just on the outside of, this or that briery bower. This I took to be the female, and, thinking so, it was easy to detect a little sideglance thrown, now and again, towards one or another of the rival suitors, in which seemed expressed the thought of a pretty, little bird (but a lady-bird) Bunthorne- 
"Round the corner I can see,

Each is kneeling on his knee."

Yet this bird may have been but another male, to whom the next unseen notes that I heard were, perhaps, due. Always I bless those birds whose sexes are plainly distinguishable from each other.

What was very noticeable in these nightingalesand the remark applies to others that I have closely listened to-was that, even when not singing against each other, they made little noises in their throats, and these, when distinctly heard, resolved themselves into a deep, guttural sound, which, though far from unpleasing, could hardly be called anything but a croak. This sound, as I have noticed, is very frequently uttered. It often commences the song, or is even intermingled with, though it can scarcely be said to belong to, it. It does not, in this case, diminish the beauty of the melody; yet, did it stand alone, the nightingale would be merely a somewhat musical croaker. Probably this is what it once has been, the low, croaking note representing the original utterance of the bird, on which the song, by successive variations, and choice of them on the part of the female, has been founded. Just as in the dull plumage of female pheasants and other birds, the males of which are splendidly adorned, or in both the sexes of some species belonging to the same families, we see the early state of their common, plain progenitors, so, in song-birds, the uninspired, workaday voice of call-note or twitter - the spoken language, as one may call it-probably represents the humble roots from which the various trees of song, with all their diversified branchings, and fluttering, 
trembling leaves, have shot up, beautifully, into the sky. How distinct in their glories are the mature males of the golden, silver, the impeyan, or our own common pheasant; how drabbily alike are the females of all of them, and they themselves in their first early plumage! So, whilst the song of the blackbird, missel, song-thrush, fieldfare, or redwing are distinct, or suggest each other only by their general quality, all have a high, harsh, scolding note, which is very much the same, except in degree, though differing in the frequency with which it is employed. Loudest and harshest of all is the fieldfare, and this bird has hardly developed a song. The missel, whose lay is very inferior to that of the song-thrush, is also a frequent and loud scolder, so that many a man, whilst alone and in the wild woods, might fancy himself within the bosom of his family. In the common thrush, however, who is such a fine singer, this note of fear is not nearly so often heard,* and its shrewish character, though still there, has been softened. In the blackbird it is still more rare, yet occasionally, if I mistake not, it is uttered. Again, the well-known note of the blackbird, when disturbed (though this varies considerably), is common, also, though in a less degree, to the thrush, $\dagger$ so that it is possible to mistake the one bird for the other. The same remarks apply to many finches and other small birds, who, whilst they sing very differently, chirp and twitter in much the same way. In all these cases, as I believe, there is a certain correspondence between the tone or pitch of the language and that of the song. From the low

* Proximity to the nest, with young, is the most frequent cause.

+ Especially when driven from the eggs. 
croak, as I have called it, of the nightingale, it would be difficult to imagine the high, clear notes of the thrush having been developed, whilst it would account for the low key in which its own are generally pitched. What I mean is-for I am not versed in musical terminology - that, in the nightingale's song, there are not those high, clear, ringing notes which we hear in that of the thrush, blackcap, skylark, and many other birds, just as in these we may listen in vain for those richer and more liquid tones which charm us so in the nightingale. Beautiful as these tones are, they do not, any more than those of other birds, include every excellence, and that particular one which they lack, being common to so many of our songsters, has come to be something which one loves and listens for, whenever bird sings upon bough. Partly because of this, perhaps, and partly because of the very preeminence of the nightingale as a singer, I have sometimes missed these franker, woodland-wilder strains whilst listening to its song, in a way in which I have never missed its own more dulcet notes from the song of lark or thrush. To say that Pindar is not also Sappho is no blame to Pindar, but the short continuance and frequent pauses in the song of the nightingale is, I think, a real fault, and from the blame of it this prima donna frequently escapes, when other sweet, but not so all-belauded, singers are taken thereupon to task. The poor blackbird, for instance, whose ditty is most "lovely-sweet," has been rated in these terms; yet, as a rule, in my experience, it sings continuously, for a longer time than does the nightingale, whose sometimes almost constant cessations, just when one's whole soul cries 
out, like Jacques, "More, more, I prythee, more," have even an irritating effect. Indeed, if this were always so it would be a serious drawback, even to a song so full of excellence. But it is not always so. Sometimes, on still, warm nights when the stars seem to breathe and tremble and the air is like a lazy kiss (and if nights are not like this in England, yet the song itself makes them seem so), the rich, full notes are poured forth in a continuous stream of melody that lasts long, and, whilst it lasts, seems to create the world afresh. Some time afterwards, indeed, one notices that the effect has not been quite so powerful, and that this crying want has still to be filled-but the dear bird has done its best.

"Sie jubelt so traurig, sie schluchzet so froh,

Vergessene Traüme erwachen,"

says Heine, whilst others say that the song is apt to keep them awake at night, and, having first paid their orthodox tribute to its supremacy over every other, will confess that they have sometimes been obliged to open the window and throw something out to put a stop to it. Yet the thought of how appreciative the world really is, and how severely a heretic in such a matter may be dealt with, shall not deter me from expressing a slight doubt as to the reality of this supremacy - or, at least, of its extent and absoluteness. Letters each year to the papers, from people who have been so fortunate as to hear the nightingale long before the nightingale is accustomed to reach our shores, have given rise to the suspicion that a thrush is, in most cases, the real performer; and if this be so, it shows that, with many, the comparative merits of the two depend upon 
its being known, for certain, which is which. For myself, I go with the general opinion in this respect, yet it is difficult to summon up in imagination the effect that the clear, joyous notes of the thrush might have upon one, did they ring out in the silence and stillness of the night. And if this is true in regard to the thrush, does it not apply still more to the skylark?-a bird whose lovely and long-continued outpouring, uttered, as it is, in the day and all around -common, and therefore, of necessity, undervaluedmay yet, as it appears to me, in spite of such a disadvantage, well challenge comparison with the song of the nightingale itself. If we look to effect, at any rate, the former bird seems to have inspired poets as highly, or almost as highly, as the latter. Then we have an opinion which, perhaps, may have been that of Shakespeare himself, who was a rare lover of music, that

The nightingale, if she should sing by day When every goose is cackling, would be thought No better a musician than the wren.

Now the nightingale does sing by day, and, as a matter of fact, she is then thought at least no better than the lark or thrush - in fact, she is, like these, often not noticed at all, as I have had some opportunities of observing. This, at least, shows that some of the effect produced upon some of us by this bird's song, is due to that added and exquisite poetry which night and silence gives to it. We have no other night-singing bird who is sufficiently common, and whose song is at the same time sufficiently distinguished for it to attract much attention, and there- 
fore the nightingale has this great advantage practically all to itself. I cannot help thinking that it owes to this that easy and unquestioned superiority which has been accorded to it in popular estimation over all our other song-birds, especially such glorious ones as the skylark, thrush, blackcap, blackbird, etc.*

It will be said that I cannot appreciate the song of the nightingale, though I am trying only properly to appreciate that of other members of the choir. Yet if I were to say that Shakespeare was full of imperfections, that Julius Casar was a dull play, King Lear a - I forget what, something uncomplimentary - play, and Richard III. such a one as allowed "the discerning admirer" (a nom de plume) to see the author's quill-driven expression whilst writing it; that, moreover, the seven ages of man was by no means a fine passage, and that Hamlet's soliloquy had been much over-rated, it would not be said, on this account, that I was unable to appreciate Shakespeare. I judge so, because others who make these and similar statements (whether they or the Baconians are the more pestilent, I find it difficult to decide) pass, apparently, for the appreciative persons, which, I suppose, they think themselves to be. Yet how they can think so puzzles me, for people who write in this way must be, really, as much bored by Shakespeare as Shakespeare would have been by them, had an introduction been possible - and surely they must have found this out. I wish the poor, gullible

* But do the musical powers of some birds differ in different countries? Never have I heard the two last $\sin$; here as I have in Germany. Germans, as we know, are very musical. Have the same general causes which__ etc., etc.? 
public would. How I should rejoice to be accusedyes, and even convicted - of having no ear for the song of the nightingale, if only it could be discovered, also, that "critics" who, with a natural incapacity for seeing beauty in beauty, yet step modestly forward to teach us, and dance as fantastically on the body of a dead poet as did ever a Lilliputian on that of the sleeping Gulliver, are neither profound nor discerning nor even literary, but merely dull dogs posing, of which sort, indeed, most "great oneyers" keep their pack. Yet I wish they could leave the imperfections of Shakespeare (which they discern in his masterstrokes) as utterly beyond them, and busy themselves only with the perfections of such Baviuses and Moeviuses as it is their wont to crown. I commend them to old Bunyan with his "'Then,' said $\mathrm{Mr}$ Blind-man, "I see clearly" "-and so pass on.

The sweet song of the nightingale has caused the more stress to be laid upon the sobriety of its colouring, the natural tendency being to exaggerate such a contrast. But now, when one watches for the bird in the shade of leafy thickets, the way in which it generally reveals itself is by a sudden flash of red or chestnut brown, a bright spot of colour which is conspicuously visible, sometimes even in the centre of a thorn-bush, and, one may almost say, brilliantly so, as its wearer flits amongst the trees and undergrowth. This brightness belongs to the tail generally, but there must, I think, be either upon or just above it-on the upper tail coverts, perhaps-a specially bright and more ruddy-hued patch which produces the effect of which I speak; and as nightingales habitually haunt wooded and umbrageous spots, it has sometimes 
occurred to me that this has been developed as a guiding star for one to follow another by, just as the white tail of the rabbit is supposed to have been. I have often watched two pursuing each other through the dim leafiness, each uttering a variant of the deep, croaking note of which I have spoken, and which answers to the call, chirp, or twitter amongst other birds. At such times the ruddy star or streak has always, as I say, been most conspicuous. Independently of this, the bird's general colouring is a pleasing olive brown which, according to position and circumstances, has a more or less glossy appearance, the tail having received the finest polish. By virtue of all this, I feel sure that, to anyone who had watched and waited for her, the nightingale would come rather as a conspicuous than a dull-looking bird, at least amongst our smaller British birds. Tits and chaffinches, as it seems to me, flash less as they flit through the trees. Therefore, when I read the eternal remarks about its dull colouring, which-and this is the bane of natural history-one writer hands down from the mouth of another through the generations, I say to myself that each and all of them have, either, never called upon the bird and stayed an hour or two, or else that they have got out of the habit-which may be also a trouble-of seeing anything other than as "it is written." So far from the nightingale being specially like a plain-bound book in which lovely songs are contained, to me it seems to offer an example of a bird distinguished both by its musical powers and-to a much lesser extent, certainly, but still not insignificantly - by its colour also. I am thinking of its tail, and particularly of that ruddy 
star or patch which, I think, is upon it, and which, little as it may seem in a stuffed specimen or one quite still or hardly seen, becomes a conspicuous feature under such circumstances as I have mentioned. That this patch, or the whole tail, means something I feel sure, but as to whether it is a badge or an ornament-whether natural or sexual selection* has been at work-I can say little. In the latter case the same force would have been brought to bear in two different directions, and this, I think, has been often the case with our song-birds, though it seems to have been agreed to talk as if the opposite were. Surely the bullfinch, chaffinch, robin, linnet, greenfinch, and others-the males of all of which show off to some extent before the females-have been selected (if at all) as much by the eye as by the ear of the latter; whilst the lyre-bird of Australia offers an example of a highly adorned species that is also conspicuously musical. The nightingale is glossy, and sometimes-in effect, at least, and in some part of itbright. It may be getting brighter, but, if so, it will probably have to rival the kingfisher before it ceases to be an encouraging symbol to those who hide a worth which they feel beneath a want which everybody can see.

No good illustration, that I know of, exists of the nightingale; none, at least, which at all resembles the bird as $I$ have seen it, either sitting, hopping, flying,

* Sexual, as I now believe. A recent lucky glimpse of nightingale courtship has assured me that I have not unconsciously exaggerated. Indeed, the ruddy glow of the broadly fanned tail, caught in the last rays of the descending sun, could hardly be exaggerated. But the colour was on all the rectrices. They alone, I think, are the patch, the star. 
singing, or silent. In natural history books, after we have been solemnly told that the male alone sings, that his song constitutes his courtship, and that, therefore, both the "she" and the "melancholy" of poets are incorrect, we are generally presented with a gaunt, scraggy-looking creature, having a woe-begone gaze which is fixed upon the moon, towards which its neck and whole body seem drawn out, as by some attractive force. This is the nightingale of convention, but when I have seen it, it has always looked the pleasingly plump, cheerful, little, brisk, active body that it really is, and when it sang it was without any "pose," in a hunched-up, careless-looking attitude, which had almost a feathered podginess about it. The legs were bent, the feathers of the ventral surface touching, or almost touching, the twig of perch, the head inclining forward at an easy angle-a cosy, homely, happy, contented appearance. I have watched one singing thus for some time. Not once did he rear himself up, so as to become long, thin, and tubey-tubby he was rather, and had not the faintest resemblance to a horrible, man-made, first-prize-for-deformity canary bird. Just in the same way, too, he will often sing on the ground, looking as homely and rotund as can be. True it is, as the natural history books tell us, that no one familiar with the bird and its habits would think of calling it or its song melancholy; therefore (as these never add), remembering Milton's famous line, let us be thankful that he as well as some other poets were not familiar with it. There has long been a nightingale of poetry and literature, grown out of its own song but having little to do with the real bird, which no one except strict scientists-and 
a literary critic or two-would wish to do away with.

With regard to the nest-building habits of the nightingale, I have only the space to say that, as in the case of the blackbird, the female alone collects and arranges the materials, being attended upon whilst she does so-though, perhaps, not quite so closely-by the male. One should be cautious, however, in concluding that such is always the case either with this or other birds, for I have watched, for some time, one of a pair of long-tailed tits bringing feathers to the nest, whilst the other kept near about, with nothing in its bill. Yet ordinarily both sexes work together in a most exemplary way. Nothing can look prettier than these little, soft, pinky, feathery things, as they creep mousily into their soft, little purse of a nest; nothing can look prettier than they do as they sit within it, pulling, pushing, ramming, patting, and arranging; finally, nothing can look prettier than they look as they again creep out of it and fly away. Their perpetual feat of turning round in the nest without dislocating the tail, is also one of those few earthly things in the seeing of which one cannot weary.

I have often tried to watch these little birds collecting, so as to see them actually find and fly away with the materials for the nest. This, however, I found more difficult than I had expected. Every time I saw them fly out of their nest, but in spite of stealthy following, I generally lost them soon after they had entered a plantation close to where, in a fir-hedge, it was. All I could be sure of was that they flew about in different directions, sometimes into tall fir-trees, some- 
times into low tangles and bushes, sometimes, too, across the road again and into different parts of the fir-hedge. "They keep, for the most part, together, and whenever they are near enough I hear their soft, subdued little 'chit chit.' As lichen, which is what they are now principally collecting, is everywhere about on the trunks of trees, etc., it would seem as though even a minute would be a long time for them to take in getting a piece and returning with it, if they took it at random; and the inference appears to be that they exercise choice and selection, and return each time from the nest with a definite idea of the kind of bit they want next."

I will here quote, from my notes, an observation I made on the way these little birds roost at night, which may, perhaps, be of interest. "On my way back I noticed some object which I took to be a dead bird, in a tall, straggling brier-bush that formed a kind of bower, inside which one could stand up Thinking that this bird might have been transfixed by a shrike, I came right under it, and, pulling down the branches with my stick, to my astonishment the object separated and became four little, fluttering, 'chittering,' long-tailed tits that had been sitting wedged close together. I stood perfectly still, and after they had 'chit, chitted' a little, and made a few little hops about the bush, two of them came back from different directions to just the same place, snoozled up to each other and were settled again for the night. Very soon, a third hopped on to the two backs and pressed himself down between them, taking no denial, and, indeed, not receiving any. The fourth remained a little longer apart, perhaps for ten minutes, 
during all which time I stood without a motion, leaning on my stick, and had, at last, the satisfaction to see him come perching down towards the bough, then perch on the three backs just as the third had done on the two, and squeeze himself in amongst them so that two were on one side of him and one on the other. All four now sat closely pressed together, three tails projecting on one side of the twig, and the fourth on the other. I sat down in the bush and made this entry, whilst the birdies-surely the prettiest little ones, almost, in the world-went to sleep.

"Next night, at about six, I took up my position in the same place, and waited. After I had sat silently for a few minutes, I saw a pair of the tits creeping softly about through the bushes adjacent, uttering the little chitter in a very subdued tone. One was soon in the actual bush, but crept out of it again and went away with the other. In another four or five minutes, however, they both return, this time coming more quickly and directly to the bush, when soon getting, from opposite sides, to very much the same part of it as before, they sidle to each other along the particular twig and then squeeze and press together so tightly that their outline on the inner side is quite lost, like that of a double cherry. Thus pressed and wedged, each little bird preens itself, the two little heads moving about and seeming to belong to one quite round body, having one tail-for their two tails are pressed, for their whole length, together. When their heads turn inwards the little birds appear to be caressing each other, and they must, I think, sometimes catch hold of each other's feathers, but it is all 
part, or intended to be part, of the process of preening themselves. This close pressing seems to be a pleasure in itself, independently of the result of warmth, for sometimes they will come unstuck, as it were, and move a little away from each other along the twig, in order to press and squeeze again. For a little, then, their tails may be separate, but soon they rejoin, and, the heads being now quiet - for they are going to sleep - and tucked closely in amongst the feathers of the breast, their outlines, never very salient, are entirely lost, and the two birds have become one perfectly globular one, without a head and with a long tail. Thus two of these long-tailed tits have returned again to roost in the same place, but the other pair do not come to the bush."

It is interesting to watch sand-martins building their nests, or, rather, excavating the tunnels in which they will afterwards be built. To see one enter one of these whilst it is yet but a few inches long, and then to see the dust powdering out at the aperture, as from the mouth of an ensconced cannon, is pretty. The sand is scratched out backwards with the feet, but the bird also uses its bill as a pickaxe, often making a series of rapid little blows with it, almost like a woodpecker, the wings, which quite cover the body, quivering at the same time. Both sexes work at the hole, and both often fly together to it, one remaining clinging at the edge whilst the other scratches out the sand from inside. I have seen one sitting just in the embrasure, quietly regarding the outer world and, thus, impeding the entrance of his partner, who at last squeezed by him with great difficulty. Sometimes three or four will descend upon 
the same hole and cling there without quarrelling; but once I saw a bird in a hole attacked by another, who flew suddenly down upon it with a little twittering scream.

Though each pair of birds excavate their own tunnel, yet the whole community, or, at any rate, a large proportion of it, will sometimes work together, sweeping on to the pit's face in a body, clinging there and burrowing, with a constant twittering, then darting off silently in a cloud and sailing and circling round in the pit's amphitheatre, making, when the sky is blue and the sun bright, a warm and delicious picture such as the Greeks must have loved to gaze on.

As each bird, however, only works at his own and his partner's hole, it is evident that this kind of social working is not the same as that of ants or bees and other such insect communities, though it has something of that appearance. Sometimes, for a short time, all the birds will keep fluttering round in small circles that only extend a little beyond the face of the cliff, not rising to a greater height than their own tunnels in it, which they almost touch each time, as they come round. They look like eddies in a stream beneath the bank, but are not so silent, for all are twittering excitedly. This is an interesting thing to see, a kind of aerial manouvres the special cause of which, if there be one, is not obvious.

But we will suppose that the birds are now all working, either inside their tunnels or clinging to the face of the cliff. All at once, either at or about the same instant of time, they all fly off, darting away, and disseminate themselves in the sky, not one being left either in or about the pit. In a few minutes 
they return, but, as is the case with the small birds at the stacks, not in nearly so instantaneous or simultaneous a manner; and this may be repeated for a greater or lesser number of times. All the remarks that I have made in regard to this phenomenon in the case of other birds apply equally here, perhaps, indeed, to a greater extent; for, as remarked, at the moment of each sudden exodus a certain number-sometimes about half-of these sand-martins will be more or less hidden within the holes they are excavating, yet out they all dart with the rest. Such sudden flights and disappearances for a few minutes, after which all come back, strike me as being extremely curious.

Sand-martins appear to be pugnacious. Indeed, they sometimes fight fiercely, and I have seen two, after closing with a sharp, shrill "charr" and struggling in the air for a little, roll down the steep declivity of sand in which the perpendicular face of the pit often ends. It, therefore, seems the more curious that they allow their holes to be taken possession of by sparrows (and, also, by tree-sparrows)-without offering any resistance. I have seen one of the latter birds sitting quietly and calmly in the mouth of a hole, whilst a pair of martins, who had, probably, excavated it, hovered excitedly just over and about him, but without doing more. On many other more or less similar occasions there has been excitement on the part of the martins, but never an attack. Yet a treesparrow, or even a sparrow, is not such a very much larger and stronger bird than a sand-martin, and, considering the numbers of the latter, as well as their greater activity and powers of flight, it seems to me an odd thing that they should submit to such a 
usurpation so tamely. If they are not capable of combining together in order to expel a stranger from the colony, this speaks little for their intelligence, as they have, at least, been generally two to one. This is a good working majority, and why, under such circumstances, an impudent sparrow should be allowed to sit quietly in the home whereinto he has intruded, I cannot quite understand. But so it is, or so, at least, it has been, in my own experience.

But I must not wrong the sparrow. Let me recall that word "impudent," and bury still more deeply another one, to wit, "unscrupulous," that I was about to make use of. A sparrow, when he thus acts, is simply annexing territory, and should have all the credit of forbearance and self-sacrifice that belongs to such an act. His motives in doing so are, no doubt, as creditable as are those which restrain him from acting similarly in the case of more powerful birds, and if a doubt of this should ever cross his mind, he need only read a newspaper or two and listen to some speeches in "the House." He will know the integrity of his own heart-then.

It seems wonderful that a bird of the swallow tribe -so aerial, and without any special structural adaptation for burrowing - should be capable of driving horizontal shafts into the face of a bank or pit, to the length, sometimes, of seven or even, it is said, nine feet. Though the excavations be in sand, yet this is often of a very firm consistency, and, moreover, in many pits, the face of which had been largely tunnelled by these birds, sand was a good deal mingled with a fairly stiff clay. Though I have not been able to watch the process of excavation from 
the commencement, so thoroughly as I should have liked to have done, yet I have seen it to a certain extent, and I will now quote from the notes which I took down on one such occasion:

"May 25th.-At the pit about 7.15 A.M. A great number of birds are working, and there is not now the same regularity in their movements-all coming to the holes and darting away together at intervalsas was the case, for a time, at least, when I first watched them. Though so late, several birds are but just commencing to make their holes, and to watch these is most interesting. Two plans seem to be employed. In the first, the bird constantly flutters its wings, whilst, with its feet, it at the same time clings to and scratches the face of the cliff. Thus it partly hovers in the air, and partly keeps itself in position with its feet, but more with the tail which is fanned out and pressed in against the cliff, like a woodpecker's against the trunk of the tree it is on. The second way is more curious. The wings, here, are partly extended, but, instead of being fluttered, they are pressed close against the sandy wall. Moving about over this, they seem to feel for every little inequality into which they can wedge themselves, and this the bird does, also, with his breast and the most available part of his body, the tail being fanned and pressed to the cliff, whilst the feet all the while are scratching vigorously. In this way a bird will sometimes crawl, or rather wedge itself, about, over the pit's face (which, though it may be perpendicular, or almost so, is yet full of roughnesses and inequalities), appearing to seek either the most yielding surface to scratch, or the best place to get fixed into whilst 
scratching ; and, in doing this, it leaves a track on the sand or gravel which is quite perceptible through the glasses, and which I believe is made by the strongly bent-in tail as well as by the feet. It thus clings with wings, tail, and body, whilst scratching, far more than clinging, with its claws."

"It may be asked what part in all this does the beak play? In those birds which I have been just now watching at some twenty paces through glasses that brought them just under my eyes, and in bright sunlight, it seemed to play none at all. It might have been expected that, in thus commencing, the martins would cling with the feet whilst working with the bill. These have certainly not done so, nor have they ever been head downwards, either now or before. I have not yet seen a sand-martin in this position, or even approaching to it. The tail, which is made to play so great a part, would here lose much of its efficacy, but I do not at all think that they never do hang like this. Within certain wide limits, birds, in my experience, act, not uniformly, but with great variety. Probably, with longer watching, I should have seen this attitude, and, also, the bill used as well as the feet. Whether it is used or not in the first commencement of an excavation, it certainly is-in the way I have described-during the later stages."

"I notice again this morning a particular hole, only about an inch deep, and at the bottom of which there is a large stone, naturally imbedded in the sand. No birds are now working at this, but, on the last occasion, one was attacked several times in succession, whilst doing so, by another. This seems as though 




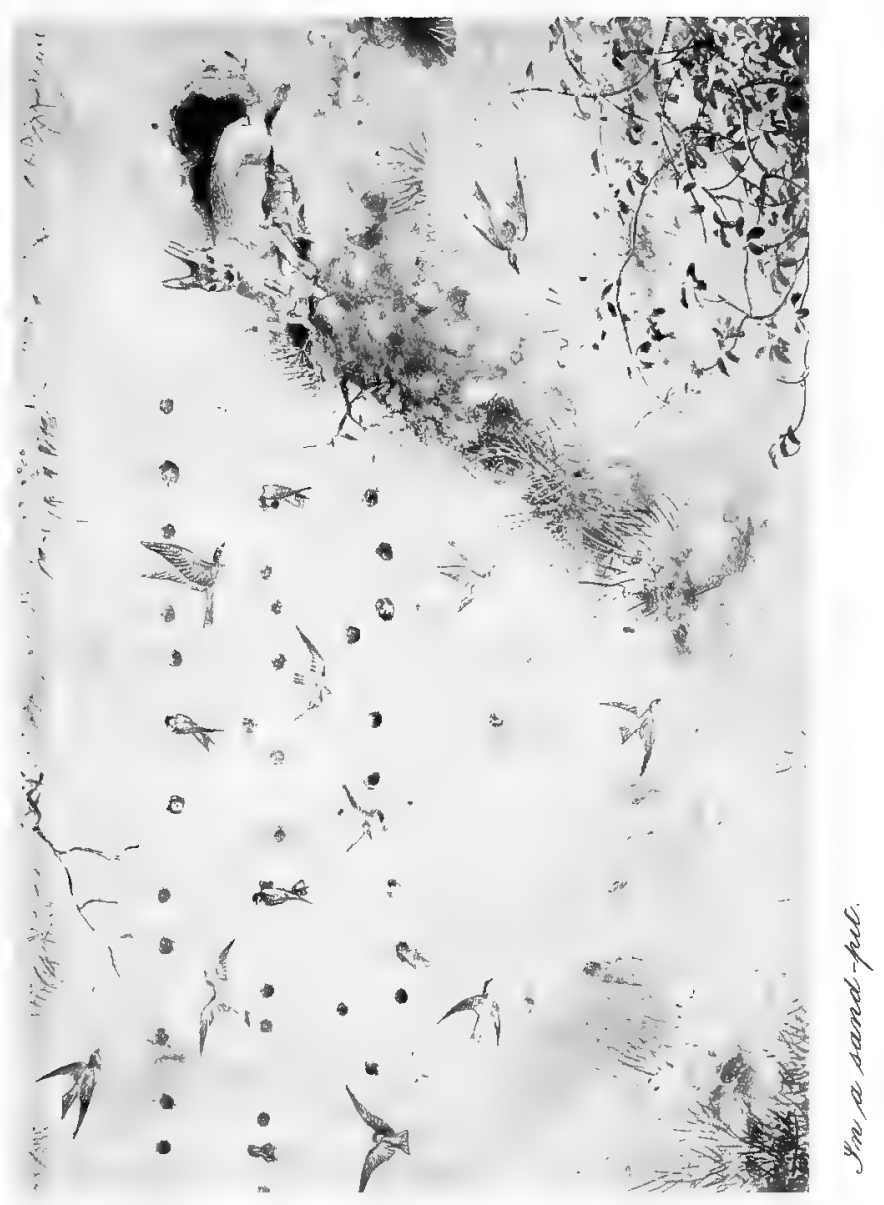



the one bird of a pair had thought the place unsuitable on account of the stone, and not allowed the other to work there. Thus delicately are matrimonial teachings conveyed amongst birds. Not one unkind word did I hear upon either side."

"Whilst watching these sand-martins, a pretty little quadrupedal picture was also presented to me. A rabbit, the mother of three, came with them all from her burrow, which was near the top of the pit where it joined the fields on one side, and couched there, delicately, in the morning sunshine. The young ones flung themselves, all three, on their backs, and, wedging themselves under her, two of them took their breakfast in this position. The third one, however, having tried in vain to get properly under her chest, made a detour, and then took her in the flank in ordinary formation, and with successful results. To see this with the warm, bright sand as a background, and the swallows flying round! Lying dozing in the morning one may have pretty dreams, but they are not often prettier than this. Blue sky, too, though it is England, and in the depth of spring!"

I have spoken of blackbirds bringing materials thirty-one times to the nest in the course of three hours, but this is very slow work, and would be, even if both birds were to bring them instead of only one. Comparatively, I mean, and the bird that I am taking as a standard of comparison is the great crested grebe. In fifty minutes a pair of these that I watched had brought between them one hundred cargoes of weed, some so large that the head of the bird carrying them was almost hidden, and some trailing on the water for a considerable way behind. Each bird dives and 
comes up with its green, shining burden, with which it at once swims to the great heap of similar material which both have collected, and which projects a few inches above the water, at but a short distance from the bank. The male is, if possible, more earnest and indefatigable in the great work than even the female, and, sometimes, he will work for a little alone, whilst she is resting. Yet, with all this, it is apparent, at once, that she is the more effective of the two, in her actual workmanship. She dives more quickly, and comes up each time with a larger load, so large, sometimes, that her head is pulled right back as she drags it along the surface of the water. She places it, too, -if this is not fancy-a little more deftly and quickly, showing in everything a higher degree of professional skill, though her colleague, besides being second only to herself in this, seems, as I say, to glow with a more ardent enthusiasm.

Huge as the mass of weeds is, which constitutes the nest of these birds, it is collected by them in an astonishingly short space of time; how short, I am not quite sure about, but this I can positively say, that whereas on a certain morning I could see no trace of it above the surface of the water, on the morning after this it was to all intents and purposes finished, though the male bird, alone, once added very slightly to it, not occupying more than a few minutes in so doing. As to this, however, it can be said, in a certain sense, that the nest never is finished, or, at any rate, not till after the female has begun to lay her eggs. Morning after morning the male brings weeds to the heap that his partner is sitting on, but as I had to leave early in 
this stage of the bird's domestic history, I cannot tell for how long he continues to do this. Probably, as in the case of the shag, and also, I believe, the moor-hen, the nest is added to during the whole time that the birds make use of it. A nest, however, may properly be considered finished from the time that it is en etat to receive the eggs and the sitting bird, and according to this, these two grebes must have built theirs between about 8.30 A.M. on one day and 6 A.M. on the next. Now, in my experience, these birds only work during the early morning, from dawn or thereabouts, up to about 8 or 9. Possibly they may begin again in the evening, or work at night, but I never saw them building, or even (before it was finished) near the nest, at any later time of the day. That the nest I speak of was not begun till after 6.30 A.M. on the one day, is practically certain, for up to that time the birds were building another one, so that unless, as I say, they worked on the evening of that day, or in the night-time, they must have begun and finished it in one morning, between dawn (as we may suppose) and 8 o'clock-and this is what I believe. If so, it seems a remarkable feat, but the swiftness with which they dive and swim up with their cargoes, and the bulk of weeds which these represent makes me think it possible, though I must confess that all the work which I actually saw on the morning in question made little perceptible difference in the size of the heap that was already there on my arrival.

Like an iceberg, the great mass of the nest is beneath the surface of the water. It seems to be woven amongst the stems of growing weeds or other 
aquatic plants, but I have noticed in it (indeed, I have seen the birds placing and carrying them) water-logged sticks of some size, one end of which is fixed amongst the mass, whilst the other sinks down into the mud, and the tangle that may spring from it. Such sticks must act as so many anchors, and may, perhaps, be the chief means by which the nest is kept stationary. To judge by the two birds which I particularly watched, the great crested grebe has the habit of building several nests, and, besides this, the male makes a small platform of weeds just off the edge of the bank, and near to the nest. Sometimes he seems in doubt whether to take his weeds to the nest or the platform, and in this hesitation, and in the building of more than one nest, we may, perhaps, see the origin of the latter structure. With regard to this, and some other points which seemed to me of interest, I may refer to a paper of mine which has lately appeared in the Zoologist.* In this I give a minute account of the nest-building and some other habits of these birds, as illustrated by a pair which I watched very closely; and I will here record my conviction that there is more to be learnt by such watching of any one species, or even any one individual bird, than in the killing or robbing of thousands.

When I say this, it is not only of the interest that there is in a creature's ways and habits that I am thinking, but also of the light that these may, at any moment, throw upon its descent and affinitiesupon all those questions and subjects which are * May Igor. 
suggested by the word "evolution" and the names of Darwin and Wallace. To have a true classificatory system seems to be, now, the grand ideal of the naturalist, and this, I suppose, must be called a high one, though it is wonderful how, in some modern works, the soul of it has been taken out of the body, so that all has become dull and pedantic again, though a flight of stairs higher up than some fifty years ago. Thus can a matter seem rich or poor as one or another treats of it. But habits and instincts are as strongly inherited as structure, so that, as it appears to me, the study of life is, even from the orthodox scientific point of view, as important as the study of death. Yet it is death that most zoologists (as they call themselves) really revel in, and, though they may not say so, one cannot help feeling that they are a great deal happier and more comfortable dissecting a body in their study than studying a life out-of-doors.

Even admitting that both ways of acquiring knowledge are equally efficacious and legitimate, yet this is very clear, that the destruction of any species ends both, in regard to it. We can no more dissect the great auk or the dodo (or blow their eggs) now than we can observe their habits. Thus it is not only beauty, but knowledge also-how great and how varied who can say? - that is being every day drained out of the world, and against this there is, as it seems to me, an insufficient protest on the part of scientific men as a body. They care too little about it. When they think of birds or beasts, it is under glass cases in museums that their mind's eye sees them, and if there is only a specimen-nay, a 
bone or a feather-in one of these, it is to them as though a nation had been saved. More, if only a specimen, or a bone or feather, can be got for a museum in which they are interested, for the sake of it such nation may perish, and of this spirit we have only lately had a salient example. In their writings, these serenities are accustomed to speak calmly of the approaching extinction of this or that more or less lovely or interesting creature-say, for instance, the lyre-bird of Australia-if, "happily," such and such a museum has been supplied, or if Professor somebody has ascertained this or that in regard to it; or professors and the public generally are exhorted to obtain such supplies or such information "before the end comes."

"Before the end comes!" Every effort should be exhausted, every nerve strained, to avert such end, which, in nine cases out of ten, could be averted if the requisite measures were taken. This way of writing, however, is not calculated to further such efforts, or to hasten the taking of such measures. Indifference, at least with regard to the greater evil, is but too clearly indicated, and to this indifference the life of species after species is sacrificed.

No one, of course, supposes that the opinions or emotions of a scientific body (and in this I mean to include more than the term strictly covers) would exercise any influence on money-seeking men or brainless and heartless women; but they might on that great army of collectors who, thinking all the while that they are in some way doing good and helping science, keep sweeping countless thousands of birds, beasts, eggs, and insects out of existence. Alas for 
these amiable basilisks, these busy little man-shaped rinderpests, who kill so well-meaningly and hate the very breath of life without ever once knowing it! if they had devoted their whole lives to picking pockets, or even to being politicians, they would have done, at the end of them, less harm-far, far less harm-in the world than they are now every day doing. Every day, through them, some specific life that is, or was, of more value than all their individual ones put together, is getting scarcer, or ceasing to be. For, surely, a beautiful butterfly, say, that, for all time, charms-and raises by charming-some number of those who see it, does more good on this earth than any single man or woman, who, "departing," leaves no "footprints on the sands of time." Homer, for instance, has left his "Iliad" and "Odyssey," and these have been, and still are, mighty in their effects. But let them once perish, and Homer will be caught up and overtaken by almost any bird or butterfly-even a brown one. Or, if Homer will not, assuredly many an English poet-laureate will be, or has been already (Pye, for instance), though his volumes in the British Museum are safe as consols. If there be any truth in this reflection, it should tend to make us a little less conceited than we are. Yet what is a little in such a matter?-" Oh, reform it altogether."

For myself, I must confess that I once belonged to this great, poor army of killers, though, happily, a bad shot, a most fatigable collector, and a poor, half-hearted bungler, generally. But now that I have watched birds closely, the killing of them seems to me as something monstrous and horrible; and, for every one that I have shot, or even only shot at 
and missed, I hate myself with an increasing hatred. I am convinced that this most excellent result might be arrived at by numbers and numbers of others, if they would only begin to do the same; for the pleasure that belongs to observation and inference is, really, far greater than that which attends any kind of skill or dexterity, even when death and pain add their zest to the latter. Let anyone who has an eye and a brain (but especially the latter), lay down the gun and take up the glasses for a week, a day, even for an hour, if he is lucky, and he will never wish to change back again. $\mathrm{He}$ will soon come to regard the killing of birds as not only brutal, but dreadfully silly, and his gun and cartridges, once so dear, will be to him, hereafter, as the toys of childhood are to the grown man.

Nor will the good effect stop here. Birds are but a part of the life on this our earth, and the hatred of destruction, once kindled by them, will, like the ripples made by a stone flung into the water, extend outwards through the whole animal and vegetable kingdom till it include, at last, man himself-yes, even the Chinese. Unfortunately, long before anything of this kind is likely to happen, all birds, except poultry, and, perhaps, a lingering sparrow or two, will have been destroyed. This seems a cheerless prospect, but, as usual (to write like an optimist), it has its brighter side. Women will then be no longer able to wear hats, to adorn which the most beautiful of earth's creatures have been ruthlessly slaughtered, and, therefore, faith in them will begin once more to revive. Faith in woman, we know, is a very important thing. A nation that has once lost it 
must either get it again, or go rapidly downhill. How much better, therefore, to get it again!

I had meant, in this last chapter, besides touching a little more fully on some points to which I have here and there referred, to say something about the heron, nightjar, cuckoo, barn-owl, wagtail, and a few other birds; but I have managed so clumsily that I now find myself at the furthest possible limit of space, without having left myself room either for the one or the other. With regard to the nightjar, I have kept an observational diary on the nesting habits of a pair of these birds, which was published in the Zoologist for, I think, September I899. From this I had intended to quote, as in the case of the great plover, but it is too late to begin now. All these birds, therefore, must wait a little, but I will not forget them should I ever write another book of this kind. 


\section{N D E X}

Animals, figures of, in heraldry may come down from savage times, 102 ; teach meaning of our high terminology, ino; word "love" properly used in connection with, Ilo; gregarious, thought-transference more likely in, 222 ; careful observation of, advisable, 223 ; slaughter of, 224 Authority, no attention to be paid to, 248

BARN-OWL, must wait a little, 336

Birds, great range of vision of most, etc., 24, 25; aerial fighting of, sometimes deceptive, 35 ; nesting habits of, must follow general habits, 48 ; will vary habits suddenly, 48. Instinct of feigning injury possessed by some, 59 ; suggested origin of, 63,64 . Pugnacity of, mingled with timidity, $74,75,76$; nervous or frenzied movements as aids to courage in, and leading to sexual display of plumage by, 76,77 , 78,79 ; association of three, 82, $83,85,90$; sexual feelings of, not always quite dormant in winter, $86,87,89$; sportings of, may be selected, 89 ; fighting of, tendency to become formal, Iog; frequent difficulty in distinguishing male and fenale of, II 2 ; slaughter of, each year, and consequent retardation of knowledge as to, I26; power of ejecting excrement to distance possessed by some, and suggested significance of this, 13I, 132 ; can "bring all heaven before our eyes," I43; female not always coy in courtship, 146 ; wings of, when opened in diving show feet are little used, 148; power of flight in aquatic, how lost or retained, 151 , I 52 ; webbed foot of aquatic, how obtained, 160 , I6I ; possible relation between opening bill and colour of gular region, 170; sea, disparity in time of laying of, 183 ; watching of at straw-stack, 199 et seq. Attempt to catch at, 200, 201 ; feeding at, 204 ; sudden simultaneous flights of small, from, and discussion of, 20I, 2IO, 2II, 2I2, 213, 2I6, $217,218,219,220,221,222$, 223 ; fighting of small, at, 208. Self-reliance of, 208, 225; most timid may be least liable to change, 226 ; wariness combined with boldness in, 226 ; various, behaving like tree-creepers, 236 ; origin of some strange actions of foreign, possibly to be traced in our own, 256 ; song of, founded on call, etc., notes in analogy with plumage, $310,3 \mathrm{II}$; correspondence between call, etc., notes and song of, 3I2 ; matrimonial teachings of, conveyed delicately, 328 ; more knowledge of, gained by watching one than by killing or robbing thousands, 332 ; killing of, silly as well as brutal, 336 ; total destruction of, approaching, 336 ; hatred of destruction of, might extend to man, 336

Blackbird, chariness of fighting sometimes shown by male, 76 ; pugnacity of hen, 76 ; at strawstack, 199-204; hen fighting with starling, 204; a charming nest-builder, 301 ; nest-building of, described, 301, 302, 303, 304. Nest plastered with mud, 
304 ; suggested origin of this habit, 304,305 ; and future development of, 305, 306. Habit of plastering of, seldom alluded to, 307 ; nest, how differing from that of thrush, 304 ; male does not sing during nest - building, 307 ; song of, unjustly rated, 312

Blackcap, song of, how differing from nightingale's, 3I 2

Blackcock, readiness to avoid a conflict shown by male, 75

Brambling, at straw-stack, I99, 202 ; beauty of, 202, 203

Bullfinch, a bud-eacer, 249 ; feeding on elms with blue-tit, 249 ; acrobatism of, 249, 250; awkwardness of, d la Harpagon, 250; manner of securing buds, 250 ; attacks blue-tit, $25^{\circ}$; an example of sexual selection acting in two directions, 3 I 8

Bunting, at straw-stack, 199

Caress, a possible origin of the, 192

Carnage, difficulty in conjuring up scenes of, nowadays, 135

Chaffinch, combats between the hens whilst collecting materials for the nest, I05. At straw-stacks in winter, 199, 201 ; numbers of, predominate, 208. Pugnacity of, and manner of fighting, 208, 209, 210 ; acting like tly-catcher, 247 ; an example of sexual selection acting in two directions, 318

Chinese, a recipe to dislike killing of, 336

Collectors, immense harm done by, 334

Coot, diving of, I58, I59; in flocks in winter, 160. Manner of feeding of, 159 ; a better diver than the moor-hen, I60; lobes of toes, how possibly acquired, 160, I6I

Cormorants (see also Shag), hop in courtship and for convenience, 49 ; their power of ejecting excrements to distance, 131 ; nest of, I3I; excelled by shag in diving, I53; popular idea of, 163 ; evil-looking appearance of, I63; Longfellow's lines on, 164 ; Milton in connection with, I64, 165 ; similarity to shag in habits, etc., I 65,166

Creature, when observed varying, dubbed new species or variety, 229

Cuckoo, must wait a little, 336

Curlew, peculiarities of, 139 ; resemblance to ibis, 139; an opposite bird, I40; inconspicuous when on ground, I 40 ; conspicuous, by contrast, in flight, I40; flight, ordinary and nuptial, of, I4I ; note of, I4I, I42 ; its connection with the prophet Jeremiah, I4I

DABCHICK, sporting of three together, with suggested explanation of, $87,88,89$; probable way of fighting, 88 ; can fly seriously, I49; his manners of diving, etc., I $54,155,156$; and claims to a tail, 156

Darwin, sexual selection as conceived by, 25 ; his comment on Bate's account of humming-bird destroyed by spider, 52; his theory that birds can admire, 255 ; origin of language, his view as to the, 289

EIDER-DUCK, courting note or male, I42; suggestions, etc., raised by, I42, I 43 ; difficult to locate, I43. The poetry of the family, I43; female pleasing, I44; beauty of male, I44. Courting actions of male, 144, 145; and of female, 145. Female active agent in being wooed, I44; demonstrations of female between two males, I 45 ; males mobbing females politely, I45; males, combats between, I45; dive as a relaxation, 145; choice and dismissal of suitors by female, 146; advances of female declined by male, 146; female not coy, I46; nesting habits of, 146, 147; male sitting inland, 
I47 ; charm of watching, etc., I4T, I48; appearance of, under water, I48, I49

GoLDFINCH, solitary at straw-stack, 203 ; beauty of, rivalling bramblings, 203; manner of feeding of, 203

Great Auk, flight, how lost by, I5I

Great Crested Grebe, manner of fighting of, I50; various ways of diving of, $16 \mathrm{I}$; grace of, $16 \mathrm{I}$, 162 ; nest-building of, 329, 330, 331,332 ; habit of building platform of male, 331,332

Great Plover, haunts of, 4 ; manner of sitting, 4. Fanciful resemblance to Don Quixote, 4, 5, I8; and to the Baron of Bradwardine, 4, 5, 20. Odd actions of, 5,6 ; chase of moths, etc. , by, $6,7,8$. Autumn dances of, 9, I0, II, I2, I3, I4, I5; suggested motive for, 15 . Wailing notes or "clamour" of, Io; ordinary flying note of, ro; nuptial or courting antics of, 15 , $16,17,18,19,20$; an oldfashioned bird, I6

Great Green Woodpecker, spiral ascent of trunk, 243; assisted by tail, 243; can descend trunk backwards, 244

Greenfinch, at straw-stack in winter, I99, 20I; feeding within three feet, 201, 202 ; manner of feeding, 202; manner of fighting, 210. Feeding on seeds of exotic fir, 23I, 232, 233, 234, 235 ; manner of loosening the seeds, $231,232,233,235,236$; curious noise made with beak in so doing, $231,232,233$; and with wings on the fir-needles, 234. An example of sexual selection acting in two directions, 318

Guillemots, diving of, 152 ; arrangement of, on ledge, 182,183 ; disparity in time of laying, I83; affectionate conduct of paired birds, I $83, \mathrm{I} 84$; attention paid to young, 184 ; feeding of young, 184, 185, 189. Incubate with face turned to cliff, 185 ; sug. gested explanation of this, 185 . Lethargy of chicks, 186. Fish carried to young in beak, 186 ; and are often headless, 186,188 ; held lengthways, 187 . Coquetry with fish, 187, I88; quarrelling of married birds with fish, I88, I89; birds with fish attacked, etc., 189, I90. Combats, frequency and character of, I90; suggested explanation of, rgo. Preening and helping to clean each other's feet, I9r, I92; fighting, usual cause of, I92; manner of, I92, I93; a fight on the brink, I93; will fight whilst incubating, I93, 194; no respect paid to incubating birds, I94; management of egg during incubation, I94; possible trace of lost nest-building instinct, I95 ; attitudes assumed, I95; resemblance to human beings, 195, I96; stones procured and swallowed, 196; life on a guillemot ledge, notes of, 196, 197, 198

Guillemot, Black, way of diving, 148 ; appearance under water, I48; appearance and character, 149; the dabchick of ocean, I48; a fair flier, I49; manner of fighting, I49, I50; and of bathing, I7 I

Gulls, Black-backed, best watched on island where they breed, 96 ; arrangement of, etc., on the gullery, 97 ; nuptial habits, antics, etc, 97,98 , III, II2; nestbuilding of, I03, 104, 105; fighting of females when collecting materials for the nest, 104, 105 ; fighting of males, 105, 106, 107; a gull melodrama, 105, 106; fighting of two causing excitement amongst others, I07 ; fighting not specialised, I08; importunity of female, I12 ; larger size of male, I I3; persecution of, by Arctic skua, II3, II4, II5; habit of forcing each other or other gulls to disgorge fish in- 
cipient, II8, II9; come near to attacking one, on one's approaching their nest, 12I; mode of attack ineffective, I 22

Gulls, Herring, fighting of, 108 , I09; power of retaining a mental image, IIO; curious behaviour of a pair, IIO, III; habit of forcing each other or other gulls to disgorge fish incipient, II8, II9; feed young by disgorging fish, II9, I20; disgorge fish for each other, I I9, I 20

HaBITS, variations of, more interesting than of structure, 228; may be marked in transitu, 229 ; plasticity of, 48

Hare, disturbing rooks, 227

Hate, oneself, a good way to, 335

Hedge-sparrow, at straw-stacks in winter, 201,202

Heine, allusion of to the nightingale, 313

Heron, must wait a little, 337

Herring, going a progress twice, I 16. Head absent in those disgorged by great skua for its young, II6, II7; possible explanations of this, II7, II8. Profusion of, brought by great skua for its young, I 8

Homer, may be caught up by a butterfly, 335

Hooded Crow, flying with peewits, 27, 28; frolicking or skirmishing with raven, I37; curious antics of, $137,13^{8}$; flying with rooks, 296 ; consorting with rooks in the fields, 296; may sometimes roost with rooks, 296; when with rooks acts as though of the same species, 296

Hudson, $\mathrm{Mr}$, views of, referred to, $79,80,8 \mathrm{I}$

KESTREL, importunity of female, I 12

Kittiwakes, habit of forcing each other or other gulls to disgorge fish incipient, II8; will turn to bay and drive off Arctic skua, 128; roosting in extraordinary numbers, 197,198

LANGUAGE, idea as to origin of, suggested by rooks, 288, 289

Larks (see Skylark)

Life, study of, as important as that of death, 332

Linnet, an example of sexual selection acting in two directions, 3 I 8

Lyre-bird, an example of a highly adorned species which is also musical, 334

Merganser, manner of diving of, I 53,154

Meves, $\mathbf{M}$., on cause of bleating in the snipe, 53

Moor-hen, becoming a partridge or plover, 48 ; an orchestra of peculiar brazen instruments, 57 . Manner of diving of, I 56, I 57 , 158 ; habit of, may be becoming established, 158 ; and may differ in different localities, 158 . Browses grass, 227; wariness of, 226; power of drawing an inference, 227; independent spirit and originality, 227, 228

Naturalist in La Plata, referred to, $79,80,8 \mathrm{I}$

Nightingale, male not singing much during nest-building, 307; song of, a vehicle of hatred and rivalry, 308. Conduct of rival males, 308 , 309 ; similar to wheatears, 308 . Conduct of female during combats of rival males, 309, 310 ; croaking notes of, 310. Song probably founded on these, 310; which would account for its low key, 3I2; how differing from that of thrush, blackcap, skylark, etc., 3 I 2 ; does not include every excellence, 312 ; frequent pauses in, 312 ; when at its best, 313 ; 
effect of, on Heine, 313 ; and on others, 313 ; sometimes mistaken for that of thrush, 3I3, 3I4; by day not more noticed than that of lark or thrush, 314; some of effect of due to night and silence, 3I4, 3I5. Sobriety of colouring exaggerated, 316 ; brightness of tail, 3I6; ruddy paich on, 316, 317 ; glossy appearance of, 317 , 318; example of a bird doubly distinguished, 3I7; may be getting brighter, 3I8; pictures of, in natural history books, 318 ; real appearance of, 319 ; sings without pose, 319 ; and sometimes on ground, 319; Milton fortunately not familiar with, 319; female alone builds nest, 319 ; is attended by male, 319

Nightjar, sound with the wings made by, 52 ; movements of, to protect young, 60,61 ; seem result of nervous shock or mental disturbance, 61 ; twitching of muscles of throat of, I79; must wait a little, 337

Night-raven, possible origin of idea of, 288

Nut-hatch, feeding on seeds of exotic fir, 23I, 232, 233, 234, 235; manner of loosening the seeds of, 233,235

ORGANISMS, plasticity of, 48

Ostrich, courting or nuptial antics of male, 169 ; incubation shared by the sexes, 169

Partridge, movements of, to protect young, 6o, 6r. At strawstack, I99, 205; coming down to, on a winter morning, 205. Soft sounds made by, 205

Peacocks, shot in India, 206

Peewit, cry of, 25; somersaults thrown by, 26; sound made with wings, 27; bridal dances of, 26, 27; flying with hooded crow, 27, 28. Attacking hen pheasant, 27; and moor-hen, 28.

Call-note on ground, 28, 29, 30 ; sporting of two, 30, 31 ; upward sweep in flight, $3 \mathrm{I}, 32$; understudying of one another, 32 ; aerial combats possible, 33, 42; aerial evolutions, remarks on, 33 , 34 ; feigning broken wing not observed, 66 ; three flying together, remarks on, etc., 83,84 , 85,86 ; roll over of compared with that of raven, 263

Penguins, flight, how lost by, I5I ; manner of diving of, $\mathrm{r}_{52}$

People, mental approach of some, 223; not explained by such terms as insight, intuition, perception, affinity, etc., 223

$\phi \eta \mu \eta$, Greek idea of the, 219; brought to mind by watching birds, 220, 221, 294

Pheasants, timidity shown by males in fighting, 75 ; at straw-stack in winter, 199, 205; beauty of male, 206. Curious low notes and piping sounds of, 207 ; not quite so soft as those of partridges, 207. Timidity of, tempered by judgment and individual temperament, 207 ; conduct of, when small birds fly off, 207, 208; males agree together, feeding, 208 ; roosting of dove-tailing with last flight home of rooks, $26 \mathrm{I}$, 262 ; trying to look like a soldier, 283,284 ; dull plumage of hen representing that of progenitor of the family, 310,31 I

Pigeons, twitching of muscles of throat of, 180

Puffin, diving of, 152 ; disparity in time of laying, 183 ; carrying fish crosswise in beak, 187

RABBIT, with young in sandpit, 328,329

Ravens, molested by gulls, r29; at first not impressed by, 129; peculiar croak of, I30; appearance, etc., of nest of, 130 ; behaviour of young in nest, 130 , 
I3I ; attempts to see feed young unsuccessful, I 32 ; add no effect to precipice, I34; plumage of, I34; look. black at a little distance, I34; ordinary flight not majestic, I34; shape of wings of, I34, I35; effect of number of, over battlefield, I35. Curious doubtful if these are nuptial, 138 ; antics in the air of, $136,137$. Skirmishing with gulls, I37; skirmishing or frolicking with hooded crow, 137 ; devoted guardians of young, 138; cunning plan adopted by, I 38, I 39

Raven Mother, the real one, I33; appearance and behaviour of, I33, I 34

Razcrbills, manner, etc., of diving of, I 5 I, 152; fish, how carried in beak by, 187

Redshanks, handsomer flying than when on ground, 23,24 ; courting actions of male, 24. Aerial and aquatic combats of, 36,37 ; at first mistaken as to nature of these, 37

Richardson's Skua, objected to as a title, $6 \mathbf{I}$

Ring Plover, nuptial flight of, $2 \mathrm{I}$, 22; courting actions of male on ground, 22,23

Robin, becoming wagtail or stiltwalker, 48; how it may develop in the future, 229; occasional aquatic habits of, out of character, 229, 230; has two figures, 230; a part of most landscapes, 230 , 23I; looks different in different places, 231 ; an example of sexual selection acting in two directions

Rooks, importunity of female, II 2 ; simultaneous flights, etc., of, 2 Io, 292, 293, 294; winter rookery or roosting-place of, $258,259,278$, 280 ; crowd of better than crowd of men, 259; aerial evolutions, sports, gambols, mancuvres, etc., of, $259,260,262,263,264,265$, $268,269,270,27 \mathrm{I}, 280,295$; peculiar burring note of, 260 , 282,283 ; powers of flight pos- sessed by, 260, 271 ; flight full of effects, 27I; how associated with starlings, 26I; chirruppy or croodling note of, 26I, 268, 269 ; last flight of, dove-tailing with roosting of pheasants, 261, 262 ; roll over of, compared with that of ravens, 263 ; two great assemblages of, mancuvrings and different conduct of, 262, 264, 265 ; difficulty of supposing that they are led, $213,265,266$; if led, should be so habitually, 266, 267; evidence against theory of leadership, 267, 268, 269, 270, 284, 285 ; the caw the business note of, 268 ; two bands flying at different elevations, 270 ; flight of, at great elevation different to usual flight, 270, 27 I ; conclusion against theory of leadership, 27I, 273 ; supposed to employ sentinels, 27I; evidence as to and conclusion against their doing so, 272,273 ; vast assemblage of, $274,277,278$; fighting of, 274, $275,276,277$; disturbed by hare, 277 ; iullaby of, $278,28 \mathrm{I}$; return of, to winter rookery in evening, $274,277,278,28 \mathrm{O}, 28 \mathrm{I}$, 292, 294, 295, 296, 297, 298, 299 ; various cries of, 281,283 , $284,286,288,291,292,299$, 300. Whishing noise made by, $28 \mathrm{I}, 282,295$; doubt as to how produced, 282. "Burring" note of, 282,283 ; morning flight of, from winter rookery, 283,284 , 285,292 ; voice of, pleasing and expressive, 283 ; talk kind of Chinese, 284 ; tits flying with, 284 ; some staying back after general flight out, 285 ; actions of, governed by two leading principles, 285 ; unknown force suggested by movements of, 285 , 286 ; some movements of, may be due to thought-transference or collective thinking, 287 ; may be origin of the night-raven, 287 , 288 ; origin of language suggested by, 288, 289; zones o 
sound and silence amongst, 289 , 290; notes of, best described as talking, 29I; method of yawning of, 29I, 292; $\phi \eta \mu \eta$, the idea of the, applied to, 294 ; psychical state of during the heimkehr, 295; wonderful scene of excitement amongst, 294, 295, 296. Found dead in plantation, 295, 296; possible reason and theory of keeper in regard to this, 296. Non-coilision of, wonderful, 295 ; consort with hooded crows in fields, 296; resembling stormcloud and rain, 298; seem as though evolving a language, 299 ; powers of modulation and inflexion in voice of, 299 ; voice of, unjustly spoken of, 299 ; vocabulary of notes of, 299, 300

Rules, to be guided by in watching birds, 248, 249

SAND-MARTINS, manner of excavating tunnels, $323,326,327,328$; both sexes excavate, 323,324 . Sometimes work socially, 324; but not as do insects, 324 . Make simultaneous flights from cliff, 324, 325 ; sometimes fight fiercely, 325 ; are victimised by sparrows and tree-sparrows, 325 ; length of their tunnels, 326

Scientific men, indifference of, to extermination, 333

Sezual selection, as conceived by Darwin, 25 ; antics, etc., not in the nature of display, no evidence against, 79; as having modified some birds both in voice and plumage, 318

Shags (see also Cormorant), power of ejecting excrement to distance possessed by, I3I ; how useful to the bird, I3I, I32; nest of, I3I. Manner of diving of, 153 ; dive uniformly, I 56 ; amiable character of, I63, I65; courtship, lovemaking of, etc., 166, 167, 168, 169, 170; courting antics like those of the ostrich, but with significant difference, I69, 170; habit of opening and shutting bill at each other, 170, I76, I77; bathing of, 170; gargoyle idylls of, I $71,172,173,174,175,176$, $177,178,179,180,181$; tendency of, to ornament nest, 174, 175, 176; change on the nest of, 175, 176, 177; feeding the young, 177, 178, 179; twitching muscles of the throat, I79, I80; character, etc., of the young, I80; guarding the nest and affairs of honour, 181, I82; manner of fighting, I8I

Skua, Arctic, diverting attention from eggs or young, 6I ; persecutes gulls, II $3, I_{14}, 127$; is safe from retributive justice, I I4 ; said only to eat fish robbed from gulls, II4; probability that it would feed by piracy exclusively, II5; not seen stooping on fish in water, II5; disgorge fish for each other, I20, I2I; attacks those approaching its nest, I2I ; swoop made in silence, 12I; mode of attack, I22, 123; blow with feet ineffective, I23; both birds often attack, but more usually only one, $\mathrm{r} 25$. Combines fraud with force, I25 ; theory as to this, 125. Polymorphism of, 126 , 127 ; sexual selection suggested as an explanation, 126, I27. Seems bolder and more aggressive than the great skua, r27 ; driven off by kittiwake, 127, I28; feared more by gulls than the great skua, 128; extreme boldness of, 139; chased by curlews, 139

Skua, Great, nuptial habits, antics, etc., 98, 99, 1OI, IO2 ; powers of flight, 99; flight seen to best advantage at sea, 99, 100; nest, IO3 ; said only to eat fish robbed from gulls, and secured in midair, II4; would probably feed by piracy exclusively, II 5 ; not seen stooping on fish in water, II5; young fed entirely on disgorged 
herrings, II5; nesting habits difficult to observe, II5, I I6; probably eats heads of herrings disgorged for young, II7, II8; has no reason to vary diet during breeding-season, as asserted, 118 ; suggested origin of its specialised method of feeding, II8, II9; attacks those approaching its nest, I21; makes swoop in silence, but utters cry whilst circling between each, I2I; blow with feet ineffective, I22; attacks almost indefinitely, I22; mode of attack, I23, 124. Attack made by both sexes, I24; an exception noted, I 24, I25; theory in regard to this, 125. Feared less by gulls than Arctic skua, I28; mobbed by gulls, 128

Skylarks, aerial combats of, 35 , 36 ; impressive hops of male in courtship, 49; song of, how differing from the nightingale's, 3I2; effect of if heard at night, 3 I 4

Snipe, a familiar example of instrumental music during flight, 52 ; modification of tail-feathers by sexual selection, 53 ; wings apparent but not real cause of bleating, $53,54,55$; different ways of descending to earth, 53 , 55,56 ; different modes of fight, 54 ; see-saw or "chack-wood" note, 54, 56; swishing of wings, 56 ; extraordinary notes of, 57 . Tail feathers less modified in female, and producing a different bleat, 57 ; but difference not great, 57,58 . Individual differences in bleat, 57,58 ; flying in circles, 58 ; bleat best in morning and evening, 58 ; flight difficult to follow, 58 ; private allotment in fields of air, 58 ; bleating of males against each other, 59 ; bleating of male and female to each other, 59; bleating of one answered vocally by the other on ground, 59. Extraordinary movements when alarmed during incubation,
$60,6 \mathrm{I}$; theory with regard to these, 63,64

Sparrows, seize burrows of sandmartins, 325 ; creditable motives of, in so doing, 325,326

Sparrows, Tree, at straw-stack in winter, I99; seize burrows of sand-martins, 325

Species, knowledge lost by destruction of any, 333

Specific life, any, of more value than most individual ones, 334

Spiders, if they had their Phidiases, 52

Spur-winged Lapwing, curious performances of, 81,82 ; suggested origin of, $82,83,84,85,86,87$, $88,89,90,91,92,93,94,95$

Starlings, acting as fly-catchers, 8 , 48 ; and as wood-peckers, 48 . Manner of feeding, 9 ; at strawstack in winter, 199, 204, 205; fighting with hen blackbird, 204 ; fighting with each other, 204, 205. Their simultaneous flights, 2 IO, 214,215 ; difficulty of explaining these and suggestions as to, 214, 215. How associated with rooks, 26I

Stock-doves, their aerial combats, 38,39 ; arising sometimes out of the ground-tourney, 4I, 42. Their ground - tourneys, 39, 40, 4I ; bowing of fighting birds to each other, 39, 40, 4I; fighting of male and female, 42, 43 ; courting bow of male to female, 43 , 44,45 ; bowing of female to male, 43, 44; bow silent or accompanying note subdued, 45 ; court on trees or on ground, 45 ; their nuptial flights in early morning, 46, 47 ; make nest in rabbit-burrows, 47

Structure, slight changes of, not easy to see, 229

THOUghT-TRANSFERENCE, as possible explanation of some movements of birds and other animals, $2 I 9,220,221,222,223,286$, 
287, 289, 290, 292, 293, 294; a retarding influence, 222 ; in man, may be reversion to more primitive method of intercommunion, 223; may be, in some ways, superior to speech

Thrush, Song of, how differing from the nightingale's, 3I2; mistaken for the nightingale's, $3{ }^{1} 3,314$; effect of if heard at night, 3 I 4

Tit, Blue, at straw-stack in winter, I99, 202 ; acts like tree-creeper, $236,237,238,239$. Ascends trunk perpendicularly, 237 ; suggested explanation of this, 242, 243. Descends trunk head downwards assisted by wings, 237, 238,245 ; suggested explanation, 245. His hardiness, 247, 248; eats buds rather than insects in them, 248, 249; attacked by bullfinch, 250; feeds on catkins of alder or insects in them, 25I, 253; his tiring-room and banqueting-hall, 253; drive each other from catkins of alder, 253 ; flying with rooks, 284

Tit, Coal, attacks fir-cones, 231 ; manner of holding them, $25 \mathrm{I}$. Ascends tree-trunks as does bluetit, 252

Tits, Long-tailed, nest-building, 320, 321 ; "chit, chit" note, 320, 321 ; roosting together, 321, 322, 323 ; returning to roost in same place, 322, 323; their prettiness, 320,321

Tit, Great, feeding on seeds of exotic fir, 231, 232, 233, 234, 235; manner of loosening the seeds, 232, 235. Probably eats seeds of indigenous firs, 252

Tree, old, winter foliage of, 201

Tree-creeper, becoming a fly-catcher, 48. Flies downwards from treetrunk, 240; but not invariably, $24 \mathrm{I}$; suggested origin of the habit, 24I. Spiral ascent not so general as asserted, 24I, 242 ; often ascends perpendicularly, 242 ; suggested origin of spiral ascent, 242, 243. Said never to descend trunk, 24I, 244; but can descend backwards, 244 ; interesting to watch, 246 ; skill in using beak, etc., 246 ; sometimes acts like fly-catcher, 247; his æsthetic beauty, 247; his hardiness, 247

Trogons, shot in Mexico, 206

Turtle-dove, courting of male on ground or in trees, 50; the nuptial flight, 50, 5 I

WAGTAIL, must wait a little, 337

Warrener, how affected by beauty, 47

Wheatear, combats and displays of rival males, $66,67,68,69,70$, $7 \mathrm{I}, 72,73,74$; his hopping out of character, 68 ; conduct of hen whilst fought for by rival males, $68,69,71,72,74,78$; chariness of fighting shown by males, 7I, 74. Antics of males not resembling a set display, 77,78 ; attempt to explain these and other antics of various birds, 74 et seq (to end of chapter). Power of retaining a mental image, IIO; conduct of rival males similar to that of nightingales

Wild Duck, intelligent feigning of injury to distract attention from young, 60, 62, 63; suggested origin of the habit, 63,64

Willow-warbler, preference for birch-trees, 253 ; pretty behaviour with the catkins of, 253 , 254,255 ; reason for this possibly asthetic, 255, 256

Wood-pigeons, courting of female by male on tree, 45 ; raucous note after pairing, 46 ; may hereafter lay in rabbit-burrows, 48 ; courting of female by male on ground, 48, 49; the clapping of wings in flight, 51 ; beauty of nuptial flight, 5I, 52; swishing or beating of wings in flight, 52 . Their simultaneous flights, 2 IO; suggested explanation as to, 2I5, 216

Wren, acting like a tree-creeper, 
$48,236,237,238,239,240$. Ascends tree-trunks perpendicularly, 237; descent of doubtful, 238; sometimes assisted by wings, 240. Suggestions as to habit and mode of tree-creeping, 242, 243

Wren, Golden - crested, amongst pine-trees, 252 ; suggesting hum. ming-bird, 252 ; examines pine- needles, 252, 253; his note, 253

YELLOW-HAMMER, at straw-stack in winter, 199, 201

ZoologisTs, have been thanatologists, 224 ; prefer death to life, 332, 333 
THE RIVERSIDE PRESS LIMITED ST BERNARD'S ROW, EDINBURGH 



\section{4}

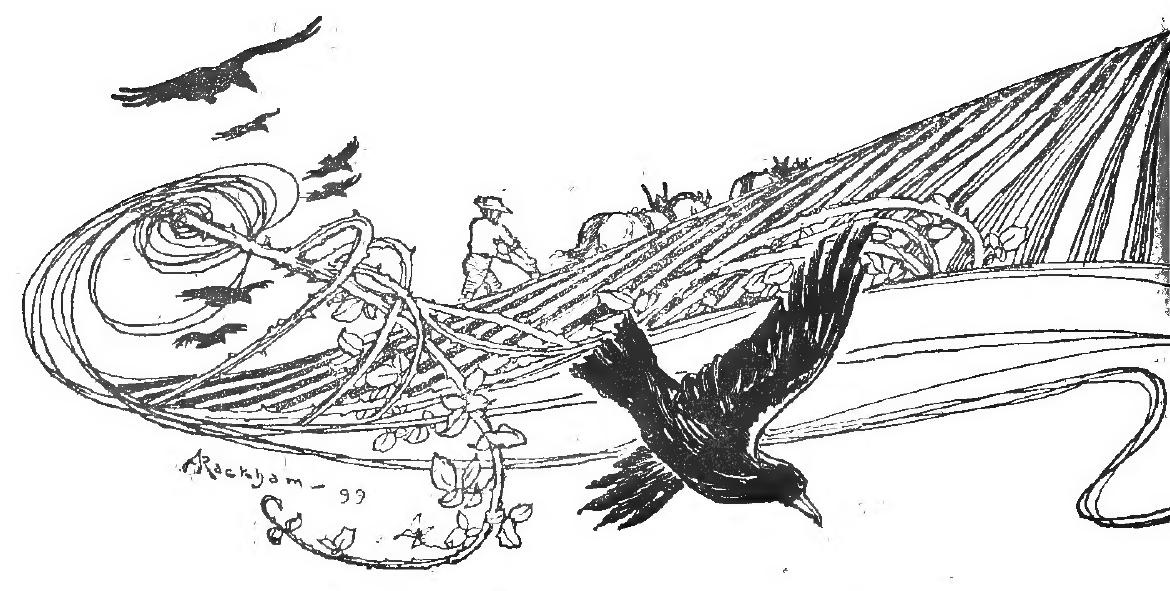




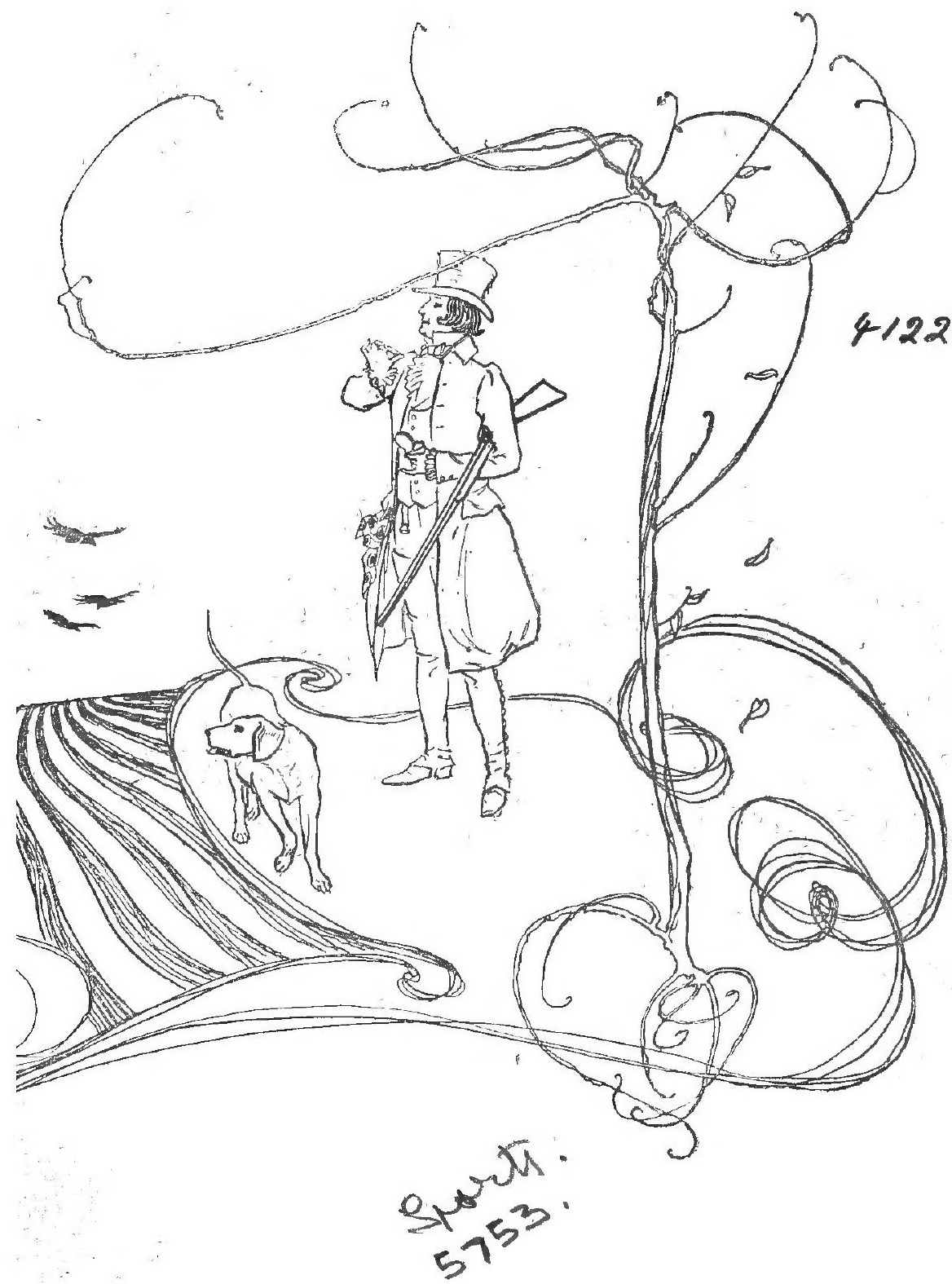




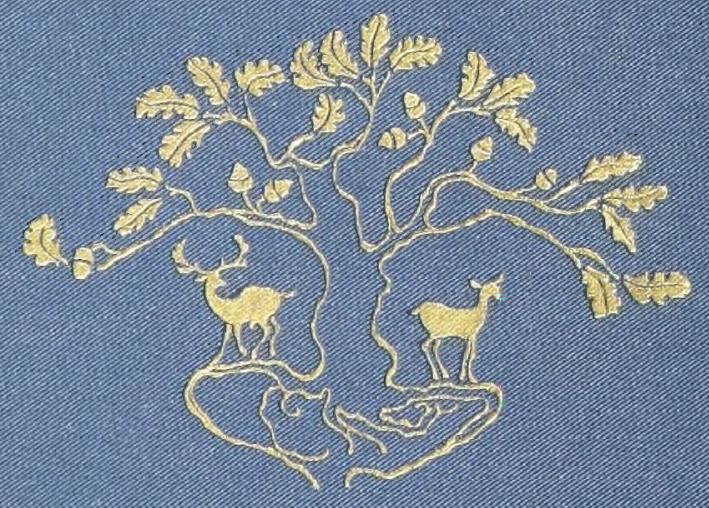

